\title{
Patient and visitor violence in general hospitals
}

Citation for published version (APA):

Hahn, S. (2012). Patient and visitor violence in general hospitals. [Doctoral Thesis, Maastricht University]. Datawyse / Universitaire Pers Maastricht. https://doi.org/10.26481/dis.20120628sh

Document status and date:

Published: 01/01/2012

DOI:

10.26481/dis.20120628sh

Document Version:

Publisher's PDF, also known as Version of record

\section{Please check the document version of this publication:}

- A submitted manuscript is the version of the article upon submission and before peer-review. There can be important differences between the submitted version and the official published version of record.

People interested in the research are advised to contact the author for the final version of the publication, or visit the DOI to the publisher's website.

- The final author version and the galley proof are versions of the publication after peer review.

- The final published version features the final layout of the paper including the volume, issue and page numbers.

Link to publication

\footnotetext{
General rights rights.

- You may freely distribute the URL identifying the publication in the public portal. please follow below link for the End User Agreement:

www.umlib.nl/taverne-license

Take down policy

If you believe that this document breaches copyright please contact us at:

repository@maastrichtuniversity.nl

providing details and we will investigate your claim.
}

Copyright and moral rights for the publications made accessible in the public portal are retained by the authors and/or other copyright owners and it is a condition of accessing publications that users recognise and abide by the legal requirements associated with these

- Users may download and print one copy of any publication from the public portal for the purpose of private study or research.

- You may not further distribute the material or use it for any profit-making activity or commercial gain

If the publication is distributed under the terms of Article $25 \mathrm{fa}$ of the Dutch Copyright Act, indicated by the "Taverne" license above, 


\section{PATIENT AND VISITOR VIOLENCE IN GENERAL HOSPITALS}


ISBN 978-94-6159-150-0

Cover photo: Skills Centre, Berne University of Applied Sciences, with permission

C Copyright Sabine Hahn, 2012

Printing: Datawyse / Universitaire Pers Maastricht 


\title{
PATIENT AND VISITOR VIOLENCE IN GENERAL HOSPITALS
}

\author{
DISSERTATION \\ to obtain the degree of Doctor at Maastricht University, \\ on the authority of the Rector Magnificus, Prof. dr. G.P.M.F. Mols \\ in accordance with the decision of the Board of Deans, \\ to be defended in public on Thursday June 28th, 2012 at 16.00 hours
}

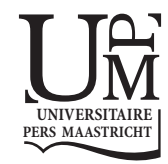




\section{SUPERVISORS}

Prof. dr. G.J. Kok

Prof. dr. T. Dassen, Charité-Universitätsmedizin Berlin, Germany

\section{CO-SUPERVISOR}

Dr. R.J.G. Halfens

\section{ASSESSMENT COMMITTEE}

Prof. dr. J. Hamers (chairman)

Prof. dr. R. De Bie

Prof. dr. J.A. Duxbury, University of Central Lancashire, United Kingdom

Prof. dr. H. Nijman, Radboud University Nijmegen

Dr. R. Ruiter 


\section{Content}

CHAPTER 1 General introduction 7

1.1. Introduction 8

1.2. Theoretical framework 9

1.3. Implication for research and practice $\quad 21$

1.4. Aim and research questions 21

1.5. Ethical considerations 22

1.6. Contents of the thesis 22

1.7. References 24

CHAPTER 2 Patient and visitor violence in general hospitals: a systematic review $\begin{array}{ll}\text { of the literature } & 27\end{array}$

2.1. Abstract 28

2.2. Introduction 29

2.3. Method 30

2.4. Results 41

2.5. Discussion 47

2.6. Conclusion and recommendations for further research 49

2.7. References 50

CHAPTER 3 Measuring patient and visitor violence in general hospitals: Feasibility of the SOVES-G-R, internal consistency and construct validity of the POAS-S and the POIS

3.1. Abstract 54

3.2. Introduction 55

3.3. Background $\quad 55$

3.4. Methods 58

\begin{tabular}{ll} 
3.5. & Results \\
\hline 3.6. & 64
\end{tabular}

3.6. Discussion 68

3.7. Conclusions 70

3.8. Relevance to clinical practice $\quad 70$

3.9. References 72

CHAPTER 4 Factors associated with patient and visitor violence experienced by nurses in general hospitals in Switzerland: A cross-sectional survey 75

$\begin{array}{ll}\text { 4.1. Abstract } & 76\end{array}$

4.2. Introduction

$\begin{array}{ll}\text { 4.3. Background } & 77\end{array}$

4.4. Methods $\quad 79$

4.5. Results 81

4.6. Discussion 88

4.7. Conclusions 91

$\begin{array}{ll}\text { 4.8. } & \text { References } \\ \end{array}$ 
CHAPTER 5 Patient and visitor violence in the general hospital, occurrence, staff interventions and consequences: A cross sectional survey 97

$\begin{array}{ll}\text { 5.1. Abstract } & 98\end{array}$

5.2. Introduction $\quad 99$

$\begin{array}{ll}\text { 5.3. Background } & 100\end{array}$

$\begin{array}{ll}\text { 5.4. The study } & 101\end{array}$

$\begin{array}{ll}\text { 5.5. Results } & 104\end{array}$

$\begin{array}{ll}\text { 5.6. Discussion } & 117\end{array}$

5.7. Conclusion and implication for clinical practice 120

5.8. References 122

CHAPTER 6 Risk factors associated with patient and visitor violence in general hospitals: Results of a multiple regression analysis $\quad 125$

$\begin{array}{ll}\text { 6.1. Abstract } & 126\end{array}$

$\begin{array}{ll}\text { 6.2. Introduction } & 127\end{array}$

6.3. Material and methods 130

6.4. Results 132

$\begin{array}{lr}\text { 6.5. Discussion } & 140\end{array}$

6.6. Conclusion 143

$\begin{array}{ll}\text { 6.7. References } & 145\end{array}$

$\begin{array}{lll}\text { CHAPTER } 7 \text { General discussion } & 149\end{array}$

7.1. Introduction 150

7.2. Main results 150

7.3. Methodological aspects 156

$\begin{array}{ll}\text { 7.4. Discussion of the results } & 157\end{array}$

7.5. Implications for health care staff and clinical practice 165

$\begin{array}{ll}\text { 7.6. Implications for research } & 166\end{array}$

$\begin{array}{ll}\text { 7.7. References } & 168\end{array}$

$\begin{array}{lll}\text { CHAPTER } 8 & \text { Summary } & 171\end{array}$

Samenvatting $\quad 179$

$\begin{array}{ll}\text { Zusammenfassung } & 187\end{array}$

$\begin{array}{ll}\text { Acknowledgements } & 197\end{array}$

$\begin{array}{lr}\text { Curriculum vitae } & 199\end{array}$ 


\section{CHAPTER ONE}

\section{General introduction}

"Vieles Gewaltige lebt, und nichts ist gewaltiger als der Mensch».

Sophokles, «Antigone» 


\subsection{INTRODUCTION}

Violence in the health care system is an ongoing priority for staff, staff managers, patients, health care authorities, the World Health Organization and international labour and nursing organisations. Is the hospital no longer a safe place either for health care staff, or for patients who are seeking help, understanding and care? A more violent society is entering the hospital, which transfers its aggression towards health care staff and patients alike (Exadaktylos et al. 2010, Stokowski 2010). Due to this, in the general hospital workplace, violence is increasingly noted as a significant threat to safety at work, quality of care and health care costs (Cooper \& Swanson 2002). All health care professions are high on the list of occupations with a serious level of workplace violence. Indeed, violence in the health sector constitutes almost a quarter of all violence at work (Bourn 2003, Chappell \& Di Martino 2006, Di Martino 2003). While in many countries various governmental initiatives (legislation, zero tolerance policies) and organisational strategies (policies/procedures, environmental aspects, staff training) have been implemented, no large-scale evaluations have been carried out to investigate reduction of workplace violence (Peek-Asa et al. 2009). Research also suggests that the present strategies have been unsuccessful, because the effects of the local work environment or context in which strategies have been implemented have not been considered (Hegney et al. 2010, Hills 2008, Paterson et al. 2005). Violence in the health care setting is often seen as part of the job and has therefore been inadequately addressed. This attitude also presents difficulties in the investigation of violence at the workplace because it contributes to under-reporting (Child \& Mentes 2010, VenturaMadangeng \& Wilson 2009). In a climate of a declining health care workforce, reduced financial resources and increasing efforts for patient safety, violence needs to be carefully addressed (Gallant-Roman 2008).

Violence occurs in all parts of the health care system and is directed against health care staff from various sources, including other health care staff, superiors, patients, relatives or people from the street (Jackson et al. 2002). Violence inflicted by patients is the most frequent kind experienced (Camerino et al. 2008, Ferns 2006, Hegney et al. 2010) and nursing staff are more likely than other health professionals to become involved in these incidences (Child \& Mentes 2010, Hegney et al. 2010). However, these results have to be interpreted with caution, because patient violence is most often only investigated in the nursing profession. Most frequently, mental health care (Wells \& Bowers 2002, Whittington et al. 1996, Winstanley \& Whittington 2004b) and emergency settings (Fernandes et al. 1999) are investigated. The comparability of this data to the general hospital setting is problematic because of different definitions and mixing of instruments, data sources and epidemiological data throughout different health care settings (Stokowski 2010, Ventura-Madangeng \& Wilson 2009). A comprehensive description of the problem is lacking and little is yet known about the detailed factors associated 
with patient and visitor violence experienced by health care staff working on general wards in general hospitals. Therefore, prevention and intervention strategies are mostly based on mixed knowledge from psychiatric and emergency care, and it is questionable how transferable this knowledge is to the specific settings without consideration of the local work climate or context (Beech \& Leather 2006, Stokowski 2010).

Until recently, there were almost no initiatives taken against workplace violence in the general hospital setting in Switzerland and other German-speaking countries. Studies addressing the problem in these countries are also limited to mental health care (Abderhalden et al. 2008, Franz et al. 2010, Needham et al. 2005, Richter \& Needham 2007, Steinert et al. 2008) and emergency settings (Needham 2001, Steck-Egli 2005). Therefore, no data is available regarding workplace violence in general hospitals for Switzerland and other German-speaking countries.

This dissertation addresses the topic of patient and visitor violence experienced by healthcare staff on general wards in the general hospital setting. As outlined above, there is a lack of knowledge concerning the problem in this setting. This thesis investigates different health care staffs' experiences regarding the extent of patient and visitor violence and the factors associated with the problem. This knowledge is important for the improvement of guidelines, prevention and intervention strategies within the various organisational and staff levels.

In the following sections, firstly the background of this severe problem will be described by analysing the definition of patient and visitor violence, and will then be followed by short explanations of the aggression models that this thesis is positioned in. Then, the theoretical background and its implications for research and practice are described and the research questions of this thesis are outlined. The chapter ends with a summary of the contents of the dissertation.

\subsection{THEORETICAL FRAMEWORK}

Throughout the times and with the socialisation of humans, governmental organisations have seized more and more responsibility and monopoly of the power. Violence (for example assault) is penalised in civilised societies. This process is still only partially successful, but it demonstrates that violence is not a new or extraordinary phenomenon of our time. However, the awareness of violence and the discourse of this workplace hazard in the health care system (Jackson et al. 2002) are new. Many countries have developed guidelines and policies that address the problem of workplace violence, including the currently criticised zero tolerance policy (Clements et al. 2005, Holmes 2006, Paterson et al. 2005). 


\section{Definition of patient and visitor violence}

In this study, patients are described as any individual participating in the health care system for the purpose of receiving therapeutic, diagnostic, or preventive procedures $^{1}$. Visitors are relatives or friends in direct or close contact with the patient, and whom are visiting or accompanying the patient in the hospital.

Defining patient and visitor violence is not easy (Ventura-Madangeng \& Wilson 2009). In the literature, there is a lack of consistency in the definitions of the terms violence, aggression and workplace violence (Anderson 2000, Child \& Mentes 2010, Milczarek 2009). According to a literature search, over 140 papers on theories of aggression exist (Bjorkly 2006). Rippon (2000) emphasised the impotency of a clear definition before research can be conducted. Also in the practice setting, there is ambiguity and no clear consensus regarding the terms violence and aggression and what constitutes a violent event. This can negatively influence the identification of workplace violence, reporting behaviour and therefore research in the field (Ventura-Madangeng \& Wilson 2009). In order to compare data, researchers in the field have to establish a clear definition of aggression and violence. Rippon (2000) compared definitions and concluded that the following factors were constant in research and literature on the subject of aggression:

- the intent of the aggressor

- a cognitive process

- the behaviour results in physical, psychological and/or emotional harm.

Therefore, according to Rippon (2000), aggression is directed and has intentions of harm (wilful or not) to a living being (oneself or other persons), whether harm results or not. The form of aggression can be physical or verbal. Aggression can be active or passive, and can be addressed directly or indirectly towards the victim. In the aggressive act, a physical weapon may or may not be used. Aggression can incorporate psychological and emotional tactics and can occur with or without anger. Rippon (2000) also outlined that in our society, the term violence is often used instead of aggression.

Anderson \& Bushman describe the distinction between aggression and violence. Human aggression is: “...any behavior directed toward another individual that is carried out with the proximate (immediate) intent to cause harm. In addition, the perpetrator must believe that the behavior will harm the target, and that the target is motivated to avoid the behavior" (Anderson \& Bushman 2002 p. 28). Aggression is not the same as violence, as violence is a more general form of aggression, “... that has extreme harm as its goal (for example, death). All violence is

1 Pubmed, MeSH-Term Definition: Patient. Year introduced: patient /education was used for indexing 1966-1979 
aggression, but many instances of aggression are not violent" (Anderson \& Bushman 2002 p. 29).

The European Risk Observatory Report (Milczarek 2009) defined work-related violence as follows: "Violence is a generic term that covers all kinds of abuse. Most definitions of forms of violence at work include homicide, assault, threats, mobbing and bullying; in effect, all behaviour that humiliates degrades or damages a person's well-being, value and dignity. In addition, the definition of a 'workplace' is elusive as increasing numbers of people earn their living on mobile sites, in homebased offices, and by teleworking. In some definitions, the term 'work-related violence' refers to both physical and psychological violence directed at employees from either outside or inside the workplace. Sometimes violence or physical violence and harassment (bullying) are separated“. In the European Risk Observatory report, the term work-related violence is used as an umbrella term for all forms of violence and aggression. The terms work-related violence or workplace violence are used to refer to all kinds of violent incidents at work, including violence, aggression, harassment (bullying-mobbing) threats, physical and psychological violence, verbal violence, sexual harassment etc. The International Labour Office et al. (2002) and the EU Commission (Cooper \& Swanson 2002) recommend using a broad definition of violence that incorporates both physical and psychological violence.

The presented definitions demonstrate that violence and aggression are not easily distinguishable from one another, especially in daily practice, and are often used synonymously (Anderson 2000, Rippon 2000). In this thesis, we therefore consider the two terms to be synonymous. Consequently, this study uses the following definition which is often used in the field of research in the health care system:

Violence refers to incidents in which health care staff are abused, threatened or assaulted in work-related circumstances (Milczarek, 2009). Patient and visitor violence has various forms and is defined as any verbal, non-verbal or physical behaviour that threatens or is harmful to others or their property (Morrison 1990):

- Verbal violence is the use of abusive or offensive language (including sexually abusive language), derogatory remarks or profane and/or obscene comments (McKenna 2004).

- Threats are warnings of intent to injure another person with or without an object or weapon, to harass (also sexually) and to physically intimidate (McKenna 2004).

- Physical assault includes slapping, pinching, pushing, shoving and spitting or kicking with or without the use of weapons (McKenna 2004).

In conclusion, there is no universal definition of aggression and violence. For researchers, it is important to use a clear definition for the description, interpretation, discussion and comparison of study results. Consequently, it is important to describe the theoretical background and the terms used to specify and define pa- 
tient and visitor violence in the research field of health care and to stimulate the discussion and the effort to establish a common comprehension.

\section{Models of aggressive behaviour}

There are many domain-limited theories about human aggression. These theories propose different sources and factors associated with aggressive behaviour. Bjorkley (2006) described the main theoretical foci of the three basic psychological theories (psychoanalysis, driven theory and social learning theory). He describes that in psychoanalytic theory, the biological and instinctive position are emphasised. To translate this position into a more objective behavioural perspective, the drive theory formulated the frustration-aggression hypothesis. In contrast to these theories, the social learning theory highlights the cognitive functions and social interaction, which suggest that aggressive behaviour emerges from a large and varied range of conditions. Further developments of theories led to even more complex theories. These theories are important in the investigation of patient and visitor violence in the general hospital setting, because they display an event of violence as a complex interplay of different factors, and they attempt to clarify the relationship of these factors to one another. One of these theories is the general aggression model (GAM) by Anderson \& Bushman (2002), which is described below in this section. This model gives a comprehensive description of the origin of violence in an interaction. Nevertheless, this model requires modification for the specific setting of workplace violence in the health care system.

An extensive review of twelve major known national guidelines and strategies from the United Kingdom, Australia, Sweden and the USA identified only three guidelines representing a model of workplace violence (Wiskow 2003). Representatively, in this section, Curbow's (2002) model of origins on violence at work in the health sector is presented. The last and most specific theoretical approach for patient violence presented in this section includes the cognitive model of patient aggression towards health care staff in the general hospital setting (Winstanley 2005). This model gives a more detailed understanding of the patient situation. These three theoretical approaches show some overlapping factors and together, build a stable base for the theoretical background of this thesis.

\section{The general aggression model}

The GAM integrates existing theories of aggressive and violent behaviour into a general model and is therefore more parsimonious and better explains aggressive and violent acts that are based on multiple motives. This aids the development of more comprehensive interventions. The GAM describes the act of a person in a situation (episode) which can lead to aggressive or violent behaviour, considering different influencing factors as the input (see Figure 1.1): (1) the person and (2) the 
situation. The routes of the situation are (3) the impact of inputs with its cognitive, affective and arousal routes. The outcomes of (4) the underlying appraisal and decision process are thoughtful action or impulsive action, which lead to (5) social encounter.

Input

(1) Person's factors are for example demographic characteristics, personality traits, gender, beliefs, attitudes, values, long-term goals and knowledge structures. These are the factors a person brings to the situation and to an individual preparedness to aggression or violence. (2) Situational factors include aggressive cues, provocation, frustration, pain and discomfort, drugs and/or incentives. Aggressive cues are objects assisting aggression-related concepts in memory. In the interaction, the provocation or perceived provocation is a very important cause of aggression and violence. Also, the experience of frustration is important. Frustration is defined as the blockage of goal attainment. Pain and discomfort for example hot temperatures, noise, and stench could have negative effects and arouse aggression or violence. Also, legal and illegal drugs or drug withdrawal can reduce frustration tolerance. Incentives are objects of desire that are not easy to achieve.

\section{Routes}

(3) Personal and situational factors influence the final outcome behaviour through the present internal state that they create. Cognition, affect, arousal and interconnections are the important factors here. Cognition factors: The input variables could activate hostile thoughts. If this happens often, the accessibility of the hostile concepts in memory increases. An example of such a highly accessible concept is a script that gets triggered very fast and leads to aggression and violence. Affective factors are mood and emotion and expressive motor responses. The input variables directly influence the affect of a person and many personality variables are related to hostility-related affects. Anderson \& Bushman describe expressive motor responses as "... the automatic reactions that occur in conjunction with specific emotions, largely in the face. Even in early infancy, unexpected pain (for example immunization, inoculations) quickly produces "a clear cut, full-faced anger expression» (Izard 1991, p. 245)" (Anderson \& Bushman 2002, p. 39). There is physiological and psychological arousal stimulated by personal characteristics or features of the situation. They do not always coincide. Arousal can persist over a long time.

\section{Outcomes}

(4) The outcomes include several complex information processes. Ranging from a more automatic (immediate appraisal) to a more controlled process (reappraisal) and leading to a decision about the reaction behaviour. (5) This reaction becomes part of the inputs for the next episode of interaction. Immediate appraisal is an automatic, relatively effortless, spontaneous process and depends upon the pre- 
sent internal state. The outcome of immediate appraisal relays to the person's characteristics (experiences) and resources (time) and the content of the immediate appraisal. The reappraisal process "... involves searching for an alternative view of the situation. It can include a search for relevant information about the cause of the event, a search for relevant memories, and a search for features of the present situation. Reappraisal may include numerous cycles as alternatives are considered and discarded. At some point the recycling process ceases and a thoughtful course of action occurs" (Anderson \& Bushman 2002 p. 41). Reappraisal decreases or increases the level of anger that could lead to coldly calculated violence.

The GAM assists in the understanding of the factors associated with patient and visitor violence in regards to the social interaction between the patient/visitor and the staff member. Provocation (caused by long waiting time), frustration (pain) and appraisal seem to be relevant factors in the occurrence of patient and visitor violence, as presented by Nijman (2002), in a model of aggression for psychiatric settings. However, because the GAM is a general model, it does not take into account the specific situation and contextual factors relevant for patient and visitor violence in the general hospital setting. More specific information about the personal factors of patients, visitors and healthcare staff, and the situation in which the violent interaction takes place is required. Nevertheless, with this additional information, the GAM model can be adapted to the general hospital setting. 


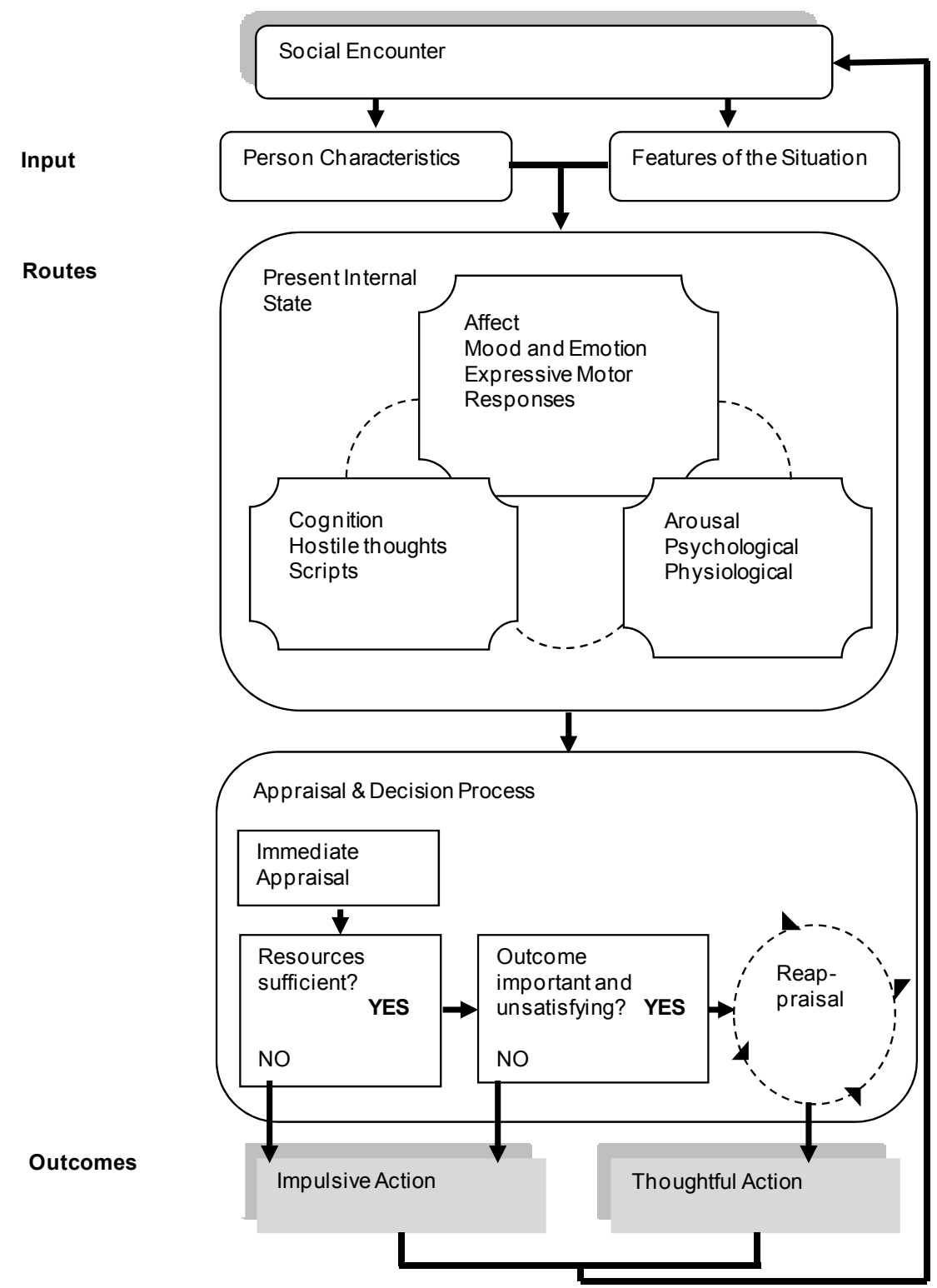

Figure 1.1: The General Aggression Model (GAM) 
Curbow (2002) presents a basic conceptual model of the origins of violence at work, on the basis of the general literature and in particular on the literature that focuses on healthcare workers. This model focuses on the interaction between health care staff and a client or other source of violence for example colleagues. The nature of the interaction is influenced by individual factors of the persons involved and "...it is embedded within the organizational, community, and societal environments. Depending upon the actual work setting (for example client's home, emergency room, critical care unit, outpatient or clinic office) and the source of aggression, the actual variables that come to play would differ in importance and in content" (Curbow 2002 p. 43). The model distinguishes between community and neighbourhood factors and has a more global perspective of the society. All of these factors are seen as interrelated. Table 1.1 shows the factors associated with patient and visitor violence against healthcare staff according to the model.

As for other models, much of the data used in this model originates from psychiatric or mental health settings, emergency or home and community settings. The most often investigated samples are nurses or health field workers (Health and Safety Executive 1997, National Institute for Clinical Evidence - NICE 2005, Zarola et al. 2008). However, data from the general hospital setting are rare (Winstanley 2005). Curbow (2002 p. 43) noted, "... the literature on causes of violence in healthcare settings is limited and fragmented, making it impossible to fill in the components of the model in a comprehensive, evidence-based manner." Nevertheless, this model encompasses a broad range of factors, and illustrates the complexity of the interaction between these factors. However, as Curbow (2002 p. 48) discusses, "... unfortunately, while there are many clues about the factors that might contribute to causing violence against health-care workers, there is little hard evidence to lead the way to finding solutions." Also, this model does not explicitly take into account which factors are of more relevance in a specific work setting or situation (for example in intermediate care) than others. Therefore, further knowledge is needed to describe the factors associated with patient and visitor violence, as well as the relations between these factors. 
Table 1.1: Factors assosiated with client violence against health care staff, Curbow 2002, page 42-43

\begin{tabular}{|c|c|c|c|c|}
\hline Factor level & \multicolumn{2}{|c|}{ Client characteristics } & \multicolumn{2}{|c|}{ Staff characteristics } \\
\hline \multicolumn{5}{|l|}{ Individual } \\
\hline Cognitive deficits & $x$ & Senile & & \\
\hline Psychiatric disorder & $x$ & & $x$ & \\
\hline Use of drugs or alcohol & $x$ & & $x$ & \\
\hline Length of stay & $x$ & & & \\
\hline $\begin{array}{l}\text { Victim of violence or other } \\
\text { trauma }\end{array}$ & $x$ & $\begin{array}{l}\text { Traumatic life events: } \\
\text { abuse, parental loss }\end{array}$ & $x$ & \\
\hline Level of hostility & $x$ & $\begin{array}{l}\text { Negative affectivity, hostile } \\
\text { attribution style low locus } \\
\text { of control }\end{array}$ & $x$ & \\
\hline Fatigue & & & $x$ & \\
\hline Level of professionalism & & & $x$ & \\
\hline $\begin{array}{l}\text { Training in violence preven- } \\
\text { tion }\end{array}$ & & & $x$ & No training \\
\hline Age & $x$ & Under 45 years & $x$ & Young \\
\hline Gender & $x$ & Male & $x$ & $\begin{array}{l}\text { Contradicting evidence (male or } \\
\text { female) }\end{array}$ \\
\hline Job title & & & $x$ & $\begin{array}{l}\text { Contradicting evidence (lower level } \\
\text { or nurses (mental health, psychia- } \\
\text { try), registered nurses }\end{array}$ \\
\hline Personality variables & $x$ & & $x$ & \\
\hline \multicolumn{5}{|l|}{ Interactional } \\
\hline Confrontational style & $x$ & $\begin{array}{l}\text { Interpret actions of others } \\
\text { in a negative or threatening } \\
\text { manner. Misattribution of } \\
\text { intent }\end{array}$ & $x$ & $\begin{array}{l}\text { Interpret actions of others in a } \\
\text { negative or threatening manner. } \\
\text { Misattribution of intent }\end{array}$ \\
\hline Rushed & & & $\mathrm{X}$ & No time to step back and reflect \\
\hline Presence of others & $x$ & & $x$ & \\
\hline \multicolumn{5}{|l|}{ Work organisation } \\
\hline Environment & $x$ & $\begin{array}{l}\text { Hot temperatures, high } \\
\text { humidity, extreme cold, } \\
\text { poor lighting and air quality, } \\
\text { high noise level, crowding }\end{array}$ & $x$ & $\begin{array}{l}\text { Hot temperatures, high humidity, } \\
\text { extreme cold, poor lighting and air } \\
\text { quality, high noise level, crowding }\end{array}$ \\
\hline Job demands and control & & & $x$ & Low supervisor support \\
\hline Wait time for service & $x$ & & & \\
\hline $\begin{array}{l}\text { Level of bureaucratic de- } \\
\text { mands }\end{array}$ & $x$ & & $x$ & \\
\hline Security features & $\mathrm{X}$ & $\begin{array}{l}\text { Lack of good trained secu- } \\
\text { rity personnel }\end{array}$ & & \\
\hline Visibility work area & $x$ & & & \\
\hline Shift worked & & & $x$ & Late night work schedule \\
\hline Staff level & & & $x$ & understaffing \\
\hline
\end{tabular}




\begin{tabular}{|c|c|c|c|c|}
\hline \multirow{2}{*}{$\frac{\text { Factor level }}{\text { Job turnover }}$} & \multicolumn{2}{|c|}{ Client characteristics } & \multicolumn{2}{|c|}{ Staff characteristics } \\
\hline & & & $x$ & Part time workers \\
\hline \multicolumn{5}{|l|}{ Community/neighbourhood } \\
\hline Level of crime & $x$ & \multicolumn{2}{|l|}{$\begin{array}{l}\text { Patient treated for gunshot } \\
\text { or knife wounds }\end{array}$} & \\
\hline Level of poverty & $x$ & & & \\
\hline Level of drug use & $x$ & & & \\
\hline Density & $x$ & \multirow[t]{2}{*}{ Lack of trust and tolerance } & & \\
\hline Home ownership & $x$ & & & \\
\hline Socioeconomic status & $x$ & \multirow[t]{3}{*}{ low } & & \\
\hline Level of gang violence & $x$ & & & \\
\hline \multicolumn{4}{|l|}{ Societal } & \\
\hline Economic situation & $x$ & & $x$ & \\
\hline $\begin{array}{l}\text { Cultural acceptance of the } \\
\text { expression of anger }\end{array}$ & $x$ & & $x$ & \\
\hline $\begin{array}{l}\text { Cultural acceptance of the } \\
\text { expression of violence }\end{array}$ & $x$ & & $x$ & \\
\hline $\begin{array}{l}\text { Increased diversity in the } \\
\text { workplace }\end{array}$ & $x$ & & $x$ & \\
\hline Shifting family structures & $x$ & & $x$ & \\
\hline
\end{tabular}

The cognitive model of patient aggression towards health care staff: the patient's perspective

The cognitive model of patient aggression towards health care staff (Winstanlay 2005) focuses on patient experiences in general hospitals. It discusses why these experiences are most often anxiety-provoking. Anxiety-provoking experience of patients and visitors is described as a direct attribution to staff action or inaction in the performance of their duties (for example physical examinations, injections, intimidating questioning). In situations other than specific hospital care, these professional tasks would be described as being violent. If patients or visitors cannot interpret these activities as legitimate professional behaviour and do not see them as positive attribution, hostile behaviour or violence may be the result. The potential for such an interpretation of the situation and violent reaction is high because of the anxiety provocation in the situation or behaviour of staff. Winstanlay (2005 p. 345) describes coercion, power and dominance of health care staff in the interaction with patients. Coercion for example occurs in situations in which staff are: "Either trying to make patients do something they would rather not, or perhaps the reverse - stopping them from doing something they wish to do. It is not perhaps very difficult to envisage coercion being used as a tool by some health care staff 
with patients they perceive to be 'misbehaving'. Patients who are not processing information effectively might not have understood a request or might merely be taking longer than normal to process what is happening, but the pressure upon staff to perform their duties as speedily as possible might actually encourage coercive behaviour." In the relationship between patients and visitors, health care staff are naturally in a more powerful role. "This distribution of power is something that all patients are probably conscious of and it might even be exploited by some staff to gain compliance" (Winstanley 2005 p. 345). Without a high level of cognitive processing, this complex interaction could easily lead to misinterpretations. Appraisal and attributional processes are not functioning optimally, because patient's processing is sometimes inhibited by cognitive impairment, other illness caused cognitive problems, alcohol and drug use and medication. Additionally, anxiety narrows perception and can also inhibit the cognitive processes. These factors are considered in the interaction of staff with patients and visitors and lead to the proposed model of aggression towards health care staff as presented in Figure 1.2.

The cognitive model of patient aggression towards health care staff is one of the few models focusing directly on the interaction between staff and patients in general hospitals. It is based on intensive research in the field of patient and visitor violence in the general hospital setting (Whittington et al. 1996, Winstanley 2005, Winstanley \& Whittington 2002, 2004a, b). The anxiety-provoking situation can be easily transferred to the situation of an anxious visitor. Therefore, this model having it's focus on the patient's or visitor's perspective, can improve the understanding regarding the difficulty of the interaction between staff and patient or staff and visitors in the general hospital setting. The model focuses strongly on the patient situation in the moment of interaction and includes marginal staff, patient or visitor and environmental characteristics. As described in the other two models, these factors influence the situation and should not be excluded. However, if other important factors are considered, such a model can provide important information about possible reasons for patient and visitor violence.

\section{Summary}

In summary, the discussed models provide important information in which to structure the complex situation of patient and visitor violence. The personal characteristics of the involved persons, the interaction, the situation in which the interaction takes place and the broader environment must all be taken into consideration. Firstly, the GAM comprehensively describes the origin of violence as being an interaction influenced by personal factors and as being embedded in a situation. When investigating patient and visitor violence, the demographic characteristics, the attitudes, the values, the experiences and preparedness, as well as the cognitive, affective and physical situation of the person are important. Curbow's model 
gives a broader overview regarding the factors associated with client violence in the health care system and also includes the characteristics of the community/neighbourhood and work organisation. Finally, the cognitive model of patient aggression towards health care staff in the general hospital setting focuses, in detail, on the patients' reaction to an anxiety-provoking situation. It fills a gap because it reflects on an incident from the patient's perspective.

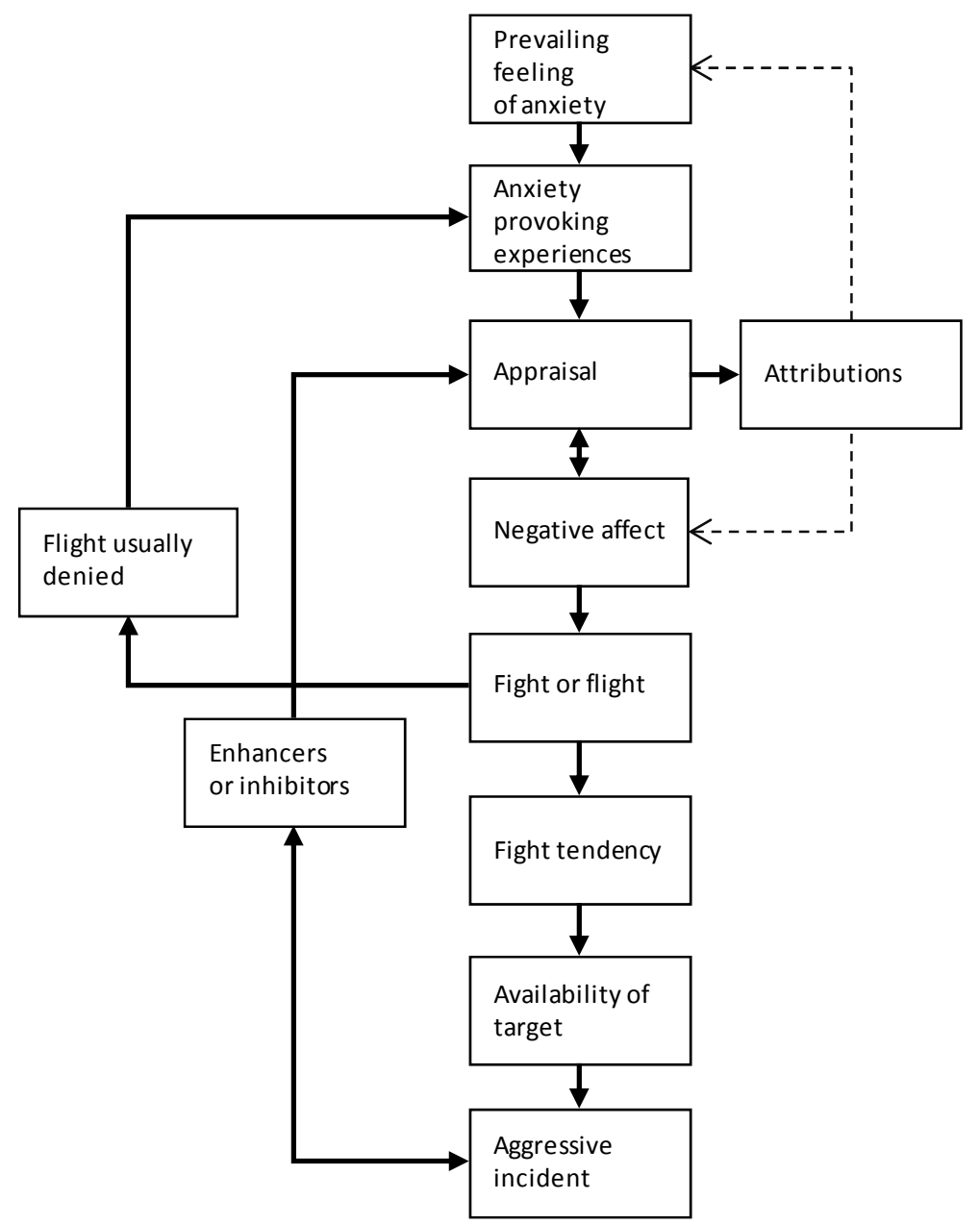

Figure 1.2: Cognitive model of patient aggression towards health care staff: The patient's perspective, Whinstanlay 2005, page 344 


\subsection{IMPLICATION FOR RESEARCH AND PRACTICE}

As discussed in the introduction and as deduced from the theoretical background, the following implications regarding the occurrence of patient and visitor violence prevail for research and practice:

- There is no description focused on the general hospital setting comparing the prevalence of patient and visitor violence experienced by health care staff working on general wards and the detailed factors associated with the problem. Therefore, there is a worldwide lack of data about the problem in this setting. This can lead to an underestimation of the problem, can be an inhibitor for comprehensive research and discussion and also contributes to lack of interventions against the problem in practice.

- There is a lack of research on patient and visitor violence in the general hospital setting, as experienced by health care staff. If, according to the theoretical models, workplace violence is in fact related to community, workplace environment, interactional and individual factors, then investigations which include these factors are important in order to describe the problem. Otherwise, practice cannot address the problem accurately and intervention strategies will not fit the specific settings. In Switzerland (and other German-speaking countries) no initiatives are present that deal with the problem. Therefore, it is important that it is also investigated in Switzerland.

- Because there are no studies addressing patient and visitor violence experienced by health care staff in the general hospital setting in German-speaking Europe, there is no instrument available to describe patient and visitor violence against health care staff in the general hospital setting in the German language. To improve the comparability of data, an internationally comparable instrument needs to be translated and culturally adapted.

\subsection{AIM AND RESEARCH QUESTIONS}

In accordance to the implications, basic knowledge about how patient and visitor violence is experienced by health care staff is required. Only if the problem is described comprehensively, can it be addressed accordingly. Otherwise, specific and effective strategies towards solving the problem cannot be improved on the organisational and personal levels. Therefore, the aim of this dissertation is to explore health care staffs' experience with patient and visitor violence on different general wards in the general hospital setting and to describe factors associated with these violent incidents. The research was conducted in the German-speaking part of Switzerland and was led by the following research questions:

- Which risk factors are described in the international research regarding patient and visitor violence against health care staff in the general hospital setting? 
- Which instruments are used to describe patient and visitor violence against health care staff in the general hospital setting and how valid and reliable are German versions of these instruments?

- How prevalent is patient and visitor violence against health care staff in the general hospital setting in Switzerland?

- What are the risk factors associated with patient and visitor violence in the general hospital setting in Switzerland?

- What support is received following patient and visitor violence and what are the emotional and physical consequences for staff involved?

- Which interventions do health care staff practise in regards to patient and visitor violence and how confident do they feel in managing violence?

\subsection{ETHICAL CONSIDERATIONS}

The local Berne Ethical Commission has approved the study. In every study, participants were provided with written information regarding the study, information regarding the aim of the study as well as the voluntary nature of participation. Informed consent was obtained with completion of the questionnaire and it's return to the research team. No names or other identifiers were used which ensured confidentiality and anonymity.

\subsection{CONTENTS OF THE THESIS}

The dissertation starts with a systematic literature review (chapter 2). This study describes what is known internationally about the frequency of patient and visitor violence against health care staff in general hospitals and which factors are associated with the problem (research questions 1 and 2).

Chapter three describes important instruments used to investigate the factors according to patient and visitor violence against health care staff in the general hospital setting and the feasibility of the Survey of Violence Experienced by Staff (German version revised) after translation to the German language and modification to the Swiss background. It also describes the validity of the shortened Perception of Aggression Scale and the Perception of Importance of Intervention Skills Scale for use in the general hospital setting (research questions 2).

The study presented in chapter four describes nurses' experiences with patient and visitor violence working on different general wards in general hospital settings in Switzerland. This study explores the related factors such as the characteristics of patients/visitors and nurses involved, the interaction between nurses and patients/visitors, as well as the environmental and organisational aspects from nurses' point of view. Additionally, this study outlines the relevance of the problem in Swiss general hospitals (research questions 3, 4, and 6). 
Chapter five describes how often health care staff experiences patient and visitor violence in Swiss general hospital settings, what interventions they use against patient and visitor violence and what consequences this workplace hazard has for the staff. These results are the first part of a comprehensive survey including 2495 health care staff working in a university hospital in Switzerland (research questions $3,4,5,6)$.

Chapter six explores, utilising multiple regression analysis, the risk factors associated with patient and visitor violence as experienced by health care staff in general hospitals in Switzerland (research question 4). 


\subsection{REFERENCES}

Abderhalden C, Needham I, Dassen T, Halfens R, Fischer JE \& Haug HJ (2007): Frequency and severity of aggressive incidents in acute psychiatric wards in Switzerland. Clinial Practice and Epidemiology in Mental Health 3, 30.

Abderhalden C, Needham I, Dassen T, Halfens R, Haug HJ \& Fischer JE (2008): Structured risk assessment and violence in acute psychiatric wards: randomised controlled trial. British Journal of Psychiatry 193, 44-50.

Anderson CA (2000) Violence and Aggression. In Encyclopedia of Psychology (Kazding AE ed.). Oxford University Press and the American Psychological Association, New York \& Washington D.D.

Anderson CA \& Bushman BJ (2002): Human aggression. Annual Review of Psychology 53, $27-51$.

Beech B \& Leather P (2006): Workplace violence in the health care sector: A review of staff training and integration of training evaluation models. Aggression and Violent Behaviour 11, 27-43.

Bjorkly S (2006) Psychological Theories of Aggression: Principles and Application to Practice. In Violence in Mental Health Settings (Richer D \& Whittington R eds.). Springer Science and Business Media, LLC, New York, pp. 27-46.

Bourn J (2003) A Safer Place to Work: Protecting NHS Hospital and Ambulance Staff from Violence and Aggression. The National Audit Office, London, p. 54.

Camerino D, Estryn-Behar M, Conway PM, van Der Heijden BIJM \& Hasselhorn HM (2008): Work-related factors and violence among nursing staff in the European NEXT study: a longitudinal cohort study. International Journal of Nursing Studies 45, 35-50.

Chappell D \& Di Martino V (2006) Violence at Work, Third edition edn. International Labour Office, Geneva, pp. 1-360.

Child RJ \& Mentes JC (2010): Violence Against Women: The Phenomenon of Workplace Violence Against Nurses. Issues in Mental Health Nursing 31, 89-95.

Clements PT, DeRanieri JT, Clark K, Manno MS \& Kuhn DW (2005): Workplace violence and corporate policy for health care settings. Nurs Econ 23, 119-124, 107.

Cooper CL \& Swanson N (2002) Workplace violence in the health sector. State of the Art. International Labour Office, International Council of Nurses, World Health Organization and Public Service International, Geneva.

Curbow B (2002) Origins of violence at work. In Workplace violence in the health sector. State of the Art (Cooper CL \& Swanson N eds.). International Labour Office, International Council of Nurses, World Health Organization and Public Service International, Geneva, pp. 35-48.

Di Martino V (2003) Workplace violence in the health sector. Relationship between work stress and workplace violence in the health sector. In Joint Programme on Workplace Violence in the Health Sector. ILO/ICN/WHO/PSI, Geneva.

Exadaktylos AK, Evangelisti A, Anghern F, Keller U, Dopke K, Ringger A, Jeger V, Zimmermann H, Laffer U \& Guggenbühl A (2010): Measuring attitudes, behaviours, and influences in inner city victims of interpersonal violence (VIVs) - a Swiss emergency room pilot study Journal of Trauma Management \& Outcomes 4, 1-7.

Fernandes CMB, Bouthillette F, Raboud JM, Bullock L, Moore CF, Christenson JM, Grafstein E, Rae S, Ouellet L, Gillrie C \& Way M (1999): Violence in the emergency department a survey of health care workers. Canadian Medical Association Journal 161, 1245-1248.

Ferns T (2006): Violence, aggression and physical assault in healthcare settings. Nursing Standard 21, $42-$ 46.

Franz S, Zeh A, Schablon A, Kuhnert S \& Nienhaus (2010): A Aggression and violence against health care workers in Germany--a cross sectional retrospective survey. BMC Health Service Research 10, 51.

Gallant-Roman MA (2008): Strategies and tools to reduce workplace violence. AAOHN J 56, 449-454. 
Health and Safety Executive (1997) Violence and aggression to staff in health services. Office of Public Sector Information, Information Policy Team, Health and Safety Executive, Kew, Richmond, Surrey TW9 4DU.

Hegney D, Tuckett A, Parker D \& Eley RM (2010): Workplace violence: differences in perceptions of nursing work between those exposed and those not exposed: a cross-sector analysis. Int J Nurs Pract 16, 188-202.

Hills D (2008): Relationships between aggression management training, perceived self-efficacy and rural general hospital nurses' experiences of patient aggression. Contemp Nurse 31, 20-31.

Holmes CA (2006): Violence, zero tolerance and the subversion of professional practice. Contemp Nurse 21, 212-227.

International Labour Office, International Council of Nurses, World Health Organisation \& Public Services International (2002) Workplace Violence in the Health Sector, Geneva.

Jackson D, Clare J \& Mannix J (2002): Who would want to be a nurse? Violence in the workplace - a factor in recruitment and retention. Journal of Nursing Management 10, 13-20.

McKenna K (2004) Study of work-related violence. Committee on Workplace Violence, North Eastern Health Board, Ireland, pp. 1-121.

Milczarek M (2009) Workplace Violence and Harassment: a European Picture. European Agency for Safety and Health at Work, EU-OSHA, Luxembourg.

Morrison E (1990): Violent psychiatric inpatients in a public hospital. Scholarly Inquiry for Nursing Practice 4, 65-82.

National Institute for Clinical Evidence - NICE (2005) Clinical Practice Guidelines Violence: The ShortTerm Management of Disturbed/Violent Behaviour in In-Patient Psychiatric Settings and Emergency Departments. Royal College of Nursing, London.

Needham I (2001) Gewalt gegenüber in der Notfallpflege in der Deutschschweiz. Notfallpflege Schweiz. Available at: www.notfallpflege.ch/text/Informationig.htm (accessed August 13 2005).

Needham I, Abderhalden C, Halfens RJG, Dassen T, Haug HJ \& Fischer JE (2005): The effect of a training course in aggression management on mental health nurses' perception of aggression: A cluster randomised controlled trial. International Journal of Nursing Studies.

Nijman HLI (2002): A model of aggression in psychiatric hospitals. Acta Psychiatrica Scandinavica 106, $142-143$.

Paterson B, Leadbetter D \& Miller G (2005): Beyond Zero Tolerance: a varied approach to workplace violence. British Journal of Nursing 14, 810-815.

Peek-Asa C, Casteel C, Allareddy V, Nocera M, Goldmacher S, Ohagan E, Blando J, Valiante D, Gillen M \& Harrison $R$ (2009): Workplace violence prevention programs in psychiatric units and facilities. Arch Psychiatr Nurs 23, 166-176.

Richter D \& Needham I (2007): Effekte von mitarbeiterbezogenen Trainingsprogrammen zum Aggressionsmanagement in Einrichtungen der Psychiatrie und Behindertenhilfe. Systematische Literaturübersicht [Effects of aggression management trainings for mental health care and disability care staff--systematic review]. Psychiatrische Praxis 34, 7-14.

Rippon TJ (2000): Aggression and violence in health care professions. Journal of Advanced Nursing 31, $452-460$.

Steck-Egli R (2005) Aggressionsereignisse auf Notfallstationen. In Philosophische Fakultät. Universität Zürich, Zürich, p. 76.

Steinert T, Eisele F, Goeser U, Tschoeke S, Uhlmann C \& Schmid P (2008): Successful interventions on an organisational level to reduce violence and coercive interventions in in-patients with adjustment disorders and personality disorders. Clinical Practice and Epidemiology in Mental Health 4, 27.

Stokowski LA (2010) Violence: Not in My Job Description. www.medscape.com.

Ventura-Madangeng J \& Wilson D (2009): Workplace violence experienced by registered nurses: a concept analysis. Nursing Praxis in New Zealand 25, 37-50. 
Wells J \& Bowers L (2002): How prevalent is violence towards nurses working in general hospitals in the UK? Journal of Advanced Nursing 39, 230-240.

Whittington R, Shuttleworth S \& Hill L (1996): Violence to staff in a general hospital setting. Journal of Advanced Nursing 24, 326-333.

Winstanley S (2005): Cognitive model of patient aggression towards health care staff: The patient's perspective. Work \& Stress 19, 340-350.

Winstanley S \& Whittington R (2002): Violence in a general hospital: comparison of assailant and other assault-related factors on accident and emergency and inpatient wards. Acta Psychiatrica Scandinavica 106 (Suppl. 412), 144-147.

Winstanley S \& Whittington R (2004a): Aggression towards health care staff in a UK general hospital: variation among professions and departments. Journal of Clinical Nursing 13, 3-10.

Winstanley S \& Whittington R (2004b): Aggressive Encounters Between Patients and General Hospital Staff: Staff Perceptions of the Context and Assailants' Levels of Cognitive Processing. Aggressive Behavior 30, 534-543.

Wiskow C (2003) Guidelines on Workplace Violence in the Health Sector. In Joint Programme on Workplace Violence in the Health Sector (ILO/ICN/WHO/PSI ed.). ILO/ICN/WHO/PSI, Geneva.

Zarola A, Leather P \& Barklamb K (2008) Work-related violence. Royal College of Nursing, London. 


\section{CHAPTER TWO}

\section{Patient and visitor violence in general hospitals: \\ a systematic review of the literature}

Hahn S, Zeller A, Needham I, Kok G, Dassen T \& Halfens RJG (2008): Patient- and visitor violence in general hospitals: A systematic review of the literature. Journal of Aggression and Violent Behavior 13, 431-441. 


\subsection{ABSTRACT}

Background. Patient and visitor violence is a complex occupational hazard for health care staff working in general hospitals.

Aim and design. In order to reduce the deficit of information regarding this kind of patient and visitor violence, a systematic literature review that describes and summarizes the current scientific knowledge on this topic was conducted.

Results. The literature search identified 84 studies. These were analyzed for research quality and those with good or moderate research quality were selected ( $n=$ 31). In most studies, a retrospective self reported cross-sectional design and a broad definition of violence were employed. Additionally, most of the questionnaires applied were developed by the researchers and utilized different retrospective time frames. Unfortunately, information about the validity of the questionnaires was often lacking.

Discussion and Conclusion. Results of this review suggest that patient and visitor violence is a serious problem for health care staff in general hospitals, especially those working in medical and surgical units. Workplace characteristics and the interaction between patients and staff are important contextual factors that can contribute to the development of violent incidents. Because the studies reviewed employed different methodologies, instruments, and definitions, comparison was difficult. We, therefore, recommend that future research use clearer conceptual frameworks and unique instruments. 


\subsection{INTRODUCTION}

Work-related violence in the health care system is a complex and dangerous occupational hazard for health care staff that has increased continuously in recent years (Beech \& Leather 2006, Cooper \& Swanson 2002). Among all occupational groups, health care workers are ranked as one of the most likely groups to experience workplace aggression (Bourn 2003, Chappell \& Di Martino 2006, Wells \& Bowers 2002). Unfortunately, the definitions of violence or aggression used in research on this topic are inconsistent. This hampers the comparison of research results (Chappell \& Di Martino 2006, Lau \& Magarey 2006, Rippon 2000). Nevertheless, numerous studies have shown that work-related violence can negatively affect the psychological and physical wellbeing of health care staff (Needham, Abderhalden, Halfens, Fischer \& Dassen 2005, Richter \& Berger, 2000, Stanko 2002). It can also impact upon their job motivation and the quality of the care they provide (Arnetz \& Arnetz 2001; Needham et al. 2005). An additional important yet often forgotten impact of work-related violence is the financial loss ensued by the health care system (Bourn 2003, McKenna 2004, Philbrick, Sparks, Hass \& Arsenault 2003). While extensive efforts have been made to understand the processes involved in patient and patient's relatives or visitor violence in psychiatric settings, relatively few attempts have been made to examine the problem in general health care settings (Cooper \& Swanson 2002, Duxbury \& Whittington 2005, Winstanley \& Whittington 2002) despite the fact that patient and visitor violence in general hospitals is a serious problem for all staff categories in all clinical departments (Hegney, Plank \& Parker 2003, Hesketh et al. 2003, Winstanley \& Whittington 2004a). Little is known about the frequency of patient and visitor violence, the context in which these events occur, and the effect of patient and visitor violence on health care staff in general hospitals (O'Connell, Young, Brooks, Hutchings \& Lofthouse 2000, Whittington, Shuttleworth \& Hill 1996, Winstanley \& Whittington 2004a). Most studies have focused on accident and emergency departments (Fernandes et al. 1999, Lau, Magarey \& McCutcheon 2006). To date, no literature review has summarized research results on patient and visitor violence in general hospitals. The main research questions in the present literature review were therefore: (1) How often does patient and visitor violence against health care staff in general hospitals occur and what is known about the different forms of violence?; (2) In which contexts does patient and visitor violence occur in general hospital settings?; and (3) What are the patient, visitor, and staff characteristics that contribute to violence? In this study, violence was considered synonymous to aggression (Rippon 2000). And patient and visitor violence was defined as any verbal, nonverbal, or physical behaviour that threatens others or property, or that actually harms others or property (Morrison 1990). 


\subsection{METHOD}

The following electronic databases were searched: Medline, Cochrane Library, Cumulative Index to Nursing and Allied Health

Literature (CINAHL), PsycINFO, Physiotherapy Evidence Database (PEDro) and Midwifery and Infant Care (MIDIRS). The search was limited to articles with abstracts in German or English published in the last 16 years (from 1990 to August, 2006). The keywords used and the search results are listed in Table 2.1. In addition to the search, the references in the articles were screened for missed research articles. Unpublished manuscripts were collected by approaching experts and colleagues with knowledge in the field. The 84 publications initially selected were first analyzed for their content according to the research questions. The following publications were excluded: (1) publications reporting on research in the field of psychiatric and accident and emergency health care (these were excluded because their settings and patients' state of health do not compare well with those in general hospitals and because in these fields literature reviews already exist) (Davis 1991, Gadon, Johnstone \& Cook 2006, Lau et al. 2006); (2) publications in which the research results were not clearly linked to a general hospital, its wards and/or its professionals; (3) publications in which the research results were not clearly assigned to patient and visitor violence against health care staff; and (4) publications that were not based on research (for example opinions, comments, or anecdotal material).

Table 2.1: Search history and results

\begin{tabular}{|c|c|c|c|c|}
\hline \multirow{2}{*}{$\begin{array}{l}\text { Keywords used } \\
\text { Limits } \\
\text { Source }\end{array}$} & \multicolumn{4}{|c|}{$\begin{array}{l}\text { (violence OR aggression OR patient assault) AND (general hospital OR workplace) } \\
\text { Published: } 1996 \text {-August 2006, only items with abstracts in English or German }\end{array}$} \\
\hline & Hits & $\begin{array}{l}\text { Selection based on } \\
\text { reading abstract } \\
\text { (checked for overlaps) }\end{array}$ & $\begin{array}{l}\text { Selection based on } \\
\text { content analysis of the } \\
\text { publication }\end{array}$ & $\begin{array}{l}\text { Selection based on } \\
\text { critical appraisal of } \\
\text { the publication }\end{array}$ \\
\hline Medline & 523 & 50 & 27 & 25 \\
\hline Cochrane & 1 & 0 & & \\
\hline CINAHL & 187 & 15 & 1 & 1 \\
\hline Psyclnfo & 204 & 4 & 1 & 1 \\
\hline PEDro & 0 & & & \\
\hline MIDIRS & 224 & 4 & 0 & \\
\hline others & & 11 & 9 & 7 \\
\hline Total publications & 1159 & 84 & 41 & $34^{\mathrm{a}}$ \\
\hline
\end{tabular}

${ }^{\mathrm{a}} 31$ studies, because three studies published results in two articles.

Following the application of the exclusion criteria, 41 publications remained. These were then critically appraised on their research quality using criteria recommended by Polit and Tatano Beck (2003). The research team selected twelve criteria upon 
which they rated the qualitative and quantitative study designs. For each criterion, the study was coded as 1 if the criterion was fulfilled and 0 if it was not. In doing this, scores were generated (maximum of 12 points). All studies that scored a minimum of 7 points and fulfilled the fourth criterion, namely "The design has no major flaws", were included for further analysis. A score of 7 or 8 was seen as indicative of adequate research quality, 9 or 10 points reflected good research quality and 11 or 12 points indicated that the study had very good research quality. In this validation process, two researchers independently assessed half of the articles ( $n=$ 22) using the same 12 criteria. The inter-rater agreement for the quality of the chosen publications was calculated using the AC1 statistic (Gwet 2002). This measure of inter-rater reliability circumvents the problem of instability accruing from differences in marginal probabilities between raters that can occur when applying the Kappa statistic. Each criterion had a very good AC1 measure and an overall AC1 score of 0.97 , which was interpreted as very good. The Kappa statistic chancecorrected measure of inter-rater reliability was also used and produced measures between 0.65 (on one item) and 1.00 (on six items), thus demonstrating a very good overall Kappa of 0.92 .

In the assessment process, 34 publications were allocated seven and more points. Three of these studies were published twice. Therefore, in the end, 31 studies were included in this review (see Table 2.2). By analyzing the content using the research questions, the following results relating to patient and visitor violence in general hospital were explored: a) methodology and study design; b) the description of violent behaviour; c) the incidence and forms of patient and visitor violence; d) the context in which patient and visitor violence occurs; e) information about perpetrators; and f) information about harmed health care staff. 


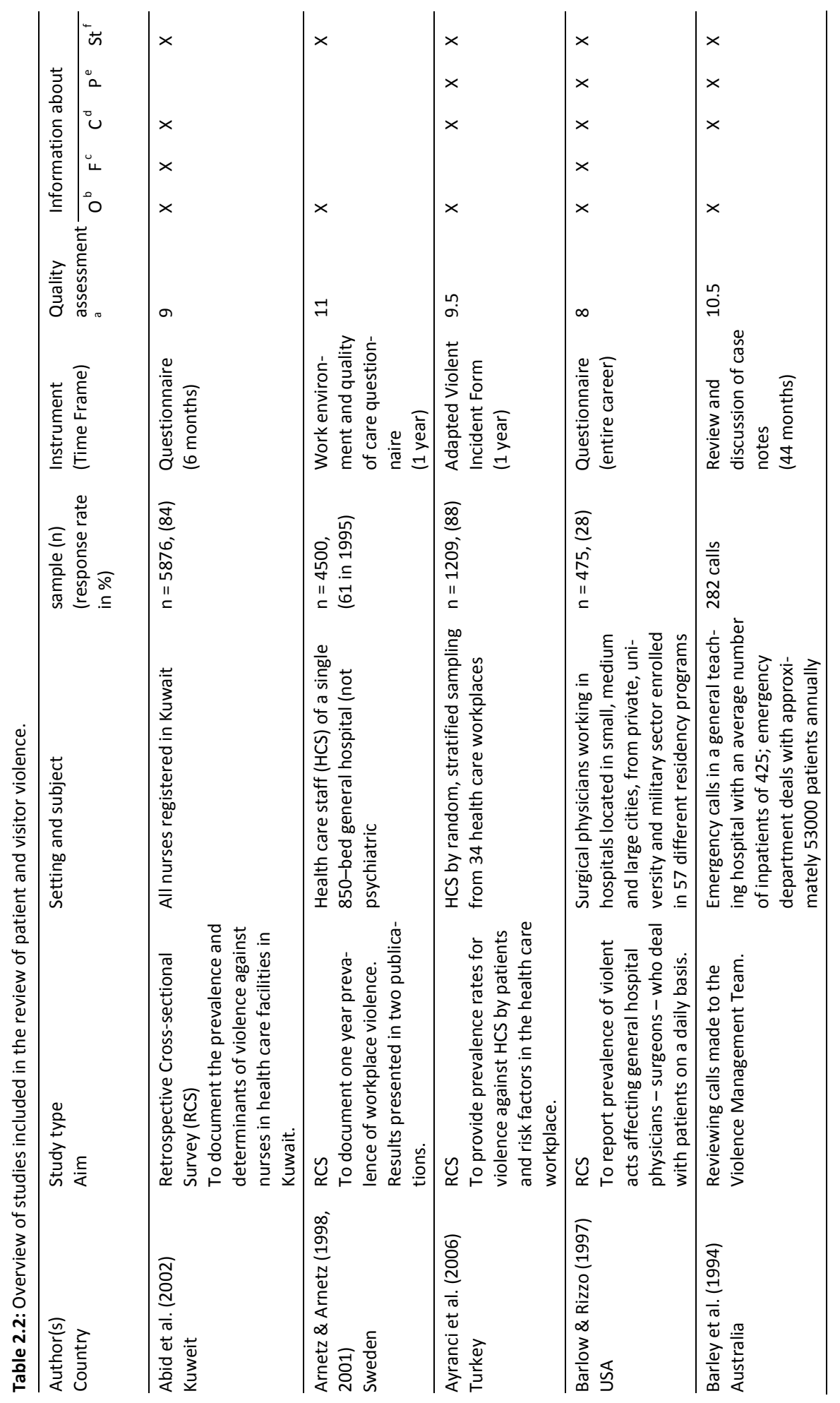




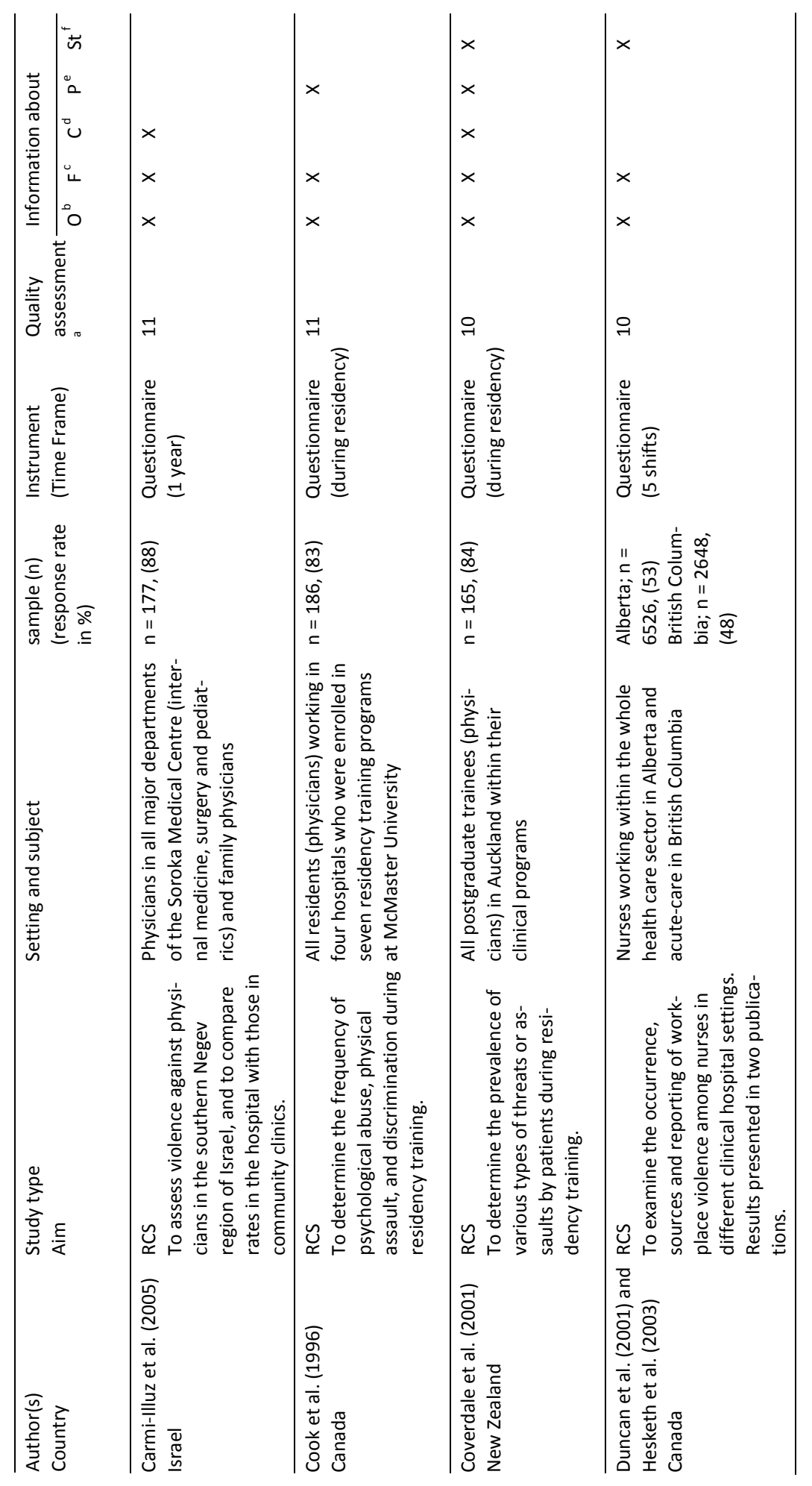




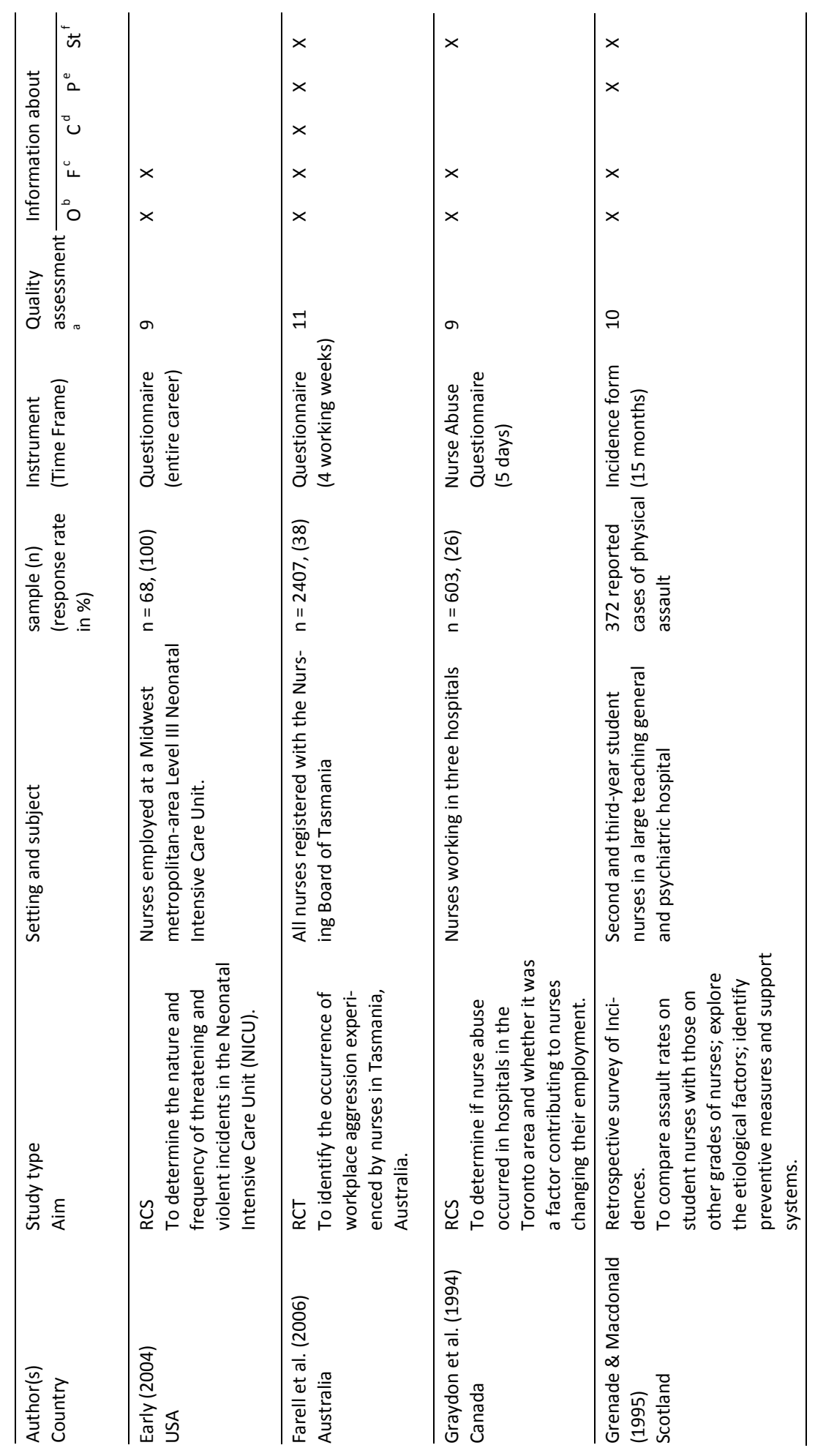




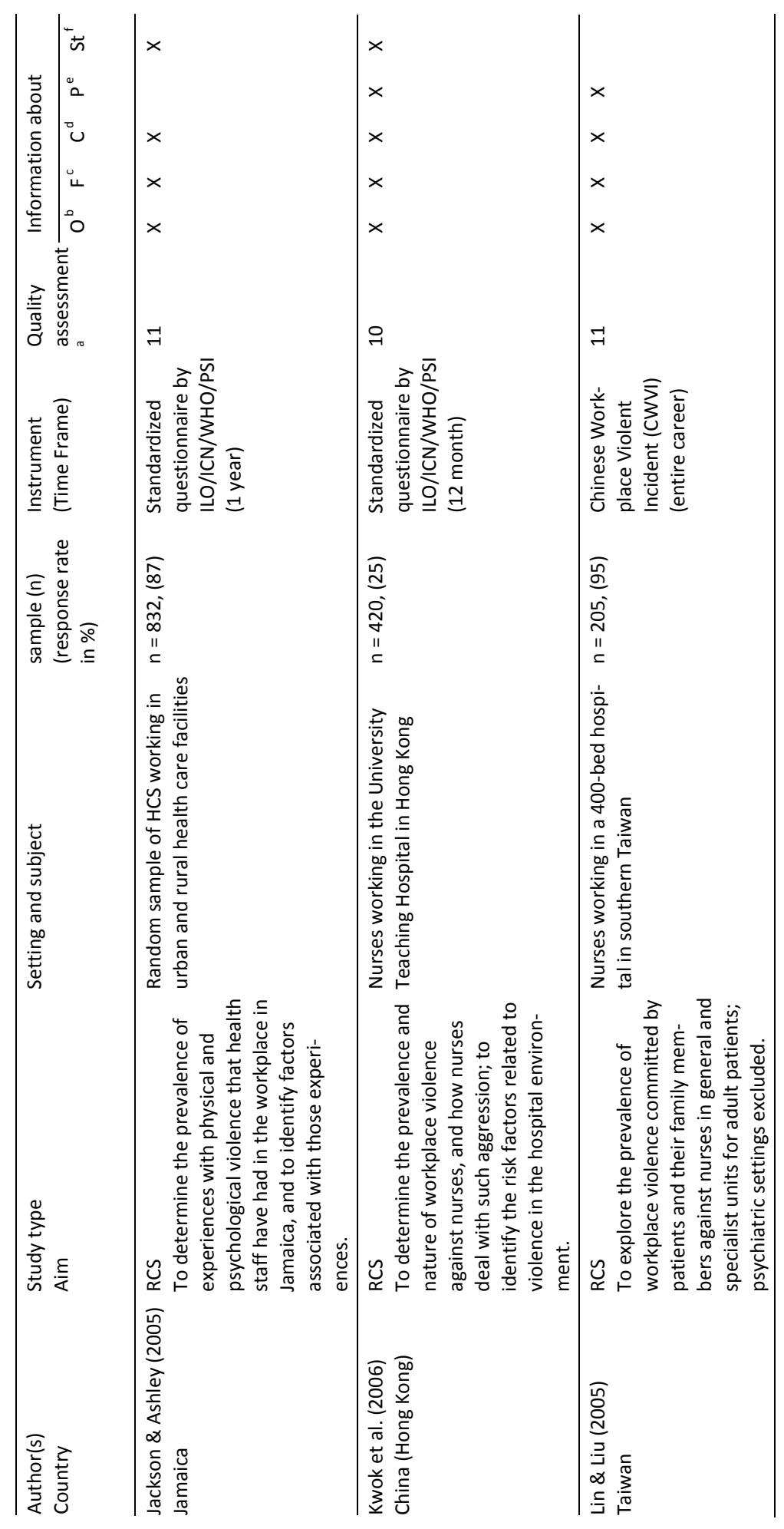




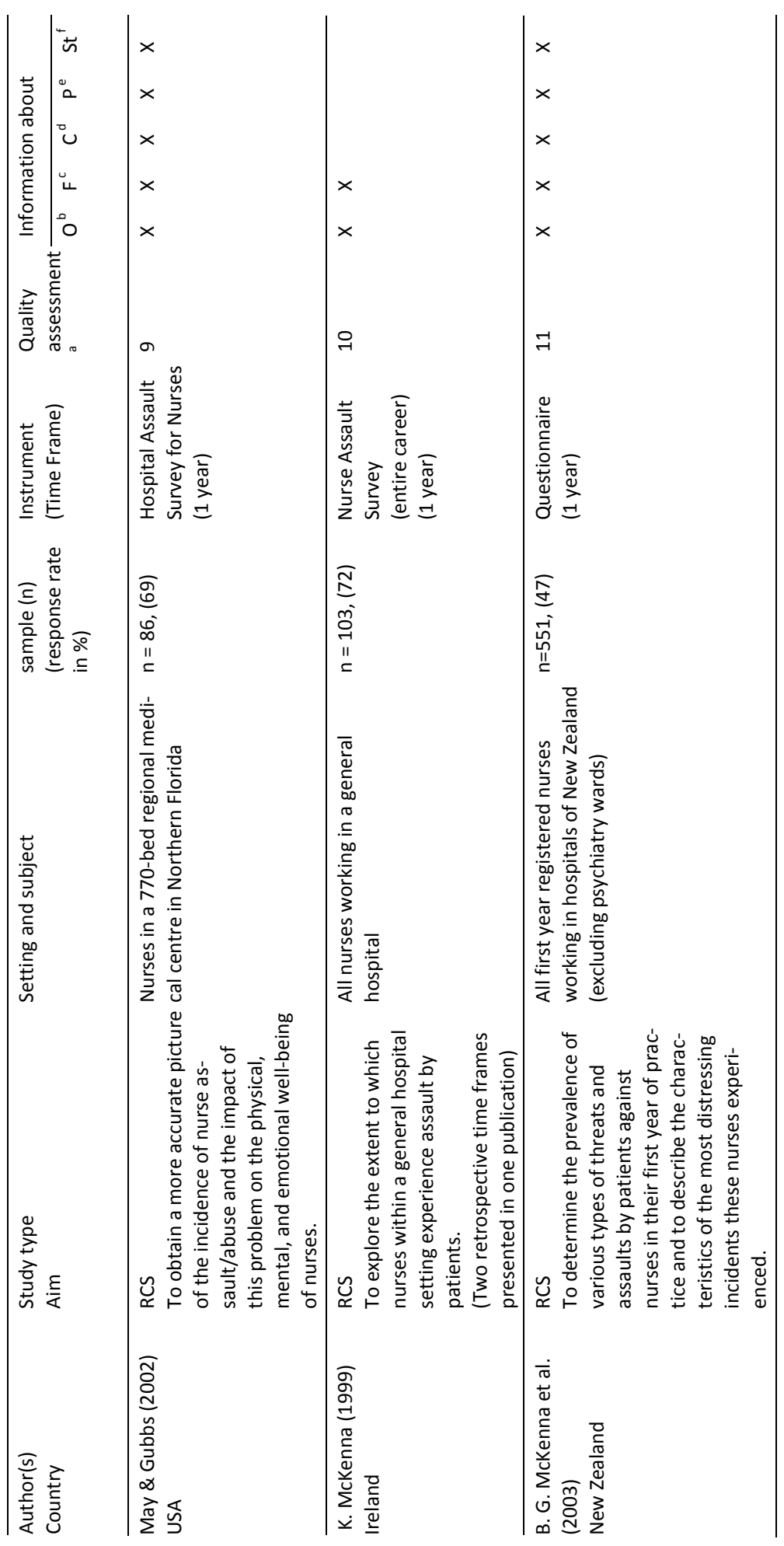




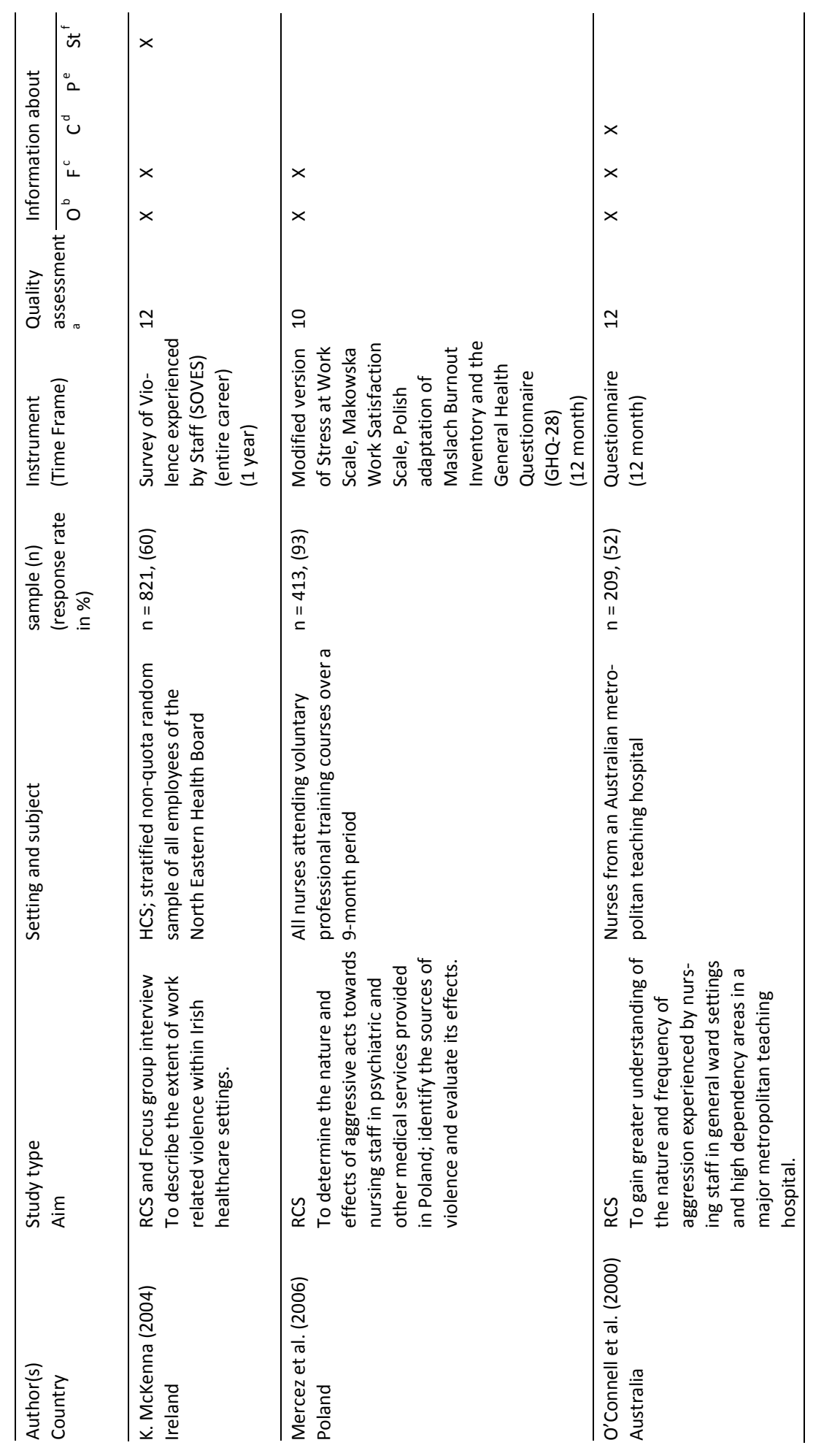




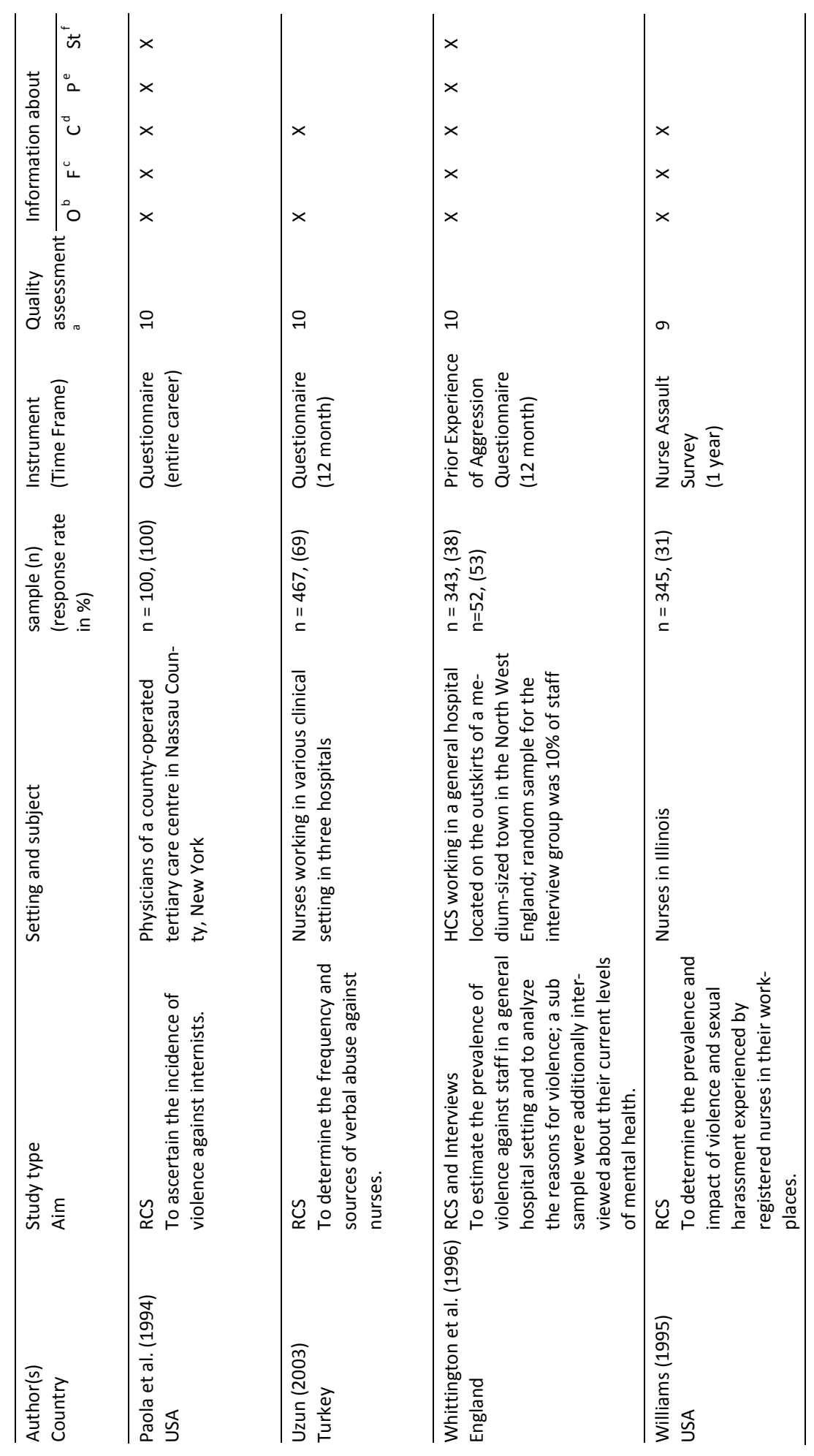




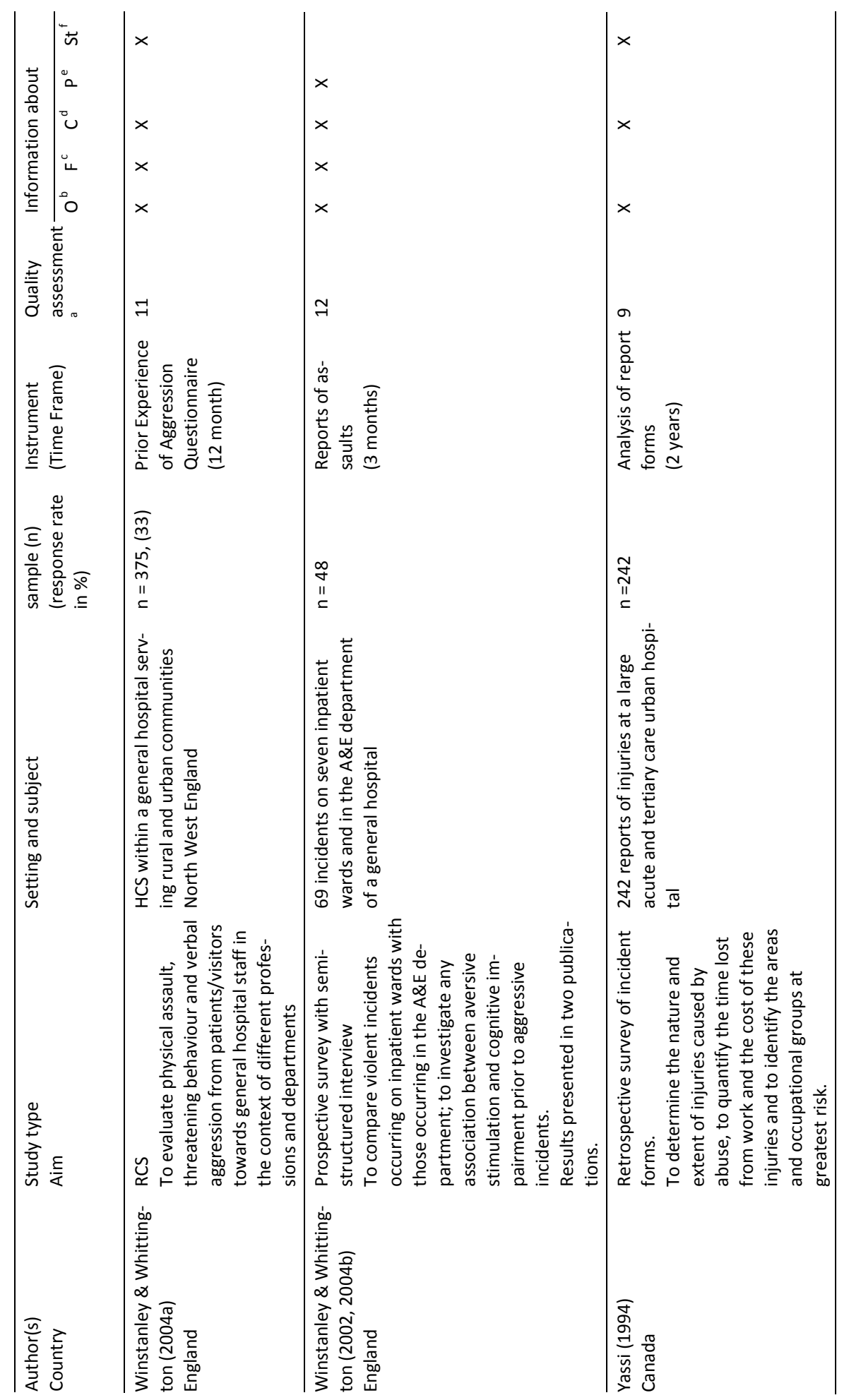




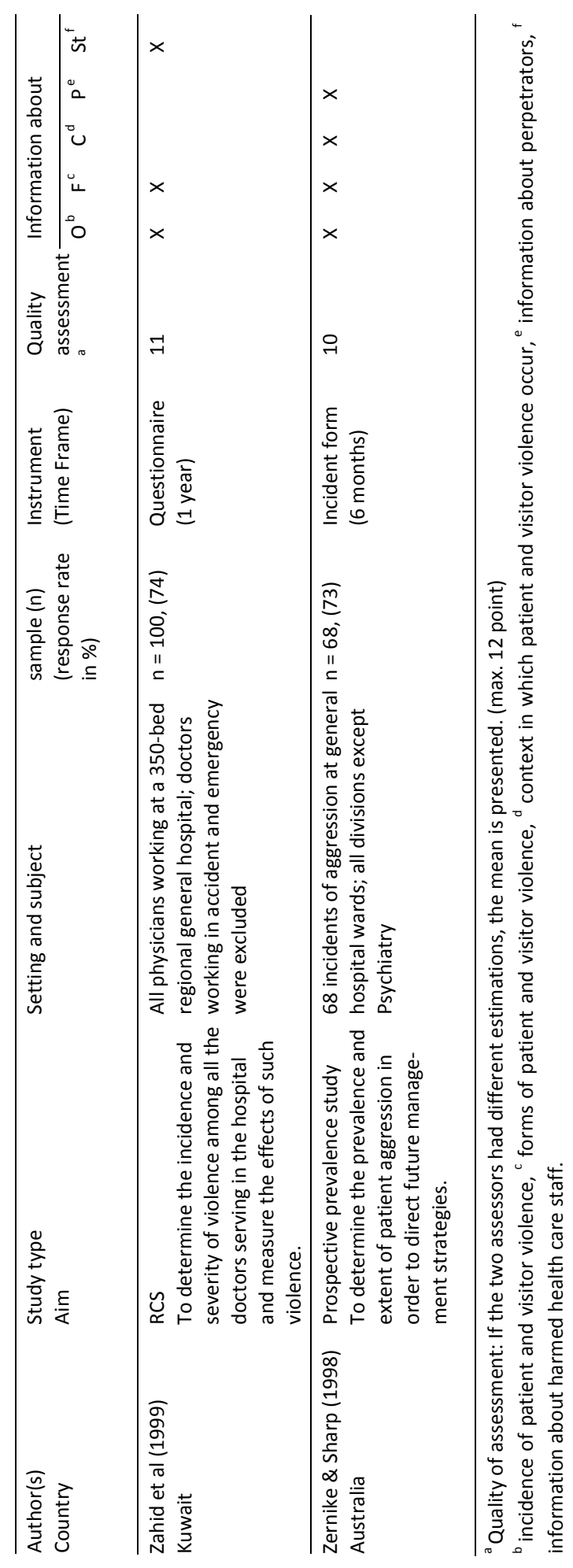




\subsection{RESULTS}

\section{Methodology and study design}

Of the 31 studies selected, 26 were retrospective cross-sectional surveys (RCS) that focused on staff experiences with different forms of patient and visitor violence in general hospitals. In these RCS, 14 investigated nurses' experiences, 6 looked at medical doctors' experiences and another 6 focused on all health care staff. Ten studies in our selection had a sample size of over 500 and most studies had a high response rate of over $60 \%$. The majority of the RCS used questionnaires developed by the individual research groups. Only five publications provided information on the validity or reliability of the instruments used. In most studies, a retrospective time frame of one year was selected (see Table 2.2).

Five studies investigated the phenomenon based on the occurrence of violent incidents. These studies used a variety of approaches and instruments. The methods used in these studies included retrospective analysis of patient and visitor violence managed by a violence management team (Brayley, Lange, Baggoley, Bond \& Harvey 1994), prospective surveys with semi-structured interviews (Winstanley \& Whittington 2002, 2004b), and retrospective surveys of patient and visitor violence forms (Grenade \& Macdonald 1995, Yassi 1994, Zernike \& Sharpe 1998). Only one study provided information on inter-observer and inter-coder reliability.

\section{Description of violent behaviour}

Of the 31 studies included, 11 provided either a minimal definition of violence or none at all. The other publications employed various terms to describe violence or aggressive behaviour. These descriptions can be categorized as psychological or physical violence (Cook et al. 1996, Jackson \& Ashley 2005). The definitions used often distinguish between verbal abuse, threatening behaviour, physical assault and sexual harassment by describing each behaviour in detail (Duncan et al., 2001; Farrell, Bobrowski \& Bobrowski 2006, McKenna 2004, Merecz, Rymaszewska, Moscicka, Kiejna \& Jarosz-Nowak 2006, Winstanley \& Whittington 2004a) (see Table 2.3). 
Table 2.3: Description of violent behaviour

\begin{tabular}{|c|c|c|c|}
\hline Violence & Behaviour & Description & Examples \\
\hline \multirow[t]{3}{*}{ Psychological } & $\begin{array}{l}\text { Verbal abuse, } \\
\text { psychological abuse, } \\
\text { emotional abuse, } \\
\text { verbal violence, emo- } \\
\text { tional violence. }\end{array}$ & $\begin{array}{l}\text { Verbal abuse is a communication } \\
\text { through words, tone or manner } \\
\text { that made people feel hurt } \\
\text { personally or professionally. }\end{array}$ & $\begin{array}{l}\text { Shouting, screaming, yelling, } \\
\text { swearing, ignoring, disre- } \\
\text { spectful comments, racial } \\
\text { harassment, attack of another } \\
\text { person through harsh words, } \\
\text { cursing, aggressive manner of } \\
\text { speech, personal insults. }\end{array}$ \\
\hline & $\begin{array}{l}\text { Threatening behaviour, } \\
\text { threats, } \\
\text { verbal threats, } \\
\text { threats of assault. }\end{array}$ & $\begin{array}{l}\text { Threatening behaviour uses } \\
\text { words, gestures, or actions with } \\
\text { the intent of intimidating, fright- } \\
\text { ening, or harming. }\end{array}$ & $\begin{array}{l}\text { Punching the wall, overturn- } \\
\text { ing furniture, banging or a } \\
\text { throwing an object, or threat- } \\
\text { ening with a knife. }\end{array}$ \\
\hline & $\begin{array}{l}\text { Verbal sexual harass- } \\
\text { ment, } \\
\text { sexual impropriety. }\end{array}$ & $\begin{array}{l}\text { Sexual harassment is a behaviour } \\
\text { that uses gestures or expressions } \\
\text { that demonstrate a lack of re- } \\
\text { spect for privacy or is sexually } \\
\text { demeaning. }\end{array}$ & $\begin{array}{l}\text { Verbal sexual transgression, } \\
\text { no respect for sexual orienta- } \\
\text { tion. }\end{array}$ \\
\hline \multirow[t]{2}{*}{ Physical } & $\begin{array}{l}\text { Physical assault, bat- } \\
\text { tery, } \\
\text { physical violence, } \\
\text { physical act, } \\
\text { physical intimidation. }\end{array}$ & $\begin{array}{l}\text { Physical assault is a physically } \\
\text { hurting contact, regardless of } \\
\text { whether an injury was sustained. }\end{array}$ & $\begin{array}{l}\text { Rough handling, hitting, } \\
\text { pushing, slapping, kicking, } \\
\text { biting, pulling, pinching, } \\
\text { grabbing, scratching, shoot- } \\
\text { ing. }\end{array}$ \\
\hline & $\begin{array}{l}\text { Sexual assault, un- } \\
\text { wanted sexual contact, } \\
\text { unwelcome sexual } \\
\text { behaviour. }\end{array}$ & $\begin{array}{l}\text { Sexual assault is forced physical } \\
\text { sexual contact. }\end{array}$ & $\begin{array}{l}\text { Forcible touching, fondling, } \\
\text { forced sexual acts, sexual } \\
\text { intercourse. }\end{array}$ \\
\hline
\end{tabular}

\section{Incidence and form of patient and visitor violence}

Over the course of the investigated period (1990 to 2006), a steady increase from less than one study per year (1990 - 1994) to more than three studies per year (2005 - 2006) on patient and visitor violence could be observed. This was considered indicative of a growing interest in the subject over the past two decades. However, it is important to note that, in recent years, the total number of publications has also increased. Further, the incidence of patient and visitor violence reported in the studies is not such that we can speak of a trend.

In six studies, the participants were asked if they had ever been a victim of patient and visitor violence at their work and, if so, what forms of violent behaviour they had ever experienced (Barlow \& Rizzo 1997, Early 2004, Lin \& Liu 2005, McKenna 1999, 2004, Paola, Malik \& Qureshi 1994). The studies highlighted that all health professions are at high risk for experiencing various forms of patient and visitor violence at some point in time throughout their career. The four studies that distinguished between patient and visitors as aggressors revealed that patients are clearly the primary aggressors, especially with respect to physical attacks (see Table 2.5). 
In 16 studies, the participants were asked if they had experienced patient and visitor violence in the past year (see Table 2.4). All investigated staff groups had experienced more verbal than physical patient and visitor violence. Since only two studies investigated physicians' experiences with patient and visitor violence (Carmi-Iluz, Peleg, Freud \& Shvartzman 2005, Zahid, al-Sahlawi, Shahid, al-Ajmi \& Awadh 1999), no conclusions on patient and visitor violence against doctors could be drawn. Nonetheless, the level of experienced violence appeared to be relatively high. In general, nurses reported more patient and visitor violence than other staff groups. In fact, about half of health care staff reported having experienced patient violence while almost all nurses reported having been exposed to patient and visitor violence. An exception was a study that presented lower numbers of patient and visitor violence incidents against nurses that had recently graduated (McKenna, Smith, Poole \& Coverdale 2003). Once again, verbal violence was more frequent than physical violence and patients were more violent than visitors. However, there were some cultural exceptions (Ayranci, Yenilmez, Balci \& Kaptanoglu 2006, Carmilluz et al. 2005).

Table 2.4: Percentage of health professionals in general hospital that reported having experienced patient and visitor violence at some point in time during their career

\begin{tabular}{|c|c|c|c|c|c|c|c|c|}
\hline \multirow[t]{2}{*}{ Authors } & \multirow[t]{2}{*}{ Profession } & \multicolumn{3}{|c|}{$\begin{array}{l}\text { patient and visitor violence } \\
\text { in } \%\end{array}$} & \multicolumn{2}{|c|}{$\begin{array}{l}\text { Patient violence } \\
\text { in } \%\end{array}$} & \multicolumn{2}{|c|}{$\begin{array}{l}\text { Visitor violence } \\
\text { in } \%\end{array}$} \\
\hline & & verbal & threats & physical & verbal & physical & verbal & physical \\
\hline $\begin{array}{l}\text { McKenna }(2004)^{a} \\
\text { Ireland }\end{array}$ & $\mathrm{HCS}$ & $60^{b}$ & $31^{b}$ & $27^{b}$ & & & & \\
\hline $\begin{array}{l}\text { Barlow \& Rizzo } \\
\text { (1997) } \\
\text { USA }\end{array}$ & $\begin{array}{l}\text { surgical } \\
\text { physicians }\end{array}$ & & 51 & 38 & 63 & & 30 & \\
\hline $\begin{array}{l}\text { Paola et al. (1994) } \\
\text { USA }\end{array}$ & physicians & 41 & & 16 & 29 & 14 & 13 & 1 \\
\hline $\begin{array}{l}\text { Early (2004) } \\
\text { USA }\end{array}$ & nurses $^{c}$ & 35 & 31 & 7.5 & & & & \\
\hline $\begin{array}{l}\text { Lin \& Liu (2005) } \\
\text { Taiwan }\end{array}$ & nurses & & & & 38 & 11 & 30 & 0 \\
\hline $\begin{array}{l}\text { McKenna (1999) } \\
\text { Ireland }\end{array}$ & nurses & & & & $\begin{array}{l}87 \\
67^{d}\end{array}$ & 50 & & \\
\hline
\end{tabular}

\footnotetext{
${ }^{a}$ Used also a time frame of one year and is therefore also included in Table 2.4.

${ }^{\mathrm{b}}$ Included violence from co-workers and others.

${ }^{c} 54 \%$ of the nurses working in the Intensive Care Unit experienced some type of violence.

${ }^{\mathrm{d}}$ Verbal threat and threat with an object.
} 
Table 2.5: Percentage of health professionals in general hospitals that reported having experienced patient and visitor violence in the past year

\begin{tabular}{|c|c|c|c|c|c|c|c|}
\hline \multirow[t]{2}{*}{ Authors } & \multirow{2}{*}{$\begin{array}{l}\text { Profes- } \\
\text { sional }\end{array}$} & \multicolumn{3}{|c|}{ Patient violence in \% } & \multicolumn{3}{|c|}{ Visitor violence in \% } \\
\hline & & verbal & threats & physical & verbal & threats & physical \\
\hline $\begin{array}{l}\text { Arnetz \& Arnetz } \\
(2001) \\
\text { Sweden }\end{array}$ & $\begin{array}{l}\text { Health care } \\
\text { staff }(\mathrm{HCS})\end{array}$ & $9^{a}$ & & & $2.5^{a}$ & & \\
\hline $\begin{array}{l}\text { Ayranci (2006) } \\
\text { Turkey }\end{array}$ & $\mathrm{HCS}$ & $15^{\mathrm{a}}$ & & & $28^{\mathrm{a}}$ & & \\
\hline $\begin{array}{l}\text { Jackson (2005) } \\
\text { Jamaica }\end{array}$ & $\mathrm{HCS}$ & 22 & 5 & 5 & 5.5 & 1 & 1.5 \\
\hline $\begin{array}{l}\text { McKenna (2004) } \\
\text { Ireland }\end{array}$ & $\mathrm{HCS}$ & 45 & 24 & 23 & 15 & 0.1 & 1.4 \\
\hline $\begin{array}{l}\text { Whittington et al. } \\
\text { (1996) } \\
\text { England }\end{array}$ & $\mathrm{HCS}$ & $\begin{array}{l}56^{a} \\
43\end{array}$ & 17 & 21 & & & \\
\hline $\begin{array}{l}\text { Winstanley \& Whit- } \\
\text { tington (2004a) } \\
\text { England }\end{array}$ & $\mathrm{HCS}$ & $68^{a}$ & 23 & 27 & & 15.5 & 1.4 \\
\hline $\begin{array}{l}\text { Carmi-Illuz et al. } \\
\text { (2005) } \\
\text { Israel }\end{array}$ & physicians & 54 & & 3 & 73 & & 6 \\
\hline $\begin{array}{l}\text { Zahid et al. (1999) } \\
\text { Kuwait }\end{array}$ & physicians & $\begin{array}{l}\text { verbal: } \\
\text { threats } \\
\text { physica }\end{array}$ & & & & & \\
\hline $\begin{array}{l}\text { Kwok et al. (2006) } \\
\text { Hong Kong }\end{array}$ & nurses & $59^{b}$ & $33^{b}$ & $16^{b}$ & $54^{b}$ & $30^{b}$ & $0.5^{b}$ \\
\hline $\begin{array}{l}\text { McKenna }(1999)^{c} \\
\text { Ireland }\end{array}$ & nurses & 80 & 37 & 47 & & & \\
\hline $\begin{array}{l}\text { Mercez et al. (2006) } \\
\text { Poland }\end{array}$ & nurses & 89 & 64 & 21 & & & \\
\hline $\begin{array}{l}\text { May \& Gubbs (2002) } \\
\text { USA }\end{array}$ & nurses & 91 & 70 & 58 & 74 & 35 & \\
\hline $\begin{array}{l}\text { O’Connel et al. (2000) } \\
\text { Australia }\end{array}$ & nurses & 84 & $10^{b}$ & 53 & $68^{b}$ & $28^{b}$ & $1^{b}$ \\
\hline $\begin{array}{l}\text { Uzun, (2003) } \\
\text { Turkey }\end{array}$ & nurses & $75-97$ & & & & & \\
\hline $\begin{array}{l}\text { Williams (1995) } \\
\text { USA }\end{array}$ & nurses & & & $\begin{array}{l}23 \\
53^{c}\end{array}$ & & & \\
\hline $\begin{array}{l}\text { McKenna et al. } \\
\text { (2003) } \\
\text { New Zealand }\end{array}$ & $\begin{array}{l}\text { new gradu- } \\
\text { ate nurses }\end{array}$ & $\begin{array}{l}13 \\
28^{\mathrm{c}}\end{array}$ & 30 & $\begin{array}{l}26 \\
13^{\mathrm{c}}\end{array}$ & & & \\
\hline
\end{tabular}


The remaining RCS explored patient and visitor violence in different retrospective time frames that varied from six months (Adib, Al-Shatti, Kamal, El-Gerges \& AlRaqem 2002) to four working weeks (Farrell et al. 2006) to the past five shifts (Duncan et al. 2001, Graydon, Kasta \& Khan 1994). Two RCS explored physicians' experiences with violence during their residency training (Cook et al. 1996; Coverdale, Gale, Weeks \& Turbott 2001). While comparisons of patient and visitor violence incidence between these studies were difficult, we did conclude that the incidence corresponded with the RCS that used a one year time frame.

Five studies investigated patient and visitor violence in general hospitals by referring to violent incidents. These studies used different methodological approaches, time frames and units to present their results. Therefore, the results relating to the incidence and forms of patient and visitor violence could not be evaluated systematically. However, they did demonstrate that patient and visitor violence is prominent in general hospitals.

\section{Context of patient and visitor violence}

Due to the varied results, it is unclear whether violent events occurred more often during the day, during visiting hours, or during night shifts (Adib et al. 2002, Lin \& Liu 2005, Zernike \& Sharpe 1998). However, we did establish that patients were often aggressive during the first two to three days after admission (Winstanley \& Whittington 2002, Zernike \& Sharpe 1998). This suggests that patient and visitor violence is in part related to organizational and workplace characteristics and to interactions between the patient, the patient's relatives and health care staff.

The organizational characteristics contributing to patient and visitor violence included procedures to check the patient's identity (Whittington et al. 1996), prolonged waiting times (Ayranci 2005, Carmi-lluz et al. 2005, May \& Grubbs 2002, Paola et al. 1994, Whittington et al. 1996), unavailability of a doctor (Whittington et al. 1996, Winstanley \& Whittington 2004b), anger about hospital policies and rules (May \& Grubbs 2002, Whittington et al. 1996), and discharge procedures (Winstanley \& Whittington 2004b).

Regarding the workplace characteristics, public general hospitals had the highest incidence of patient and visitor violence in three studies (Ayranci et al. 2006, Barlow \& Rizzo 1997, Farrell et al. 2006). Not taking emergency departments into consideration, the highest incidence of violence was observed in medical wards (Ayranci 2005, Jackson \& Ashley 2005, O'Connell et al. 2000, Williams 1995, Yassi 1994), surgical settings (Brayley et al. 1994, Coverdale et al. 2001, Kwok et al. 2006, O'Connell et al. 2000, Uzun 2003, Whittington et al. 1996, Winstanley \& Whittington 2004a) and intensive care units (May \& Grubbs 2002). Women and child care or paediatric clinical settings were also listed as high risk settings for verbal abuse or threatening behaviour (McKenna, Poole, Smith, Coverdale \& Gale 2003, Uzun 2003, Winstanley \& Whittington 2004a, Yassi 1994). 
The following characteristics of patient and health care provider interactions that contribute to patient and visitor violence were found in the studies: misunderstandings or disputes regarding medical issues (Lin \& Liu 2005), patients thinking that they are not being taken seriously (Lin \& Liu 2005), dissatisfaction with treatment or physician (Carmi-Iluz et al. 2005, Paola et al. 1994), physical contact during the provision of care or during a physical assessment (Adib et al. 2002, Winstanley \& Whittington 2004b) that is accompanied by pain or that crosses boundaries relating to intimate areas or private spheres (Whittington et al. 1996), frustration with the patients' intention, enforced personal care and enforced medical treatment (Winstanley \& Whittington 2004b), or the disagreement over care provision and treatment by staff (Winstanley \& Whittington 2004b) or by the patient (Carmi-Iluz et al. 2005, Whittington et al. 1996).

\section{Characteristics of violent patients and visitors}

Patients between the ages of 15 and 40 (Ayranci 2005, Barlow \& Rizzo 1997, Brayley et al. 1994, McKenna et al. 2003) and between the ages of 70 and 85 (Brayley et al. 1994) were found to be the most aggressive. Additionally, the review showed that perpetrators of violence tend to be male (Brayley et al. 1994, Cook et al. 1996, Coverdale et al. 2001, Farrell et al. 2006, Kwok et al. 2006, McKenna et al. 2003). The patient's state of health was also an important factor. Altered mental health states that may incline a patient to be aggressive included: recovering from unconsciousness, prolonged organic brain syndrome (May \& Grubbs 2002, Whittington et al. 1996, Winstanley \& Whittington 2004b), dementia (Brayley et al. 1994, Zernike \& Sharpe 1998), delirium, confusion and /or high arousal (Brayley et al. 1994, Grenade \& Macdonald 1995, Lin \& Liu 2005, Whittington et al. 1996, Winstanley \& Whittington 2004b), alcohol or illegal drug intoxication or withdrawal (Brayley et al. 1994. Grenade \& Macdonald 1995, Lin \& Liu 2005, May \& Grubbs 2002, Whittington et al. 1996, Winstanley \& Whittington 2004b, Zernike \& Sharpe 1998) and mental illness, mental handicap or psychiatric history (Brayley et al. 1994, Paola et al. 1994, Whittington et al. 1996).

Visitors tended to be aggressive towards ambulance personnel (McKenna et al. 2003) or paediatric staff (Winstanley \& Whittington 2004a). Further, intoxication and stress were also mentioned as contributing factors to violent behaviour (Lin \& Liu 2005, May \& Grubbs, 2002).

\section{Characteristics of harmed health care staff}

In general, male nurses were at higher risk for patient and visitor violence (Adib et al., 2002; Farrell et al., 2006; McKenna et al., 2003) and, in the study conducted by Coverdale et al. (2001), female physicians were more likely to report having been sexually harassed. The mean ages of staff reporting having been exposed to vio- 
lence seemed to be lower than that of staff reporting no exposure to violence (Duncan et al. 2001, Farrell et al. 2006, Jackson \& Ashley 2005, Whittington et al. 1996). Less job experience was also found to be indicative for higher risk rates of patient and visitor violence (Adib et al. 2002, Ayranci et al. 2006, Graydon et al. 1994, Whittington et al. 1996).

For staff groups, nurses were at highest risk for experiencing patient and visitor violence in a one year retrospective time frame (Ayranci 2005, Jackson \& Ashley 2005, Winstanley \& Whittington 2004a). This was also the case in an analysis of incident reports over a time period of two years (Yassi 1994). For occupational therapists, laboratory technicians, and physical therapists or midwives, decreased risks were found in studies with a one year retrospective time frame (Arnetz, Arnetz \& Soderman 1998, Whittington et al. 1996).

\subsection{DISCUSSION}

The main results of this study demonstrate that patient and visitor violence is a prominent professional risk for health care professions. On average, $50 \%$ have experienced verbal patient and visitor violence and $25 \%$ have experienced physical patient and visitor violence. Important factors contributing to patient and visitor violence are the hospital organizational context, interactions between patients, patient visitors and health care staff, and the health of the patient. Additionally, the results have shown that nurses are clearly at highest risk for patient and visitor violence.

Health care professionals working in general hospitals are at high risk for experiencing various forms of violence at some point during their career and also during the time frame of one year. Studies most often discriminate between verbal and physical violence. Threats and verbal violence are more common among patients than visitors. Additionally, patients tend to be more violent than visitors. This corresponds with the results of reviews conducted by Beech \& Leather (2006) and by Wells \& Bowers (2002).

The results presented here suggest that the context in which health care staff work also contributes to the development of patient and visitor violence incidents. Some organizational procedures, such as prolonged waiting times and difficult interactions between professionals and patients/visitors, can be considered customer unfriendly and therefore increase the likelihood of patient and visitor violence (Hinson \& Shapir, 2003). Adequate management strategies are needed to improve this situation (Chappell \& Di Martino 2006).

Interactions in which patient or visitors endure frustrating experiences also contribute to patient and visitor violence in general hospitals. Examples include procedures that induce pain and/or anxiety and procedures that encouraged the patient to feel as though he or she is not being taken or treated seriously (Winstanley 2005). In order to deal with this, health care staff need to apply careful and 
adequate strategies that ensure the safety and comfort of the patient, and to do this, health care staff need knowledge, experience, and special education (Beech 1999, Winstanley 2005). Professionals should also consider the characteristics of the workplace, the characteristics of the patient-provider interaction and the patient's current health state when attempting to prevent violence and intervene in a professional manner (Duxbury 2002, Duxbury \& Whittington 2005, Whittington \& Wykes 1996).

The patient's health state can also contribute to violent incidents. For example, patients with reduced cognitive abilities often have difficulty understanding situations adequately. This may lead us to believe that some patient and visitor violence is inevitable, and thus also imply that the risks for patient and visitor violence are higher in some wards. However, instead of simply accepting patient and visitor violence as a reality in these wards, health care staff should assess the extent to which patients or relatives have problems understanding the situation and then attempt to increase that understanding. As stated above, these situations require specific interventions and the temporal resources of staff (Winstanley \& Whittington 2004b).

Within the complex context of patient and visitor violence, there seems to be an association between a high frequency of violence in the past year and staff groups who have close patient contact in stressful situations. This may explain why nurses are at higher risk for patient and visitor violence. Additionally, it is not surprising that younger staff and staff with less experience have higher risk rates for patient and visitor violence. However, to date, there are only a few studies that investigate this topic specifically and the results are ambiguous.

\section{Limitations of the study}

This literature review investigating patient and visitor violence against health care staff in 31 studies has several limitations. Firstly, each study revealed only a limited part of this complex phenomenon. Second, as the studies investigated employed different definitions of violent or aggressive acts, the comparative analysis must be interpreted with caution (Chappell \& Di Martino 2006, Lau \& Magarey 2006, Rippon 2000). Third, the research results reported in most articles were derived from surveys that asked health care staff to recollect past experiences. As a result, recall bias cannot be excluded. Fourth, the studies showed methodological heterogeneity in terms of design (retrospective versus prospective), method (different questionnaires, interviews, and incidents forms), research population (health care staff, physicians, or nurses) and cultural backgrounds thus complicating comparisons. Fifth, in many studies, results relating to patient and visitor violence are partial results derived from studies that focused on workplace violence in general. These studies therefore lack detailed information on patient and visitor violence. Lastly, 
despite having employed an extensive research strategy, publication bias cannot be excluded.

A major limitation is the inconsistent use of the research variables aggression and violence. Often the term violence was used and descriptions were categorized either psychological or physical violence. This distinction is important because both forms of violent behaviour can seriously affect the victims of assaults (Beech \& Leather 2006) and because violence tends to occur along a continuum from verbal to physical attacks (Hinson \& Shapiro 2003). In accordance with the explanation provided by Rippon (2000), it appears as though violence and aggression were often used synonymously. Clearly, defining aggression and violence in such a way that the definition is clear but not too limiting remains a major challenge when conducting and presenting studies.

\subsection{CONCLUSION AND RECOMMENDATIONS FOR FURTHER RESEARCH}

The results of this review demonstrate the complex interplay between the various factors that contribute to patient and visitor violence. Patient and visitor violence occurs frequently in general hospitals and manifests predominately in the form of psychological violence. Organizational and workplace characteristics as well as patient-provider interactions are important contextual factors that can impact the incidence of patient and visitor violence. Additionally, patients with a disturbed mental health state sometimes react violently during interactions with health care staff. Nurses are most frequently targeted. In order to better comprehend and ultimately prevent violence between patients/relatives and health care staff, future research projects should aim to develop a complex model that includes organizational, situational, personnel-related and interaction-related factors. Additionally, since studies investigating this complex process in general hospitals are limited, more research is necessary.

Patient and visitor violence seems to be dependent on the social and cultural context of the health care system. Consequently, it is difficult to compare patient and visitor violence studies. Future studies should endeavour to use a clear conceptual framework regarding patient and visitor violence. Additionally, dialogue and discussions amongst members of the research community should be encouraged so that a more consistent definition of aggression and violence can be developed. Given the wide range of instruments used to investigate patient and visitor violence, we further recommend that researchers validate instruments so that comparisons can be effectively made. 


\subsection{REFERENCES}

Adib SM, Al-Shatti AK, Kamal S, El-Gerges N \& Al-Raqem M (2002): Violence against nurses in healthcare facilities in Kuwait. International Journal of Nursing Studies 39, 469-478.

Arnetz JE \& Arnetz BB (2001): Violence towards health care staff and possible effects on the quality of patient care. Social Science and Medicine 52, 417-427.

Arnetz JE, Arnetz BB, \& Soderman E (1998): Violence toward health care workers. Prevalence and incidence at a large, regional hospital in Sweden. American Association of Occupational Health Nurses 46, 107-114.

Ayranci U (2005): Violence toward health care workers in emergency departments in west Turkey. Journal of Emergency Medicine 28, 361-365

Ayranci U, Yenilmez C, Balci Y \& Kaptanoglu C (2006): Identification of violence in Turkish health care settings. Journal of Interpersonal Violence 21, 276-296.

Barlow CB \& Rizzo AG (1997): Violence against surgical residents. The Western Journal of Medicine 167, 74-78.

Beech B (1999): Sign of the times or the shape of things to come? A 3-day unit of instruction on 'aggression and violence in health settings for all students during pre-registration nurse training'. Nurse Education Today 19, 610-616.

Beech B \& Leather P (2006): Workplace violence in the health care sector: A review of staff training and integration of training evaluation models. Aggression and Violent Behaviour 11, 27-43.

Bourn J (2003): A Safer Place to Work: Protecting NHS Hospital and Ambulance Staff from Violence and Aggression. London: The National Audit Office.

Brayley J, Lange R, Baggoley C, Bond M \& Harvey P (1994): The violence management team. An approach to aggressive behaviour in a general hospital. Medical Journal of Australia 15, 254-258.

Carmi-Iluz T, Peleg R, Freud T \& Shvartzman P (2005): Verbal and physical violence towards hospital- and community-based physicians in the Negev: an observational study. Bio Med Central Health Service Research 5, 1-6.

Chappell D \& Di Martino V (2006): Violence at Work. (Third edition ed.). Geneva: International Labour Office.

Cook DJ, Liutkus JF, Risdon CL, Griffith LE, Guyatt GH \& Walter SD (1996): Residents' experiences of abuse, discrimination and sexual harassment during residency training. McMaster University Residency Training Programs. Canadian Medical Association Journal 154, 1657-1665.

Cooper CL \& Swanson N (2002) Workplace violence in the health sector. State of the Art. International Labour Office, International Council of Nurses, World Health Organization and Public Service International, Geneva.

Coverdale J, Gale C, Weeks S \& Turbott S (2001): A survey of threats and violent acts by patients against training physicians. Medical Education 35, 154-159.

Davis S (1991): Violence by psychiatric inpatients: a review. Hospital and Community Psychiatry 42, 585590.

Duncan SM, Hyndman K, Estabrooks CA, Hesketh K, Humphrey CK, Wong JS, Acorn S \& Giovannetti P (2001): Nurses' experience of violence in Alberta and British Columbia hospitals. Canadian Journal of Nursing Research 32, 57-78.

Duxbury J (2002): An evaluation of staff and patient views of and strategies employed to manage inpatient aggression and violence on one mental health unit: a pluralistic design. Journal of Psychiatric and Mental Health Nursing 9, 325-337

Duxbury J \& Whittington R (2005): Causes and management of patient aggression and violence: staff and patient perspectives. Journal of Advanced Nursing 50, 469-478.

Early MR (2004): Recognizing and managing violence in the NICU. Neonatal Network 23, 31-34.

Farrell GA, Bobrowski C \& Bobrowski P (2006): Scoping workplace aggression in nursing: findings from an Australian study. Journal of Advanced Nursing 55, 778-787. 
Fernandes CMB, Bouthillette F, Raboud JM, Bullock L, Moore CF, Christenson JM, et al. (1999): Violence in the emergency department a survey of health care workers. Canadian Medical Association Journal 161, 1245-1248.

Gadon L, Johnstone L, \& Cook D (2006): Situational variables and institutional violence: A systematic review of the literature. Clinical Psychology Review 26, 515-534.

Graydon J, Kasta W \& Khan P (1994): Verbal and physical abuse of nurses. Canadian Journal of Nursing Administration 7, 70-89.

Grenade G \& Macdonald E (1995): Risk of physical assaults among student nurses. Occupational Medicine (London) 45, 256-258.

Gwet K (2002): Inter-Rater Reliability: Dependency on Trait Prevalence and Marginal Homogeneity. Series: Statistical Methods For Inter-Rater Reliability Assessment, Retrieved 8th August, 2006, from http://www.stataxis.com/files/articles/inter_rater_reliability_dependency.pdf

Hegney D, Plank A \& Parker V (2003): Workplace violence in nursing in Queensland Australia: A selfreported study. International Journal of Nursing Practice 9, 261-268.

Hesketh KL, Duncan SM, Estabrooks CA, Reimer MA, Giovannetti P, Hyndman K, et al. (2003): Workplace violence in Alberta and British Columbia hospitals. Health Policy 63, 311-321.

Hinson J \& Shapiro M (2003): Violence in the workplace: awareness and prevention. Australian Health Review 26, 84-91.

Jackson M \& Ashley D (2005): Physical and psychological violence in Jamaica's health sector. Revista Panamericana de Salud Pública/Pan American Journal of Public Health 18, 114-121.

Kwok RP, Law YK, Li KE, Ng YC, Cheung MH, Fung VK, Kwok KT, Tong JM, Yen PF \& Leung WC (2006): Prevalence of workplace violence against nurses in Hong Kong. Hong Kong Medical Journal 12, 6-9

Lau JB \& Magarey J (2006): Review of research methods used to investigate violence in the emergency department. Accident and Emergency Nurse 14, 111-116.

Lau JB, Magarey J \& McCutcheon H (2006): Violence in the emergency department: A literature review. Australian Emergency Nursing Journal 7, 27-37.

Kwok RP, Law YK, Li KE, Ng YC, Cheung MH, Fung VK, Kwok KT, Tong JM, Yen PF \& Leung WC (2006): Prevalence of workplace violence against nurses in Hong Kong. Hong Kong Medical Journal 12, 6-9

May DD \& Grubbs LM (2002): The extent, nature, and precipitating factors of nurse assault among three groups of registered nurses in a regional medical centre. Journal of Emergency Nursing 28, 11-17..

McKenna B, Smith NA, Poole SJ \& Coverdale JH (2003): Horizontal violence: experiences of Registered Nurses in their first year of practice. Journal of Advanced Nursing 42, 90-96.

McKenna, B. G., Poole, S. J., Smith, N. A., Coverdale, J. H., \& Gale, C. G. (2003). A survey of threats and violent behaviour by patients against registered nurses in their first year of practice. International Journal of Mental Health Nursing, 12(1), 56-63.

McKenna BG, Poole SJ, Smith NA, Coverdale JH \& Gale CG (2003): A survey of threats and violent behaviour by patients against registered nurses in their first year of practice. International Journal of Mental Health Nursing 12, 56-63.

McKenna K (2004) Study of work-related violence. Committee on Workplace Violence, North Eastern Health Board, Ireland, pp. 1-121.

Merecz D, Rymaszewska J, Moscicka A, Kiejna A \& Jarosz-Nowak J (2006): Violence at the workplace-a questionnaire survey of nurses. European Psychiatry 21, 442-450.

Morrison E (1990): Violent psychiatric inpatients in a public hospital. Scholarly Inquiry for Nursing Practice 4, 65-82.

Needham I, Abderhalden C, Halfens RJ, Fischer JE \& Dassen T (2005): Non-somatic effects of patient aggression on nurses: a systematic review. Journal of Advanced Nursing 49, 283-296.

O'Connell B, Young J, Brooks J, Hutchings J \& Lofthouse J (2000): Nurses' perceptions of the nature and frequency of aggression in general ward settings and high dependency areas. Journal of Clinical Nursing 9, 602-610. 
Paola F, Malik T \& Qureshi A (1994): Violence against physicians. Journal of General Internal Medicine 9, 503-506.

Polit DF \& Tatano Beck C (2003) Nursing research: principles and methods, 7 edn. Lippincott Williams \& Wilkins, Philadelphia.

Philbrick J, Sparks M, Hass M \& Arsenault S (2003): Workplace violence: The legal costs can kill you. American Business Review, 21, 84-90.

Richter D \& Berger K (2000): Physische und psychische Folgen bei Mitarbeitern nach einem Patientenübergriff: Eine prospektive Untersuchung in sechs psychiatrischen Kliniken. ArbeitsmedizinSozialmedizin-Umweltmedizin 35, 357-362.

Rippon TJ (2000): Aggression and violence in health care professions. Journal of Advanced Nursing 31, $452-460$.

Stanko EA (2002): Knowledge about the impact of violence at work in the health sector. University of Manchester: Institute of Science and Technology, United Kingdom. National Institute of Occupational Safety and Health, United States.

Uzun $O$ (2003): Perceptions and experiences of nurses in Turkey about verbal abuse in clinical settings. Journal of Nursing Scholarship 35, 81-85.

Wells J \& Bowers L (2002): How prevalent is violence towards nurses working in general hospitals in the UK? Journal of Advanced Nursing 39, 230-240.

Whittington R, Shuttleworth S \& Hill L (1996): Violence to staff in a general hospital setting. Journal of Advanced Nursing 24, 326-333.

Whittington R \& Wykes T (1996): An evaluation of staff training in psychological techniques for the management of patient aggression. Journal of Clinical Nursing 5, 257-261.

Williams M (1995): The prevalence and impact of violence and sexual harassment of registered nurses in the workplace. Chart 92, 5-6.

Winstanley S (2005): Cognitive model of patient aggression towards health care staff: The patient's perspective. Work \& Stress 19, 340-350.

Winstanley S \& Whittington R (2002): Violence in a general hospital: comparison of assailant and other assault-related factors on accident and emergency and inpatient wards. Acta Psychiatrica Scandinavica 106 (Suppl. 412), 144-147.

Winstanley S \& Whittington R (2004a): Aggression towards health care staff in a UK general hospital: variation among professions and departments. Journal of Clinical Nursing 13, 3-10.

Winstanley S \& Whittington R (2004b): Aggressive Encounters Between Patients and General Hospital Staff: Staff Perceptions of the Context and Assailants' Levels of Cognitive Processing. Aggressive Behavior 30, 534-543.

Yassi A (1994): Assault and abuse of health care workers in a large teaching hospital. Canadian Medical Association Journal 151, 1273-1279.

Zahid MA, al-Sahlawi KS, Shahid AA, al-Ajmi MT \& Awadh JA (1999): Violence towards doctors: prevalence and effects. Hospital Medicine 60, 414-418.

Zernike W \& Sharpe P (1998): Patient aggression in a general hospital setting: do nurses perceive it to be a problem? International Journal of Nursing Practice 4, 126-133. 


\section{CHAPTER THREE}

\section{Measuring patient and visitor violence in general hospitals:}

Feasibility of the SOVES-G-R, internal consistency and construct validity of the POAS-S and the POIS

Hahn S, Müller M, Needham I, Dassen T, Kok G \& Halfens RJG (2011): Measuring patient and visitor violence in general hospitals: feasibility of the SOVES-G-R, internal consistency and construct validity of the POAS-S and the POIS. Journal of Clinical Nursing. 20, 2519-2530. 


\subsection{ABSTRACT}

Aims. To investigate the feasibility of a survey measuring patient and visitor violence after translation and modification, namely the Survey of Violence Experienced by Staff (German version revised) and to validate the shortened Perception of Aggression Scale (POAS-S) and the Perception of Importance of Intervention Skills Scale (POIS) after adaptation for use in a general hospital setting.

Background. The use of different approaches and research instruments for investigating patient and visitor violence negatively influences the comparability of studies. Typically, general hospitals use self-administered surveys. However, support for these instruments' validity is insufficient.

Methods. Between November 2006-January 2007, 291 nurses working in general hospitals in the German-speaking region of Switzerland completed the SOVES-G-R, the POAS-S and the POIS (response rate $=71 \%$ ).

Results. The participants' responses demonstrated a need for modifications to enhance the feasibility of the SOVES-G-R in two categories, namely experiences with patient and visitor violence in 'the past 12 months' and in 'the past working week'. The POAS-S revealed the same factor solution as in earlier studies, with two factors explaining $38 \%$ of variance. In the POIS, two factors were distinguished: (1) structured interventions and evaluation and (2) the importance of preventive measures.

Conclusions. The SOVES-G-R, the POAS-S and the POIS are adequate for investigating factors influencing the occurrence of patient and visitor violence in general hospitals. Given the changes in the SOVES-G-R and the moderate size of our sample, further testing with a larger sample is recommended.

Relevance to clinical practice. The instruments help determine which clinical settings have a greater risk of patient and visitor violence and the specific factors that influence this risk. This can facilitate the implementation of situation-specific preventive measures against patient and visitor violence in general hospitals. 


\subsection{INTRODUCTION}

Globally, work-place violence is considered an occupational burden (Camerino et al. 2008). In the health care system, violence is not restricted to high-risk areas such as emergency rooms and psychiatric settings (Hahn et al. 2008, Wells \& Bowers 2002). The most common form of violence in hospitals is patient and visitor violence (Camerino et al. 2008). However, research on PVV in general hospitals is still in its infancy (Hahn et al. 2008). Typically, retrospective cross-sectional surveys (RCS) of staff experiences are used. Studies to assess PVV at the moment of its occurrence and qualitative approaches using in-depth interviews are also rarely performed (Hahn et al. 2008). The RCS in general health care settings use a large variety of self-administered survey questionnaires to investigate workplace violence. However, the theoretical background of these survey questionnaires is seldom described and detailed information about the validity of the questionnaires is rare (Hahn et al. 2008). Further the instruments currently used manly encompass some single factors (like interaction process or patient characteristics) in the occurrence of PVV. This could limit the focus on the problem and conceal the description of the complexity of the situation and the important influencing factors, explaining existing conflicting study results (Hahn et al. 2008).

To strengthen the focus on the challenging problem of PVV three instruments were combined to include the relevant factors in the occurrence of PVV in general hospitals: the German version of the Survey of Violence Experienced by Staff (SOVES, McKenna, 2004) revised (SOVES-G-R), the shortened Perception of Aggression Scale (POAS-S, Needham et al. 2004) and the Perception of Importance of Intervention Skills Scale (POIS, developed by the authors). In this cross-sectional study, feasibility of the translated and face-validated SOVES-G-R was investigated and validity of POAS-S and the POIS was tested for use in German-speaking general hospitals.

\subsection{BACKGROUND}

The International Labour Office et al. (2002) and the EU Commission (Cooper \& Swanson 2002) recommend using a broad definition of violence that incorporates both physical and psychological violence. The terms 'violence' and 'aggression' are not easily defined and distinguished from one another (Anderson 2000, Rippon 2000). Consequently, in this study, the two terms are considered to be synonymous. PVV is defined as any verbal, non-verbal or physical behaviour that is threatening to others or to property, or physical behaviour that actually harms people or property (Morrison 1990).

According to recent study results (Camerino et al. 2008, Hahn et al. 2008) the development of PVV in general hospitals is a complex process including a number of factors: (i) patients' and/or visitors' characteristics. It includes gender (Coverdale 
et al. 2001, Farrell et al. 2006, Kwok et al. 2006), age (Ayranci 2005, Brayley et al. 1994, McKenna et al. 2003), health condition (Lin \& Liu 2005, May \& Grubbs 2002, Winstanley \& Whittington 2004b) and emotional state (Winstanley 2005, Winstanley \& Whittington 2004b). Problems with the health condition and emotional state can lead to difficulties understanding the situation adequately or to knowledge problems in the situation (Hahn \& Needham 2008, Hahn et al. 2008); (ii) staff characteristics like profession (Ayranci 2005, Jackson \& Ashley 2005), gender (Coverdale et al. 2001), age (Duncan et al. 2001, Farrell et al. 2006, Jackson \& Ashley 2005), job experience (Adib et al. 2002, Graydon et al. 1994, Whittington et al. 1996), the attitude to the causes of PVV (Duxbury 1999, 2002), the perception of violence (Jansen et al. 2005a, Whittington \& Higgins 2002), their consequences (Farrell et al. 2006, McKenna 2004, Winstanley \& Whittington 2004a), the closeness of patient contact (Adib et al. 2002, Winstanley \& Whittington 2004b) and training level in aggression management (Beech \& Leather 2006); (iii) because PVV is an interactional process, staff-patient and visitor interactions in the treatment process seem to be very important in the development of PVV (Lin \& Liu 2005, Winstanley 2005, Winstanley \& Whittington 2004b); (iv) the architectural and organisational work environment in which these interactions take place seems to plays an important role in the occurrence of PVV (Hahn et al. 2009, Hahn et al. 2008). PVV can result from organisational procedures, such as checking identity (Whittington et al. 1996), prolonged waiting times (Ayranci 2005, Carmi-lluz et al. 2005), lack of physician availability (Whittington et al. 1996, Winstanley \& Whittington 2004b), discharge procedures (Winstanley \& Whittington 2004b), imposition of hospital policies and rules (May \& Grubbs 2002, Whittington et al. 1996) (see Figure 3.1); (v) at last PVV also appears to be dependent on the social context or cultural background of the health care system (ILO et al. 2002).

Different quantitative methods were used to investigate PVV in general hospitals. In a recent literature review, Hahn et al. (2008) found 26 surveys based on RCS design and five incidence studies investigating PVV based on the occurrence of PVV in general health care settings. The questionnaires used in the RCS collected personal and workplace data from health care staff as well as information on the occurrence and forms of violence experienced during a specified time frame. According to the research aim of the different studies, further questions examine some single important factors in the occurrence of PVV. Seldom a combination of factors was included to investigate associations between factors (Hahn et al. 2008).

RCS only provide a snapshot view of the object being examined and their validity across different contexts is questionable (Grimes \& Schulz 2002). However, surveys are still important tools for investigating PVV in the new field of general hospitals. They can provide information about frequencies and differences between groups, times and places (Newsted et al. 1998). If the known important factors in the occurrence of PVV are included, associations between these factors 
can be described. This may resolve the limited focus on the problem and allow to describe the complex situation in order to improve knowledge and to implement effective prevention and intervention strategies in practice. This study therefore evaluates the SOVES-G-R and validates the POAS-S and the POIS for use in the general hospitals in German-speaking region of Switzerland.

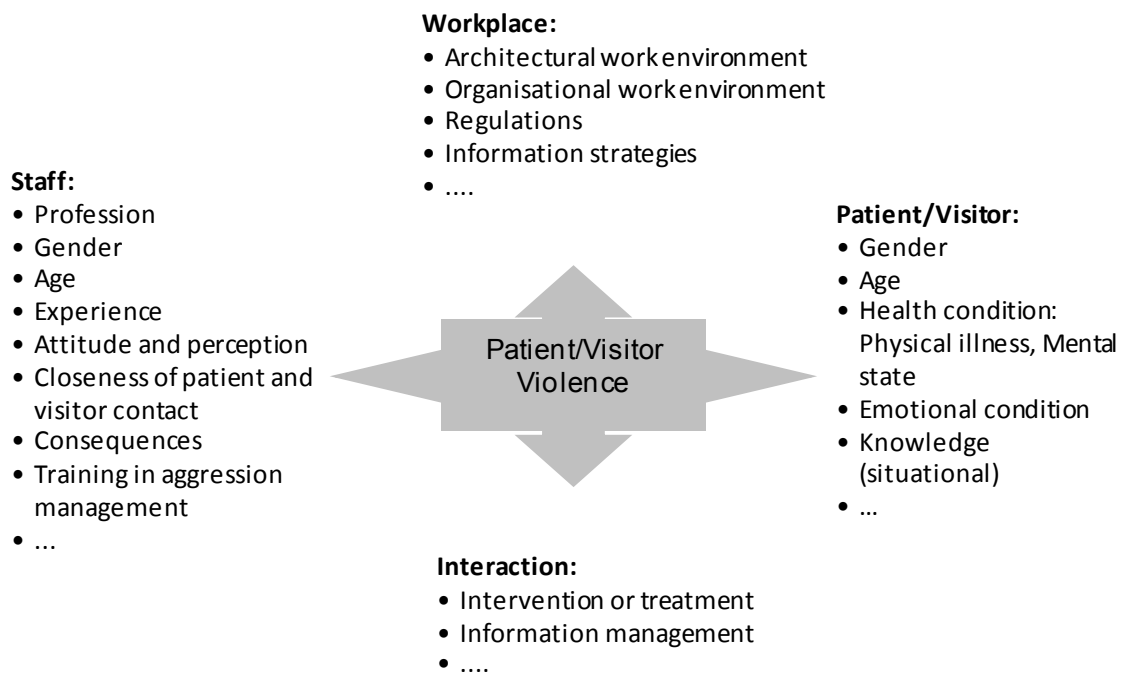

Figure 3.1: Factors related to patient and visitor violence in general hospitals

The research questions were:

- How do nurses evaluate the feasibility of the SOVES-G-R?

- What is the internal consistency and the construct validity of the POAS-S?

- What is the internal consistency and construct validity of the POIS scale in handling PVV?

\subsection{METHODS}

\section{Design}

A retrospective cross-sectional survey was conducted between November 2006 and January 2007 with a sample of nursing staff working in general hospitals in the German-speaking region of Switzerland.

\section{instruments}

To our knowledge, there are no questionnaires concerning PVV against health care staff in German-speaking areas that include significant factors related to PVV in general hospitals and that correspond to our proposed working model (see Figure 
3.1). In Switzerland, no PVV information from general hospitals was available for different clinical settings. Therefore, we chose instruments that provided data that could be integrated into our proposed working model and were comparable with international data.

\section{background of the soves-G-R}

McKenna (2004) developed the SOVES questionnaire to investigate workplace violence and to collect data on involved health care staff, patients, visitors and the workplace environment. The SOVES consists of five sections.

Section $A$ is concerned with demographic characteristics and participant attributes. Section B investigates the experience of workplace violence using closedended questions on having ever experienced verbal abuse, threats and physical assaults as well as the source and frequency of violence in the past year and three open-ended questions about the activity being performed when violence was experienced. Frequency of reported verbal violence, threats and physical assaults is determined using visual analogue scales (VAS) that range from none reported to all reported and three open-ended questions ask participants to provide reasons for non-reporting (Section C). The consequences of violence are investigated with a closed-ended question regarding sick leave after experiencing violence capturing how many periods of sick leave were taken in the past year. This is followed by a closed-ended questions asking for the length of the longest leave. The consequences of the last physical assault are evaluated using three answer possibilities, namely none, minor injuries or major injuries. Three VAS-scales investigate the emotional consequences of experiencing violence and 21 statements use 5-point Likert scales to measure support received or needed after violence. One closedended question clarifies whether the employer had a formal support policy after violent incidences (Section D). Finally, Section E uses closed-ended questions to determine the level and the content of the training. Two VAS evaluate confidence in dealing with verbally and physically aggressive individuals and one VAS regards the necessity for training. The importance of certain training skills at the current workplace is measured with eight statements answered with 5-point Likert scales ranging from strongly disagree to strongly agree.

Content validity of the SOVES was ascertained by a panel of eight experts from the European Violence in Psychiatry Research Group, who agreed with its content (McKenna 2004). In addition, the SOVES underwent a trial run by 44 health care staff and was used in a study with 821 health care staff. The subscales of the SOVES achieved good levels of internal consistency (Cronbach's alphas 0.87-0.91) (McKenna 2004).

The SOVES was carefully translated and back-translated (Polit \& Tatano Beck 2003, Wang et al. 2006). The sources of violence from co-workers and others were excluded from all sections of the German version of the SOVES (SOVES-G), since 
they were outside the purview of our study. All $100 \mathrm{~mm}$ VAS were substituted by Likert scales to allow for computerised data entry. Some of the relevant factors in our working model to investigate the occurrence of PVV (Figure 3.1) are not included in the SOVES. Therefore, the POAS-S (Needham et al. 2004) and the POIS were also used in this study.

\section{The POAS-S}

According to prevention and intervention strategies used in aggression management, the perception of aggression is an influential factor (Abderhalden et al. 2002, Jansen et al. 2005a). The German version of the POAS-S consists of 12 items answered with 5-point Likert scales, that when combined, encompass two factors. Aggression is perceived in factor one (6 items) as a dysfunctional/undesirable phenomena and in factor two (6 items) as a functional/comprehensible phenomena. These factors represent positive and negative perceptions of aggression. This dual perception of aggression identifies violent behaviour as not simply unwanted nor as merely something that has to be prevented with intervention strategies (Abderhalden et al. 2002).

The POAS-S was tested in Swiss psychiatric care settings and demonstrated satisfactory internal consistency with a Cronbach's alpha of 0.69 for factor 1 (aggression is perceived as a dysfunctional/undesirable phenomena) and 0.67 for factor 2 (aggression is seen as a functional/comprehensible phenomena). The average testretest reliability after 4,14 and 70 days was $r=0.76$ for factor 1 and $r=0.77$ for factor 2. Cumulatively, the two factors account for $39.4 \%$ of the total variance (Needham et al. 2004).

\section{The POIS}

Attitudes on the causes of patient aggression, perceptions of aggression and its management are strongly connected. These relations influence the use of prevention and intervention strategies in the occurrence of PVV (Duxbury et al. 2008, Hahn et al. 2006). Consequently, the researchers developed a scale using nine items reflecting common prevention and intervention strategies to measure perceptions of the importance of PVV intervention skills in general hospitals, for example verbal interactions/communication with potentially violent individuals or self-awareness in interactions with patients/clients/family members, utilising a 3point Likert scale (1= important, 2 = moderately important, $3=$ not important).

\section{Relevance and content validity of the SOVES-G, the POAS-S and the POIS}

The SOVES-G, the POAS-S and the POIS were validated by a panel of nine Germanspeaking experts in the field of aggression in the health care system. These experts evaluated the instruments for relevance and content validity. Good validity was 
defined as $80 \%$ of the experts rating the question as either relevant or very relevant. Good content validity index (CVI) for the total questionnaire was defined as at least $80 \%$ of all questions being rated as relevant or better (Polit \& Tatano Beck 2003). The percentage of questions that obtained approval from $80 \%$ or more of the experts on relevance and adequacy was $86 \%$.

\section{Comprehensibility and face validity of the SOVES-G, the POAS-S and the POIS for use in general hospitals}

To evaluate the comprehensibility and face validity of the SOVES-G, the POAS-S and the POIS for general hospitals, a cognitive pre-test was used according the process described by Peterson (2000) and Prüfer \& Rexroth (2000). In the cognitive pretest, 17 health care professionals aged 20 to 47, of which 16 were female, participated. Six general nurses, two psychiatric nurses, one physiotherapist, one medical doctor, one medical assistant, six students participated (two nursing, two physiotherapy, two midwifery). The participants of the pre-test read the questions to the researcher, responded orally to the questionnaire and answered structured questions on their understanding of the terms and scales used in the questionnaire. The general probing (participants answered questions about their understanding of the questions) (Prüfer \& Rexroth 2000) revealed the necessity to modify only some of the wording of the questionnaire to enhance comprehensibility according to the Swiss German vernacular and local clinical practices (cultural adaptation). Necessity to enhance the section structure of the SOVES-G to improve content orientation was also revealed. Some items were moved to other sections and section D was modified with questions about experiences with PVV in the past working week. This allowed for more accurate recall provided deeper insight into violent incidents and enhanced international comparability. Participants evaluated these changes clarified the structure of the questionnaire. The category selection probing, a systematic procedure in which participants' understanding of the answer categories for particular questions is tested (Prüfer \& Rexroth 2000), revealed no problems. The participants therefore answered structured questions in which they convey their reasons for choosing a particular answer category or scale class. Overall, the analysis suggested that the SOVES-G questions (because of the modification renamed to SOVES-G Revised, SOVES-G-R), the POAS-S statements and the POIS statements were comprehensible, comprehensive and meaningful. The participants agreed that the questions were relevant to actual practice in Swiss general hospitals (face validity). However, the participants criticised the time required to fill in the questionnaire (30 to 60 minutes) as too long. This negatively influenced their motivation to fill in the questions. Table 3.1 provides an overview of the comparison and changes between the original SOVES and the SOVES-G-R. 


\section{Sample}

A non-probability purposive sampling strategy was used for recruitment. In all, 410 nurses were contacted. Participants were recruited from two groups. First group (n $=114$ ) were participating in a postgraduate nursing education program in the Canton of Zurich from the Nursing Association of Switzerland and were working in different general hospitals. The second group included all of the 296 nurses working in four typical general hospitals in the Canton of Berne. The criteria for inclusion were direct contact with patients and visitors, employment in a general hospital and adequate command of the German language. The sample did not include nurses working in psychiatric units. Mental health care in Switzerland is provided in specialised hospitals.

Table 3.1: Overview of the SOVES Irish and SOEVES German version revised

\begin{tabular}{llll}
\hline Question & Version & Section & Example of Question ${ }^{1}$ \\
\hline Personal data and data & Irish & A & Please indicate whether you are: \\
pertaining to the workplace. & German & A & Employment percentage? (please check the \\
& & & relevant field) \\
& & $\square 90$ to 100\% (full time) \\
& & $\square 51$ to 89\% (part time) \\
& & $\square$ up to 50\% (part time or relief)
\end{tabular}

Ever experienced workplace Irish B B During your professional career, have you ever

violence during professional German B experienced violence from a patient or family career.

member?

$\square$ yes $\square$ no

If yes, which forms of violence have you experi-

enced? (please check all relevant fields)

$\square$ verbal

$\square$ threats

$\square$ physical aggression

Experience with workplace Irish B In your present workplace, have you been subviolence during the last 12 German C jected to verbal abuse toward you from a patient months. The same questions or family member/visitor during the past 12 for each form of workplace violence.

Activity being performed when violence most often occurs with the same questions for each form of workplace violence. months? $\square$ yes $\square$ no If yes, mark the category that best describes the source(s) and frequency of the verbal abuse (please mark all relevant boxes): ... Please describe briefly the activity being performed when occurrences of verbal violence most frequently occurred during the past 12 months: ...

Experience with PVV in the past German D In the past working week, were you exposed to working week. verbal abuse and/or threats and/or physical assault/attack? $\square$ yes $\square$ no If yes, please mark the categories which best describe the source(s) and frequency of these assaults/attacks (please mark all relevant boxes): 


\begin{tabular}{|c|c|c|c|}
\hline Question & Version & Section & Example of Question $^{1}$ \\
\hline $\begin{array}{l}\text { Formal reporting of each form } \\
\text { of workplace violence. }\end{array}$ & $\begin{array}{l}\text { Irish } \\
\text { German }\end{array}$ & $\begin{array}{l}\mathrm{C} \\
\mathrm{E}\end{array}$ & $\begin{array}{l}\text { Please indicate how often you have formally } \\
\text { reported patient- and family/visitor violence } \\
\text { against yourself in the workplace. } \\
\text { never reported } \square \text {, few/some reported } \square \text {, } \\
\text { approximately half reported } \square \text {, almost all re- } \\
\text { ported } \square \text {, all reported } \square\end{array}$ \\
\hline $\begin{array}{l}\text { Consequences of workplace } \\
\text { violence and support after } \\
\text { workplace violence. }\end{array}$ & $\begin{array}{l}\text { Irish } \\
\text { German }\end{array}$ & $\begin{array}{l}\mathrm{D} \\
\mathrm{E}\end{array}$ & $\begin{array}{l}\text { Have occurrence of verbal abuse, threats or } \\
\text { physical assaults in your present workplace ever } \\
\text { resulted in you taking time of duty? (Please check } \\
\text { as appropriate) } \\
\square \text { yes } \square \text { no } \\
\text { If yes, please indicate how many days in the past } \\
12 \text { months you stayed away from work because } \\
\text { of verbal abuse, threats or physical assaults/ } \\
\text { attacks: ... }\end{array}$ \\
\hline $\begin{array}{l}\text { Experiences with education and } \\
\text { training against PVV and the } \\
\text { importance of intervention } \\
\text { skills to train. }\end{array}$ & $\begin{array}{l}\text { dirish } \\
\text { German }\end{array}$ & $\begin{array}{l}\mathrm{E} \\
\mathrm{G}\end{array}$ & $\begin{array}{l}\text { Have you ever received education/training in the } \\
\text { management of potentially violent individuals? } \\
\square \text { yes } \square \text { no } \\
\text { Did this include (please check all answers that } \\
\text { apply): } \\
\square \text { Identification and assessment of potentially } \\
\text { violent individuals. } \\
\square \text { Setting boundaries/limits with potentially } \\
\text { violent individuals. } \\
\square \text { Verbal interactions/communication with } \\
\text { potentially violent individuals. } \\
\square \text { Breakaway techniques. } \\
\text {... }\end{array}$ \\
\hline $\begin{array}{l}\text { Support after workplace } \\
\text { violence. }\end{array}$ & $\begin{array}{l}\text { Irish } \\
\text { German }\end{array}$ & $\begin{array}{l}\mathrm{D} \\
\mathrm{F}\end{array}$ & $\begin{array}{l}\text { Support in my workplace is available to me when } \\
\text { needed after experiencing verbal abuse, threats } \\
\text { and physical assaults/attacks. } \\
\square \text { I disagree completely, } \square \text { I disagree somewhat, } \\
\square \text { don't know, } \square \text { I agree some-what, } \\
\square \text { I agree totally. }\end{array}$ \\
\hline
\end{tabular}

${ }^{1}$ According to the research aim the German version asks specific about patient and visitor violence.

\section{Data collection}

For the first group ( $n=114$ ), the educational institution where these nurses were studying granted the researchers permission to ask the students to participate in the study. A nursing instructor recruited and informed participants about the study. The survey questionnaire was made available at the beginning of a teaching lesson. For the second group, four nursing directors from four typical general hospitals were asked by the principal investigator to participate in the study. The hospitals were comparable in size, level of specialization and services for patient care, population according to the Swiss Federal Statistical Office (Bundesamt für Statistik 2006). Permission to participate was granted by the heads of nursing staff of these hospitals. The head nurses of each ward, who had previously been personally in- 
formed about the study by the principal investigator, recruited all nursing staff ( $n=$ 296) with information meetings on each ward. Willing participants received the questionnaires along with written information on the study. The questionnaires were completed during working hours. All questionnaires were returned anonymously via business-reply mail.

\section{Ethical considerations}

The local Ethics Committee approved this study. Participants were provided with written information about the study, the aim and the voluntary nature of participation. By filling in the questionnaire, they provided informed consent to participate in the study. To ensure confidentiality and anonymity, no names or other identifiers were used.

\section{Statistical analyses}

Demographic characteristics of the participants, the response rate and the completion rates of the items were analysed using descriptive statistics to assess feasibility of the SOVES-G-R. In order to identify factors from the POAS-S and POIS and determine the correlation of each item to the respective factor, an exploratory factor analysis (PCA with varimax rotation) was performed. Components with eigenvalues of 1.0 or greater were extracted (Polit \& Tatano Beck 2003). Data homogeneity of the POAS-S and the POIS were tested using the Kaiser-Meyer-Olkin (KMO) Measure of Sampling Adequacy test. A KMO over 0.7 data were considered homogeneous. Only variables with loadings of 0.45 and above were interpreted. For internal consistency, i.e. the degree to which items within a subscale reflect the same concept, Cronbach's alpha coefficient was calculated for the POAS-S and the POIS factors. These data analyses were conducted using SPSS 15.0.

\subsection{RESULTS}

\section{Demographic characteristics}

Seventy-one nurses from the postgraduate nursing education group (response rate $=62 \%$ ), and 220 nursing staff from the hospital group (response rate $=74 \%$ ) completed the questionnaire (total $n=291$, response rate $=71 \%$ ). The nurses in the two groups did not differ significantly with respect to their socio-demographic characteristics (gender, professional experience overall and at current workplace, level of employment, and time spent in direct patient contact). Participants from the general hospital group were, however, slightly older and were more likely to have a postgraduate diploma. The demographic characteristics of the participants are described in Table 3.2. Almost all the nurses were female (93.8\%), a majority 
were between 19 and 44 years old (74.9\%) and were registered nurses (77\%). A majority had more than 10 years of professional experience $(66 \%)$ in the health care system. Also, $43 \%$ had between one and four years experience and $47 \%$ had more than ten years experience in their present position. Over $50 \%$ worked full time and over $55 \%$ spent over $60 \%$ of their working time in direct patient contact.

Table 3.2: Demographic characteristics of nursing staff

\begin{tabular}{|c|c|c|c|}
\hline \multirow[t]{2}{*}{ Demographic characteristics } & \multirow[t]{2}{*}{ Specification } & \multicolumn{2}{|c|}{ Total $(n=291)$} \\
\hline & & $\mathrm{n}$ & $\%$ \\
\hline \multirow[t]{3}{*}{ Gender } & female & 272 & 93.8 \\
\hline & male & 18 & 6.2 \\
\hline & missing & 1 & 0.3 \\
\hline \multirow[t]{4}{*}{ Age (years) } & $19-30$ & 100 & 34.4 \\
\hline & $30-44$ & 118 & 40.5 \\
\hline & over 45 & 72 & 24.7 \\
\hline & missing & 1 & 0.3 \\
\hline \multirow[t]{4}{*}{ Education level (\%) } & registered nurses & 185 & 63.6 \\
\hline & obtained postgraduate diploma & 40 & 13.7 \\
\hline & not registered & 65 & 22.3 \\
\hline & missing & 1 & 0.3 \\
\hline \multirow{5}{*}{$\begin{array}{l}\text { Professional experience in health } \\
\text { care services (years) }\end{array}$} & $0-4$ & 26 & 8.9 \\
\hline & $5-9$ & 62 & 21.3 \\
\hline & $10-15$ & 57 & 19.6 \\
\hline & over 15 & 135 & 46.4 \\
\hline & missing & 11 & 6.4 \\
\hline \multirow{5}{*}{$\begin{array}{l}\text { Professional experience in present } \\
\text { position (years) }\end{array}$} & less than 1 & 27 & 9.3 \\
\hline & $1-4$ & 127 & 43.6 \\
\hline & over $4-10$ & 80 & 27.5 \\
\hline & over 10 & 57 & 19.6 \\
\hline & missing & 0 & 0 \\
\hline \multirow[t]{8}{*}{ Workplace } & Surgery & 88 & 30.2 \\
\hline & Medical ward & 79 & 27.1 \\
\hline & Intensive/OP/Anesthesia/Intermediate care & 30 & 10.3 \\
\hline & Outpatient & 28 & 9.6 \\
\hline & Emergency & 26 & 8.9 \\
\hline & Women and child care & 14 & 4.8 \\
\hline & Rehabilitation & 13 & 4.5 \\
\hline & Other & 13 & 4.5 \\
\hline \multirow{5}{*}{$\begin{array}{l}\text { Level of employment (\%) } \\
\text { (Full time, part time) }\end{array}$} & $81-100$ & 158 & 54.3 \\
\hline & $61-80$ & 64 & 22.0 \\
\hline & $41-60$ & 39 & 13.4 \\
\hline & up to 40 & 27 & 9.3 \\
\hline & missing & 3 & 1.0 \\
\hline \multirow{5}{*}{$\begin{array}{l}\text { Time spent in direct patient/client } \\
\text { contact (\%) }\end{array}$} & $81-100$ & 39 & 13.4 \\
\hline & $61-80$ & 122 & 41.9 \\
\hline & $41-60$ & 93 & 32.0 \\
\hline & up to 40 & 35 & 12.1 \\
\hline & missing & 2 & 0.7 \\
\hline
\end{tabular}




\section{Feasibility of the SOVES-G-R}

An indication for evaluating an instrument's feasibility is the response rate. The sample received a good response rate of $71.0 \%$. In addition, the response behaviour of the participants to the different question formats and the answering categories was evaluated (completion rate). Most respondents did not use the openended questions to respond in detail but rather replied with short answers using key words and did not provide deeper insight. In Section C (PVV in the past 12 month), participants experienced problems describing the situation/activity they were performing when they experienced PVV because too many aggressive incidents had been experienced in the past 12 months. Often, the patient's diagnosis was inserted instead of a description of the situation in which the incidents most often occurred. However, these open-ended questions were completed only with at least one word by $82.8 \%$ for verbal violence, $79.7 \%$ for threats and $90.2 \%$ for physical violence by the participants having experienced PVV in the past 12 months.

The open-ended questions regarding the reasons for non-reporting in Section $E$ (formal reporting) were completed by only $14.0 \%$ (verbal violence), $57.0 \%$ (threat) and $62.0 \%$ (physical violence) of nurses who did not report PVV. The open-ended question about the diagnoses of aggressive patients in the past working week in Section $D$ was not affected. The first frequency category was selected most often for the multiple choice questions in Section C on the frequency of PVV (1 to 10 experiences of PVV in the past 12 months). Completion rate in this category for verbal violence, threats and physical assault were $88.9 \%, 98.2 \%$ and $65.2 \%$, respectively. A similar completion rate was observed for the questions regarding experiencing PVV in the past working week in Section D. The response category 'one time in the past week' was selected by $67.6 \%$ for verbal violence, $57.1 \%$ for threats and $66.7 \%$ for physical aggression.

\section{Reliability and validity of POAS-S AND POIS}

In order to verify the construct validity of the POAS-S, factor analysis was performed. The Kaiser-Meyer-Olkin (KMO) measure of adequacy was 0.72 . The scree plot showed a two-factor solution with eigenvalues of 2.0 or greater. In total, this explained $38.0 \%$ of the variance (see Table 3.3 for factor loadings). Cronbach's alpha was 0.59 for factor 1 (aggression is perceived as a dysfunctional/undesirable phenomena) and 0.68 for factor 2 (aggression is seen as a functional/comprehensible phenomena). 
Table 3.3: Principal Component Analysis with Varimax rotation demonstrating factors and factor loading of shortened Perception of Aggression Scale (POAS-S)

\begin{tabular}{lllll}
\hline Nr. & Item & Factor & \multicolumn{2}{l}{ Component } \\
& Aggression... & 1 & 2 \\
\hline 1 & is violent behaviour to others and self & 1 & .463 & -.157 \\
2 & is a conscious battery against someone & 1 & .567 & .044 \\
3 & is to hurt others mentally or physically & 1 & .727 & -.111 \\
4 & is any action of physical violence & 1 & .546 & .102 \\
5 & is a disturbing intrusion to dominate health care staff & 1 & .596 & .264 \\
6 & is any expression that makes someone else feel unsafe, threatened or hurt & 1 & .527 & -.109 \\
7 & is emotionally blowing off steam & 2 & -.021 & .473 \\
8 & opens new pathways in care and treatment & 2 & -.097 & .589 \\
9 & helps the health care staff to see the patient from another point of view & 2 & .126 & .704 \\
10 & is an emotion like laughing and crying & 2 & -.166 & .645 \\
11 & is an expression of protection of private sphere & 2 & .159 & .666 \\
12 & is the start of a positive staff - patient relationship & 2 & -.021 & .657 \\
& \% of Variances & & 20.76 & 17.24 \\
\hline
\end{tabular}

The construct validity of the POIS was also checked using factor analysis. The KMO was 0.76 . The scree plot showed a two-factor solution with eigenvalues of 1.0 or greater. These two factors together explained $44.3 \%$ of the total variance. The factor loadings of the varimax rotated solution are presented in Table 3.4. The dimensions behind the perception that intervention skills are important were, in factor 1 (6 items), that structured interventions and evaluation to manage PVV are important and, in factor 2 ( 3 items), that prevention measures are important in the management of PVV and in potentially violent situations. The two factors had Cronbach's alphas of 0.67 for factor 1 (structure and evaluation) and 0.52 for factor 2 (prevention).

Table 3.4: Principal Component Analysis with Varimax rotation demonstrating factors and factor loading of the Perception of importance of Intervention Skills scale (POIS).

\begin{tabular}{llrrr}
\hline Nr. & Item & \multicolumn{2}{c}{ Factor } & \multicolumn{2}{c}{ Component } \\
& Importance of abilities and skills in handling PVV & 1 & 2 \\
\hline 1 & Team interventions & 1 & .697 & .055 \\
2 & Safe physical restraints for individuals & 1 & .495 & .257 \\
3 & Self-awareness in interactions with patients/clients/family members & 1 & .591 & -.036 \\
4 & Theories of aggression & 1 & .608 & .092 \\
5 & Analysis of the situation with the team & 1 & .661 & .195 \\
6 & Follow-up discussions about the situation with patients/clients/family & 1 & .620 & .117 \\
& members & & & .767 \\
7 & Identification and assessment of potentially violent individuals & 2 & .001 & .767 \\
8 & Verbal interaction/communication with potentially violent individuals & 2 & .072 & .777 \\
9 & Setting boundaries/limits with potentially violent individuals & 2 & .297 & .549 \\
& \% of Variance & & 30.19 & 14.12 \\
\hline
\end{tabular}




\subsection{DISCUSSION}

To date, no comprehensive self-reported questionnaire on PVV in the German language has been available to measure PVV in general hospital settings. Therefore, this study combined the SOVES-G-R, the POAS-S and the POIS to create a single survey that included relevant factors influencing the occurrence of PVV against nurses in general hospitals. While the SOVES-G-R is adequate for investigating experiences of nurses with PVV in general hospital settings, this study detected various problems with completing the questionnaire, especially with open-ended question recall and memory bias. Therefore, adaptations to the SOVES-G-R are discussed. The internal consistency of the POAS-S was moderate and, as the current version does not cover some aspects of the perception of aggression, revision is needed. The POIS revealed two important factors indicating that attitudes of nurses focus not only on structured intervention but also on preventive measures for dealing with PVV. This could lead to different intervention strategies emphasising either an intervention-oriented strategy when aggression occurs or a more preventive de-escalation strategy to anticipate PVV.

The study reported here explored a particular aspect of feasibility and did not investigate the respondent burden. However, the SOVES-G-R captures nurses' experiences with PVV in general hospital settings based on 291 responses, corresponding to a response rate of $71.0 \%$. Also the demographic characteristics of the participating nursing staff describes a typical sample of nurses in the Swiss health care system with respect to age, education level, professional experiences, employment factors and workplace (Jaccard Ruedin et al. 2009). Therefore the feasibility for nursing staff seems good. However, there were problems completing the questionnaire, in particular with respect to the open-ended questions problems suggesting difficulties to describe the situation and the activity being performed when experiencing PVV in the past 12 months. Too many experiences of PVV may be difficult to distinguish (Collins 2003) and therefore conclusive open-ended answers can be problematic. To improve accuracy of the answers, the open-ended questions could be analysed for content to develop a multiple-choice answering format based on nurses' experiences (Mayring 2002). These new categories should describe the most prominent experience of PVV in the past working week as new closed-ended or multiple choice questions. This may reduce recall and memory bias and enhance the quality of the information provided (Mummendey 1999) regarding the characteristics of the aggressive patient and/or visitor (emotional state, gender, age, patient diagnosis), the expected organisational processes and attributes as sources of PVV, and reactions to the most impressionable assault. The closed-ended questions about experiences of PVV in the past 12 months run the risk that one outstanding experience with PVV will override the entire recall process. However, these questions allow for the analysis of experience of PVV over a longer period and offer the potential for comparability with other questionnaires, 
such as the Workplace Violence in the Health Sector Country Case StudyQuestionnaire developed by ILO et al. (2003).

The answering behaviour on the multiple choice questions in Sections B and C (the first frequency category was chosen more often) suggests that nursing staff in general hospitals did experience less PVV than those working in mental health care. Therefore, it seems important to adapt the SOVES-G-R to the cultural background of the general hospital setting and the health care system (ILO et al. 2002). This will allow for further reduction of the frequency categories in the answer choices thus leading to improved accuracy of answers. The question regarding the past 12 months should be reduced from five to four categories (1 time, 2-10 times, 11-20 times over 20 times) and, for the past working week, answers should be changed from five to three possibilities (1 time, 1-5 times, over 5 times).

The internal consistency of the POAS-S with a Cronbach's alpha of 0.59 for factor 1 (aggression is perceived as a dysfunctional/undesirable phenomena) and 0.68 for factor 2 (aggression is seen as a functional/comprehensible phenomena) was moderate according to the interpretation scheme of Nunnaly and Bernstein (1994). All results were comparable to the Needham et al.'s (2004) result obtained from mental health nurses in psychiatric health care settings. As in earlier studies (Abderhalden et al. 2002, Needham et al. 2004), the two factors explain only $38 \%$ of the variance. Therefore, the proportion of variance explained is moderate but common for this type of research. The items in the current version of POAS-S evidently did not cover some aspects of the perception of aggression. Perhaps the POAS-S is too limited a scale to comprehensively measure the perception of aggression and needs to include emotional aspects such as those Abderhalden et al. (2002) suggested. For a more comprehensive measurement, the Attitude of Aggression Scale (ATAS by Jansen et al. 2005b) consisting of 18 items could be used. The ATAS comprises five subscales: 1) Offensive, in the sense of insulting and unacceptable behaviour; 2) Communicative, in the sense of a signal to enhance the therapeutic relationship; 3) Destructive, a component indicating the threat of or an actual act of physical harm or violence; 4) Protective, indicating the defence of physical and emotional space; 5) Intrusive, expressing the intention to damage property or injure others. The internal consistency of the five subscales was satisfactory and the German version explains $62.7 \%$ of the variance (Jansen et al. 2005b). However, further use with a larger interdisciplinary sample of health care staff could provide necessary results about the validity of the shortened POAS-S for use in general health care settings.

The two factors derived from the POIS showed moderate consistency and explained $44 \%$ of the variance. The two factors show two different strategies in the management of aggression. In the first factor, the management of the situation and reflection after the situation are emphasised. In the second, the prevention strategy before an aggressive event occurs is emphasised. To more adequately investigate perceptions of the importance of intervention skills, more typical prevention 
and intervention strategies for PVV, such as caring for cognitively or emotionally disturbed patients in general hospitals, should be included in the POIS.

\section{Limitations}

Various limitations apply to this study. In our effort to generate a PVV instrument that is based on a working model and open to international comparison, changes in the structure of the SOVES-G-R were made. We moved some items to other sections Section to facilitate participants' concentration and to encourage more accurate answers. However, we did not test the influence of question order on responses and this change in order may have led participants to choose certain answers (Prüfer \& Rexroth 2000). The fact that the 114 postgraduate nurses were allowed to complete the questionnaire at the beginning of a lesson could have also positively influenced the response rate. However, the overall response rate was very high. As the sample consisted only of nursing staff, the adequateness of the analysed answering categories for interdisciplinary use remains unknown.

\subsection{CONCLUSIONS}

This study evaluated the feasibility of the SOVES-G-R and tested the validity of the POAS-S and the POIS. The SOVES-G-R presented in this study is the first validated self-administered German language questionnaire that captures PVV in general hospitals. It shows a good feasibility and allows clinical practitioners to understand the questions appropriately. The study results showed that for a more adequate investigation of the perception of aggression and the perception of intervention strategies, the items of the POAS-S and POIS should be revised carefully. Given the proposed adaptations to the SOVES-G-R, the moderate internal consistency and construct validity of the POAS-S and the POIS and the moderate sample size of nursing staff employed in this study, we recommend further testing of the instruments in a larger sample which includes other health professionals. Instruments are now available which generate comparable data in English and German and allow for data comparison between these linguistic areas.

\subsection{RELEVANCE TO CLINICAL PRACTICE}

The SOVES-G-R, the POIS and the POAS-S can be used to monitor nurses' experiences or reflect PVV in the specific setting of general hospitals. This is a first step for reducing PVV and enables clinical management to identify settings with a higher exposure or specific factors in the occurrence of PVV (for example prolonged waiting times). Staff training can be adapted accordingly. Additionally, on a personal level the detailed analysis enables staff to react in a more adequate way. Therefore 
systematic monitoring is important for clinical practice and belongs to an overall strategy protecting staff, patients and visitors from violence. 


\subsection{REFERENCES}

Abderhalden C, Needham I, Friedli TK, Poelmans J \& Dassen T (2002): Perception of aggression among psychiatric nurses in Switzerland. Acta Psychiatrica Scandinavica 106, 110-117.

Adib SM, Al-Shatti AK, Kamal S, El-Gerges N \& Al-Raqem M (2002): Violence against nurses in healthcare facilities in Kuwait. International Journal of Nursing Studies 39, 469-478.

Anderson CA (2000) Violence and Aggression. In Encyclopedia of Psychology (Kazding AE ed.). Oxford University Press and the American Psychological Association, New York \& Washington D.D.

Ayranci U (2005): Violence toward health care workers in emergency departments in west Turkey. Journal of Emergency Medicine 28, 361-365.

Beech B \& Leather P (2006): Workplace violence in the health care sector: A review of staff training and integration of training evaluation models. Aggression and Violent Behaviour 11, 27-43.

Brayley J, Lange R, Baggoley C, Bond M \& Harvey P (1994): The violence management team. An approach to aggressive behaviour in a general hospital. Medical Journal of Australia 15, 254-258.

Bundesamt für Statistik (2006) Krankenhaustypologie. Statistik der stationären Betriebe des Gesundheitswesens. In (available in French and German at www.statistik.admin.ch) (Bundesamt für Statistik ed.). Schweizerische Eidgenossenschaft, Eidgenössisches Departement des Innern EDI, Neuchatel.

Camerino D, Estryn-Behar M, Conway PM, van Der Heijden BIJM \& Hasselhorn HM (2008): Work-related factors and violence among nursing staff in the European NEXT study: a longitudinal cohort study. International Journal of Nursing Studies 45, 35-50.

Carmi-Iluz T, Peleg R, Freud T \& Shvartzman P (2005): Verbal and physical violence towards hospital- and community-based physicians in the Negev: an observational study. Bio Med Central Health Service Research 5, 1-6.

Collins D (2003): Pretesting survey instruments: an overview of cognitive methods Quality of Life Research 12, 229-238.

Cooper CL \& Swanson N (2002) Workplace violence in the health sector. State of the Art. International Labour Office, International Council of Nurses, World Health Organization and Public Service International, Geneva.

Coverdale J, Gale C, Weeks S \& Turbott S (2001): A survey of threats and violent acts by patients against training physicians. Medical Education 35, 154-159.

Duncan SM, Hyndman K, Estabrooks CA, Hesketh K, Humphrey CK, Wong JS, Acorn S \& Giovannetti P (2001): Nurses' experience of violence in Alberta and British Columbia hospitals. Canadian Journal of Nursing Research 32, 57-78.

Duxbury J (1999): An exploratory account of registered nurses experience of patient aggression in both mental health and general nursing setting. Journal of Psychiatric and Mental Health Nursing 6, 107114.

Duxbury J (2002): An evaluation of staff and patient views of and strategies employed to manage inpatient aggression and violence on one mental health unit: a pluralistic design. Journal of Psychiatric and Mental Health Nursing 9, 325-337.

Duxbury J, Hahn S, Needham I \& Pulsford D (2008): The Management of Aggression and Violence Attitude Scale (MAVAS): a cross-national comparative study. Journal of Advanced Nursing 62, 596-606.

Farrell GA, Bobrowski C \& Bobrowski P (2006): Scoping workplace aggression in nursing: findings from an Australian study. Journal of Advanced Nursing 55, 778-787.

Graydon J, Kasta W \& Khan P (1994): Verbal and physical abuse of nurses. Canadian Journal of Nursing Administration 7, 70-89.

Grimes DA \& Schulz KF (2002): Descriptive studies: what they can and cannot do. Lancet 359, 145-149. 
Hahn S, Afzali M, Richter D, Metzenthin P, Marguet H \& Scheuermann A (2009) Aggression Management in General Hospitals: A joint Nursing Science - Design Research Project. Workshop. In The 6th European Congress on Violence in Clinical Psychiatry. (Needham I, Callaghan P, Palmsteirna T, Nijman H \& Oud N eds.). KAVANAH, Stockholm, pp. 147-150.

Hahn S \& Needham I (2008): Anxiety and stress as a fertile field for aggression [Angst und Stress als Nährboden für Aggressionen]. Krankenpflege, Soins Infirmière 101, 19-21.

Hahn S, Needham I, Abderhalden C, Duxbury JAD \& Halfens RJG (2006): The effect of a training course on mental health nurses' attitudes on the reasons of patient aggression and its management. Journal of Mental Health and Psychiatric Nursing 13, 197-204.

Hahn S, Zeller A, Needham I, Kok G, Dassen T \& Halfens RJG (2008): Patient- and visitor violence in general hospitals: A systematic review of the literature. Journal of Aggression and Violent Behavior 13, 431-441.

ILO, ICN, WHO \& PSI (2002) Framework Guidelines for Addressing Workplace Violence in the Health Sector. In Joint Programme on Workplace Violence in the Health Sector. International Labour Office, Geneva.

ILO ICN WHO PSI (2003) Workplace Violence in the Health Sector: Country Case Studies Research Instruments Survey Questionnaire (English). Joint Programme on Workplace Violence in the Health Sector. ILO/ICN/WHO/PSI, Geneva, pp. 1-14.

International Labour Office, International Council of Nurses, World Health Organisation \& Public Services International (2002) Workplace Violence in the Health Sector, Geneva.

Jaccard Ruedin H, Weaver F, Roth M \& Widmer M (2009) Personnel de santé en Suisse - Etat des lieux et perspectives jusqu'en 2020. Observatoire suisse de la santé, Neuchâtel, p. 116.

Jackson M \& Ashley D (2005): Physical and psychological violence in Jamaica's health sector. Revista Panamericana de Salud Pública/Pan American Journal of Public Health 18, 114-121.

Jansen GJ, Dassen TW \& Groot Jebbink G (2005a): Staff attitudes towards aggression in health care: a review of the literature. Journal of Psychiatric and Mental Health Nursing 12, 3-13.

Jansen GJ, Middel B \& Dassen TW (2005b): An international comparative study on the reliability and validity of the attitudes towards aggression scale. International Journal of Nursing Studies 42, 467477.

Kwok RP, Law YK, Li KE, Ng YC, Cheung MH, Fung VK, Kwok KT, Tong JM, Yen PF \& Leung WC (2006): Prevalence of workplace violence against nurses in Hong Kong. Hong Kong Medical Journal 12, 6-9.

Lin YH \& Liu HE (2005): The impact of workplace violence on nurses in South Taiwan. International Journal of Nursing Studies 42, 773-778.

May DD \& Grubbs LM (2002): The extent, nature, and precipitating factors of nurse assault among three groups of registered nurses in a regional medical centre. Journal of Emergency Nursing 28, 11-17.

Mayring P (2002) Einführung in die Qualitative Sozialforschung. Beltz Verlag, Weinheim und Basel.

McKenna BG, Poole SJ, Smith NA, Coverdale JH \& Gale CG (2003): A survey of threats and violent behaviour by patients against registered nurses in their first year of practice. International Journal of Mental Health Nursing 12, 56-63.

McKenna K (2004) Study of work-related violence. Committee on Workplace Violence, North Eastern Health Board, Ireland, pp. 1-121.

Morrison E (1990): Violent psychiatric inpatients in a public hospital. Scholarly Inquiry for Nursing Practice 4, 65-82.

Mummendey HD (1999) Die Fragebogen-Methode. Hans Huber, Bern.

Needham I, Abderhalden C, Dassen T, Haug HJ \& Fischer JE (2004): The perception of aggression by nurses: psychometric scale testing and derivation of a short instrument. Journal of Psychiatric and Mental Health Nursing 11, 36-42.

Newsted PR, Huff SL \& Munro MM (1998): Survey Instruments and Information Systems. Management Information System Management Centre, University of Minnesota 22, 553-554.

Nunnaly J \& Bernstein I (1994) Psychometric theory. McGraw-Hill, New York. 
Peterson RA (2000) Construction effective questionnaires. Sage Publication, Beverly Hills (CA).

Polit DF \& Tatano Beck C (2003) Nursing research: principles and methods, 7 edn. Lippincott Williams \& Wilkins, Philadelphia.

Prüfer C \& Rexroth M (2000) Zwei-Phasen - Pretesting. ZUMA, Mannheim, pp. 1-21.

Rippon TJ (2000): Aggression and violence in health care professions. Journal of Advanced Nursing 31, $452-460$.

Wang W, Lee H \& Sj F (2006): Challenges and Strategies of Instrument Translation. Western Journal of Nursing Research 28, 310-321.

Wells J \& Bowers L (2002): How prevalent is violence towards nurses working in general hospitals in the UK? Journal of Advanced Nursing 39, 230-240.

Whittington R \& Higgins L (2002): More than zero tolerance? Burnout and tolerance for patient aggression amongst mental health nurses in China and the UK. Acta Psychiatrica Scandinavica 106, 37-40.

Whittington R, Shuttleworth S \& Hill L (1996): Violence to staff in a general hospital setting. Journal of Advanced Nursing 24, 326-333.

Winstanley S (2005): Cognitive model of patient aggression towards health care staff: The patient's perspective. Work \& Stress 19, 340-350.

Winstanley S \& Whittington R (2004a): Aggression towards health care staff in a UK general hospital: variation among professions and departments. Journal of Clinical Nursing 13, 3-10.

Winstanley S \& Whittington R (2004b): Aggressive Encounters Between Patients and General Hospital Staff: Staff Perceptions of the Context and Assailants' Levels of Cognitive Processing. Aggressive Behavior 30, 534-543. 



\section{CHAPTER FOUR}

\section{Factors associated with patient and visitor violence experienced by nurses in general hospitals in Switzerland: A cross-sectional survey}

Hahn S, Müller M, Needham I, Kok G, Dassen T \& Halfens RJG (2010): Factors associated with patient and visitor violence experienced by nurses in general hospitals in Switzerland: A cross-sectional survey. Journal of Clinical Nursing 19, 3535-3546. 


\subsection{ABSTRACT}

Background. Patient and visitor violence is a complex occupational hazard among health care professions, with nursing in general, experiencing the highest rate of patient and visitor violence. International research has found that staff and patient attributes, interaction between staff and patients, as well as environmental characteristics are important factors associated with the occurrence of patient and visitor violence. Previous studies, however, have only partially described these factors in the general hospital setting. Mainland European general hospital settings are even less well researched.

Aims. To explore nurses' experiences with patient and visitor violence, as well as other related factors, in Swiss general hospital settings.

Design. A retrospective cross-sectional survey was conducted in 2007.

Methods. A total of 291 nurses working in different clinical departments in general hospitals provided data. The questionnaire used was a modified German version of the Survey of Violence Experienced by Staff.

Results. The findings revealed that $72 \%$ of nurses had experienced verbal patient and visitor violence and $42 \%$ physical patient and visitor violence in the past 12 months. Also, $23 \%$ were physically injured and $1.4 \%$ took one or more days of sick leave. Patient and visitor violence was distressing for the nursing staff. A higher risk of patient and visitor violence was observed among registered nurses who were nursing anxious or cognitively impaired patients, who worked in rehabilitation units with longer-term nurse-patient/nurse-relative interactions and when working in settings with an absence of formal procedures for patient and visitor violence.

Conclusions. The results indicate that the clinical setting has little impact on the occurrence of patient and visitor violence. Patient and visitor violence appears to be influenced more by the additional factors specific to the type of interaction and situation. Research should follow up on these specific findings to further improve policies, procedures and intervention strategies.

Relevance to clinical practice. To prevent patient and visitor violence, Swiss general hospitals should take into consideration the risk factors associated with patient and visitor violence. Existing policies, procedures and staff education should be improved on. 


\subsection{INTRODUCTION}

Work-related violence in the health care system is a significant occupational hazard for health care staff (Beech \& Leather 2006, Cooper \& Swanson 2002). In comparison to all other occupational groups, health care professionals are at higher risk for experiencing workplace violence (Bourn 2003, Chappell \& Di Martino 2006, Wells \& Bowers 2002). Work-related violence can negatively affect the psychological and physical well being of health care staff (Needham et al. 2005, Richter \& Berger 2000, Stanko 2002), as well as job motivation and quality of care (Arnetz \& Arnetz 2001, Needham et al. 2005). Work-related violence can also result in considerable financial loss for the health care system (McKenna 2004, Philbrick et al. 2003). The most significant work-related violence in the health care system is patient and visitor violence (PVV) (Camerino et al. 2008, Ferns 2006).

$\mathrm{PVV}$ is considered to be any verbal, non-verbal, or physical behaviour that is threatening to others or to property, as well as physical behaviour that harms others or damages property (Morrison 1990). Aggressive behaviour has various forms. Verbal violence is the use of abusive or offensive language (including sexually abusive language), derogatory remarks or profane and/or obscene comments. Threats are warnings of an intent to injure another person with or without an object or weapon, to harass (also sexually) and to physically intimidate. Physical assault includes slapping, pinching, pushing, shoving, spitting or kicking, with or without the use of weapons (McKenna 2004).

Extensive efforts have been made to understand PVV in psychiatric settings (Bowers et al. 2006, Duxbury \& Whittington 2005, Richter \& Whittington 2006); however, less effort has been given in general health care settings (Cooper \& Swanson 2002). Certain staff and patient attributes (Farrell et al. 2006, McKenna et al. 2003), risky interactions (Adib et al. 2002, Lin \& Liu 2005) as well as environmental characteristics (Kwok et al. 2006, Uzun 2003) have been identified as important factors leading to PVV in general hospitals. In general hospitals worldwide, there is a lack of research-based knowledge regarding PVV and its precursors and causes. Guidelines for aggression and violence management often synthesise findings based on violence in the mental health inpatient setting (Winstanley \& Whittington 2002, 2004a). This setting has some similarities with the general health care setting, but there are many differences that make generalisation across the settings difficult (Winstanley \& Whittington 2004b). In this study, a survey of PVV in the general hospital setting was conducted, using an existing instrument to gather data on the severity of the problem and its related factors.

\subsection{BACKGROUND}

Hahn et al. (2008) found in a comprehensive literature review that, in the year prior to data collection, $50 \%$ of health care professionals in general hospitals have ex- 
perienced verbal PPV and 25\% have been subjected to physical PVV. In general, nurses tend to report PVV more than other health care professionals; however, incident reporting of PVV is not routine practice in general hospitals. Typically, violence in this setting is underreported (Beech \& Leather 2006, Fernandes et al. 1999). The true incidence of PVV is unknown, since indices often use different criteria for definition and incidents are commonly considered a work-related problem (Beech \& Leather 2006, St-Pierre \& Holmes 2008).

The mean age of staff reporting exposure to violence during the past five shifts or the past 4-12 months, appears to be lower than the age for staff reporting no exposure to violence (Duncan et al. 2001, Farrell et al. 2006, Jackson \& Ashley 2005). Fewer years of job experience may also be indicative of higher risk rates for occurrence of PVV (Adib et al. 2002, Graydon et al. 1994, Whittington et al. 1996).

Several studies revealed that patients tend to be more violent than visitors (Beech \& Leather 2006, Camerino et al. 2008), with some cultural exceptions in countries such as Turkey (Ayranci 2005) and Israel (Carmi-Iluz et al. 2005). Male patients between the ages of 15-40 (Barlow \& Rizzo 1997, McKenna et al. 2003) and between 70 and 85 (Brayley et al. 1994) act most frequently aggressive (Coverdale et al. 2001, Farrell et al. 2006, Kwok et al. 2006). Studies have found that violent patients suffer from a variety of health conditions, including cognitive impairment, confusion or delirium (Lin \& Liu 2005, May \& Grubbs 2002), dementia (Brayley et al. 1994, Zernike \& Sharpe 1998), alcohol and illegal drug intoxication or withdrawal (May \& Grubbs 2002, Whittington et al. 1996, Winstanley \& Whittington 2004b) and mental health challenges (Brayley et al. 1994, Paola et al. 1994).

Staff-patient interactions in which patients or visitors endure frustrating experiences such as pain, anxiety or the feeling that they are not being taken seriously, appear to be precursors for PVV in general hospitals (Winstanley 2005, Winstanley \& Whittington 2004b). The type of medical specialty also plays an important role as an environmental factor. However, apart from emergency departments and psychiatric wards, little information is available on the type of clinical settings that experience a high incidence of violence (Hahn et al. 2008). Additionally, PVV can result from organisational procedures, such as checking identity (Whittington et al. 1996), prolonged waiting times (Ayranci 2005, Carmi-lluz et al. 2005), lack of physician availability (Whittington et al. 1996, Winstanley \& Whittington 2004b), imposition of hospital policies and rules (May \& Grubbs 2002, Whittington et al. 1996) and discharge procedures (Winstanley \& Whittington 2004b).

PVV is related to staff and patient characteristics and their interactions, as well as environmental characteristics. Previous studies have only partially described these factors related to PVV and the existing results are conflicting. Most of the evidence on PVV originates from hospitals in North America and the UK. Mainland European general hospitals are less well researched. The aim of this study was therefore to explore nurses' experience with PVV in general hospital settings in Switzerland. Related factors such as the characteristics of patients/visitors and 
nurses involved, the interaction between nurses and patients/visitors, as well as the environmental and organisational aspects were also investigated.

\subsection{METHODS}

\section{Design}

A retrospective cross-sectional survey using a sample of nursing staff working in a variety of wards, was conducted in general hospitals in the German-speaking part of Switzerland.

\section{Sample}

A non-probability purposive sampling strategy was used for recruitment. In total, 410 nurses typical of the nursing population employed in Swiss general hospitals were contacted. This number allowed for a moderate sample size considering the small Swiss health care workforce (Jaccard Ruedin et al. 2009). Participants were recruited from two typical groups. The first group included all of the 114 nurses participating in the postgraduate nursing education program from the Nursing Association of Switzerland. These participants were employed in a variety of general hospitals. The second group included all of the 296 nurses working in four typical general hospitals. These four hospitals were comparable in size, services for patient care and in hospital policies. The inclusion criteria were: working in nursing care, direct contact with patients/visitors and an adequate command of the German language. The exclusion criteria were nursing staff working in psychiatric units.

\section{Data collection}

The study was conducted between November 2006 - January 2007 and data was collected using a questionnaire. For the first group $(n=114)$, the educational institution where the nurses studied granted the researchers permission to conduct the study. A nursing teacher recruited participants and informed them about the study. The questionnaire was given to the participants at the beginning of a teaching lesson. For the second group ( $n=296)$, permission to participate was granted by heads of nursing staff departments in general hospitals. The head nurses, who had previously been personally informed about the study by the principal investigator, informed and recruited all nursing staff on their wards. Willing participants received the questionnaires along with written information regarding the study. The questionnaires were completed during work hours and returned anonymously via business-reply mail. 


\section{Instrument}

The questionnaire used was adapted from the Survey of Violence Experienced by Staff (SOVES) (McKenna 2004). The SOVES includes questions about staff and patient characteristics, as well as their interactions and environmental characteristics related to PVV. It is designed to gather information from health care staff who experienced verbal violence, threats or physical violence in the workplace in the remote (ever experienced during their whole career) or near past (the past 12 months prior data collection). After translation into German using reverse translation (Polit \& Tatano Beck 2003, Wang et al. 2006), changes according to the research aim were made to the original instrument. The SOVES German version (SOVES-G) was validated by a panel of nine German-speaking researchers in the field of aggression in the health care system from Germany, Austria and Switzerland. These experts judged the questions of the SOVES-G as relevant and valid by content validity index (Polit \& Tatano Beck 2003). The SOVES-G included six sections. Section A contained questions about the characteristics and attributes of health care staff. In accordance to the research aim, sources of violence in coworkers and others were excluded in all sections. Section B examined experiences with PVV during the professional career. Section $C$ investigated experience with threats, verbal and physical PVV during the past 12 months using close-ended questions. It then investigated, for each form of PVV, the activities being performed when PVV most often occurred, using open-ended questions. Section D contained questions regarding experiences with PVV that had occurred during the past working week. This allowed for a more accurate recall of events, giving deeper insight into the violent incidence. In section $E$, formal reporting behaviour along with the consequences of PVV were examined and available support systems after having experienced PVV were also analysed. Also included in section E were the 12 items of the shortened Perception of Aggression Scale (POAS-S). Lastly, in section F, closeended questions examined the training contents and investigated using nine statements, the importance of intervention skills in handling PVV in daily practice. The POAS-S (Needham et al. 2004) was used to investigate, as a component of the nurses' characteristics, nurses' attitudes towards PVV. According to prevention and intervention strategies in aggression management, the perception of aggression is seen as an important influencing factor in PVV (Abderhalden et al. 2002, Jansen et al. 2005). The POAS-S consisted of 12 items presented as statements on aggression, which together encompassed two factors. These two factors encompassed two different attitudes regarding PVV. The first factor, using six items, inferred that PVV is a dysfunctional and/or undesirable phenomena ('aggression is conscious battery against someone'). The second factor, also using six items, inferred that PVV is a functional/comprehensible phenomena ('aggression opens new pathways in care and treatment'). The statements were answered with a five-point Likert scale from 1 = complete disagreement to $5=$ total agreement. The POAS-S, developed and 
tested by Needham et al. (2004), demonstrated satisfactory internal consistency with Cronbach's alphas of 0.69 for factor 1 and 0.67 for factor 2 . The average retest reliability after four, 14 and 70 days was $r=0.76$ for factor 1 and $r=0.77$ for factor 2.

\section{Ethical considerations}

This study was approved by the local Ethical Commission. Willing nursing participants received a written description of the study that outlined the aims of the study, the methods to be employed, the questionnaires and the voluntary nature of participation. To ensure confidentiality and anonymity, no names or other identifiers were used.

\section{Analysis}

Standard descriptive statistics were used to describe and summarise the data. Associations between categorical variables were tested using chi-square tests. All data analyses were conducted using SPSS 15; $p<0.01$ was considered statistically significant.

\subsection{RESULTS}

\section{Participants}

Of those nurses approached to participate $(n=410), 291$ nursing staff working in a variety of general hospital units participated in the study (response rate $=71 \%$ ). From the postgraduate nursing education group, 71 nurses (response rate $=62 \%$ ) participated and from the hospital group, 220 nursing staff (response rate $=74 \%$ ) completed the questionnaire. The nurses in the two groups did not differ significantly with respect to their socio-demographic characteristics (gender, overall professional experience, professional experience at current workplace, employment level and time spent in direct patient contact). Nurses in the general hospital group were slightly older and had more often already obtained a postgraduate diploma, in comparison with the nurses in the postgraduate education sample. The sociodemographic characteristics of the participants are shown in Table 4.1. 


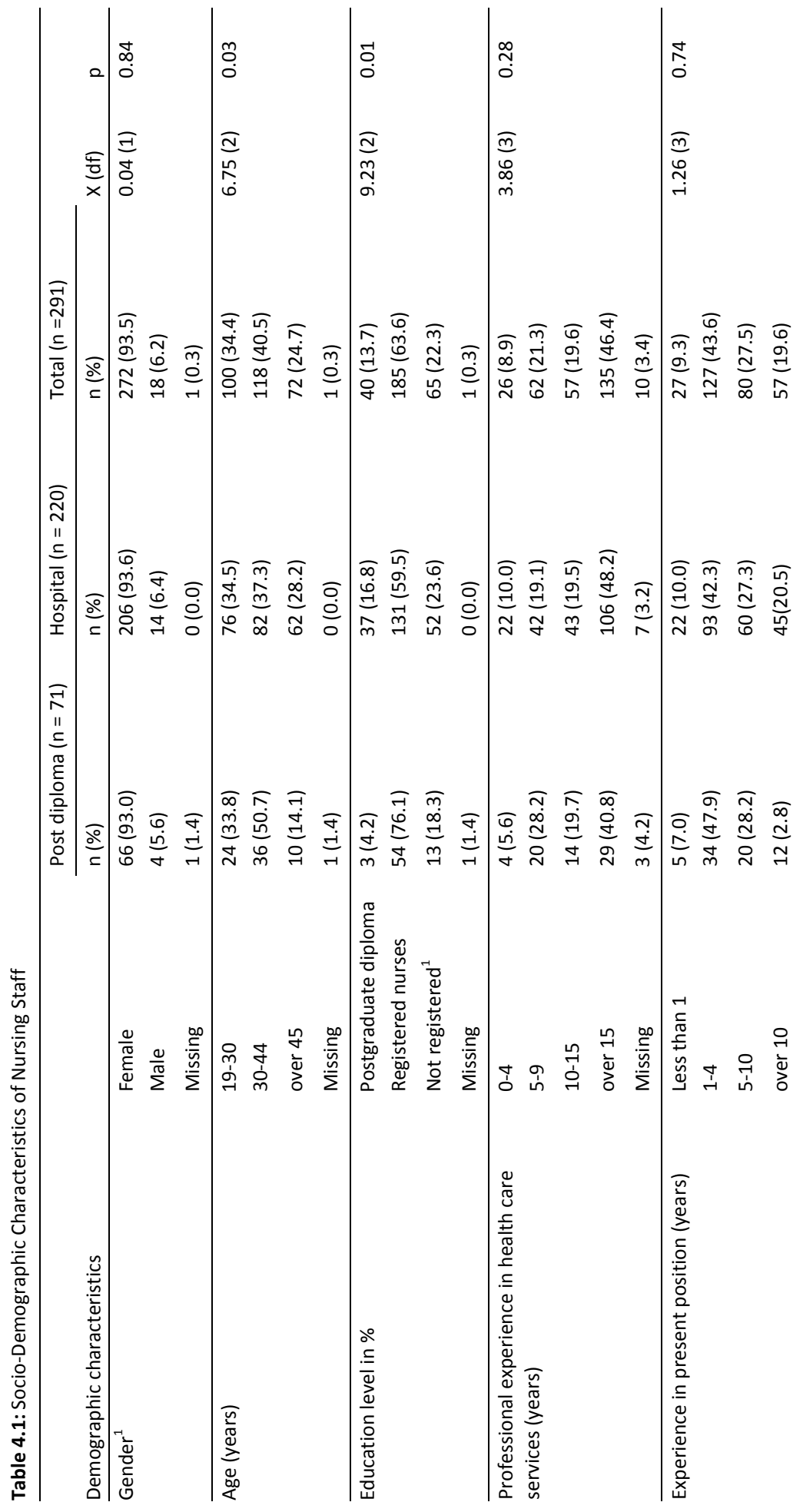

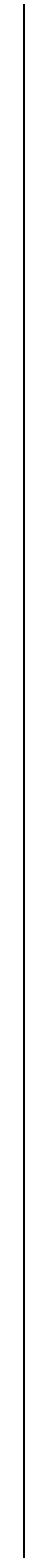




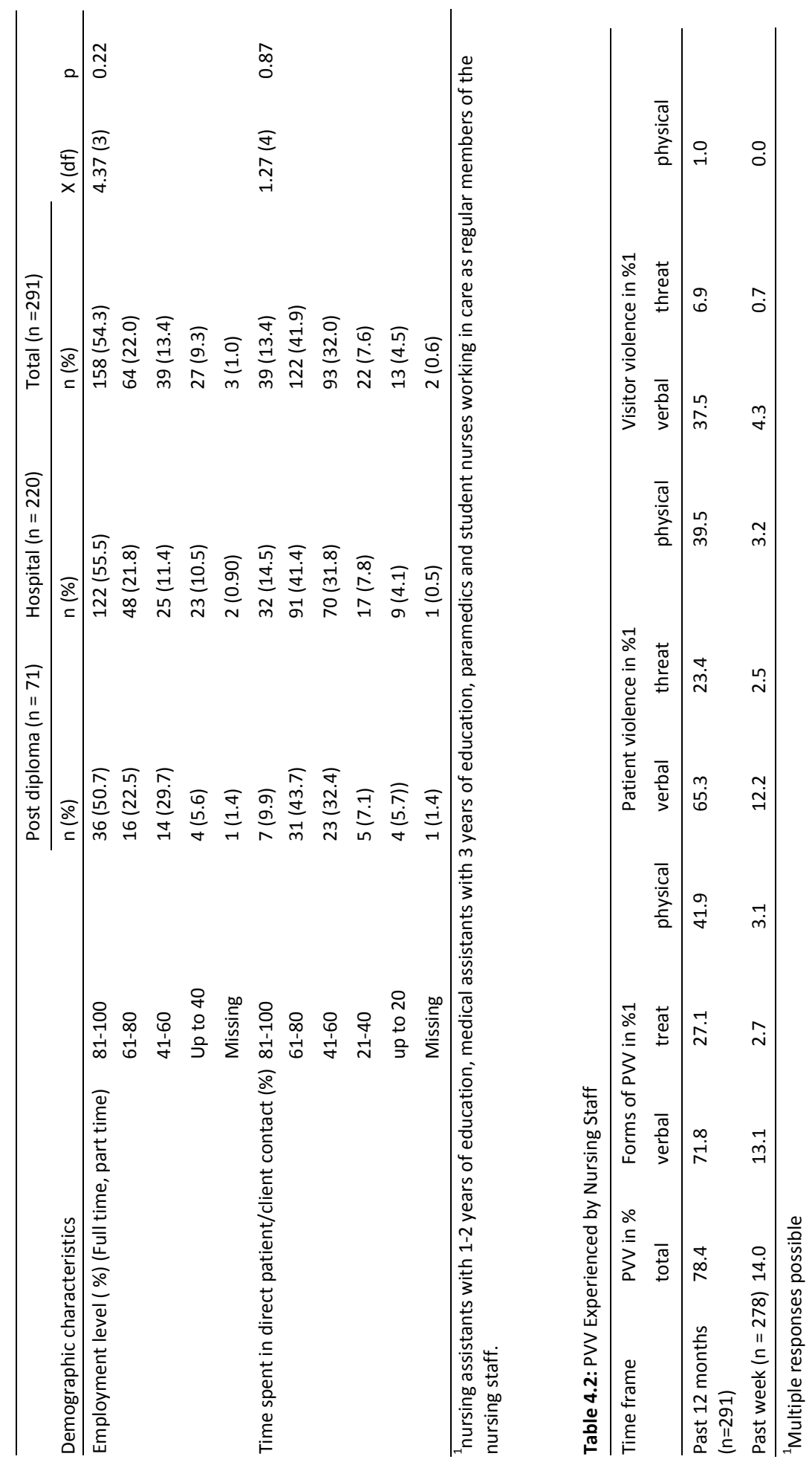




\section{Occurrence and forms of PVV}

Almost all nurses (95\%) had experienced PVV during their career. Verbal violence was the most frequent form of violence experienced during the past 12 months at their present workplace $(71.8 \%)$, followed by physical violence $(41.9 \%)$ and threats (27.1\%). Violent behaviour occurred much more frequently with patients than with visitors. During the past working week, $14.0 \%(n=39)$ of the nurses had experienced PVV (see Table 4.2).

\section{Environmental characteristics and forms of PVV}

When considering workplace characteristics and the different forms of PVV experienced in the past 12 months, the descriptive analyses demonstrated that nurses working in maternity wards and in outpatient clinics experienced the lowest levels of PVV, with incidence rates of $57.1 \%$ and $53.6 \%$, respectively. Table 4.3 illustrates that workplace PVV was most often experienced by nurses working in intensive and intermediate care units, in rehabilitation units and in emergency rooms (all over $84 \%)$. Chi square analyses revealed significant associations between the clinical setting and the reported threats and physical PVV experienced.

Only $7.6 \%(n=22)$ of the nurses confirmed that their hospital had an official policy with a formal PVV reporting procedure. Unfortunately, many nurses (44\%, $n$ $=128$ ) did not know whether or not there was a formal policy or procedure. However, $80.5 \%(n=234)$ asserted that supervisors were supportive after occurrences of violence. More nursing staff working without official policies and formal procedures for dealing with PVV experienced PVV (verbal violence $=85.8 \%, n=105$, threats $=40.8 \%, n=45$, physical violence $=57.8 \%, n=67)$, than nurses working in hospitals with a policy (verbal violence $=63.6 \%, n=14$, threats $=22.7 \% n=5$, physical violence $=27.3 \%, n=6$ ) or nurses who did not know if their hospital had such a policy (verbal violence $=61.4 \%, n=78$, threats $=16.4 \%, n=21$, physical violence $=$ $34.5 \%, n=41$ ) (verbal violence $\chi^{2}=19.38$, d.f. $=2, p=0.0001$, threats $\chi^{2}=18.72$ d.f. $=2, p=0.0001$, physical violence $\chi^{2}=15.77$, d.f. $=2, p<0.0001$ ).

With regards to organisational processes, nurses identified different reasons during the week prior to completion of the questionnaire, for the occurrence of PVV. During this time frame, of the 39 nurses that had experienced PVV, the most common reasons cited were long waiting times $(n=10)$, numerous medical examinations and tests $(n=8)$, enforcement of hospital rules $(n=8)$ and staff shortages $(n=8)$. 
Table 4.3: Workplace PVV Experienced by Nursing Staff

\begin{tabular}{|c|c|c|c|c|}
\hline \multirow[t]{2}{*}{ Workplace } & \multicolumn{4}{|c|}{ PVV in past 12 months $^{1}$} \\
\hline & total PVV \% & verbal \% & threats \% & physical \% \\
\hline $\begin{array}{l}\text { Intensive care, intermediate care } \\
(n=29)\end{array}$ & 90.0 & 89.7 & 53.3 & 71.4 \\
\hline Rehabilitation units $(n=13)$ & 84.6 & 84.6 & 46.2 & 61.5 \\
\hline Emergency units $(n=26)$ & 84.6 & 84.6 & 26.9 & 38.5 \\
\hline Surgical units $(n=88)$ & 81.8 & 70.5 & 20.5 & 38.8 \\
\hline Medical units $(n=79)$ & 79.7 & 73.4 & 31.6 & 55.8 \\
\hline Other units $(n=13)$ & 76.9 & 69.2 & 15.4 & 41.7 \\
\hline Mother \& child care units $(n=14)$ & 57.1 & 50.0 & 14.3 & 15.4 \\
\hline Out-patient clinics $(n=26)$ & 53.6 & 50.0 & 10.7 & 11.1 \\
\hline \multirow[t]{5}{*}{ Total $(n=291)$} & 78.2 & 72.1 & 27.1 & 44.2 \\
\hline & Chi square test & Chi square test & Chi square test & Chi square test \\
\hline & $x 2$ (d.f) & $\chi 2$ (d.f) & $x 2$ (d.f) & $\chi 2$ (d.f) \\
\hline & $17.88(7)$ & $17.90(7)$ & $21.48(7)$ & $31.93(7)$ \\
\hline & $p=0.01$ & $p=0.01$ & $p=0.003$ & $\mathrm{p}<0.001$ \\
\hline
\end{tabular}

${ }^{1}$ Multiple responses possible about form of aggression, missing 3

\section{Characteristics of patients and visitors involved}

Among the violent incidents reported in the past 12 months prior to completion of the questionnaire, the majority of the involved patients were either diagnosed with dementia $(34.6 \%, n=45)$ or with drug or alcohol abuse $(21.0 \%, n=48)$. Less frequently mentioned diagnoses were delirium $(12.7 \%, n=29)$, psychiatric illness $(7.9 \%, n=18)$ and pain $(5.7 \%, n=13)$.

In the week prior to completion the questionnaire, 39 nursing staff reported 34 incidents of patient violence and 8 incidents of visitor violence (female $n=3$, male $n$ $=5)$. The majority of violent patients were male (77\%). Violent patients were usually over 74 years of age and had a variety of medical diagnoses, which caused cognitive impairment. Of the 42 incidents from the past week, violent patients and visitors showed signs of anxiety $(n=25)$, stress $(n=12)$, deficits in comprehending the situation $(n=18)$, excessive demands $(n=23)$ and uncertainty $(n=12)$.

\section{Characteristics of nurses involved}

Chi square analysis was employed to test the association between the attributes of nursing staff, during the past 12 months, having had experienced violence $(78.4 \%$, $n=228$, ) and those not having had $(21.6 \%, n=63$,$\left.) . Registered nurses ( R N^{\prime} s\right)$ and nurses with a postgraduate diploma experienced more PVV than non-RN's. PVV was experienced more often by nurses working with patients over 65 years of age. A higher level of verbal PVV was reported by nursing staff spending over $40 \%$ of their working time in direct contact with patients, or having more than four years 
experience in the health care sector. A positive association was found between nurses' experience with PVV and the perceived necessity for a training course in aggression management (Table 4.4). Chi square analysis revealed no significant associations between experiences of PVV and the socio-demographic characteristics of gender, age and employment level. No significant associations were found between experiences of PVV and the training level of nursing staff, or the perception of aggression (POAS-S). Similar results were found regarding the perception of support after an incidence.

Almost all staff ( $n=36$ of 39 ) who had experienced PVV in the past working week were RN's. They had all worked for over four years in the health care system and $95 \%$ had spent more than $40 \%$ of their working time in direct contact with patients. All had cared for adults and older people over 65 years of age. The majority $(95 \%)$ had worked at least one year in medical (33.3\%) and surgical $(20.5 \%)$ wards.

\section{Characteristics of interactions at risk}

Many incidents associated with violence during the past 12 months, were when nurses were required to assist with close physical interventions or intimate functions (43\%). Other situations associated with higher incidences of violence were negotiating patients' or visitors' treatment acceptance (11\%), discussing decline of care or treatment with patients or visitors (21\%) or providing counselling in difficult situations (7\%). 
Table 4.4: Attributes of Nursing Staff Involved in PVV

\begin{tabular}{|c|c|c|c|}
\hline \multirow[t]{2}{*}{ Attributes } & \multicolumn{3}{|c|}{ PVV in past 12 months } \\
\hline & Verbal $(n=289)$ & Threats $(n=290)$ & Physical $(n=275)$ \\
\hline \multirow[t]{2}{*}{ Education level: } & yes & yes & yes \\
\hline & $\mathrm{n}(\%)$ & $\mathrm{n}(\%)$ & $\mathrm{n}(\%)$ \\
\hline $\begin{array}{l}\text { Registered nurses and nurses with } \\
\text { postgraduate diploma }\end{array}$ & $172(76.4)$ & $70(31.1)$ & $107(48.2)$ \\
\hline \multirow[t]{5}{*}{ Not registered nurses } & $37(57.8)$ & $9(13.8)$ & $15(28.3)$ \\
\hline & Chi square test & Chi square test & Chi square test \\
\hline & $x 2=8.64$ & $\chi 2=7.58$ & $x 2=6.86$ \\
\hline & d.f. $=1$ & d.f. $=1$ & d.f. $=1$ \\
\hline & $p=0.003$ & $p=0.006$ & $p=0.009$ \\
\hline \multirow[t]{3}{*}{ Patient group: } & Verbal $(n=290)$ & Threats $(n=288)$ & Physical $(n=270)$ \\
\hline & yes & yes & yes \\
\hline & n (\%) & $\mathrm{n}(\%)$ & $\mathrm{n}(\%)$ \\
\hline over 65 years & $140(80.9)$ & $53(30.6)$ & $89(52.7)$ \\
\hline \multirow[t]{5}{*}{$0-65$ years } & $69(59.0)$ & 2622.0 & $33(30.8)$ \\
\hline & Chi square test & Chi square test & Chi square test \\
\hline & $x 2=16.70$ & $x^{2}=2.62$ & $x 2=12.64$ \\
\hline & d.f. = 1 & d.f. = 1 & d.f. $=1$ \\
\hline & $p=0.0001$ & $p=0.10$ & $p<0.0001$ \\
\hline \multirow{3}{*}{$\begin{array}{l}\text { Time spent in direct patient/client } \\
\text { contact: }\end{array}$} & Verbal $(n=287)$ & Threats $(n=289)$ & Physical $(n=274)$ \\
\hline & yes & yes & yes \\
\hline & $\mathrm{n}(\%)$ & $\mathrm{n}(\%)$ & $\mathrm{n}(\%)$ \\
\hline over $40 \%$ & $190(50.0)$ & $71(28.0)$ & $112(45.7)$ \\
\hline \multirow[t]{5}{*}{$0-40 \%$} & $17(74.8)$ & $6(17.1)$ & $8(27.6)$ \\
\hline & Chi square test & Chi square test & Chi square test \\
\hline & $x^{2}=9.12$ & $x 2=1.83$ & $x 2=3.46$ \\
\hline & d.f. = 1 & d.f. = 1 & d.f. = 1 \\
\hline & $p<0.003$ & $p=0.17$ & $p=0.063$ \\
\hline \multirow{3}{*}{$\begin{array}{l}\text { Professional experience in health } \\
\text { care services: }\end{array}$} & Verbal $(n=280)$ & Threats $(n=280)$ & Physical ( $n=268$ ) \\
\hline & yes & yes & yes \\
\hline & $\mathrm{n}(\%)$ & $\mathrm{n}(\%)$ & $\mathrm{n}(\%)$ \\
\hline $0-4$ years & $12(46.2)$ & $5(27.6)$ & $112(45.5)$ \\
\hline \multirow[t]{5}{*}{ Over four years } & $190(74.8)$ & $70(19.2)$ & $7(31.8)$ \\
\hline & Chi square test & Chi square test & Chi square test \\
\hline & $x^{2}=9.63$ & $x 2=0.83$ & $x 2=1.53$ \\
\hline & d.f. = 1 & d.f. $=1$ & d.f. = 1 \\
\hline & $p=0.02$ & $p=0.36$ & $p=0.21$ \\
\hline \multirow{3}{*}{$\begin{array}{l}\text { Attitude importance of interven- } \\
\text { tion skills: }\end{array}$} & Verbal $(n=287)$ & Threats $(n=288)$ & Physical $(n=273)$ \\
\hline & yes & yes & yes \\
\hline & n (\%) & $\mathrm{n}(\%)$ & n (\%) \\
\hline Not important & 19 (55.9) & $6(17.1)$ & $10(33.3)$ \\
\hline Moderately important & $46(59.3)$ & $14(18.2)$ & $28(37.8)$ \\
\hline \multirow[t]{5}{*}{ Very important } & $142(80.7)$ & $59(33.5)$ & $84(49.7)$ \\
\hline & Chi square test & Chi square test & Chi square test \\
\hline & $x 2=16.74$ & $x 2=8.45$ & $x 2=4.69$ \\
\hline & d.f. $=2$ & d.f. $=2$ & d.f. $=2$ \\
\hline & $p<0.0001$ & $p=0.01$ & $p=0.096$ \\
\hline
\end{tabular}




\section{Consequences of PVV for nursing staff}

Despite high levels of PVV, the majority of participants (80\%) felt confident about their verbal intervention skills, however only $50 \%$ felt confident about their physical intervention skills. Out of the participants having experienced PVV in the past 12 months, $1.4 \%(n=3)$ took one to five days sick leave as a result of PVV. The emotional impact of PVV was rated by many nursing staff as moderate to more upsetting (verbal $37.4 \%, n=78$, threats $51.6 \%, n=41$, physical $48.4 \%, n=59$ ) (see Table 4.5). Participants reported damaged or destroyed spectacles or jewellery $(5.3 \%, n=$ $7)$, destroyed clothing $(1.5 \%, n=2)$, physical injuries not requiring treatment or first aid $(28.6 \%, \mathrm{n}=38)$ and physical injuries requiring medical consultation and/or treatment $(0.8 \%, n=1)$ as a result of a violent incident.

As described in the section on environmental characteristics, supervisors were assessed as supportive after an incident of PVV. However, only $20.3 \%(n=59)$ of the nurses involved discussed the incident with their supervisors. Most often they discussed it with colleagues $(48.5 \%, \mathrm{n}=141)$ or with family or friends $(35.8 \%, \mathrm{n}=$ 104). PVV was often documented in care plans (verbal $65.4 \%, n=136$; threats $72.7 \%, n=58$, physical $73.5 \%, n=86$ ) when an official form to systematically report PVV was unavailable.

Table 4.5: Emotional Impact of PVV on Nursing Staff

\begin{tabular}{llll}
\hline & \multicolumn{2}{l}{ Emotional impact of PVV } & \\
Emotion & Verbal PVV $(\mathrm{n}=209)$ & Threats $(\mathrm{n}=79)$ & Physical $(\mathrm{n}=122)$ \\
\hline Not upsetting & $\mathrm{n}(\%)$ & $\mathrm{n}(\%)$ & $\mathrm{n}(\%)$ \\
Slightly upsetting & $32(15.3)$ & $12(15.2)$ & $17(13.9)$ \\
Moderately upsetting & $99(47.4)$ & $27(34.2)$ & $16(37.7)$ \\
Quite upsetting & $58(27.8)$ & $27(34.2)$ & $39(32.0)$ \\
Very upsetting & $20(9.6)$ & $11(13.9)$ & $16(13.1)$ \\
\hline
\end{tabular}

\subsection{DISCUSSION}

PVV is a complex occupational hazard for nurses, including nurses in Switzerland. The results of this study indicate that the organisational and workplace characteristics, as well as the attributes of patient and staff, were important factors in the genesis of violent incidents.

The results from the 12 month period ( $71.8 \%$ verbal and $41.9 \%$ physical PVV) as well as from the past (14.0\% PVV) prior to the completion of the questionnaire, indicated that nursing staff in general hospitals faced a high risk of experiencing PVV. Other studies confirm that PVV is a major problem for nursing staff and showed comparable prevalence rates between countries (Kwok et al. 2006, Merecz 
et al. 2006, O'Connell et al. 2000). Due to the differences in the outcome variables it is difficult to compare the results between studies. In this study the outcome variables are divided into three categories (verbal, threats and physical). As a result, a greater range of PVV may have been captured than in other European studies (Camerino et al. 2008). Definitions of PVV with health care staff vary greatly, thus hampering the interpretation and comparison of research results (Chappell \& Di Martino 2006, Lau \& Magarey 2006). The self-assessment of the 12 months period could have been affected by recall bias. However, as most studies in the field of PVV use a 12 month self-assessment time frame, this procedure was adopted to allow for international comparison. A one week time frame was additionally used in this study to reduce recall bias (Graydon et al. 1994). With this studies' moderate sample size, to have used only a one week time period would have resulted in very limited answers $(n=39)$ and only allowed for description of the situation.

With over $70 \%$ reporting having experienced verbal violence and 50 to $70 \%$ having experienced physical violence during the 12 month period, PVV was clearly a common occurrence for nurses in all wards, excluding outpatient clinics and in maternity wards. However, the results indicated that the clinical setting had little influence on the occurrence of PVV, except in the case of threats and physical violence. Due to the cross-sectional and retrospective study design, no causal conclusions could be drawn. However, PVV in this study seemed to be related to additional factors specific to the type of interaction and situation as mentioned by Cooper and Swanson (2002), Duxbury and Whittington (2005) and Winstanley (2005). This could explain some contradictory international findings regarding high levels of PVV in emergency units (Lau et al. 2006), medical wards (Ayranci 2005, Jackson \& Ashley 2005, O'Connell et al. 2000), surgical settings (Kwok et al. 2006, Uzun 2003, Winstanley \& Whittington 2004a) and intensive care units (May \& Grubbs 2002). Maternity units or paediatric settings were also listed as being high risk settings for verbal abuse or threatening behaviour (McKenna et al. 2003, Winstanley \& Whittington 2004a, Yassi 1994).

Interestingly, this study found high levels of PVV in rehabilitation units (61.5\%), which is a distinct form of long term care. Nurses working in rehabilitation units provide supportive care and educate patients and their significant others on illness management and symptom control. Typically, hospitalisations and nurse-patient and/or nurse-relative interactions are longer term in these units than in other clinical settings. Additionally, the work is more intensive over a longer period of time. These wards differ from other units in the duration of their hospitalisations, the intensity of the work required and the long term relationships established between staff and patients and/or visitors. It was presumed that these patients and their relatives often have erroneous preconceptions that recovery would be more rapid and may therefore be more impatient about their progress or dissatisfied with treatment. Often these patients must come to terms with living with a chronic illness or a decrease and/or loss of normal functioning. They must learn to cope 
with the resulting obstacles in everyday life. This could lead to frustration, anxiety or anger that may manifest itself in problematic interactions with nursing staff, aggressive behaviour and a higher occurrence of PVV.

The results are comparable to that of other studies in those organisational characteristics such as staff shortages, long waiting times, the necessity of performing numerous medical examinations and the presumed need to enforce hospital rules with patients and visitors are present. The staff may need to be more cautious when these organisational characteristics are present (Ayranci 2005, Carmi-lluz et al. 2005, May \& Grubbs 2002). Switzerland has one of the most expensive health care systems in the world, paid by patients' private insurances (Bundesamt für Statistik 2007). We assume that given the high cost of health care, patients and relatives expect a well-functioning health care system with effective procedures. An interdisciplinary quality improvement approach, examining organisational processes, diagnostic procedures and hospital rules, would be helpful in reducing the known precursors of PVV.

As revealed in other studies, this study demonstrates that PVV is mainly initiated by patients (Ayranci 2005, Camerino et al. 2008, Farrell et al. 2006). The results indicate that male patients over the age of 65 and those with medical diagnoses resulting in cognitive impairment, appear more likely to become aggressive. Nurses must take these factors into consideration to prevent aggressive behaviour. Patients experiencing dementia, drug and/or alcohol abuse and delirium may have considerable difficulty comprehending their situation, which then further affects nurse-patient interactions. The results also reveal that anxiety, stress, difficulty in comprehending the situation, excessive demands and uncertainty may trigger aggressive behaviour. Consequently, it is important that nurses have the knowledge and ability to assess such situations, to put preventive measures in place and to intervene appropriately (Winstanley \& Whittington 2004b).

In contrast to the results of former studies (Taylor 2000, Wells \& Bowers 2002), this study demonstrates that nurses with a postgraduate diploma and over four years of professional experience report more PVV than non-registered or less experienced nurses. This result may be due to the age structure of the sample $(64 \%$ over 29 years old) and that it is a sample in which the majority of nurses have had more than four years of professional experience. In Switzerland this study correlates to the demographic aging of the nursing profession (Jaccard Ruedin et al. 2009)

Similar to the results of Adib et al. (2002) and Winstanley and Whittington (2004b), this study reveals that the interactions carrying the greatest risk for PVV are those with close physical contact between nursing staff and patients, or when it is necessary for nurses to encroach on patients' private zones (Whittington et al. 1996). Furthermore, verbal communications regarding treatment or care problems also carry a high risk for PVV. Nurses should be aware that in many of these situations patients or visitors may become anxious and experience feelings of helpless- 
ness, anger and frustration, which could possibly lead to PVV (Winstanley 2005). To prevent PVV, it is important to recognise situations that may evoke fear or anxiety in patients and their families. Nurses should respond to the needs of patients and visitors with empathy and establish a safe atmosphere by considering patient autonomy and the individual personalities of patients and visitors.

The emotional impact of PVV appears to be a burden for nursing staff and could lead to considerable health problems (Needham et al. 2005, Stanko 2002). When dealing with aggressive incidents, support from colleagues, family and friends seems to be more helpful than that provided by supervisors. With only a minority of general hospitals offering an official policy including formal reporting procedures for PVV in Switzerland, it appears that in this sample, this workplace problem is not sufficiently addressed. It seems that a universal approach towards prevention, including monitoring and/or post treatment of PVV in the general hospital setting in Switzerland is lacking in spite of recommendations (International Council of Nurses (ICN) 2001, McPhaul \& Lipscomb 2004, SBK 2001). The results of this study suggest that the presence of an official hospital policy for dealing with PVV will likely reduce the perception of the occurrence of PVV by nurses. Actions to counteract PVV should include a strong commitment to violence prevention in the workplace, sufficient resources for security, risk assessment, monitoring, training in violence prevention and management, as well as care for victims (Beech \& Leather 2006, Jackson et al. 2002, Swanson et al. 2002). The results further suggest that the use of interdisciplinary prevention programs in Swiss general health settings would be beneficial. There is also insufficient training for dealing with PVV in nursing education (Nau et al. 2007). Most of the specific training programs include strategies useful in psychiatric or geriatric settings and include diffusing the aggression or using breakaway techniques to promote personal safety. However, they do not address some of the problems described in this study that arise in general hospitals. Not surprisingly, only $20 \%$ of general nurses had attended such training and $50 \%$ reported having insufficient confidence in their ability to manage physical aggression in the general health care setting.

\subsection{CONCLUSIONS}

PVV in general hospitals is a serious workplace problem for nurses and is not restricted to high risk areas like emergency and psychiatric wards. This study explores, for the first time in Switzerland, various factors that contribute to PVV. PVV seems to be influenced by the social context or cultural milieu of the health care system and is therefore not easily internationally comparable. Due to the moderate sample size of this study, no useful logistic regression could be calculated. However, in contrast to other studies, the results indicate that the clinical setting has little impact on the occurrence of PVV. PVV seems to depend on additional factors specific to the type of interaction and situation. Based on the existing knowledge, 
future research should more closely investigate these risk factors and how they interact and lead to the escalation of a situation. Policies, procedures and intervention strategies can then be developed or improved on. Future research could include qualitative analysis to achieve more detailed perspectives with these situations. Inclusion of quantitative research projects with larger sample sizes would facilitate the analysis of complex models and the inclusion of organisational, situational, personnel and interactional factors.

\section{Relevance to clinical practice}

Nursing elderly and cognitively impaired patients suffering from anxiety or prone to anger is a challenging situation for nurses. To deal professionally with these complex situations in the general hospital setting, instruments based on the existing knowledge, need to be developed to predict and monitor PVV. Adequate intervention strategies also need to be implemented competently and professionally to manage PVV.

\section{Contributions}

Study design: $\mathrm{SH}, \mathrm{RJGH}, \mathrm{THD}$

Data collection and analysis: $\mathrm{SH}, \mathrm{MM}$

Manuscript preparation: SH, MM, IN, ThD, GK, RJGH

\section{Conflict of interest}

There is no conflict of interest in this study

\section{Acknowledgment}

The authors would like to thank all participants of the study, who completed the many surveys. We are also very grateful to the head nurses of the general hospitals, who enabled us to investigate their wards. Furthermore, we thank the centre for further education of the Nursing Association of Switzerland, Zurich, for support. 


\subsection{REFERENCES}

Abderhalden C, Needham I, Friedli TK, Poelmans J \& Dassen T (2002): Perception of aggression among psychiatric nurses in Switzerland. Acta Psychiatrica Scandinavica 106, 110-117.

Adib SM, Al-Shatti AK, Kamal S, El-Gerges N \& Al-Raqem M (2002): Violence against nurses in healthcare facilities in Kuwait. International Journal of Nursing Studies 39, 469-478.

Arnetz JE \& Arnetz BB (2001): Violence towards health care staff and possible effects on the quality of patient care. Social Science and Medicine 52, 417-427.

Ayranci U (2005): Violence toward health care workers in emergency departments in west Turkey. Journal of Emergency Medicine 28, 361-365.

Barlow CB \& Rizzo AG (1997): Violence against surgical residents. The Western Journal of Medicine 167, 74-78.

Beech B \& Leather P (2006): Workplace violence in the health care sector: A review of staff training and integration of training evaluation models. Aggression and Violent Behaviour 11, 27-43.

Bourn J (2003) A Safer Place to Work: Protecting NHS Hospital and Ambulance Staff from Violence and Aggression. The National Audit Office, London, p. 54.

Bowers L, Jeffery D, Simpson A, Daly C, Warren J \& Nijman H (2006): Junior staff changes and the temporal ecology of adverse incidents in acute psychiatric wards. Jounal of Advanced Nursing 57, 153-160.

Brayley J, Lange R, Baggoley C, Bond M \& Harvey P (1994): The violence management team. An approach to aggressive behaviour in a general hospital. Medical Journal of Australia 15, 254-258.

Bundesamt für Statistik (2007) Kosten und Finanzierung des Gesundheitswesens 2005 ((BFS) BfS ed.). Schweizerische Eidgenossenschaft, Neuchatel, Schweiz.

Camerino D, Estryn-Behar M, Conway PM, van Der Heijden BIJM \& Hasselhorn HM (2008): Work-related factors and violence among nursing staff in the European NEXT study: a longitudinal cohort study. International Journal of Nursing Studies 45, 35-50.

Carmi-Iluz T, Peleg R, Freud T \& Shvartzman P (2005): Verbal and physical violence towards hospital- and community-based physicians in the Negev: an observational study. Bio Med Central Health Service Research 5, 1-6.

Chappell D \& Di Martino V (2006) Violence at Work, Third edition edn. International Labour Office, Geneva, pp. 1-360.

Cooper CL \& Swanson N (2002) Workplace violence in the health sector. State of the Art. International Labour Office, International Council of Nurses, World Health Organization and Public Service International, Geneva.

Coverdale J, Gale C, Weeks S \& Turbott S (2001): A survey of threats and violent acts by patients against training physicians. Medical Education 35, 154-159.

Duncan SM, Hyndman K, Estabrooks CA, Hesketh K, Humphrey CK, Wong JS, Acorn S \& Giovannetti P (2001): Nurses' experience of violence in Alberta and British Columbia hospitals. Canadian Journal of Nursing Research 32, 57-78.

Duxbury J \& Whittington R (2005): Causes and management of patient aggression and violence: staff and patient perspectives. Journal of Advanced Nursing 50, 469-478.

Farrell GA, Bobrowski C \& Bobrowski P (2006): Scoping workplace aggression in nursing: findings from an Australian study. Journal of Advanced Nursing 55, 778-787.

Fernandes CMB, Bouthillette F, Raboud JM, Bullock L, Moore CF, Christenson JM, Grafstein E, Rae S, Ouellet L, Gillrie C \& Way M (1999): Violence in the emergency department a survey of health care workers. Canadian Medical Association Journal 161, 1245-1248.

Ferns T (2006): Violence, aggression and physical assault in healthcare settings. Nursing Standard 21, $42-$ 46.

Graydon J, Kasta W \& Khan P (1994): Verbal and physical abuse of nurses. Canadian Journal of Nursing Administration 7, 70-89. 
Hahn S, Zeller A, Needham I, Kok G, Dassen T \& Halfens RJG (2008): Patient- and visitor violence in general hospitals: A systematic review of the literature. Journal of Aggression and Violent Behavior 13, 431-441.

International Council of Nurses (ICN) (2001) Nurses, always there for you: united against violence, Geneva.

Jaccard Ruedin H, Weaver F, Roth M \& Widmer M (2009) Personnel de santé en Suisse - Etat des lieux et perspectives jusqu'en 2020. Observatoire suisse de la santé, Neuchâtel, p. 116.

Jackson D, Clare J \& Mannix J (2002): Who would want to be a nurse? Violence in the workplace--a factor in recruitment and retention. Journal of Nursing Management 10, 13-20.

Jackson M \& Ashley D (2005): Physical and psychological violence in Jamaica's health sector. Revista Panamericana de Salud Pública/Pan American Journal of Public Health. 18, 114-121.

Jansen GJ, Dassen TW \& Groot Jebbink G (2005): Staff attitudes towards aggression in health care: a review of the literature. Journal of Psychiatric and Mental Health Nursing 12, 3-13.

Kwok RP, Law YK, Li KE, Ng YC, Cheung MH, Fung VK, Kwok KT, Tong JM, Yen PF \& Leung WC (2006): Prevalence of workplace violence against nurses in Hong Kong. Hong Kong Medical Journal 12, 6-9.

Lau JB \& Magarey J (2006): Review of research methods used to investigate violence in the emergency department. Accident and Emergency Nurse 14, 111-116.

Lau JB, Magarey J \& McCutcheon H (2006): Violence in the emergency department: A literature review. Australian Emergency Nursing Journal 7.

Lin YH \& Liu HE (2005): The impact of workplace violence on nurses in South Taiwan. International Journal of Nursing Studies 42, 773-778.

May DD \& Grubbs LM (2002): The extent, nature, and precipitating factors of nurse assault among three groups of registered nurses in a regional medical centre. Journal of Emergency Nursing 28, 11-17.

McKenna BG, Poole SJ, Smith NA, Coverdale JH \& Gale CG (2003): A survey of threats and violent behaviour by patients against registered nurses in their first year of practice. International Journal of Mental Health Nursing 12, 56-63.

McKenna K (2004) Study of work-related violence. Committee on Workplace Violence, North Eastern Health Board, Ireland, pp. 1-121.

McPhaul K \& Lipscomb JA (2004): Workplace violence in health care recognized but not regulated. Online Journal of Issues in Nursing 9, 1-17.

Merecz D, Rymaszewska J, Moscicka A, Kiejna A \& Jarosz-Nowak J (2006): Violence at the workplace-a questionnaire survey of nurses. European Psychiatry 21, 442-450.

Morrison E (1990): Violent psychiatric inpatients in a public hospital. Scholarly Inquiry for Nursing Practice 4, 65-82.

Nau J, Dassen T, Halfens R \& Needham I (2007): Nursing students' experiences in managing patient aggression. Nurse Education Today 27, 933-946.

Needham I, Abderhalden C, Dassen T, Haug HJ \& Fischer JE (2004): The perception of aggression by nurses: psychometric scale testing and derivation of a short instrument. Journal of Psychiatric and Mental Health Nursing 11, 36-42.

Needham I, Abderhalden C, Halfens RJ, Fischer JE \& Dassen T (2005): Non-somatic effects of patient aggression on nurses: a systematic review. Journal of Advanced Nursing 49, 283-296.

O'Connell B, Young J, Brooks J, Hutchings J \& Lofthouse J (2000): Nurses' perceptions of the nature and frequency of aggression in general ward settings and high dependency areas. Journal of Clinical Nursing 9, 602-610.

Paola F, Malik T \& Qureshi A (1994): Violence against physicians. Journal of General Internal Medicine 9, 503-506.

Philbrick J, Sparks M, Hass M \& Arsenault S (2003): Workplace violence: The legal costs can kill you. American Business Review 21, 84-90.

Polit DF \& Tatano Beck C (2003) Nursing research: principles and methods, 7 edn. Lippincott Williams \& Wilkins, Philadelphia. 
Richter D \& Berger K (2000): Physische und psychische Folgen bei Mitarbeitern nach einem Patientenübergriff: Eine prospektive Untersuchung in sechs psychiatrischen Kliniken. ArbeitsmedizinSozialmedizin-Umweltmedizin 35, 357-362.

Richter D \& Whittington R (2006) Violence in Mental Health Settings: Causes, Consequences, Management. Springer Science \& Business Media, New York.

SBK (2001) Leitfaden zum Umgang mit Gewalt am Arbeitsplatz. Schweizer Berufsverband der Krankenschwestern und Krankenpfleger SBK Sektion SG TG AI AR, International Council of Nurses, St. Gallen.

St-Pierre I \& Holmes D (2008): Managing nurses through disciplinary power: a Foucauldian analysis of workplace violence. Journal of Nursing Management 16, 352-359.

Stanko EA (2002) Knowledge about the impact of violence at work in the health sector. In Workplace violence in the health sector. State of Art (Copper CL \& Swanson N eds.). Institute of Science and Technology, United Kingdom. National Institute of Occupational Safety and Health, United States, University of Manchester, pp. 49-60.

Swanson NG, Grubb PL \& Sauter SL (2002) Approaches to anti-violence and achieved impact in the health sector. In Workplace violence in the health sector. State of the Art. University of Manchester, Institute of Science and Technology, United Kingdom. National Institute of Occupational Safety and Health, United States, pp. 62-70.

Taylor D (2000): Student preparation in managing violence and aggression. Nusing Standard: official newspaper of the Royal College of Nursing 14, 39-41.

Uzun $O$ (2003): Perceptions and experiences of nurses in Turkey about verbal abuse in clinical settings. Journal of Nursing Scholarship 35, 81-85.

Wang W, Lee H \& Sj F (2006): Challenges and Strategies of Instrument Translation. Western Journal of Nursing Research 28, 310-321.

Wells J \& Bowers L (2002): How prevalent is violence towards nurses working in general hospitals in the UK? Journal of Advanced Nursing 39, 230-240.

Whittington R, Shuttleworth S \& Hill L (1996): Violence to staff in a general hospital setting. Journal of Advanced Nursing 24, 326-333.

Winstanley S (2005): Cognitive model of patient aggression towards health care staff: The patient's perspective. Work \& Stress 19, 340-350.

Winstanley S \& Whittington R (2002): Violence in a general hospital: comparison of assailant and other assault-related factors on accident and emergency and inpatient wards. Acta Psychiatrica Scandinavica 106 (Suppl. 412), 144-147.

Winstanley S \& Whittington R (2004a): Aggression towards health care staff in a UK general hospital: variation among professions and departments. Journal of Clinical Nursing 13, 3-10.

Winstanley S \& Whittington R (2004b): Aggressive Encounters Between Patients and General Hospital Staff: Staff Perceptions of the Context and Assailants' Levels of Cognitive Processing. Aggressive Behavior 30, 534-543.

Yassi A (1994): Assault and abuse of health care workers in a large teaching hospital. Canadian Medical Association Journal 151, 1273-1279.

Zernike W \& Sharpe P (1998): Patient aggression in a general hospital setting: do nurses perceive it to be a problem? International Journal of Nursing Practice 4, 126-133. 



\section{CHAPTER FIVE}

\section{Patient and visitor violence in the}

general hospital, occurrence, staff interventions and consequences: A cross sectional survey

Hahn S, Hantikainen V, Needham I, Dassen T, Kok G \& Halfens RJG (2011): Patient and visitor violence against health care staff in Switzerland, contributing factors, interventions and consequences: A cross sectional survey. Journal of Advanced Nursing Epub ahead of print, Mar 1. doi: 10.1111/j.1365-2648.2012.05967.x. 


\subsection{ABSTRACT}

Aim. This study focuses on the experience of healthcare staff with regard to patient and visitor violence in a general hospital. The occurrence of patient and visitor violence, staffs' interventions and the consequences of violence for different professions are investigated.

Background. There are a lack of studies describing the factors influencing the occurrence of patient and visitor violence, intervention strategies and consequences. Existing studies often focus on nurses' experiences and single interactive factors between staff and patients/visitors involved.

Method. A cross-sectional survey was conducted in 2007 including 2495 staff working on different wards in a Swiss university general hospital. The questionnaire used was the Survey of Violence Experienced by Staff German Version-Revised.

Findings. Half of the staff experienced patient and visitor violence in the past 12 months and $11 \%$ in the past week. The age of the staff and the length of experience in their present workplace influenced the exposure to patient and visitor violence. Violence occurred mainly when staff carried out tasks involving close personal contact. Only $16 \%$ of the staff were trained in aggression management. The feeling of confidence in managing patient and visitor violence depended significantly on the organisational attitude towards violence. The principal interventions used were calming and informative discussion.

Conclusion. In order to prevent patient and visitor violence and improve management strategies, training which focuses on communication skills, which is specific to the professional context, and which emphasises patient centeredness, need to be designed and implemented. A strong organisational commitment is imperative to reduce violence. 


\section{What is already known about this topic?}

- Patient and visitor violence is an occupational hazard that occurs across all health care settings. Most previous research has focused on mental health and emergency care settings.

- Previous research on patient and visitor violence has concentrated on nurses' experiences and results regarding other health care staff are limited and conflicting.

- Both the individual and the interactive factors of engagement with involved staff and patients/visitors are important in the occurrence of violence.

\section{What this paper adds}

- High levels of patient and visitor violence are observed among all health care professions in general hospitals as well as in emergency settings, recovery rooms, anaesthesia, intermediate care, step-down and intensive care units.

- Individual, interactional, and work organisational factors were collectively investigated so as to describe any associations between them in which patient and visitor violence occurs.

- Training in aggression management does not influence the level of confidence in dealing with violence and, an absence of organisational policies and procedures regarding violence did negatively influence the level of confidence of staff.

\section{Implications for practice and/or policy}

- The results indicate that a strong organisational commitment is imperative to prevent or reduce patient and visitor violence and eliminate barriers in reporting violent incidents.

- Specialised training is needed focusing on verbal communication skills and improving professional skills to enhance patients' and visitors' feelings of safety.

- Future research should evaluate the effects of verbal and physical interventions on violence in relation to individual, interactional and organisational factors.

\subsection{INTRODUCTION}

Consistent findings in international literature argue that patient and visitor violence (PVV) against health care staff (HCS) is the most important work-related violence concern in the health care system (Camerino et al. 2008, Roche et al. 2010, Ferns 2006). While the subject has been widely studied in recent years, most PVV has been investigated in either mental health or emergency care settings (Wells \& Bowers 2002, Ryan \& Maguire 2006). Similarly, existing guidelines (National Institute for Clinical Evidence 2005) and intervention strategies (Beech \& Leather 2006) also mainly focus on these settings. The majority of HCS are employed in general hospitals outside of these specific care environments; however, PVV is equally 
present in their workplace. Therefore, more information regarding the factors associated with PVV is needed to ensure appropriate and effective prevention and intervention strategies in the general hospital setting (Winstanley \& Whittington 2004a, Winstanley \& Whittington 2004b, Shields \& Wilkins 2009). A cross-sectional study was conducted in order to learn more, in particular, regarding the violent situations, the interventions used to de-escalate and the consequences of PVV for HCS.

\subsection{BACKGROUND}

The varying study designs and definitions of PVV used in research (Hahn et al. 2008) complicate the comparability of results. PVV has various forms, and in this study, PVV was defined as any verbal, non-verbal or physical behaviour that is threatening to HCS or to property, or physical behaviour that actually harms HCS or damages property (Morrison 1990). Only a few studies have explored the experiences of different HCS professions with PVV. Data are available from Sweden (Arnetz \& Arnetz 2001), Turkey (Ayranci 2005, Ayranci et al. 2006), Jamaica (Jackson \& Ashley 2005), Ireland (McKenna 2004) and the United Kingdom (Whittington et al. 1996, Winstanley \& Whittington 2004a). The results showed that between 9 and $24 \%$ of HCS experienced verbal aggression and between 5 and $21 \%$ experienced physical assaults. Studies in general hospitals usually investigated the occurrence of violence for nursing staff only and reported that almost all nurses had experienced verbal PVV in the past 12 months (Camerino et al. 2008, Hahn et al. 2008). Experiences of other staff have been only sporadically explored. Carmi-Illuz et al. (2005) \& Zahid et al. (1999) revealed that between 24 and 57\% of physicians experienced PVV in the past 12 months and Boyle et al. (2007) highlighted that $87.5 \%$ of Australian paramedics had experienced at least one form of violence in the same time period. $61 \%$ of radiographers working in hospitals in Hong Kong experienced PVV during the past three years (Ng et al. 2009). Arnetz et al (1998) and Whittington et al. (1996) found lower risks for occupational therapists, laboratory technicians, physical therapists and midwives in comparison to nurses and medical doctors.

PVV is also difficult to define because of the numerous, complex factors that influence the occurrence of violent situations (Camerino et al. 2008). Research on the causes and factors related to PVV is limited and fragmented (Curbow 2002). The majority of existing studies only investigate nurses' experiences in combination with single factors relating to PVV (Hahn et al. 2008, Shields \& Wilkins 2009). According to these studies (1) the individual characteristics of nurses (Farrell et al. 2006, Adib et al. 2002, Jansen et al. 2005) and of patients (Farrell et al. 2006, Kwok et al. 2006, Winstanley \& Whittington 2004b), (2) the staff-patient and visitor interactions (Winstanley 2005, Lin \& Liu 2005), (3) the characteristics of the work environment (Whittington et al. 1996), and (4) the official organisational hospital policies (Beech \& Leather 2006, Richards 2003) seem important in the occurrence 
of PVV. Conceptual models, when defining what leads to workplace violence in the health care sector, generally include the following factors: individual, interactional, organisational, community/neighbourhood, and societal (Curbow 2002). Curbow (2002) discusses three levels of factors. The first is the individual and interaction level in which violence is perceived as a stressful interaction aggravated by a vicious cycle of misconceptions, frustration, and anger. Second, is the organisational level which encompasses the influencing factors within the work environment; the third pertains to the society with its community and neighbourhood factors. Due to limited evidence, it is not possible to complete this model in an elaborate manner and factors discussed as important in relation to PVV are inconsistent (Lau et al. 2006, Ferns 2005, Gacki-Smith et al. 2009).

Many countries have adopted occupational health and safety legislation, along with policies which emphasise a requirement for appropriate training in aggression management (Pich et al. 2010, Chappell \& Di Martino 2006). Despite this, there is little research which explores strategies to prevent, defuse and manage PVV. Specifically, research is lacking for post incidence management and the consequences for HCS (Stanko 2002, Swanson et al. 2002, Beech \& Leather 2006). Within the literature, it is consistently found that psychiatric nurses reported negative effects on their psychological and physical well-being (Richter \& Berger 2000, Needham et al. 2005, Bonner and McLaughlin 2007) due to workplace violence.

The literature reveals a lack of studies describing a coherent, non-fragmented analysis of the situations in which PVV occurs, and which is based upon the experiences of different HCS professions working in a variety of units in the general hospital setting. Additionally, very little is known about the interventions used by HCS to manage these situations, the consequences for HCS and the support required after an incident. This lack of knowledge impedes the development of adequate prevention and intervention strategies at the organisational level, and hampers the improvement of prevention and de-escalation strategies for HCS.

\subsection{THE STUDY}

\section{Aim}

The aim of the study was to describe the occurrence of patient and visitor violence, measures for HCS dealing with this situation and the consequences of PVV from the perspective of different HCS working on different wards in a general hospital.

\section{Design}

A cross-sectional survey employing postal questionnaires was conducted between May and July 2007 including HCS in all wards of a Swiss university general hospital. 


\section{Sample}

The participating hospital is one of five university hospitals in Switzerland providing a wide variety of services in a large number of specializations for physical illnesses. There are no psychiatric units in this hospital. All HCS with patient contact ( $\mathrm{n}=$ 4845) were invited to participate in the study. The inclusion criteria for HCS were those staff working in direct contact with patients/visitors and an adequate command of the German language. The sample includes the following HCS professions: (1) nurses \& midwifes, (2) medical doctors, (3) physical therapists, occupational therapists \& dieticians, (4) ward secretaries, medical assistants \& radiology assistants, (5) nursing assistants or less qualified nursing staff and (6) other HCS (for example laboratory workers). The sample of HCS, described in Table 5.1, is typical for HCS in the Swiss health care system according to gender (77.9\% female), age (more than $80.0 \%$ over 30 years old), professions (52.7\% nurses), professional experiences (more than 60\% over 5 years), employment level (most often 90-100\%) and ward types (Jaccard Ruedin et al. 2009).

\section{Data collection}

All HCS member matching the inclusion criteria received written information about the aim and background of the study one month before the questionnaires were sent out to their workplace. After this information, all HCS received the questionnaires along with written short information on the study and explanations about the voluntary nature of participation. The questionnaires were completed during work hours and were returned anonymously by business-reply mail.

\section{Ethical considerations}

The local Ethical Commission approved the study. The nurse and therapeutic staff director as well as the medical director were previously informed personally about the study by the principal investigator and supported the study. To ensure anonymity, no names or other identifiers were used.

\section{Instrument}

The Survey of Violence Experienced by Staff, German Version-Revised (SOVES-G-R) (Hahn et al. 2011, Hahn et al. 2010), was employed for data collection. The SOVESG-R is based on the Irish version of McKenna (2004), and was translated and tested for use in the German language and for the general hospital setting. The content validity was tested by an expert panel in the field of aggression in health care systems. The instrument was judged as relevant with good content validity. The comprehensibility and face validity for general hospitals was tested by cognitive pretesting (Prüfer \& Rexroth 2000) involving different health professions. This analysis 
suggested that the SOVES-G-R questions were comprehensible, comprehensive and meaningful for actual practice in Swiss general hospitals (face validity) (Hahn et al. 2011).

The SOVES-G-R explores the following three factors: (1) individual characteristics, (2) interactions and (3) the organisational work environment. It allows HCS to describe threats and experiences with PVV using the closed-ended questions for "the previous 12 months" and in the "previous working week". This distinction is useful when investigating the most frequently reported forms of violence (Camerino et al. 2008, ILO et al. 2003). Verbal violence includes the use of abusive or offensive language, derogatory remarks or profane and/or obscene comments. Threats are defined as warnings with the intent to injure staff with or without an object or weapon, or to harass and/or to physically intimidate them. Physical violence includes slapping, pinching, pushing, shoving and spitting or kicking, with or without the use of weapons (McKenna 2004). The individual characteristics (factor 1) of HCS are investigated utilising closed-ended questions regarding demographic characteristics, profession, job experience, closeness of patient and visitor contact, consequences of PVV and training level in aggression management. HCS's feeling of confidence and the emotional and physical impact of PVV are examined with a five point Likert scale. Sick leave and support required or received after experiencing PVV is examined with closed-ended questions. The SOVES-G-R further explores the individual characteristics of patients and/or visitors of the most prominent incident of PVV experienced in the previous working week with multiple choice and closed questions (factor 1 ). These questions ask about demographic data, emotional condition and situational knowledge of violent patients and/or visitors. The health condition of the patient is investigated utilising closed-ended questions about physical illness and mental state. Multiple choice and closed-ended questions are used to elicit staff-patient and staff-visitor interactions (factor 2) and the occurrence of PVV, the information strategies and the interventions against PVV are explored with multiple choice and closed-ended questions. Finally, the organisational work environment (factor 3 ) is described utilising closed-ended questions such as waiting time, noise and the official policy or position of the institution regarding PVV.

\section{Data analysis}

Standard descriptive statistics were used to describe and summarise the data. Associations between categorical variables were tested with chi-square tests. All data analyses were conducted using SPSS 16.0. (SPSS Inc. Chicago, IL, USA). Given multiple testing a $p$-value of less than 0.01 was considered statistically significant. 


\subsection{RESULTS}

\section{Participants}

HCS $(n=2495)$ working in different general hospital units completed and returned questionnaires within this study, resulting in a response rate of $51.5 \%$. Response rates varied across the participating HCS professions, with the lowest rate from medical doctors (39.6\%) and the highest from nurses \& midwife (58.1\%). The majority of the participants were female (82.0\%), almost half were between 30 and 45 years old and had between 0 and 4 years experience at the present workplace. Most of the participants (55.2\%) were working full time. Only $16.4 \%$ of the participants were trained in aggression management. Training levels varied for the different staff professions and age groups with nurses \& midwifes and youngest staff having the highest level (all data presented in Table 5.1). 


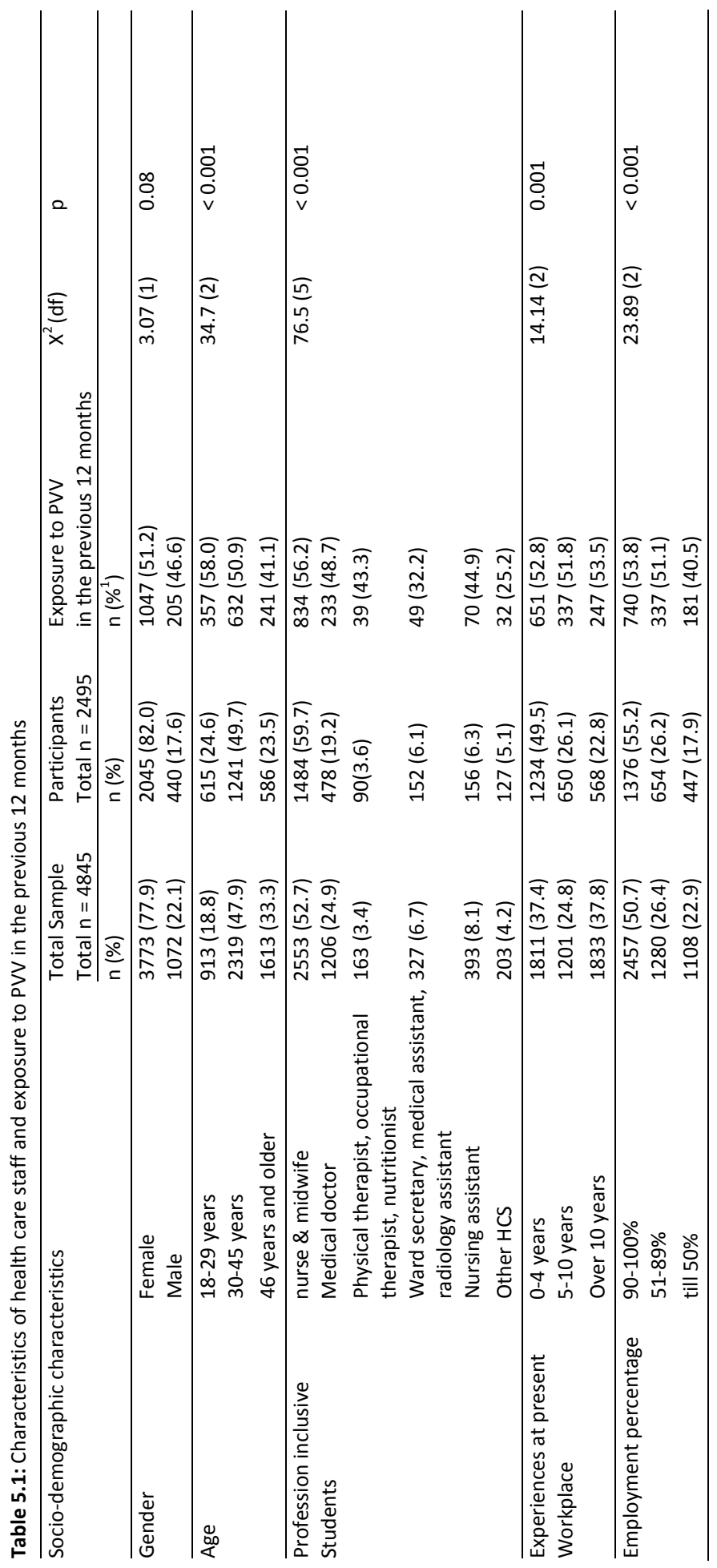




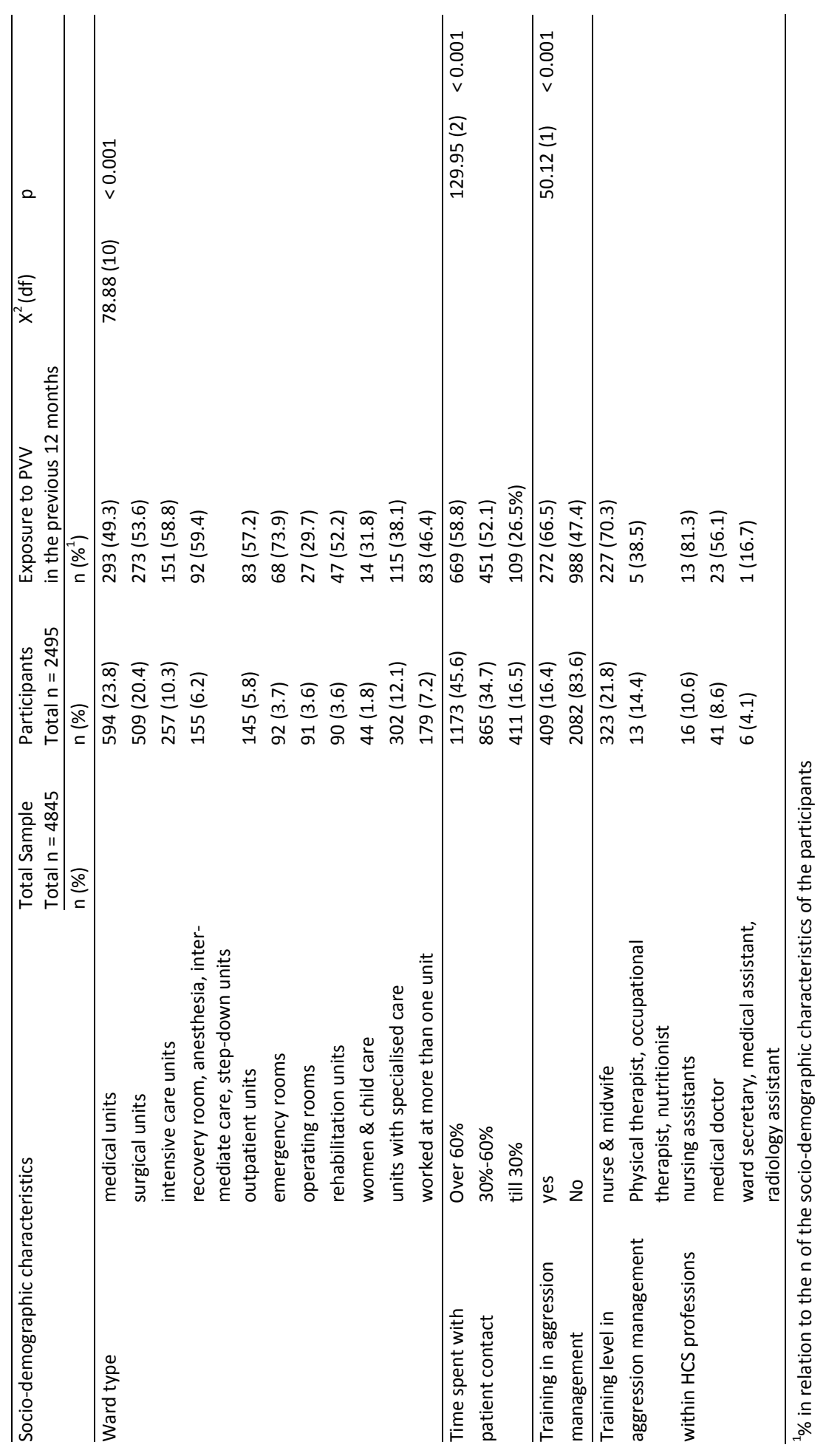




\section{Patient and visitor violence}

In the 12 months prior to data collection, 50.5\% of the HCS experienced PVV. Verbal and physical PVV were experienced by $45.9 \%$ and $16.9 \%$ of the participants respectively, while $15.6 \%$ experienced threats. The highest frequency of verbal PVV was 210 times (25.6\%) and once for physical PVV and threats (8.5\% and $8.1 \%$ ). Visitor violence was found to be less frequent, than violence by patients (see Table 5.2). Table 5.1 demonstrates that the younger the HCS, the more exposed they are to $\operatorname{PVV}\left(\chi^{2}=34.7\right.$, d.f. $\left.=2, p<0.001\right)$. Exposure to PVV is also different among HCS professions, with nurses $\&$ midwifes $(56.6 \%)$ being most exposed $\left(\chi^{2}=76.5\right.$, d.f. $=5$, $p<0.001)$. Staff working between 5 to 10 years at the present workplace were less exposed to PVV than less and more experienced co-workers $\left(\chi^{2}=14.1\right.$, d.f. $=2, p<$ $0.001)$. HCS with employment of more than $50 \%$ were more exposed to PVV than those working less $\left(\chi^{2}=23.9\right.$, d.f. $\left.=2, p<0.001\right)$. Furthermore, the more time staff spend in direct contact with patient the more they are exposed to PVV ( $\chi^{2}=126.95$, d.f. $=3, p<0.001$ ). Most patient contact (over $60 \%$ of working time) had physical therapists, occupational therapists \& dieticians (64.4\%), followed by nurses $\&$ midwifes $(55.1 \%)$ and medical doctors (38,9\%). When comparing the occurrence of PVV for different wards in the previous 12 months, the analysis showed that HCS working in emergency rooms (73.9\%), in recovery rooms, anaesthesia, intermediate care \& step-down units (59.4\%), in intensive care (58.8\%) and in outpatient units (57.2\%) experienced the highest level of PVV $\left(\chi^{2}=78.9\right.$, d.f. $\left.=10, p<0.001\right)$. No significant association was found between PVV experienced and gender or between frequencies $(1,2-10$, over 10 times in the previous 12 month) of PVV and characteristics of the HCS. 


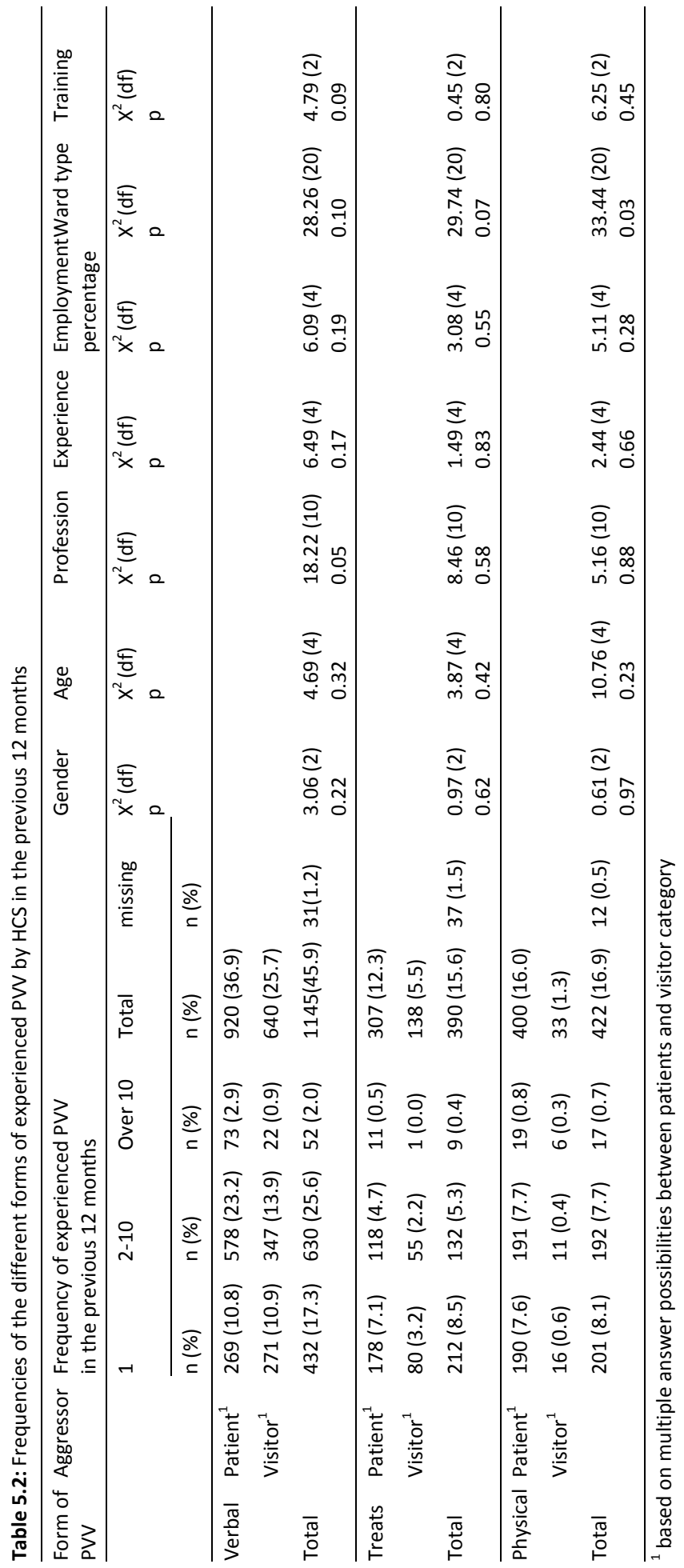


In the working week prior to data collection 284 (11.4\%) of the participating HCS experienced PVV- with the most frequent typology of PVV being verbal (66.9\%), followed by physical violence (19.7) and threats (7.0\%). In the past working week nurses \& midwifes (13.5\%) were the most exposed profession to PVV $\left(\chi^{2}=21.0\right.$, d.f. $=5, p<0.001)$. The comparison between wards in the past working week showed that HCS working in emergency rooms $(21.7 \%)$, in recovery rooms, anaesthesia, intermediate care \& step-down units (59.4\%), in intensive care (58.8\%) and in outpatient units (16.4\%) experienced the highest level of PVV $\left(\chi^{2}=22.7\right.$, d.f. $=10, p<$ 0.012 ). No significant association was found between the experience of PVV and gender, age, length of experience at present workplace and employment (Table 5.3). The demographic characteristics and health status of violent patients were described by 206 HCS. The majority of these patients were male $(58.7 \%)$ and most often aged between 50 and 74 years. Violent patients suffered more frequently from mental and/or behavioural disorders (11.7\%) and from cardiovascular conditions (10.2\%) than from other diagnoses. In $37.3 \%$ of the incidents the cognitive state of patients was important; confusion occurred most frequently. Withdrawal from substances was only important in emergency rooms and disturbance after anaesthesia was only mentioned in the recovery room, anaesthesia, intermediate care \& step-down units. Anxiety, excessive demands, insecurity in the situation and dissatisfaction with therapy were rated by $69.4 \%$ of participants as important emotional factor of patients and visitors before PVV occurred (see Table 5.3).

Looking at the nature of interaction, PVV occurred when HCS were engaged in medical, diagnostic and therapeutic tasks, counselling or supporting patients $(70.8 \%)$ or visitors $(28.5 \%)$. The level of information of patients and visitors was an important factor for PVV (48.2\%) in the previous working week (see Table 5.3), which was consistent in the different ward types.

Across all wards, $44.7 \%$ of the participants considered environmental factors as related to PVV. Waiting time and patients having to go through a number of examinations and tests were important in all ward types for the occurrence of violent incidences. Having too little time and noise were only important in the recovery room, anaesthesia, intermediate care \& step-down units. Enforcement of institutional bans was mentioned as an influencing factor only by HCS working at rehabilitation units. 


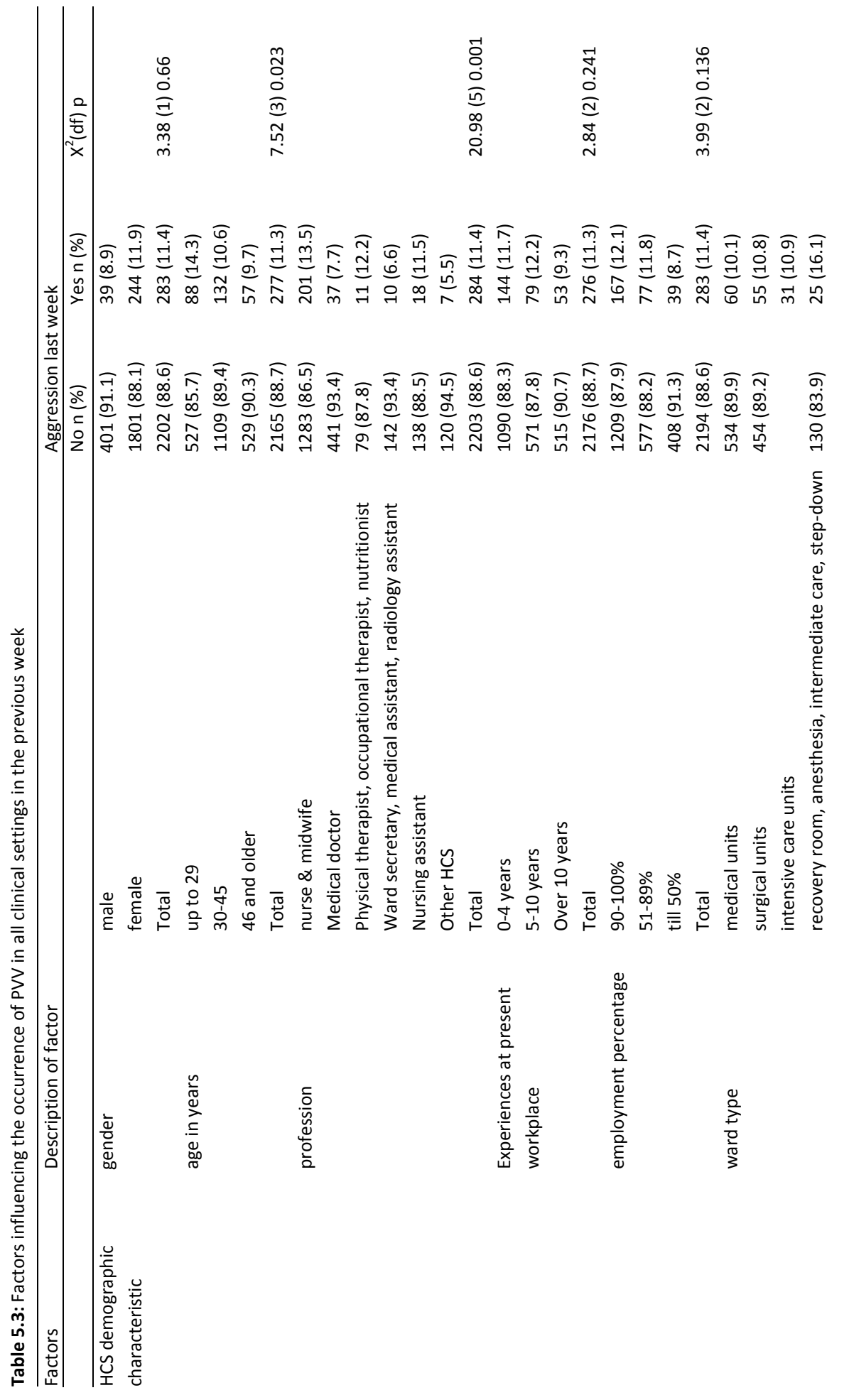




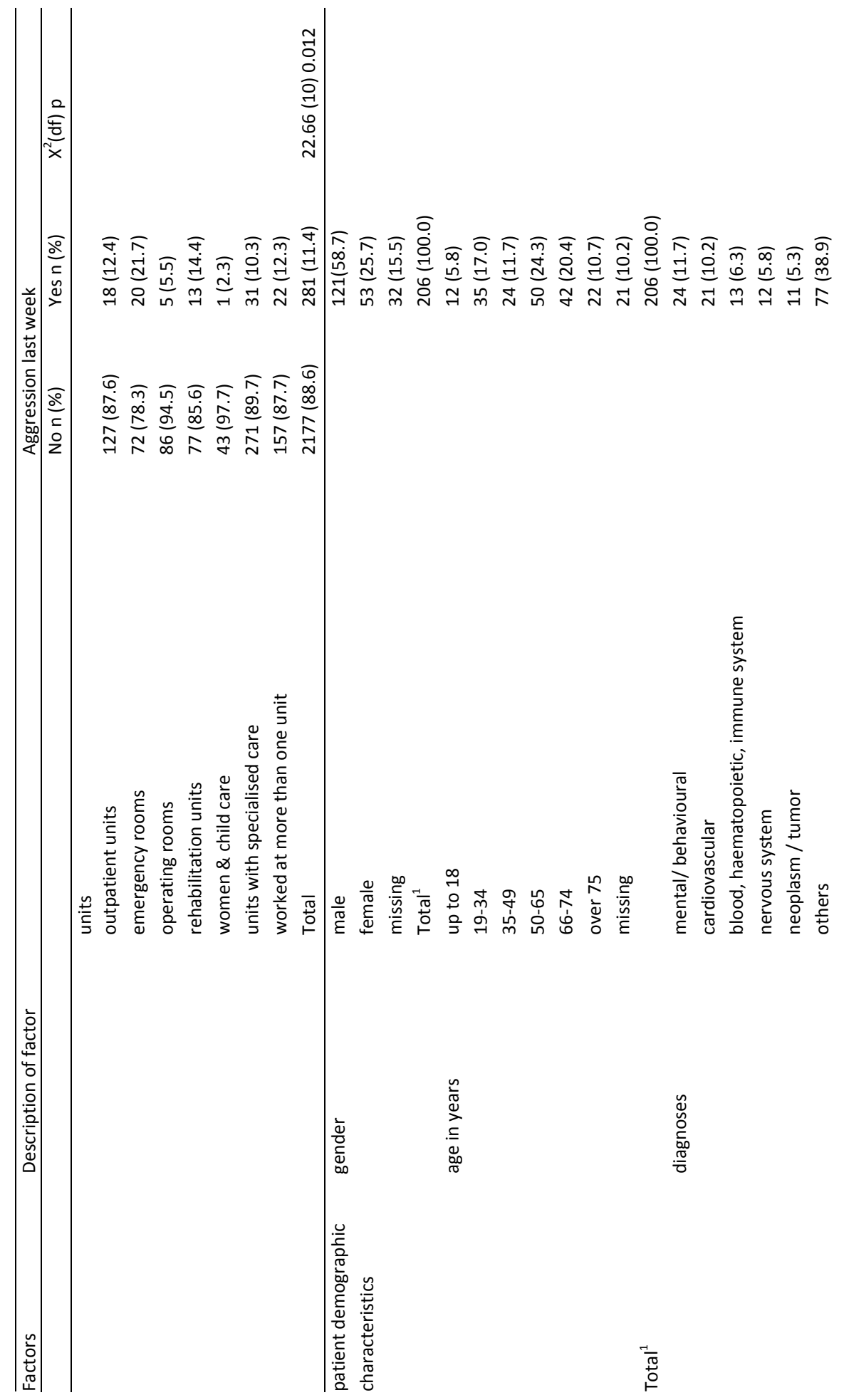




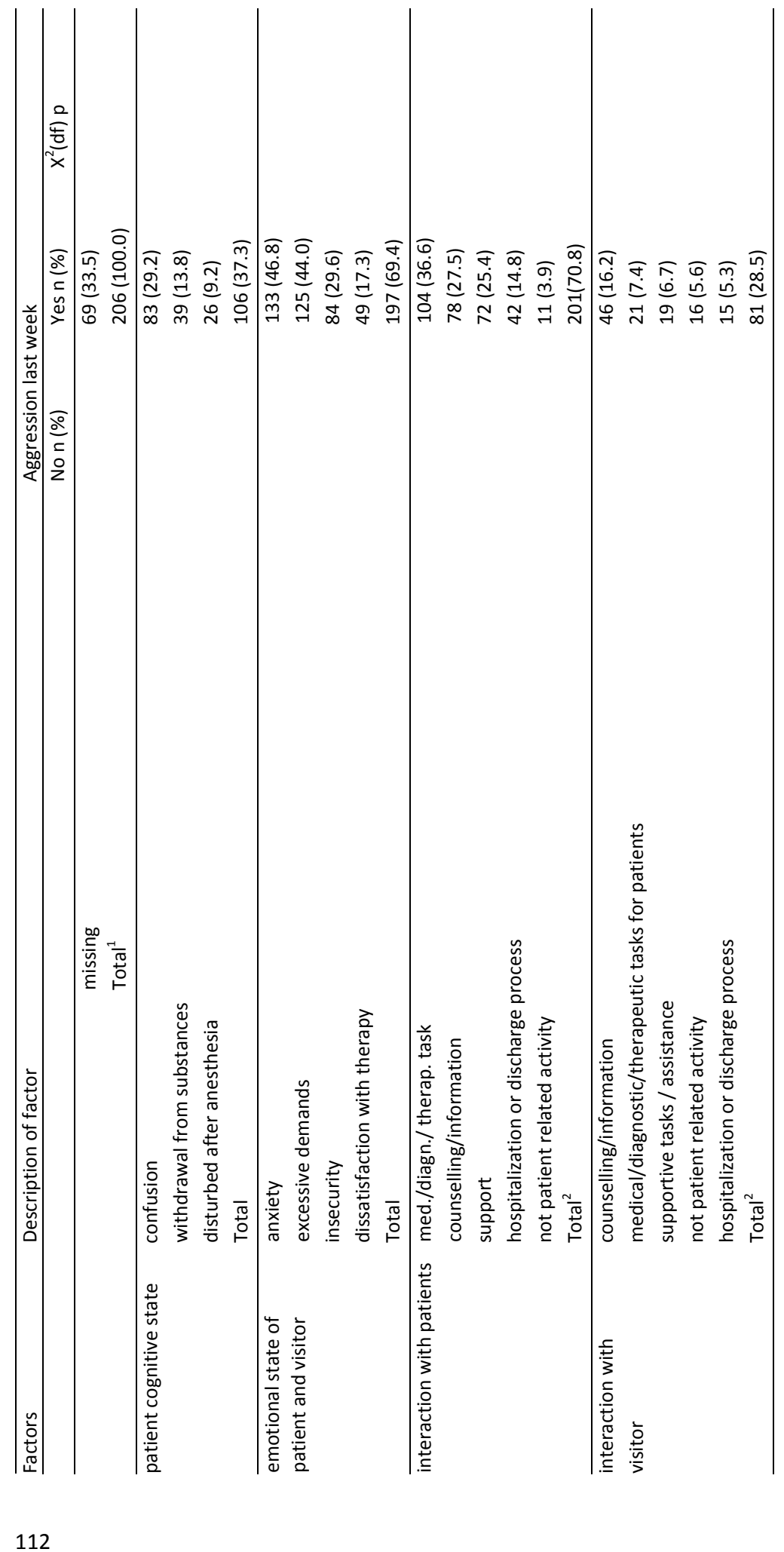




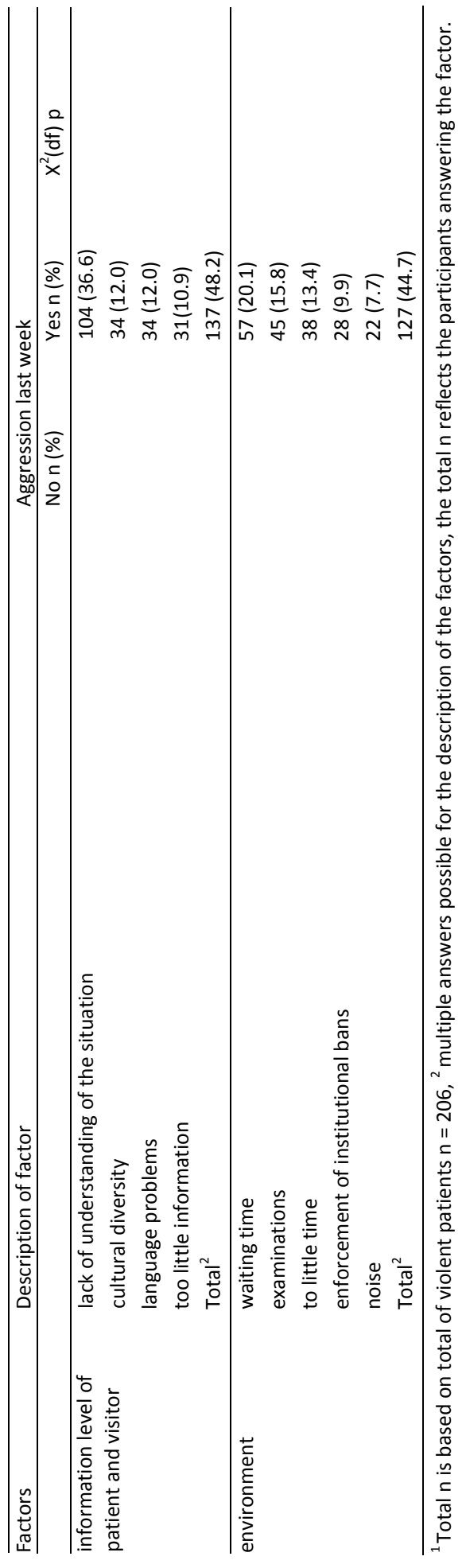




\section{Interventions}

The management of PVV in the previous working week was described by 251 participants. They used a total of 466 short time interventions. In combination and with other interventions calming and informative discussion (62.2\%), leaving the situation (25.1\%), urging the person to stop the behaviour $(22.3 \%)$ and administration of prescribed medication $(21.5 \%)$ were the frequently used short-term interventions. Long time interventions included the use of sedative medication and shielding from precipitating stimuli. Coercive measures encompassed the use of mechanical restraint with belts in bed (waistband, five-point-fixation, or hand/foot fixation), coercive medication and transfer to another ward (see Table 5.4). When managing verbal PVV, HCS mostly felt confident (44.5\%) in managing physical PVV they most frequently did not feel confident (50.3\%). Medical doctors felt confident in handling verbal aggression than other HCS and ward secretaries, medical and radiology assistants felt confident in handling physical aggression $\left(\chi^{2}=34.9\right.$, d.f. $=$ $12, p<0.001$ verbal PVV, $\chi^{2}=45.4$ d.f. $=12, p<0.001$ physical PVV) (see Table 5.5).

Table 5.4: Intervention against PVV

\begin{tabular}{|c|c|c|c|}
\hline Intervention Type & Intervention & $\mathrm{n}^{1}(\%)$ & $\left(n^{2}\right) \%$ \\
\hline \multirow[t]{11}{*}{ Short time intervention } & calming and informative discussion & $156(33.5)$ & 62.2 \\
\hline & left the situation & $63(13.5)$ & 25.1 \\
\hline & urged to stop the behaviour & $56(12.0)$ & 22.3 \\
\hline & administered prescribed medication & $54(11.6)$ & 21.5 \\
\hline & did not take notice & $39(8.4)$ & 15.5 \\
\hline & alarmed to get help & $38(8.6)$ & 15.1 \\
\hline & used bodily force & $19(4.1)$ & 7.5 \\
\hline & others & $19(4.0)$ & 7.5 \\
\hline & called the police & $11(2.4)$ & 4.4 \\
\hline & guided person to a quiet place & $8(1.7)$ & 3.2 \\
\hline & sent the person away & $3(0.6)$ & 1.2 \\
\hline Total & & $466(100.0)$ & (251) 100.0 \\
\hline \multirow[t]{3}{*}{ Long time intervention } & sedative medication & $52(46.8)$ & 55.3 \\
\hline & shield from stimulus & $24(21.6)$ & 25.5 \\
\hline & others & 35 (31.5) & 37.3 \\
\hline Total & & $111(100.0)$ & (94) 100.0 \\
\hline \multirow[t]{4}{*}{ Coercive measures } & mechanical restraint & $21(42.8)$ & 50.0 \\
\hline & coercive medication & $16(32.7)$ & 38.0 \\
\hline & transfer to an other ward & $11(22.5)$ & 26.1 \\
\hline & ban from the hospital & $1(2.0)$ & 2.4 \\
\hline Total & & $49(100.0)$ & (41) 100.0 \\
\hline
\end{tabular}

${ }^{1} \mathrm{n}=$ based on multiple answer possibilities, ${ }^{2} \mathrm{n}=$ based on incidences 


\section{Consequences and support}

For almost $90 \%$ of the participants who experienced verbal and for over $60 \%$ of those who experienced physical violence the emotional impact was upsetting (see Table 5.5). Among the 1260 HCS who experienced PVV in the previous 12 months, $2 \%$ needed between one and five days of sick leave and $0.2 \%$ stayed more than one week away from work. Some HCS (13.5\%) were slightly physically injured but did not require medical treatment or fist aid, while $1.5 \%$ required medical treatment. In 3.8\% of incidents of PVV, HCS's glasses or clothing were damaged or ruined.

Approximately $8.7 \%$ of the participants were aware of an official organisational anti-violence strategy. If the workplace had an official position, HCS felt more con-

fident $\left(\chi^{2}=23.2\right.$, d.f. $=4, p<0.001$ verbal PVVV, $\chi^{2}=12.5$ d.f. $=4, p<0.014$ physical PVV). The attendance of training in aggression management did not significantly influence HCS's feelings of confidence in dealing with PVV.

The participants discussed occurrences of PVV with superiors (16.4\%), with team colleagues $(37.7 \%)$, with friends $(13.8 \%)$ and with family members $(20.5 \%)$. For $67.2 \%$ of the participating HCS, superiors were supportive after PVV. Official reporting opportunities for PVV was available for $7.1 \%$ of HCS, but only $1.1 \%$ used this system. Most often (36.6\%) PVV was reported in the patent documentation. 


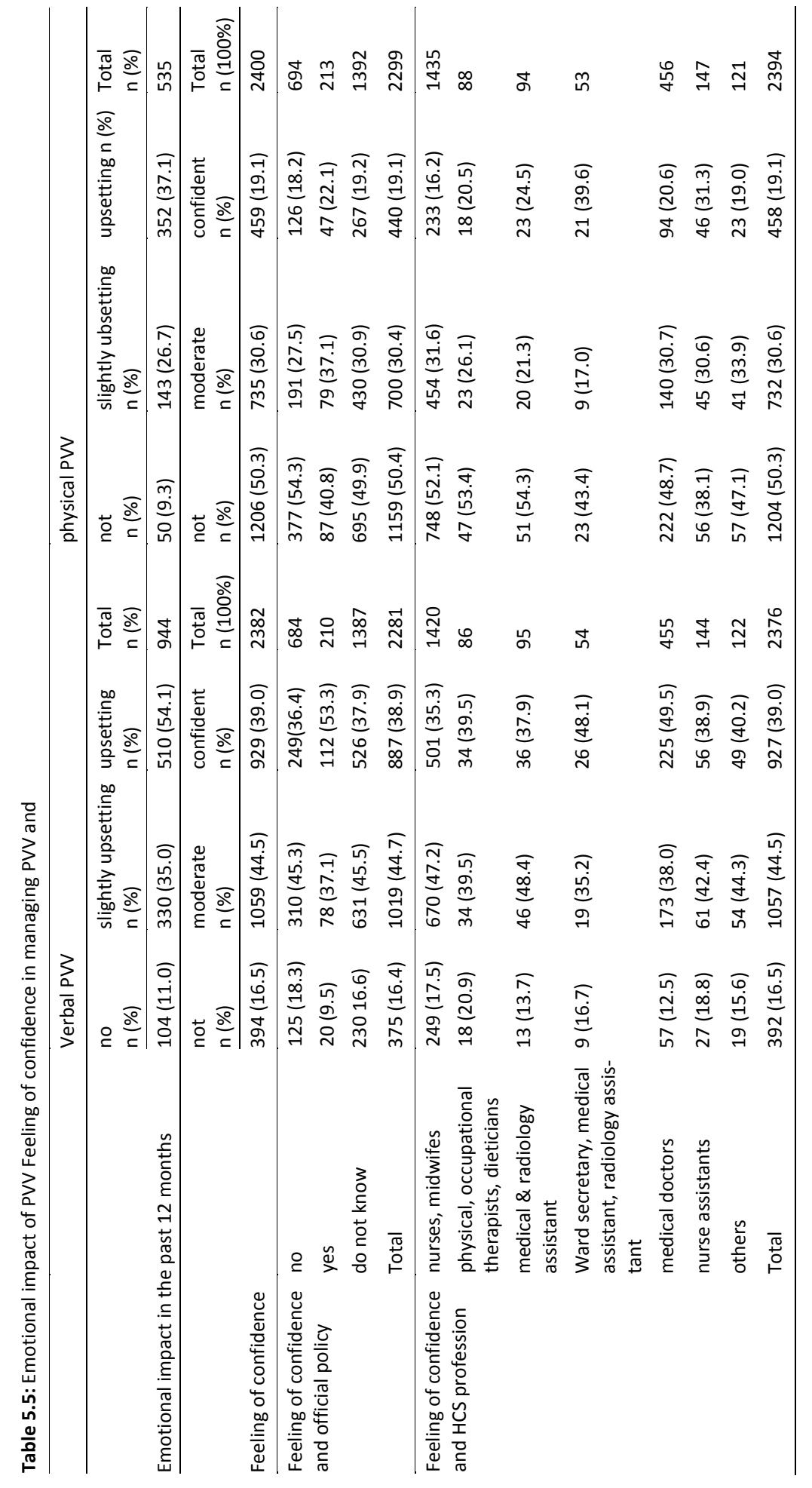




\subsection{DISCUSSION}

\section{Limitations}

A cross-sectional design has been used; therefore, no conclusions about the causality of the relations can be drawn. Another concern might be that self-assessment of the 12 month period was affected by recall bias. However, as most studies in the field of PVV use a 12 month self-assessment time frame, this procedure is important to follow in order to allow for the best possible comparison. To gain insight into the specific characteristics of the incidences and to reduce recall bias, a one week time frame was utilised (Graydon et al. 1994). Even though the total sample size was large (2495 participants), the number of participants experiencing PVV drastically decreased for the one week time period $(n=284)$. This affected the possibility of inferential statistical analysis and allowed only for description of the situation. In comparison to the total sample, participating HCS were slightly more frequently female, younger, less experienced at the present workplace and worked more often between $90-100 \%$. The greater level of participation among this cohort could relate to the higher exposure of this group to PVV, as observed in other studies (Kamchuchat et al. 2008, Nau et al. 2007, Estryn-Behar et al. 2008). Participation could also be biased by greater awareness about PVV in the younger age group, because in German speaking countries only younger HCS, and in particular nurses, have a training in aggression management (Hahn et al. 2010, Nau et al. 2009a). Nevertheless, the participants reflect typical HCS working in Swiss general hospitals.

\section{PVV and related factors}

This study is the first investigation of PVV against HCS in the general hospital setting in Switzerland and one of the few studies related to individual interactional and organizational factors in relation to PVV. The results of the study show that all HCS are highly likely to experience PVV, but younger and inexperienced HCS and nurses \& midwives reporting the highest level of PVV. Working in the emergency room, recovery room, anaesthesia, intermediate care $\&$ step-down units as well as in intensive care seems to have an increased risk for this occupational hazard. The participating HCS reported insecurity in managing PVV. Most staff felt upset after experiencing PVV, but only a minority of workplaces have an official policy or formal reporting procedures available for PVV. Likewise, regular staff training in the prevention or management of aggression and violence is not common and this is perhaps reflected in some intervention strategies used in managing episodes of physical violence. 
This dataset comes from a large representative sample of one hospital with a high response rate. The findings confirm existing evidence that HCS in general hospitals experience high levels of PVV, in particular of verbal violence. Hahn et al. (2008) and Gascon et al. (2009) also described the high level of verbal violence HCS encountered in a 12 month time frame. Other research has also reported that younger HCS are more exposed to PVV (Jackson \& Ashley 2005, Whittington et al. 1996). The issue of youthfulness may also be associated with experience - inexperienced staff reported higher levels of exposure to PVV than their more experienced colleagues. Furthermore, the exposure to PVV is higher for HCS with close patient contact and staff with higher employment percentage. We can therefore assume that the closer the patient and/or visitors contact and the longer the timeframe of contact, the more PVV is experienced. It seems that not only the age but also the experience at the present workplace and the length of time spent in contact with patients is relevant for the exposure to PVV. A possible explanation for this is that the more time HCS spend with patients the more they are confronted with the problems of these patients and their families. According to Benner (1984) nurses with little practice at their current workplace do not have enough experience to recognize the totality of a situation or discern which aspects of a situational dilemma are most salient or important. Equally, they may not have the skills to predict and defuse violent situations (Shields \& Wilkins 2009).

Surprisingly, the present study found highest levels for staff with over 10 years of experience at the current workplace (Table 5.1). Staff working longer than 10 years in their current workplace could have become too accustomed to daily routine and may therefore be less supportive to the needs of patients or visitors. The behaviour of those with the least and longest experience could result in poor communication with patients or visitors and may raise the risk for PVV.

The characteristics of violent patients need to be considered in terms of the overall characteristics of those treated during the period of the study. The minimum data set reveals that patients were most often male (55\%), 7\% were up to 18 years, $19 \%$ between 19 and 34 years, 13\% between 35 and 49 years, 27\% between 50 and 65 years, $23 \%$ between $66-74$ and $12 \%$ over 74 years old. Therefore we cannot conclude that male patients were more violent than females and that a particular age group was more violent. The diagnoses recorded in the minimum data set with lower relative ratio than in the results were mental and/or behavioural disorders ( $11.7 \%$ violent patients vs. $4.0 \%$ treated patients) and diagnoses of the blood, the haematopoietic or immune system (6.3\% violent patients vs. $1.0 \%$ treated patients) (see Table 5.3).

As an organizational environmental factor, this study confirms the highest risk for PVV is in emergency rooms (Lau et al. 2006, Gacki-Smith et al. 2009, Winstanley \& Whittington 2004a). However, over $58 \%$ of HCS working in the recovery room, anaesthesia, intermediate care \& step-down units and in intensive care experienced PVV during the 12 month period prior to data collection. Almost half of the 
participants reported that environmental factors contribute to PVV (44.7\%) in the working week prior to data collection. Waiting time and exposure to many examinations and tests were cited most frequently. These findings are also consistent with that of previous studies (Carmi-Iluz et al. 2005, Whittington et al. 1996, May \& Grubbs 2002). Medical examinations and waiting time are common features in university hospitals and depending on the procedures or medical diagnosis (known or unknown) the patients and visitors' information level is low. Therefore frequent feelings of anxiety associated with PVV seem to be a logical consequence (GackiSmith et al. 2009, Ferns 2005). The results reveal that depending on the specific ward type the nature of the environmental factors is different. This supports the need for a separate assessment and analysis of risk factors for each ward type and requires a nuanced approach to the development and implementation of appropriate prevention strategies.

The discussion above and the results reveal that factors in the interaction which lead to PVV depend on the one hand on the professional experience of HCS, the nature of the professional tasks being engaged in, including close patient contact (medical and therapeutic tasks, supportive tasks) and communication skills (patient and visitor counselling) and on the other hand on influencing factors within the work environment. It seems important therefore, to promote communication skills and a clear information management system at both an individual practitioner and organisational level. Such communication should consider the physiological, psychological and emotional state of patients and visitors as well as sociocultural and capacity issues (cognitive impairment, cultural diversity, language problems etc.). It seems that communication skills like appropriate use of language (patient and visitors understand what HCS is talking about) coherent nonverbal body language and paralanguage (used to modify meaning and convey emotion), adequate voice intonation and eye contact are important factors in professional engagement with patients and visitors.

The HCS's intervention strategy of calming and the use of informative discussion (62.2\%) seem adequate when PVV occurs. However, leaving the situation (25.1\%) or urging the person to stop the behaviour (22.3\%) may not meet the patients and visitors needs, and could escalate and lead to the application of coercive measures. In the Swiss health care system, coercive measures are legal when patients are in danger of harming themselves or others. These intervention strategies could reflect the extensive uncertainty or lack of knowledge, in particular with how to deal with physical PVV. It also reflects the reality of the working situation in which HCS are responsible for more than one patient. Nau et al. (2009b) and Richter \& Needham (2007) described the improvement of feelings of confidence after attendance of a training program in aggression management. However, in this study we did not find such an effect. This could reflect the lack of appropriate trainings available for the specific situations that HCS in general hospitals are confronted with. Training in aggression management for PVV has to consider commu- 
nication and prevention strategies relevant to the different ward types, and the specific work situations of different HCS. The uncertainty is also related to the lack of an organisational response to the problem. In this study, an official reporting system was available for only $8.7 \%$ of HCS, and very few used this system. The results therefore support the importance of an adequate organisational strategy (Beech \& Leather 2006, Gacki-Smith et al. 2009).

The emotional impact of PVV for HCS appears to be moderate and physical injuries are rare. However, because several HCS did suffer from serious consequences and had to take sick leave, the impact of PVV, at the individual level, should not be underestimated. Most HCS felt that supervisors were supportive after PVV. However, only $16.4 \%$ had actually discussed PVV with their superiors. This result is congruent with previous research (Hahn et al. 2010), and is not surprising, as only a minority of workplaces offer official policy and reporting procedures for PVV. The results of this and other studies (Hahn et al. 2010, Beech \& Leather 2006, Gacki-Smith et al. 2009) suggest that the existence of an official position and an organisational response to PVV could significantly increase HCS's confidence and performance in the management of violent incidents. Therefore, it seems important that general hospitals in Switzerland also develop and articulate an official policy and position against workplace violence and PVV, especially since such a policy is an international recommendation (International Council of Nurses 2001).

\subsection{CONCLUSION AND IMPLICATION FOR CLINICAL PRACTICE}

The results of this study suggest that HCS are at high risk of verbal PVV. To improve prevention and management strategies and to reduce the prevalence of PVV staff need appropriate training. This training has to consider communication skills, appropriate management of PVV available for the specific situation HCS in general hospitals have to deal with and equally needs to emphasise patient centred care, empathic interaction and the particular ward type. This seems very important in emergency room, recovery room, anaesthesia, intermediate care \& step-down units and in intensive care. Adequate strategies in dealing with PVV are not only the responsibility of staff. The results of this study indicate that a strong organisational commitment is imperative to reduce PVV and eliminate barriers in reporting violent incidences. For a safe workplace, an interdisciplinary task force should identify "hot risk area" of PVV in the general hospital setting with an incident reporting system. Depending on these results an intervention plan has to be developed for preventing, responding to, training and controlling PVV. Also specialised security teams could disburden HCS from physical management strategies in these difficult situations (Brayley et al. 1994, Gacki-Smith et al. 2009).

In research little attention has been given to the effectiveness of de-escalation and intervention strategies against PVV and in particular on coercive measures. 
Therefore further research should evaluate these strategies. Additionally, future research should better describe the genesis of PVV including all the risk factors recognised as important. Large sample sizes for sophisticated statistical analyses will be needed. Until presently, the violent situations have primarily been investigated from staff's experiences. For a comprehensive understanding patient and visitors view in research will also be required. 


\subsection{REFERENCES}

Adib SM, Al-Shatti AK, Kamal S, El-Gerges N \& Al-Raqem M (2002): Violence against nurses in healthcare facilities in Kuwait. International Journal of Nursing Studies 39, 469-478.

Arnetz JE \& Arnetz BB (2001): Violence towards health care staff and possible effects on the quality of patient care. Social Science and Medicine 52, 417-427.

Arnetz JE, Arnetz BB \& Soderman E (1998): Violence toward health care workers. Prevalence and incidence at a large, regional hospital in Sweden. American Association of Occupational Health Nurses 46, 107-114.

Ayranci U (2005): Violence toward health care workers in emergency departments in west Turkey. Journal of Emergency Medicine 28, 361-365.

Ayranci U, Yenilmez C, Balci Y \& Kaptanoglu C (2006): Identification of violence in Turkish health care settings. Journal of Interpersonal Violence 21, 276-296.

Beech B \& Leather P (2006): Workplace violence in the health care sector: A review of staff training and integration of training evaluation models. Aggression and Violent Behaviour 11, 27-43.

Benner P (1984) From novice to expert: Excellence and power in clinical nursing practice. AddisonWesley, Menlo Park, CA, pp. 1-307.

Berthou A, Junger A \& Kossaibati S (2005) Test des Schweizer Nursing Minimum Data Sets (CH-NMDS) (Test II), Schlussbericht. Nursing Data Switzerland, Ecublens, CH, pp. 1-99.

Bonner G \& McLaughlin S (2007) The psychological impact of aggression on nursing staff. British Journal of Nursing, 16, 810-814.

Boyle M, Koritsas S, Coles J \& Stanley J (2007): A pilot study of workplace violence towards paramedics. Emergency Medicine Journal 24, 760-763.

Brayley J, Lange R, Baggoley C, Bond M \& Harvey P (1994): The violence management team. An approach to aggressive behaviour in a general hospital. Medical Journal of Australia 15, 254-258.

Camerino D, Estryn-Behar M, Conway PM, van Der Heijden BIJM \& Hasselhorn HM (2008): Work-related factors and violence among nursing staff in the European NEXT study: a longitudinal cohort study. International Journal of Nursing Studies 45, 35-50.

Carmi-Iluz T, Peleg R, Freud T \& Shvartzman P (2005): Verbal and physical violence towards hospital- and community-based physicians in the Negev: an observational study. Bio Med Central Health Service Research 5, 1-6.

Curbow B (2002) Origins of violence at work. In Workplace violence in the health sector. State of the Art (Cooper CL \& Swanson N eds.). International Labour Office, International Council of Nurses, World Health Organization and Public Service International, Geneva, pp. 35-48.

Estryn-Behar M, van der Heijden B, Camerino D, Fry C, Le Nezet O, Conway PM \& Hasselhorn HB (2008): Violence risks in nursing - results from the European 'NEXT' Study. Occupational Medicine (Lond) 58, 107-114.

Farrell GA, Bobrowski C \& Bobrowski P (2006): Scoping workplace aggression in nursing: findings from an Australian study. Journal of Advanced Nursing 55, 778-787.

Ferns T (2005): Terminology, stereotypes and aggressive dynamics in the accident and emergency department. Accident and Emergency Nurse 13, 238-246.

Ferns T (2006): Violence, aggression and physical assault in healthcare settings. Nursing Standard 21, $42-$ 46.

Gacki-Smith J, Juarez AM, Boyett L, Homeyer C, Robinson L \& MacLean SL (2009): Violence against nurses working in US emergency departments. Journal of Nursing Administration 39, 340-349.

Gascon S, Martinez-Jarreta B, Gonzalez-Andrade JF, Santed MA, Casalod Y \& Rueda MA (2009): Aggression towards health care workers in Spain: a multi-facility study to evaluate the distribution of growing violence among professionals, health facilities and departments. International Journal of Occupational and Environmental Health 15, 29-35. 
Graydon J, Kasta W \& Khan P (1994): Verbal and physical abuse of nurses. Canadian Journal of Nursing Administration 7, 70-89.

Hahn S, Müller M, Needham I, Dassen T, Kok G \& Halfens RJG (2011): Measuring patient and visitor violence in general hospitals: feasibility of the SOVES-G-R, internal consistency and construct validity of the POAS-S and the POIS. Journal of Clinical Nursing. 20, 2519-2530.

Hahn S, Müller M, Needham I, Kok G, Dassen T \& Halfens RJG (2010): Factors associated with patient and visitor violence experienced by nurses in general hospitals in Switzerland: A cross-sectional survey. Journal of Clinical Nursing 19, 3535-3546.

Hahn S, Zeller A, Needham I, Kok G, Dassen T \& Halfens RJG (2008): Patient- and visitor violence in general hospitals: A systematic review of the literature. Journal of Aggression and Violent Behavior 13, 431-441.

International Council of Nurses (2001) Nurses, always there for you: united against violence, Geneva.

Jaccard Ruedin H, Weaver F, Roth M \& Widmer M (2009) Personnel de santé en Suisse - Etat des lieux et perspectives jusqu'en 2020. Observatoire suisse de la santé, Neuchâtel, p. 116.

Jackson M \& Ashley D (2005): Physical and psychological violence in Jamaica's health sector. Revista Panamericana de Salud Pública/Pan American Journal of Public Health. 18, 114-121.

Jansen GJ, Dassen TW \& Groot Jebbink G (2005): Staff attitudes towards aggression in health care: a review of the literature. Journal of Psychiatric and Mental Health Nursing 12, 3-13.

Kamchuchat C, Chongsuvivatwong V, Oncheunjit S, Yip TW \& Sangthong R (2008): Workplace violence directed at nursing staff at a general hospital in southern Thailand. Journal of Occupational Health 50, 201-207.

Kwok RP, Law YK, Li KE, Ng YC, Cheung MH, Fung VK, Kwok KT, Tong JM, Yen PF \& Leung WC (2006): Prevalence of workplace violence against nurses in Hong Kong. Hong Kong Medical Journal 12, 6-9.

Lau JB, Magarey J \& McCutcheon H (2006): Violence in the emergency department: A literature review. Australian Emergency Nursing Journal 7, 27-37.

Lin YH \& Liu HE (2005): The impact of workplace violence on nurses in South Taiwan. International Journal of Nursing Studies 42, 773-778.

May DD \& Grubbs LM (2002): The extent, nature, and precipitating factors of nurse assault among three groups of registered nurses in a regional medical centre. Journal of Emergency Nursing 28, 11-17.

McKenna K (2004) Study of work-related violence. Committee on Workplace Violence, North Eastern Health Board, Ireland, pp. 1-121.

Morrison E (1990): Violent psychiatric inpatients in a public hospital. Scholarly Inquiry for Nursing Practice 4, 65-82.

National Institute for Clinical Evidence - NICE (2005) Clinical Practice Guidelines Violence: The ShortTerm Management of Disturbed/Violent Behaviour in In-Patient Psychiatric Settings and Emergency Departments. Royal College of Nursing, London.

Nau J, Dassen T, Halfens R \& Needham I (2007): Nursing students' experiences in managing patient aggression. Nurse Education Today 27, 933-946.

Nau J, Dassen T, Needham I \& Halfens R (2009a): The development and testing of a training course in aggression for nursing students: a pre-and post-test study. Nurse Education Today 29, 196-207.

Nau J, Halfens R, Needham I \& Dassen T (2009b): The De-Escalating Aggressive Behaviour Scale: development and psychometric testing. Journal of Advanced Nursing 65, 1956-1964.

Needham I, Abderhalden C, Halfens RJ, Fischer JE \& Dassen T (2005): Non-somatic effects of patient aggression on nurses: a systematic review. Journal of Advanced Nursing 49, 283-296.

Ng KY, J., Cheung I, Chung A \& White P (2009): Workplace Violence-A Survey of Diagnostic Radiographers Working in Public Hospitals in Hong Kong. Journal of Occupational Health 51, 355-363

Prüfer C \& Rexroth M (2000) Zwei-Phasen - Pretesting. ZUMA, Mannheim, pp. 1-21.

Pich J., Hazelton M., Sundin D. \& Kabl A. (2010) Patient-related violence against emergency department nurses. Nursing and Health Sciences, 12, 268-274. 
Richards J (2003) Management of workplace violence victims. In Joint Programme on Workplace Violence in the Health Sector (ILO/ICN/WHO/PSI ed.). International Labour Office, International Council of Nurses, World Health Organisation, Public Services International, Geneva, pp. 1-40.

Richter D \& Berger K (2000): Physische und psychische Folgen bei Mitarbeitern nach einem Patientenübergriff: Eine prospektive Untersuchung in sechs psychiatrischen Kliniken. ArbeitsmedizinSozialmedizin-Umweltmedizin 35, 357-362.

Richter D \& Needham I (2007): Effekte von mitarbeiterbezogenen Trainingsprogrammen zum Aggressionsmanagement in Einrichtungen der Psychiatrie und Behindertenhilfe. Systematische Literaturübersicht [Effects of aggression management trainings for mental health care and disability care staff--systematic review]. Psychiatrische Praxis 34, 7-14.

Roche M, Diers D, Duffield C \& Catling-Paull C (2010): Violence Toward Nurses, the Work Environment, and Patient Outcomes. Journal of Nursing Scholarship 42, 13-22.

Ryan D \& Maguire J (2006): Aggression and violence - a problem in Irish Accident and Emergency departments? Journal of Nursing Management 14, 106-115.

Shields M \& Wilkins K (2009): Factors related to on-the-job abuse of nurses by patients. Health Reports 20, 7-19.

Stanko EA (2002) Knowledge about the impact of violence at work in the health sector. In Workplace violence in the health sector. State of Art. (Copper CL \& Swanson N eds.). University of Manchester, Institute of Science and Technology, United Kingdom. National Institute of Occupational Safety and Health, United States., Manchester, pp. 49-60.

Swanson NG, Grubb PL \& Sauter SL (2002) Approaches to anti-violence and achieved impact in the health sector. In Workplace violence in the health sector. State of Art. (Copper CL \& Swanson N eds.). University of Manchester, Institute of Science and Technology, United Kingdom. National Institute of Occupational Safety and Health, United States., Manchester, pp. 62-70.

Wells J \& Bowers L (2002): How prevalent is violence towards nurses working in general hospitals in the UK? Journal of Advanced Nursing 39, 230-240.

Whittington R, Shuttleworth S \& Hill L (1996): Violence to staff in a general hospital setting. Journal of Advanced Nursing 24, 326-333.

Winstanley S (2005): Cognitive model of patient aggression towards health care staff: The patient's perspective. Work \& Stress 19, 340-350.

Winstanley S \& Whittington R (2004a): Aggression towards health care staff in a UK general hospital: variation among professions and departments. Journal of Clinical Nursing 13, 3-10.

Winstanley S \& Whittington R (2004b): Aggressive Encounters Between Patients and General Hospital Staff: Staff Perceptions of the Context and Assailants' Levels of Cognitive Processing. Aggressive Behavior 30, 534-543.

Zahid MA, al-Sahlawi KS, Shahid AA, al-Ajmi MT \& Awadh JA (1999): Violence towards doctors: prevalence and effects. Hospital Medicine 60, 414-418. 


\section{CHAPTER SIX}

\section{Risk factors associated with patient and visitor violence in general hospitals: Results of a multiple regression analysis}

Hahn S, Müller M, Hantikainen V, Dassen T, Kok G \& Halfens RJG (for second revision in the International Journal of Nursing Studies): Risk factors associated with patient and visitor violence against health care staff in general hospitals: Results of a multiple regression analysis. 


\subsection{ABSTRACT}

Background: Patient and visitor violence (PVV) is the most dangerous occupational hazard that health care staff must contend with. Staff training is recommended to prevent and manage PVV. There is minimal research focusing on risk factors associated with PVV in general hospital settings. Therefore, staff training is mostly based upon expert knowledge and knowledge from psychiatric and emergency settings.

Objectives: This study investigates health care staffs' experiences with PVV in order to describe risk factors related to PVV that occur in general hospital settings.

Design: A retrospective cross-sectional survey was conducted in 2007.

Setting: A university general hospital in Switzerland.

Participants: 2495 out of 4845 health professionals participated (58.0\% nurses \& midwives, $19.2 \%$ medical doctors, $3.6 \%$ physical therapists, occupational therapists \& nutritionists, $6.1 \%$ ward secretaries, medical \& radiology assistants, $6.3 \%$ nursing assistants or less qualified nursing staff and $5.1 \%$ other staff). All had direct patient contact and $82 \%$ were female.

Methods: Data were collected via questionnaires using the Survey of Violence Experienced by Staff German-Version-Revised, the German version of the shortened Perception of Aggression Scale and the Perception of Importance of Intervention Skills Scale. Descriptive statistics and multiple logistic regression analyses were used.

Results: Risk factors associated with PVV depend upon the form of violence. Those trained in aggression management and/or those who work predominantly with patients over 65 years of age experience twice as much PVV as others. Staff working in emergency rooms, outpatient units, intensive care units, recovery rooms, anesthesia, intermediate care and step-down units also experience PVV more often. When health care staff are older in age, are from the medical profession, are students, or when they have an attitude rating preventive measures as being less important and aggression as emotionally letting off steam, they experience less PVV.

Conclusion: Training could change the perception and the recognition of PVV, and could therefore increase the risk of experiencing PVV. The health care staffs' specific occupation, their attitude, their age, the patient's age, the communication and the workplace are all relevant risk factors. Further studies should investigate the impact of aggression management training and other measures that would reduce PVV. 


\section{What is already known about the topic?}

- Patient and visitor violence (PVV) is an occupational hazard for all health care staff.

- High levels of PVV exist not only in psychiatric and emergency room settings, but also in recovery room, anesthesia, intermediate care, step-down and intensive care settings.

- Factors related to PVV are the characteristics of the health care staff and of the patients/visitors, the interactions between staff and patient/visitor during the treatment process, and the characteristics of the work environment, as well as the organisational procedures where the interactions take place.

\section{What this paper adds}

- The most important risk factor influencing the experience of healthcare staff with regard to PVV is training in aggression management, the risk perhaps caused by a shift in the perception of violence initiated by the training.

- Younger age of staff is a risk factor important for all forms of PVV, particularly for verbal violence.

- Medical doctors' risk of experiencing PVV is only half as high as that of other health care staff.

- Working with patients over 65 years of age increases the risk for PVV due to specific health conditions of older people, and perhaps also because they may feel a lack of safety in a highly technological environment.

\subsection{INTRODUCTION}

\section{Introduction}

Although incidents of violence occur in all workplace environments, it is well known that health professionals have the highest risk (Chappell and Di Martino, 2006, Hahn et al., 2008). Workplace violence has serious consequences for the involved staff, as well as for the entire health care system. Patients are the most frequent group that afflict violence upon health care staff (Camerino et al., 2008, Hahn et al., 2008). In order to prevent and manage patient and visitor violence (PVV) and to improve staff safety, strategies focusing on the organizational and individual level are recommended(ILO et al., 2002, International Council of Nurses, 2001). Although many countries have adopted occupational health and safety legislation and policies, evidence supporting these recommendations is limited (Chappell and Di Martino, 2006, Pich et al., 2010).

Nursing associations and labour unions called for intervention effectiveness research and more widespread protective regulations (International Council of Nurses, 2001, International Labour Office et al., 2002). Current research, however, describes only a small fraction of the problem caused by PVV (Campbell et al., 2011, Chappell and Di Martino, 2006). The majority of research has explored the preva- 
lence of PVV (Hahn et al., 2008, Koritsas et al., 2009) and has focused mainly on nurses' experiences and/or on psychiatric or emergency settings (Camerino et al., 2008, Campbell et al., 2011). Larger settings, such as medical, surgical, women \& newborn, pediatrics, rehabilitation, ambulatory care (Hahn et al., 2008) or geriatric care (Zeller et al., 2009) have been investigated to a lesser extent.

Definitions in the literature on violence are inconsistent (Bjorkly, 2006, Hahn et al., 2008). This impedes both research and the development of prevention and intervention strategies when combating PVV (Chappell and Di Martino, 2006, Lau and Magarey, 2006). This inconsistency is connected to the fact that in the field of human aggression, no current theoretical approach can describe all forms of violence (Selg et al., 1997). In this study, violence refers to incidents in which health care staff are abused, threatened or assaulted in work-related circumstances. PVV is defined as any verbal, non-verbal or physical behaviour that threatens or is harmful to others or to their property. (Morrison, 1990).

Despite the increased attention given to violence, very few studies have investigated risk factors associated with PVV in accident \& emergency (Ferns, 2005), geriatric (Kamchuchat et al., 2008) or in general health care settings (Lanza et al., 2006). In order to develop appropriate assessment and prevention strategies, studies investigating risk factors were conducted in the field of psychiatric and mental health care (Amore et al., 2008, Bjorkly et al., 2009, Flannery et al., 2006). Based upon these studies, the occurrence of PVV in mental health care is explained utilizing social-interactional models (Richter and Whittington, 2006).

Evidence regarding risk factors is crucial in order to conduct prevention and intervention studies and to evaluate and enhance training programs (McPhaul and Lipscomb, 2004, Wells and Bowers, 2002). There are a lack of theoretical models and research that explore the predisposing factors for PVV in the general hospital setting, or that describe the reasons for violent behaviour (Campbell et al., 2011, Koritsas et al., 2009). Therefore, a working model to investigate risk factors was developed for this study, including the results of prevalence and descriptive studies about PVV in general hospitals. As factors in the model, the following are included: (1) characteristics of health care staff, (2) characteristics of patients and/or visitors, (3) the staff to patient and visitor interactions in the treatment process, (4) the characteristics of the work environment and organisational procedures, and (5) the social context or cultural background of the health care system (Hahn et al., 2010, ILO et al., 2002). This working model describes factors similar to the model of Curbow (2002) and is described by Hahn et al. (2011). Table 6.1 lists the five factors in more detail.

As discussed above, the evidence of risk factors included in the working model is limited. The aim of the present study is, therefore, to explore risk factors of patient and visitor violence directed against health care staff from the perspective of different staff groups working in different wards in general hospital settings. 


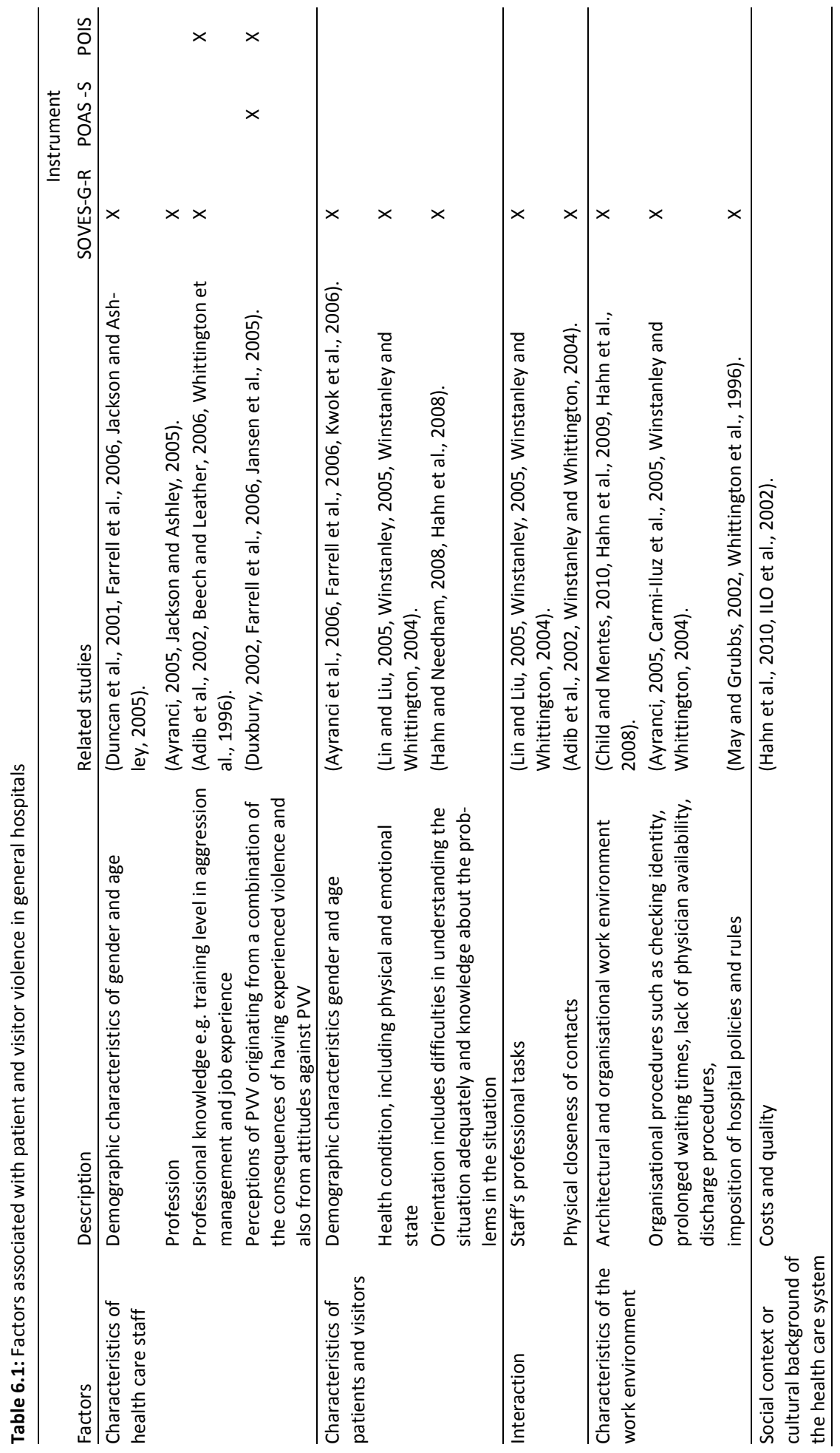




\subsection{MATERIAL AND METHODS}

\section{Design and setting}

A retrospective cross-sectional survey utilizing postal questionnaires was conducted between May and July 2007. It included all health care staff from every unit in one Swiss university hospital.

\section{Sample}

The participating hospital is one of five university hospitals in Switzerland. It provides a wide range of services, has a large variety of specializations and provides treatment of physical illnesses for a population of approximately two million people. Over 220'000 patients are treated yearly by almost 5'000 health care staff members. In Switzerland, it is common that there are no psychiatric units included in this type of hospital.

For this study, a total of 4845 nurses \& midwifes, medical doctors, physical therapists, occupational therapists \& nutritionists, ward secretaries, medical assistants \& radiology assistants, nursing assistants or less qualified nursing staff and other health care staff (e.g. laboratory workers) were invited to participate. Inclusion criteria were working in direct contact with patients/visitors and having an adequate command of the German language. The sample correlated with the typical characteristics of other health care staff working in Switzerland in accordance to gender ( $77.9 \%$ female), age (more than $80.0 \%$ over 30 years old), profession $(52.7 \%$ nurses), professional experience (more than $60 \%$ over 5 years), employment level (most often 90-100\%) and work place (Berthou et al., 2005, Jaccard Ruedin et al., 2009). The wards included were: medical, surgical and rehabilitation, emergency, outpatient clinics, intensive \& intermediate care, operating rooms, maternity, women \& newborn, pediatrics and other wards with specialized care for physically ill patients.

\section{Data collection}

All health care staff with patient/visitor contact received a personal letter with information regarding the aim and content of the study. One month after distribution, all health care staff received the questionnaires along with brief written information regarding the study and explanation of the voluntary nature of participation. The questionnaires were completed during work hours and were returned anonymously via business-reply mail. 


\section{Instrument}

Four out of the five factors associated with the risk of experiencing PVV, (1) the characteristics of health care staff, (2) the characteristics of patients, (3) the interaction, and (4) the organizational work environment were measured by means of three instruments: The Survey of Violence Experienced by Staff German-VersionRevised (SOVES-G-R), the German version of the shortened Perception of Aggression Scale (POAS-S) and the Perception of Importance of Intervention Skills Scale (POIS).

The SOVES-G-R is based on the Irish version of McKenna (2004) and was translated and tested for use in the German language and in the general hospital setting. The German version achieved good face validity and feasibility (Hahn et al., 2011, Hahn et al., 2010). The SOVES-G-R explores patients' and/or visitors' verbal and physical violence, including threats, that were experienced by health care staff during the previous 12 months and the previous working week. For a detailed description of the SOVES-G-R, see Hahn et al. 2011.

Along with the SOVES-G-R, the health care staffs' attitudes regarding PVV were measured with the POAS-S. This assessment tool consists of of 12 items answered on a 5-point Likert scale, which encompasses two factors. The first factor includes the health professionals' attitude that aggression is viewed as a dysfunctional/undesirable phenomena and the second factor maintains the attitude that aggression is viewed as a functional/comprehensible phenomena. The average test-retest reliability of the POAS-S was sufficient for Swiss mental health care. Also, the internal consistency of the two factors, tested in Swiss general hospital settings, was satisfactory (Hahn et al., 2011).

As the third instrument, the POIS was utilized. The nine items, answered on a 3-point Likert scale. It reflects two dimensions of the perception regarding prevention and intervention strategies in the de-escalation or management process of violent situations in general hospitals. In dimension one, six items focus on the importance of structured interventions, on safe physical restraints and on the evaluation of managing PVV utilizing team intervention techniques. There are three items which focus on the importance of preventive measures in factor two (identification and assessment, communication skills and setting boundaries/limits with potentially violent individuals). The construct validity of the POIS was tested by Hahn et al. (2011) using factor analysis. The two factors explained $44.3 \%$ of the total variance and had a Cronbach's alpha's of 0.67 for factor 1 (structure and evaluation) and 0.52 for factor 2 (prevention). 


\section{Data analysis}

Standard descriptive statistics were used to describe and summarize the data. Multiple logistic regression analysis was applied to develop a risk-factor model. The binary outcome variables consisted of having experienced PVV in the past 12 months and having experienced PVV in the past week. We began with a model that included all of the available explanatory variables and selected variables based on the Aikake Information Criterion (AIC) and the Bayesian Information Criterion (BIC). This then led to predictions regarding the experience of PVV based on one or more variables, considering their interrelation. Odds ratios were calculated to describe the influence of the variables in regards to the risk of experiencing PVV. All data analyses were conducted with the R statistical package Version 2.8.1 (R Development Core Team, 2008). A p value of less than 0.01 was considered statistically significant.

\section{Ethical considerations}

The study was supported by the nursing, therapeutic and medical staff directors and was approved by the local Ethical Commission. They had all been previously personally informed regarding the study by the principal investigator. To ensure anonymity, no names or other identifiers were used.

\subsection{RESULTS}

\section{Participants}

The questionnaire was completed and returned by 2495 health care staff from different general hospital units (response rate $=51.55 \%$ ). Response rates varied among the participating staff, with the highest rates coming from nurses \& midwives $(58.11 \%)$ and the lowest from medical doctors (39.63\%). The majority of the participants were female ( $82.02 \%)$, with almost half being between 30 and 45 years of age and having between 0 and 4 years of experience at the present workplace. Most of the participants (55.2\%) were working full-time. Only $16.05 \%$ of the participants were trained in aggression management. The proportions of staff with training varied among the different professions, age groups and unit types. Nurses \& midwives, staff working in rehabilitation units and the youngest staff members had received the most training (see Table 6.2). The participating staff did not differ in gender, professional experience, degree of employment or workplace from nonparticipating staff, but were slightly younger and had accordingly less professional experience (see Table 6.2). 
Table 6.2: Characteristics of health care staff

\begin{tabular}{|c|c|c|c|}
\hline \multirow[t]{2}{*}{ Characteristics } & & \multirow{2}{*}{$\begin{array}{l}\text { Total } \\
\text { Sample } \\
n=4845 \\
n(\%)\end{array}$} & \multirow{2}{*}{$\begin{array}{l}\text { Total } \\
\text { Participants } \\
\mathrm{n}=2495 \\
\mathrm{n}(\%)\end{array}$} \\
\hline & & & \\
\hline \multirow[t]{2}{*}{ Gender } & Female & $3773(77.87)$ & $2045(81.96)$ \\
\hline & Male & $1072(22.13)$ & $440(17.63)$ \\
\hline \multirow[t]{3}{*}{ Age } & $16-29$ years & $913(18.84)$ & $615(24.64)$ \\
\hline & $30-45$ years & $2319(47.86)$ & $1241(49.73)$ \\
\hline & 46 years and older & $1613(33.29)$ & $586(23.49)$ \\
\hline \multirow{6}{*}{$\begin{array}{l}\text { Profession inclusive } \\
\text { students }\end{array}$} & Nurse \& midwife & $2553(52.69)$ & $1484(59.47)$ \\
\hline & Medical doctor & $1206(24.89)$ & $478(19.15)$ \\
\hline & $\begin{array}{l}\text { Physical therapist, occupational therapist, } \\
\text { nutritionist }\end{array}$ & $163(3.36)$ & $90(3.60)$ \\
\hline & $\begin{array}{l}\text { Ward secretary, medical assistant, radiology } \\
\text { assistant }\end{array}$ & $327(6.75)$ & $152(6.09)$ \\
\hline & Nursing assistant & $393(8.11)$ & $156(6.25)$ \\
\hline & Other HCS & $203(4.19)$ & $127(5.09)$ \\
\hline \multirow{3}{*}{$\begin{array}{l}\text { Experiences at } \\
\text { present workplace }\end{array}$} & $0-4$ years & $1811(37.38)$ & $1234(49.45)$ \\
\hline & $5-10$ years & $1201(24.79)$ & $650(26.05)$ \\
\hline & Over 10 years & $1833(37.83)$ & $568(22.76)$ \\
\hline \multirow{3}{*}{$\begin{array}{l}\text { Employment per- } \\
\text { centage }\end{array}$} & $90-100 \%$ & $2457(50.71)$ & $1376(55.15)$ \\
\hline & $51-89 \%$ & $1280(26.42)$ & $654(26.21)$ \\
\hline & $\leq 50 \%$ & $1108(22.87)$ & $447(17.91)$ \\
\hline \multirow[t]{11}{*}{ Ward type } & Medical units & & $594(23.80)$ \\
\hline & Surgical units & & $509(20.40)$ \\
\hline & Intensive care units & & $257(10.30)$ \\
\hline & $\begin{array}{l}\text { Recovery room, anesthesia, intermediate care, } \\
\text { step-down units }\end{array}$ & & $155(6.21)$ \\
\hline & Outpatient units & & $145(5.81)$ \\
\hline & Emergency rooms & & $92(3.68)$ \\
\hline & Operating rooms & & $91(3.64)$ \\
\hline & Rehabilitation units & & $90(3.60)$ \\
\hline & Maternity \& newborn, pediatrics & & $44(1.76)$ \\
\hline & Units with specialized care & & $302(12.10)$ \\
\hline & Worked at more than one unit & & $179(7.17)$ \\
\hline
\end{tabular}




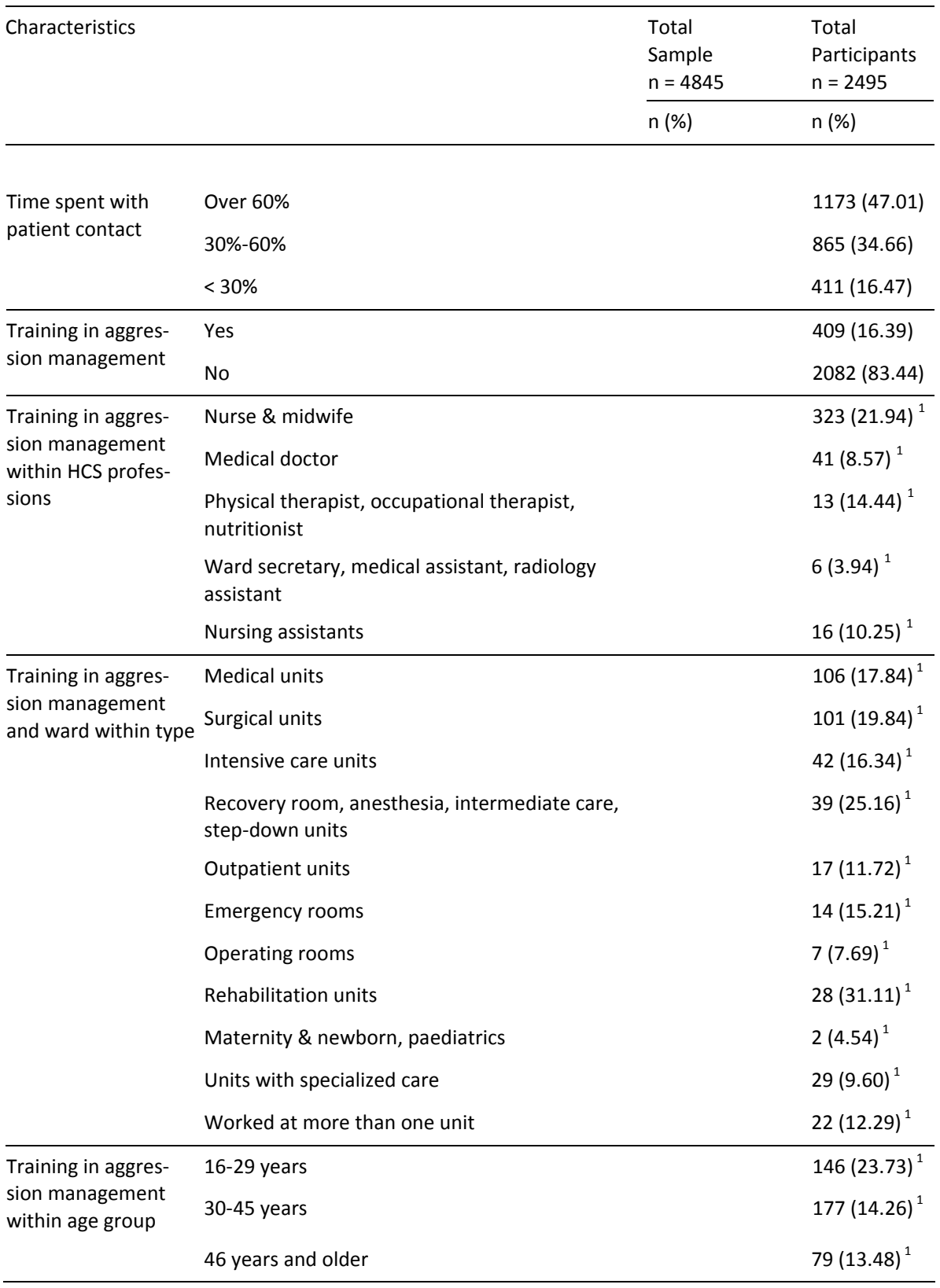

${ }^{1} \%$ in relation to the $n$ of the participating staff group 


\section{Prevalence of PVV}

Almost all participants (85\%) had experienced PVV during their career. Furthermore, in total, 1260 participants (50.50\%) had experienced PVV during the 12 months prior to data collection. Of these participants, $45.99 \%$ had experienced verbal PVV, 16.91\% physical PVV and $15.63 \%$ had experienced threats. In the week prior to data collection, $11.43 \%(n=284)$ of the participants had experienced PVV. Of these health care staff, $66.91 \%$ experienced verbal violence, $19.72 \%$ physical violence and $7.04 \%$ experienced threatening behaviour.

\section{Factors associated with violent situations in general hospitals}

Factors associated with PVV during the past 12 months

A regression model was fitted for factors associated with PVV experienced in the past 12 months. The factors are described in Table 6.1. Predictive variables in the final model were: health professionals' age and training in aggression management, ward type, patients' age and visitor group (see Table 6.3). Experiencing PVV was negatively associated with health professionals' age. Older staff experienced less PVV in comparison to those between the age of 16 to 29. Staff having received training in aggression management had almost double the odds (OR $=1.92$ ) of experiencing violence, in comparison to staff who had not received training. On the one hand, working in wards such as operating rooms, women \& newborn and pediatrics reduced the estimated odds of experiencing PVV by half, in comparison to those working in medical wards. On the other hand, working in emergency rooms and outpatient wards doubled the odds and working in intensive care, recovery rooms, anesthesia, intermediate care or step-down units led to 1.42 times higher odds of experiencing violence (during the past 12 months), in comparison to those working in medical wards. For staff working predominantly with patients 65 years of age and older, the risk was 1.47 times higher than for staff working with patients 65 years of age and younger. Also, for staff working most often with visitors such as husbands/wives, the odds of experiencing violence were 1.42 times higher. 


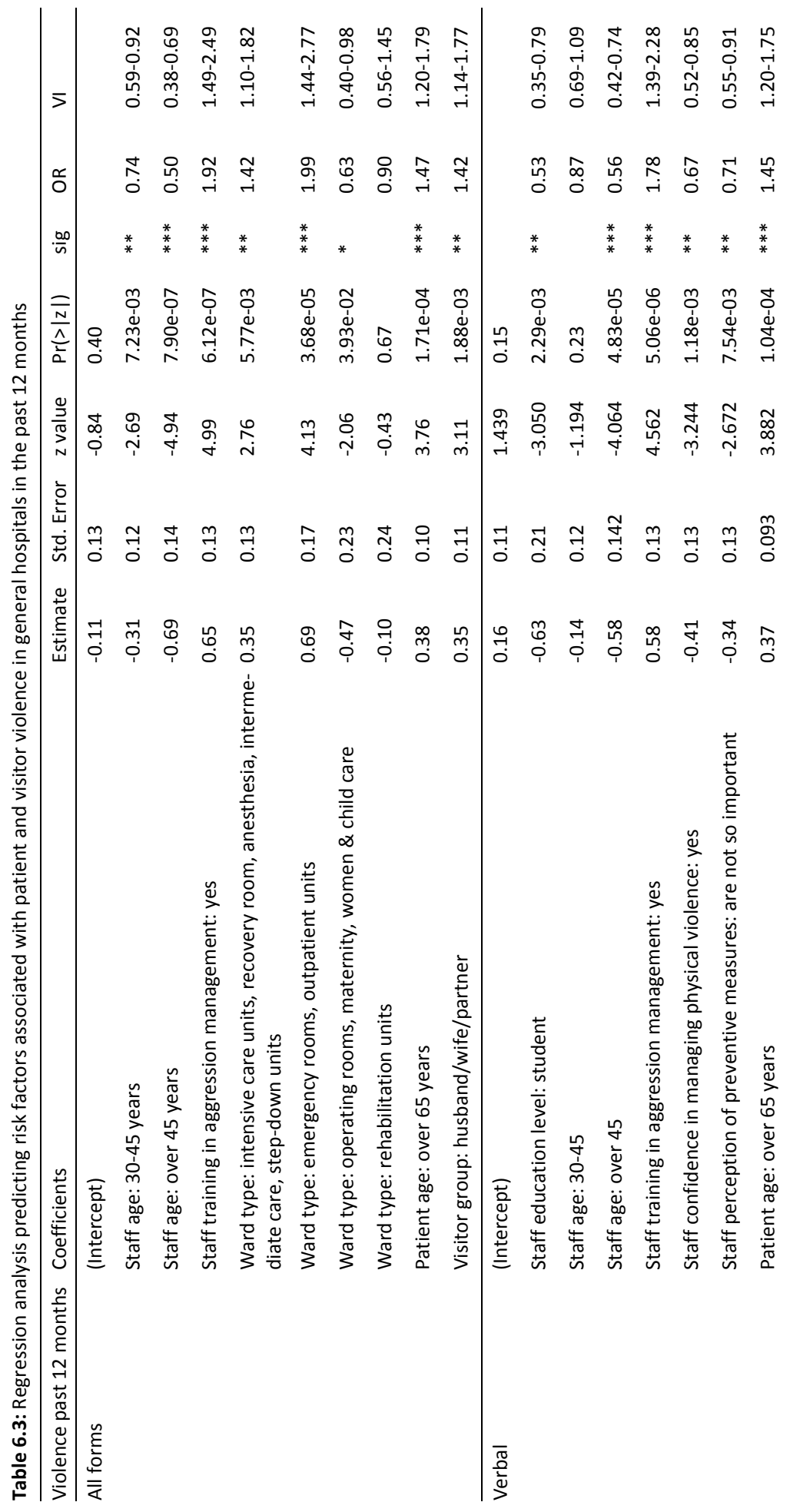




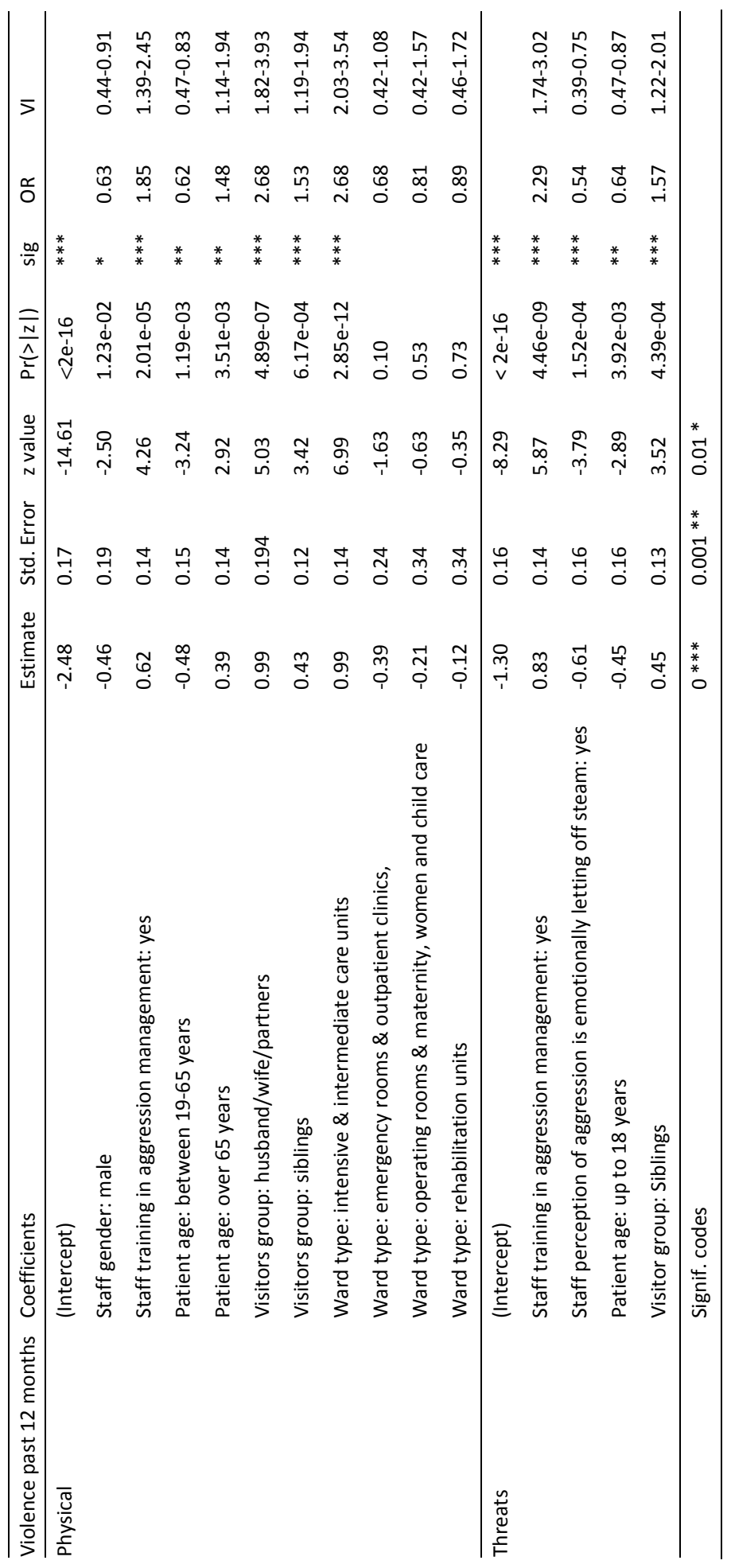


Based upon the full model, the variable selection process resulted in a regression model for verbal violence with the following important variables: health care staffs' education level, age, training in aggression management, confidence in managing physical violence, perception of preventive measures and patients' age. Table 6.3 shows that during the past 12 months, health care staff experienced more verbal violence when they had training in aggression management $(O R=1.78)$ and when they were working with the patients in the age group 65 years of age and older (OR $=1.45$ ).

The dominant variables for health professionals experiencing physical violence were their gender and training in aggression management, patient age, visitor group and ward type. Table 6.3 shows that on the variable level, the estimated odds of experiencing physical violence during the past 12 months were almost doubled for staff trained in aggression management $(O R=1.84)$. Staff working with patients 65 years and older experienced more physical violence $(O R=1.48)$ than staff working predominantly with younger patients. Health care staff working mostly with husband/wife/partner or sibling visitors had higher estimated odds of experiencing physical violence ( $O R=2.67$ and 1.52 , respectively) than with those working with visitors such as parents, children, other family members or friends/acquaintances. There were very high estimated odds of experiencing physical violence for health professionals working in intensive \& intermediate care units (2.68), in comparison to those working in medical wards.

The dominant variables in experiencing threats during the past 12 months were health care staff who had received training in aggression management and whose perception that aggression is emotionally letting off steam, patient age and visitor group. Table 6.3 shows that for staff with training in aggression management, the estimated odds were more than doubled $(O R=2.29)$ in comparison to untrained staff. Staff working mostly with the visitor group siblings had a higher estimated risk of experiencing threats $(O R=1.56)$ than staff working mostly with visitor group husband/wife/partner. Staff with the perception that aggression is emotionally letting off steam appeared to be less likely to experience threats (OR = $0.54)$ than staff with the perception that aggression is violent behaviour to others and the self. Staff working most often with patients aged up to 18 years (OR $=0.63$ ) had a lower risk than staff working with older patient groups.

\section{Factors associated with PVV in the past week}

Again, a regression model was calculated for factors associated with PVV experienced in the past week. After starting with the full model, the dominant variables were determined and used for further analysis. Predictors in this model were: health professionals' training in aggression management, patient age and visitor 
group. Table 6.4 shows that the dependent variable of experiencing PVV during the past week was positively associated with having training in aggression management (with odds twice as high as untrained staff; OR, 2.04) and with working with the siblings of visitors (with odds 1.53 times higher in comparison to the visitors husband/wife/partner).

Table 6.4: Regression analysis predicting risk factors associated with patient and visitor violence in general hospitals during the past week

\begin{tabular}{|c|c|c|c|c|c|c|c|}
\hline Coefficients & Estimate & Std. Error & z-value & $\operatorname{Pr}(>|z|)$ & sig & OR & VI \\
\hline (Intercept) & -2.28 & 0.13 & -17.75 & $<2 \mathrm{e}-16$ & $* * *$ & & \\
\hline $\begin{array}{l}\text { Staff training in aggression manage- } \\
\text { ment: yes }\end{array}$ & 0.69 & 0.15 & 4.49 & $7.24 \mathrm{e}-06$ & $* * *$ & 2.04 & $1.48-2.71$ \\
\hline Patient age: up to 18 years & -0.39 & 0.18 & -2.13 & 0.03 & $*$ & 0.68 & $0.48-0.97$ \\
\hline Patient age: over 65 years & 0.32 & 0.14 & 2.30 & 0.02 & $*$ & 1.38 & $1.05-1.83$ \\
\hline Visitor group: siblings & 0.45 & 0.13 & 3.27 & $1.08 \mathrm{e}-03$ & $* *$ & 1.53 & $1.19-2.04$ \\
\hline Signif. codes: & $0 * * *$ & $0.001 * *$ & $0.01 *$ & & & & \\
\hline
\end{tabular}

Because of differences in the levels of PVV experienced for various health care staff groups, as reported in the literature, a second regression model was fitted including a variable for the staff groups. This additional variable did not significantly improve the model fit and had no effect on the set of variables selected. However, medical doctors' risk of experiencing aggression was significantly lower than the risk for nurses \& midwives (OR=0.58) (see Table 6.5). All other regression estimates were similar to the earlier model.

Table 6.5: Regression analysis predicting risk factors associated with patient and visitor violence in general hospitals during the past week for different staff groups

\begin{tabular}{|c|c|c|c|c|c|c|c|c|}
\hline & Coefficients & Estimate & Std. Error & z-value & $\operatorname{Pr}(>|z|)$ & sig & OR & VI \\
\hline & (Intercept) & -2.14 & 0.14 & -15.40 & $<2 \mathrm{e}-16$ & $* * *$ & & \\
\hline \multirow[t]{5}{*}{ Staff group } & $\begin{array}{l}\text { Physical therapist, occupa- } \\
\text { tional therapist, nutritionist } \\
\text { and other health care staff }\end{array}$ & -0.20 & 0.31 & -0.66 & 0.50 & & 0.82 & $0.45-1.49$ \\
\hline & $\begin{array}{l}\text { Ward secretary, medical } \\
\text { assistant, radiology assistant }\end{array}$ & -0.25 & 0.39 & -0.65 & 0.52 & & 0.78 & $0.37-1.66$ \\
\hline & Nursing assistant & -0.25 & 1.05 & -0.24 & 0.81 & & 0.78 & $0.09-6.11$ \\
\hline & Medical doctor & -0.55 & 0.21 & -2.69 & 0.01 & $* *$ & 0.58 & $0.39-0.86$ \\
\hline & $\begin{array}{l}\text { Training in aggression } \\
\text { management: yes }\end{array}$ & 0.62 & 0.16 & 3.98 & $6.8 \mathrm{e}-05$ & $* * *$ & 1.87 & $1.37-2.53$ \\
\hline \multirow[t]{2}{*}{ Patient age } & up to 18 years & -0.40 & 0.18 & -2.19 & 0.03 & $*$ & 0.67 & $0.47-0.96$ \\
\hline & over 65years & 0.31 & 0.14 & 2.16 & 0.03 & $*$ & 1.36 & $1.03-1.79$ \\
\hline Visitors group & Siblings & 0.43 & 0.14 & 3.15 & $0.2 \mathrm{e}-02$ & $* *$ & 1.54 & $1.18-2.02$ \\
\hline Signif. codes: & & $0 * * *$ & $0.001 * *$ & $0.01 *$ & & & & \\
\hline
\end{tabular}




\subsection{DISCUSSION}

The aim of this study was to explore the experience of health care staff with PVV in order to describe important factors associated with PVV for the general hospital setting. This study confirmed existing evidence that PVV is a significant problem for health care staff in general hospitals, and that verbal violence is the most prevalent form experienced (Camerino et al., 2008, Moreno-Casbas et al., 2011). The results distinguished different risk factors for different forms of PVV.

\section{Characteristics of health care staff}

As described in the working model, the characteristics of health care staff are a significant precondition for the situation, as well as for the individual preparedness for violence in the interaction. The findings confirmed existing evidence that younger health care saff have a significantly higher risk factor for all forms of violence (Farrell et al., 2006, Jackson and Ashley, 2005), especially for verbal violence in the general hospital setting. Verbal violence is perhaps easier to engage in with younger staff, but does not appear to be related to less experience when performing professional tasks. Experience at the present workplace did not appear as a statistically relevant risk factor. We therefore assume that different age-related communication skills, behavioural strategies important for organizational commitment and an understanding between staff (Carver and Candela, 2008, Hills, 2010) are also relevant in the occurrence of PVV.

In contrast to the results of former studies (Nau et al., 2010), this study revealed that students experienced PVV less frequently than other staff. Students are most often young and inexperienced, but in this study they have half the risk of experiencing PVV in comparison to other staff. Switzerland has excellent practical training and mentorship programs for all students in the practical field. HCS in the field of practical teaching are often specially trained in creating learning situations, supervising students in practice and difficult events. Students are therefore not alone in potentially violent situations and less confronted with these difficult situations. This could influence the behaviour of staff and patients alike and could be an effective protection against PVV.

Confidence in managing physical violence and rating preventive measures against PVV as unimportant, reduce the risk of experiencing verbal PVV. Also, rating aggression as emotionally letting off steam reduces the risk of threats. All of these factors seem to be an expression of staffs' feelings or attitudes regarding PVV. Studies showed that attitude has a significant influence on staffs' appraisal of violence in a situation, as well as on the strategies used to manage the incident (Duxbury et al., 2008, Jansen et al., 2005). The reflection about personal attitudes and about the attitude's influence on professional behaviour seems to be an important factor in improving staffs' prevention strategies against PVV. 
During the past week, medical doctors had experienced significantly less violence than other staff groups. We assume that this result is related to the medical doctor's professional behaviour, role or to the job characteristics. In the university general hospital, medical doctors are occupied with diagnostic tasks and providing adequate therapy, which offers them a high professional status. Contact with the patients and visitors are most often short and focused. Other health care staff monitor the patient or implement therapy for prolonged periods. Staff other than medical doctors, have therefore the potential to be more exposed to the negative physical and psychological impacts of illness and treatment, which may then lead to PVV. This result did not occur in the statistical model as described in the time frame of PVV experienced in the past 12 months. Perhaps the time frame of 12 months makes it difficult to recall the number of events experienced and could therefore be responsible for this difference (recall bias).

Although the results indicate that having training in aggression management increases the risk of experiencing PVV, this finding requires careful reflection. Training in aggression management is widely available, however, in Switzerland, there is a lack of training specifically focused on staff working in general hospital settings (Hahn et al., 2010). In addition, there is a lack of evidence of the effectiveness of the available training (Beech and Leather, 2006, National Institute for Clinical Evidence - NICE, 2005, Richter and Needham, 2007). Only a few studies describe an effect of having received such training. For example, effects such as the confidence of staff in the prevention and handling of violent situations, as well as with the knowledge improvement of the staff (Beech and Leather, 2006, Richter and Needham, 2007). Recent results (Nau et al., 2010) reported better performance of student nurses in de-escalating aggressive behaviour after receiving training. However, no reduction in the number of violent incidents after training has been confirmed (Beech and Leather, 2006, Richter and Needham, 2007). In contrast, some studies revealed a higher level of violent incidences after training. Richter and Hegney (2003) or Richter and Needham (2007) concluded that this could be due to a shift in the perception of violence initiated by the training, because of health professionals' increased awareness of PVV. This effect could also be relevant for this study. Training could then be regarded not as risk factor, but as a tool to enable staff in recognizing and responding to violent behaviour with prevention or intervention strategies. On the other hand, increased recognition and confidence in prevention and de-escalating techniques, combined with possibly inadequate techniques for specific settings, could lead to a higher risk of PVV. Trained staff could therefore be more often involved in violent situations. It seems very important to reflect the specific situations in which staff in different clinical settings are involved with PVV, and to develop situational specific training. The effects of the training must then also be investigated. 


\section{Characteristics of patients and visitors}

The results reveal that working with people over 65 years of age is a risk factor for PVV in a general hospital setting. Studies examining the specific situation of older persons in the technological environment of a general hospital are rare (Winstanley, 2005). Diagnoses of violent patients often include cognitive impairment, confusion or delirium (Lin and Liu, 2005, May and Grubbs, 2002), dementia (Brayley et al., 1994, Zernike and Sharpe, 1998), alcohol and illegal drug intoxication or withdrawal mental health challenges (May and Grubbs, 2002, Whittington et al., 1996, Winstanley and Whittington, 2004). Hahn et al. (2010) assert that these illnesses may make it difficult for patients to understand the situation and its context in hospitals. We assume that some of these diagnoses are more prevalent within older age patient groups and could lead to anxiety, stress, difficulty in comprehending the situation, excessive demands and uncertainty. These are cognitive states and emotions which could turn into violent behaviour (Ferns, 2005, Gacki-Smith et al., 2009, Winstanley, 2005).

The finding that working with husbands/wife/partners or siblings is a significant risk factor for physical violence, has not been discussed in literature nor has it been included in this working model. This finding requires further research in order to develop more knowledge about this result

\section{Characteristics of staff-patient/visitor interactions}

No risk factor clearly emerged for staff-patient and -visitor interactions. However, because verbal violence is the most frequently experienced form of violence, verbal communications skills to calm patients and visitors and to create a safe environment seem to be very important for prevention and de-escalation strategies.

\section{Characteristic of the work environment and organisational procedures}

This study confirmed the results of earlier studies that emergency rooms, outpatient and intensive care units, recovery room, anesthesia, intermediate care and step-down units are workplaces with a high risk for PVV (Hahn et al., 2008).

\section{Methodological considerations}

The total sample size of this study was large $(n=2495)$ and the response rate adequate. This provided the possibility of logistic regression analysis. However, in the one-week time period, the number of participants experiencing PVV reduced drastically $(n=284)$. The outcome variables were divided into three categories (verbal, threats and physical), possibly leading to a greater range of PVV captured than in other studies. The definition of PVV among different health care staff varies, influencing the answers of staff and perhaps leading to different answering behaviour. 
The different definitions used for the term "violence" and the differences in the outcome variables in the research field deter the interpretation and comparison of research results (Chappell \& Di Martino 2006, Lau \& Magarey 2006).

For the 12- month period, the self-assessment could have been affected by recall bias. This includes the problem of over-reporting and involves the fact that one outstanding violent incident could influence the memory as well as the reporting. It could, however, also have influenced underreporting, because staff that experienced massive or frequent PVV may have left the workplace and therefore not have participated in this study. However, most studies in the field of PVV use a 12month time frame (Hahn et al., 2008), and this procedure was adopted to allow for international comparison. The one-week time frame used in this study could have reduced recall bias (Graydon et al. 1994) and therefore made some differences (like between medical doctors and other staff groups) more explicit. The cross-sectional design of the study does not allow causal conclusions.

\subsection{CONCLUSION}

This study demonstrates that PVV in general hospitals is a serious workplace problem for all health care staff, and is not restricted to high-risk areas, such as emergency and psychiatric wards. With the large sample size, this study facilitates the analysis of complex models and assists in identifying necessary areas of training in aggression management. It also identifies the health professionals' attitude and age, the age of the patient, the communication and the workplace as relevant risk factors. These factors are therefore important in order to implement adequate prevention strategies on an organisational and a personal level. Verbal and nonverbal communication strategies emerged as significant competences in the prevention and de-escalation of violent situations.

In order to improve adequate training in aggression management, the following should be considered: Verbal and non-verbal communication strategies should be a leading topic, especially for younger staff. To create safer situations as described in the education situation with students, a two-person approach (two staff members) in handling difficult situation may be considered for the general hospital. Both the reflection of attitudes and feelings regarding PVV and the professional tasks/roles need to be considered when identifying personal risk behaviour, or the potential risk in a situation. Staff groups working in emergency rooms, outpatient units and intensive care units, recovery room, anesthesia, intermediate care and step-down units are at a greater risk of experiencing PVV and should have regular workplace specific training and support in managing violent situations. However, it should not be forgotten that training could change the perception and the recognition of violence and could therefore lead to a higher level of violence experienced.

As the perspective of the patient/visitor involved in PVV is almost nonexistent in research, the discussions and conclusions regarding risk factors of PVV reflect 
only one side of all involved parties. Future researchers should therefore consider qualitative approaches, such as Grounded Theory, in order to investigate the entire interaction leading up to PVV. The results of this study stress the need for further studies investigating the impact of aggression management training in reducing PVV. However, if training does lead to a higher sensitivity to violence and if it does influence the perception of the participants, longitudinal research, which would investigate this phenomenon with mediation analyses, should be conducted. Additionally, intervention studies should measure the effect of specific strategies against PVV. More information is required concerning the consequences of PVV on health professionals, the quality of care (e.g. the seriousness of the PVV) and the intent to leave the workplace or profession.

\section{Contributions}

Study design: $\mathrm{SH}, \mathrm{RJGH}, \mathrm{THD}, \mathrm{VH}$

Data collection: $\mathrm{SH}, \mathrm{VH}$

Data analysis: $\mathrm{SH}, \mathrm{MM}$

Manuscript preparation: SH, MM, VH, ThD, GK, RJGH

\section{Conflict of interest}

There is no conflict of interest in this study

\section{Acknowledgment}

The authors would like to thank the University Hospital of Berne, which enabled us to conduct this study. We are also very grateful to all health care staff members who completed the many surveys. 


\subsection{REFERENCES}

Amore M, Menchetti M, Tonti C, Scarlatti F, Lundgren E, Esposito W \& Berardi D (2008): Predictors of violent behavior among acute psychiatric patients: clinical study. Psychiatry Clin Neurosci 62, 247255.

Beech B \& Leather P (2006): Workplace violence in the health care sector: A review of staff training and integration of training evaluation models. Aggression and Violent Behaviour 11, 27-43.

Berthou A, Junger A \& Kossaibati S (2005) Test des Schweizer Nursing Minimum Data Sets (CH-NMDS) (Test II), Schlussbericht. Nursing Data Switzerland, Ecublens, CH, pp. 1-99.

Bjorkly S (2006) Psychological Theories of Aggression: Principles and Application to Practice. In Violence in Mental Health Settings (Richer D \& Whittington R eds.). Springer Science and Business Media, LLC, New York, pp. 27-46.

Bjorkly S, Hartvig P, Heggen FA, Brauer H \& Moger TA (2009): Development of a brief screen for violence risk (V-RISK-10) in acute and general psychiatry: An introduction with emphasis on findings from a naturalistic test of interrater reliability. Eur Psychiatry 24, 388-394.

Brayley J, Lange R, Baggoley C, Bond M \& Harvey P (1994): The violence management team. An approach to aggressive behaviour in a general hospital. Medical Journal of Australia 15, 254-258.

Camerino D, Estryn-Behar M, Conway PM, van Der Heijden BIJM \& Hasselhorn HM (2008): Work-related factors and violence among nursing staff in the European NEXT study: a longitudinal cohort study. International Journal of Nursing Studies 45, 35-50.

Campbell JC, Messing JT, Kub J, Agnew J, Fitzgerald S, Fowler B, Sheridan D, Lindauer C, Deaton J \& Bolyard R (2011): Workplace violence: prevalence and risk factors in the safe at work study. American College of Occupational and Environmental Medicine 53, 82-89.

Carver L \& Candela L (2008): Attaining organizational commitment across different generations of nurses. J Nurs Manag 16, 984-991.

Chappell D \& Di Martino V (2006) Violence at Work, Third edition edn. International Labour Office, Geneva, pp. 1-360.

Curbow B (2002) Origins of violence at work. In Workplace violence in the health sector. State of the Art (Cooper CL \& Swanson N eds.). International Labour Office, International Council of Nurses, World Health Organization and Public Service International, Geneva, pp. 35-48.

Duxbury J, Hahn S, Needham I \& Pulsford D (2008): The Management of Aggression and Violence Attitude Scale (MAVAS): a cross-national comparative study. Journal of Advanced Nursing 62, 596-606.

Farrell GA, Bobrowski C \& Bobrowski P (2006): Scoping workplace aggression in nursing: findings from an Australian study. Journal of Advanced Nursing 55, 778-787.

Ferns T (2005): Terminology, stereotypes and aggressive dynamics in the accident and emergency department. Accident and Emergency Nurse 13, 238-246.

Flannery RB, Jr., Laudani L, Levitre V \& Walker AP (2006): Precipitants of psychiatric patient assaults on staff: three-year empirical inquiry of the Assaulted Staff Action Program (ASAP). Int J Emerg Ment Health 8, 15-22.

Gacki-Smith J, Juarez AM, Boyett L, Homeyer C, Robinson L \& MacLean SL (2009): Violence against nurses working in US emergency departments. Journal of Nursing Administration 39, 340-349.

Hahn S, Hantikainen V, Müller M, Needham I, Dassen T, Kok G \& Halfens R (2008a) Violence against health care staff in general hospitals: An underestimated problem? In Proceedings of the first International Conference on Workplace Violence in the Health Sector - Together, Creating a Safe Work Environment (Needahm I KM, O'Brien-Pallas L, McKenna K, Tucker R, Oud N ed.). Kavanah, Amsterdam

Hahn, S., Müller, M., Needham, I., Dassen, T., Kok, G., Halfens, R.J.G., 2011. Measuring patient and visitor violence in general hospitals: feasibility of the SOVES-G-R, internal consistency and construct validity of the POAS-S and the POIS. Journal of Clinical Nursing. 20 (17-18), 2519-2530. 
Hahn S, Müller M, Needham I, Kok G, Dassen T \& Halfens RJG (2010): Factors associated with patient and visitor violence experienced by nurses in general hospitals in Switzerland: A cross-sectional survey. Journal of Clinical Nursing 19, 3535-3546.

Hahn S, Zeller A, Needham I, Kok G, Dassen T \& Halfens RJG (2008b): Patient- and visitor violence in general hospitals: A systematic review of the literature. Journal of Aggression and Violent Behavior 13, 431-441.

Hegney D, Plank A \& Parker V (2003): Workplace violence in nursing in Queensland Australia: A selfreported study. International Journal of Nursing Practice 9, 261-268.

Hills L (2010): Being part of a multi-generational medical practice team. Journal of Medical Practice Management 26, 94-98.

ILO, ICN, WHO \& PSI (2002) Framework Guidelines for Addressing Workplace Violence in the Health Sector. In Joint Programme on Workplace Violence in the Health Sector. International Labour Office, Geneva.

International Council of Nurses (2001) Unitet Against Violence. International Council of Nurses, Geneva (Switzerland).

International Labour Office, International Council of Nurses, World Health Organisation \& Public Services International (2002) Workplace Violence in the Health Sector, Geneva.

Jaccard Ruedin H, Weaver F, Roth M \& Widmer M (2009) Personnel de santé en Suisse - Etat des lieux et perspectives jusqu'en 2020. Observatoire suisse de la santé, Neuchâtel, p. 116.

Jackson M \& Ashley D (2005): Physical and psychological violence in Jamaica's health sector. Revista Panamericana de Salud Pública/Pan American Journal of Public Health. 18, 114-121.

Jansen GJ, Dassen TW \& Groot Jebbink G (2005): Staff attitudes towards aggression in health care: a review of the literature. Journal of Psychiatric and Mental Health Nursing 12, 3-13.

Kamchuchat C, Chongsuvivatwong V, Oncheunjit S, Yip TW \& Sangthong R (2008): Workplace violence directed at nursing staff at a general hospital in southern Thailand. J Occup Health 50, 201-207.

Koritsas S, Boyle M \& Coles J (2009): Factors associated with workplace violence in paramedics. Prehosp Disaster Med 24, 417-421.

Lanza ML, Zeiss RA \& Rierdan J (2006): Non-physical violence: a risk factor for physical violence in health care settings. AAOHN J 54, 397-402.

Lau JB \& Magarey J (2006): Review of research methods used to investigate violence in the emergency department. Accident and Emergency Nurse 14, 111-116.

Lin YH \& Liu HE (2005): The impact of workplace violence on nurses in South Taiwan. International Journal of Nursing Studies 42, 773-778.

May DD \& Grubbs LM (2002): The extent, nature, and precipitating factors of nurse assault among three groups of registered nurses in a regional medical centre. Journal of Emergency Nursing 28, 11-17.

McKenna K (2004) Study of work-related violence. Committee on Workplace Violence, North Eastern Health Board, Ireland, pp. 1-121.

McPhaul K \& Lipscomb JA (2004): Workplace violence in health care recognized but not regulated. Online Journal of Issues in Nursing 9, 1-17.

Moreno-Casbas T, Fuentelsaz-Gallego C, González-María E \& Contreras-Moreira M (2011) RN4CAST Nurses' reports of working conditions and their consequences for retention and quality. RN4CAST Europ. Available at: http://www.rn4cast.eu/attachments/RN4CAST_ICN\%20MALTA\%202011\%20\%20s210.pdf (accessed 20.05. 2011).

Morrison E (1990): Violent psychiatric inpatients in a public hospital. Scholarly Inquiry for Nursing Practice 4, 65-82.

National Institute for Clinical Evidence - NICE (2005) Clinical Practice Guidelines Violence: The ShortTerm Management of Disturbed/Violent Behaviour in In-Patient Psychiatric Settings and Emergency Departments. Royal College of Nursing, London.

Nau J, Halfens R, Needham I \& Dassen T (2010): Student nurses' de-escalation of patient aggression: a pretest-posttest intervention study. Int J Nurs Stud 47, 699-708. 
Needham I, Abderhalden C, Dassen T, Haug HJ \& Fischer JE (2004): The perception of aggression by nurses: psychometric scale testing and derivation of a short instrument. Journal of Psychiatric and Mental Health Nursing 11, 36-42.

Philbrick J, Sparks M, Hass M \& Arsenault S (2003): Workplace violence: The legal costs can kill you. American Business Review 21, 84-90.

Pich J, Hazelton M, Sundin D \& Kable A (2010): Patient-related violence against emergency department nurses. Nursing and Health Sciences 12, 268-274.

R Development Core Team (2008) R: A Language and Environment for Statistical Computing. R Foundation for Statistical Computing, Vienna, Austria. http://www.R-project.org. Available at: http://www.R-project.org (accessed 15.04. 2011).

Richter D \& Needham I (2007): Effekte von mitarbeiterbezogenen Trainingsprogrammen zum Aggressionsmanagement in Einrichtungen der Psychiatrie und Behindertenhilfe. Systematische Literaturübersicht [Effects of aggression management trainings for mental health care and disability care staff--systematic review]. Psychiatrische Praxis 34, 7-14.

Richter D \& Whittington R (2006) Violence in Mental Health Settings: Causes, Consequences, Management. Springer Science \& Business Media, New York.

Selg H, Mees U \& Berg D (1997) Psychologie der Aggressivität. Hogrefe, Verlag für Psychologie, Göttingen, Bern, Toronto, Seattle.

Wells J \& Bowers L (2002): How prevalent is violence towards nurses working in general hospitals in the UK? Journal of Advanced Nursing 39, 230-240.

Whittington R, Shuttleworth S \& Hill L (1996): Violence to staff in a general hospital setting. Journal of Advanced Nursing 24, 326-333.

Winstanley S (2005): Cognitive model of patient aggression towards health care staff: The patient's perspective. Work \& Stress 19, 340-350.

Winstanley S \& Whittington R (2004): Aggressive Encounters Between Patients and General Hospital Staff: Staff Perceptions of the Context and Assailants' Levels of Cognitive Processing. Aggressive Behavior 30, 534-543.

Zeller A, Hahn S, Needham I, Kok G, Dassen T \& Halfens RJ (2009): Aggressive behavior of nursing home residents toward caregivers: a systematic literature review. Geriatr Nurs 30, 174-187.

Zernike W \& Sharpe P (1998): Patient aggression in a general hospital setting: do nurses perceive it to be a problem? International Journal of Nursing Practice 4, 126-133 

CHAPTER SEVEN

General discussion 


\subsection{INTRODUCTION}

This dissertation has investigated factors associated with patient and visitor violence against health care staff in order to describe this workplace hazard in general hospitals. Workplace violence refers to incidents in which health care staff are abused, threatened or assaulted in work-related circumstances. Patient and visitor violence has various forms and is defined as any verbal, non-verbal or physical behaviour that threatens or is harmful to others or their property (Morrison 1990). In accordance to the research questions presented in chapter one, this dissertation first summarised the international knowledge available regarding the topic. Following that, a survey instrument was translated into German, and adapted to the research aim as well as to the cultural background of the Swiss general hospital setting. After including two more instruments to cover the most important factors, all utilised instruments were tested with a sample of nurses $(n=291)$. Lastly, with a sample of health care staff $(n=2495)$, the prevalence, the staff interventions, the consequences of and associated factors with patient and visitor violence from the perspective of health care staff, was described for the first time in Switzerland.

In this seventh chapter, the main findings of the presented studies are summarised and the methodological aspects of this dissertation are critically reviewed. After discussion of the results, the implications for research and clinical practice are outlined.

\subsection{MAIN RESULTS}

\section{Important factors described in international research related to patient and visi- tor violence}

Question one of this thesis (which risk factors) was addressed in chapter two with a literature review. The results of this review showed that very few studies have addressed the problem of patient and visitor violence against health care staff in general hospitals. The review further showed that the factors contributing to patient and visitor violence have been inconsistently described. However, a complex interplay between the various factors was demonstrated. These results along with the theoretical background, have led to a new working model regarding what the important factors are in association with patient and visitor violence in the general hospital setting. These factors are presented in chapter three.

\section{Instruments used to describe patient and visitor violence}

The review in chapter two also addressed the second research question (which instruments have been used). Several different survey instruments exist which describe patient and visitor violence against health care staff in the general hospital 
setting. Most often these instruments are survey questionnaires developed by the researchers and information regarding the validity or reliability of the instruments used is seldom available. For example, even with the standardised questionnaire 'The Country Case Studies Research Instruments Survey Questionnaire' by ILO/ICN/WHO/PSI (2003), there was no data available regarding the validity or the reliability. The Survey of Violence Experienced by Staff (SOVES) by McKenna (2004), developed in a European context with support of the European Violence in Psychiatry Research Group, did however, present good content validity and internal consistency (chapter three). Unfortunately, none of the questionnaires included all of the factors related to patient and visitor violence and they only partially corresponded to the proposed working model. Also, no questionnaires concerning patient and visitor violence against health care staff were available in German.

In order to fill this gap, as discussed in chapter three, the SOVES was carefully translated and then reverse translated. Furthermore, the Survey of Violence Experienced by Staff German version revised (SOVES-G-R), the shortened Perception of Aggression Scale (POAS-S) and the Perception of Importance of Intervention Skills Scale (POIS) were successfully validated for relevance and content validity by a panel of experts. The comprehensibility and face validity of the three instruments were approved by health care staff. The internal consistency of the POAS-S and the POIS showed moderate results and therefore, for both instruments, revision was advised.

\section{Prevalence of patient and visitor violence}

Two studies were conducted to answer the third research question (prevalence of patient and visitor violence), with one study being conducted with nurses ( $n=291)$ and one with health care staff $(n=2495)$. The results are presented in chapter four and five, and confirmed that almost all health care staff had experienced patient and visitor violence during their career. In the 12 months prior to data collection, almost $80 \%$ of the participants of the nursing sample and $50 \%$ of the health care staff sample had experienced patient and visitor violence. Verbal violence was the most frequent form of violence experienced during the past 12 months in the nursing sample $(72 \%)$ and in the health care staff sample $(46 \%)$, followed by physical violence (nurses $=42 \%$, health care staff $=17 \%$ ) and threats (nurses $=27 \%$, health care staff $=16 \%)$. In the week prior to data collection, $14 \%$ of participants in the nursing sample and $11 \%$ of health care staff had experienced patient and visitor violence. Also in the past working week, verbal violence was the most prevalent in both samples. In general, patients acted more violently than visitors. 


\section{Risk factors associated with patient and visitor violence}

Question four investigates what the associated risk factors are for patient and visitor violence. In accordance to the study results presented in chapters four, five and six, the main factors associated with patient and visitor violence against health care staff are condensed and become the first model of important factors associated with patient and visitor violence in general hospitals (see Figure 7.1 at page 151).

\section{The characteristics of patients}

The studies revealed the following characteristics that are often concomitantly present in patients with the occurrence of violence: health state of reduced cognitive abilities or impairment, alcohol or illegal drug intoxication or withdrawal, pain, mental or behavioural disorders or disorders of the blood, the haematopoietic or immune system. The importance of these diagnoses for violent behaviour was dependent upon the ward type. The emotional conditions associated with violent behaviour were frustration, dissatisfaction, patients thinking that they were not being taken seriously, anxiety, stress, excessive demands and uncertainty. Consistent with these results, violent patients had deficits in comprehending the situation and the level of information provided was low. The results about violent patients' gender are inconsistent, and the results regarding the age of violent patients shows a broad range with a tendency of being over 65 years of age.

\section{The characteristics of visitors}

According to health care staff, the emotional states of violent visitors were described as: anxious, having excessive demands, insecurity regarding the situation and dissatisfaction with therapy. Also, an important characteristic of violent visitors was having received a low level of information. There was a tendency of violence occurring more among the male gender.

\section{The characteristics of health care staff}

Exposure to violence is different among health care staff professions, with nurses and midwives being the most exposed, and with medical doctors having a significantly lower risk of experiencing violence in comparison to other staff groups. The younger the health care staff, the more they are exposed to patient and visitor violence, particularly to verbal violence. Also, health care staff working with patients over 65 years of age experienced more violence. No significant association was found between violence experienced and gender. The more time staff spent in direct contact with patients, the more they were exposed to violence. Accordingly, staff employed $50 \%$ or more, experienced more violence. Staff working most often with the husband/wife/partner had a higher estimated risk of experiencing physical 
violence, whereas staff working mostly with the visitor group siblings had a higher estimated risk of both physical violence and threats. No significant associations were found between the experiences of violence of staff and the perception of aggression (POAS-S). Similar results were found regarding the perception of support after an incidence. Staff with the perception that aggression is emotionally letting off steam appeared to be less likely to experience threats than staff with the perception that aggression is violent behaviour towards others. Only $16 \%$ of staff had training in aggression management. Staff with training were more at risk to experience violence. In the nursing sample, a positive association was found between nurses' experience with violence and the perceived necessity for training in aggression management. Most of the staff felt confident regarding their verbal intervention skills. Only half of the staff felt confident regarding their physical intervention skills. Medical doctors felt more confident in the handling of verbal aggression than other health care staff, and ward secretaries, medical and radiology assistants felt confident in the handling of physical aggression. Receiving training in aggression management did not significantly influence health care staff's feelings of confidence when dealing with violence.

\section{Consequences}

The emotional impact of patient and visitor violence was moderately upsetting to the participants. Of the participating 1260 health care staff that had experienced patient and visitor violence in the previous 12 months, $2 \%$ needed between one and five days of sick leave and $0.2 \%$ stayed more than one week away from work. Over $13 \%$ of health care staff were slightly physically injured, while approximately $1 \%$ required medical treatment. In almost $4 \%$ of the incidents, health care staffs' glasses or clothing were damaged.

\section{The characteristics of interaction}

The following three main topics concerning patient and visitor violence emerged in the interaction with health care staff: (1) close physical contact in medical, diagnostic and therapeutic interventions, (2) negotiating patients' or visitors' treatment acceptance and (3) providing counselling in difficult situations.

Intervention strategies:

To manage patient and visitor violence, staff used many different short-term interventions. In combination with other interventions, calming and informative discussions were most often used. Leaving the situation, urging the person to stop the behaviour and administration of prescribed medication were frequently used as short-time interventions. Long-term interventions included the use of sedative medication and shielding from precipitating stimuli. Coercive measures encompassed the use of mechanical restraints with belts in bed (waistband, five-pointfixation, or hand/foot fixation), coercive medication and transfer to another ward. 
Patient and visitor violence was most often experienced in emergency rooms, recovery rooms, anaesthesia, intermediate care \& step-down units, intensive care and in rehabilitation units. There seems to be an association between the form of violence experienced and the work environment, with intensive \& intermediate care units having a high level of risk for physical violence and outpatient clinics having a high level of risk for verbal violence.

Only a minority of the participants confirmed that their workplace had an official organisational anti-violence strategy or policy with a formal reporting procedure for violent incidences, and not many had used this system. Violent incidences were reported in the patient documentation. Staff working in workplaces having an official position regarding violence, experienced less incidents and felt more confident. The most common reasons for patient and visitor violence were long waiting times, patients having to endure a number of examinations and tests, enforcement of institutional bans, staff shortages and noise. The relative importance these factors seemed to depend upon the particular workplace.

Overall, the participants rated superiors as being supportive after violent incidences, but it was most often discussed with colleagues and family. 


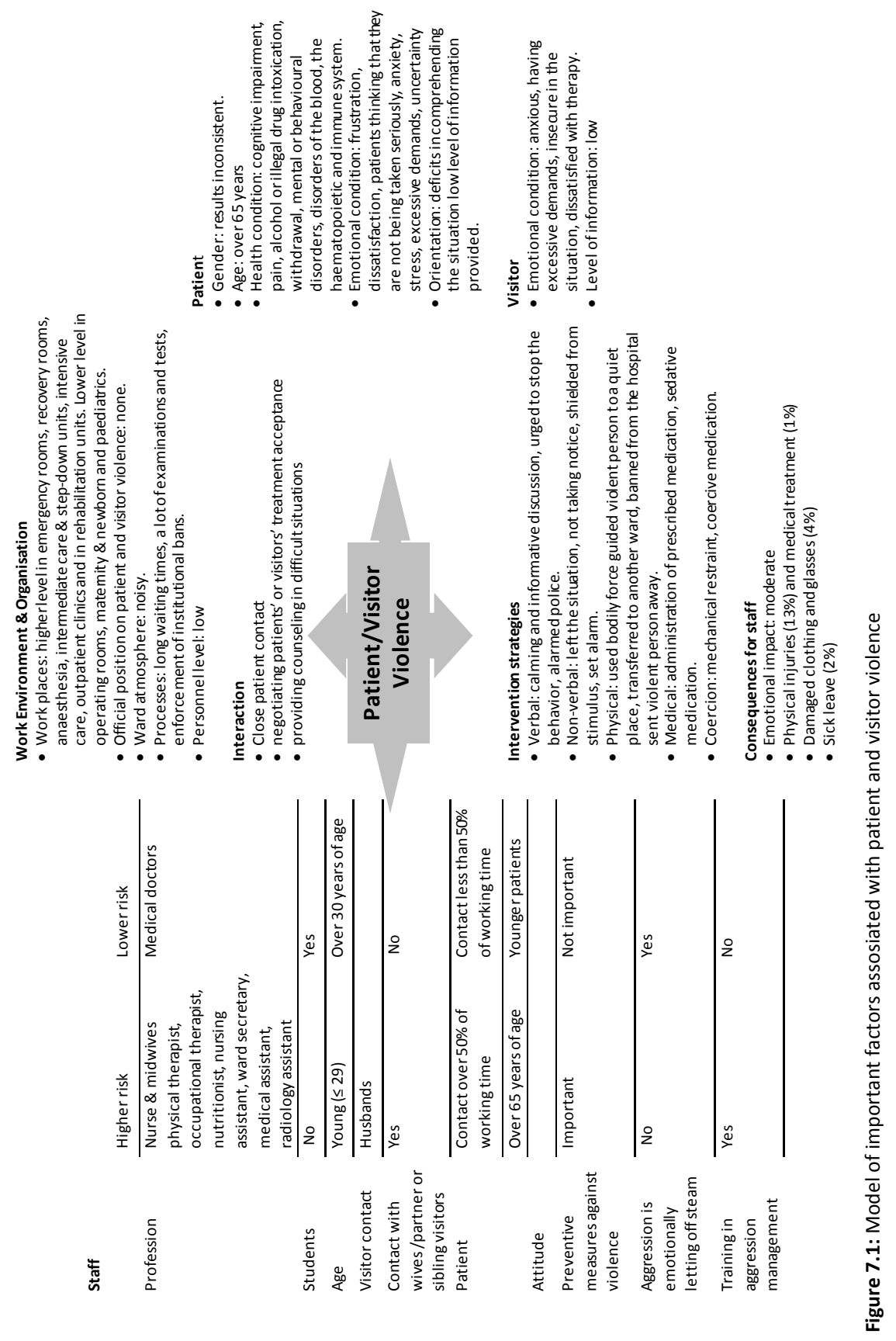




\subsection{METHODOLOGICAL ASPECTS}

The major limitations of the individual studies in this thesis were discussed in the respective chapters.

Strengths of this thesis are the careful translation, reverse translation and pretesting of the SOVES and the testing of the POIS and POAS-S. This assisted in determining if the respondents understood the meaning of the questions in the same way as the researchers. It also improved feasibility which may have led to the high response rate. However, the testing also revealed validity problems of the POAS- $S$ and the POIS, therefore some results regarding attitude have to be interpreted with caution. A further strength is the high response rate and the comparable characteristics of participants with the Swiss workforce in the general hospital setting. This improves transferability of the results to other Swiss general hospital settings.

As previously discussed in chapters five and six, the major limitation is the cross-sectional retrospective design of the studies. Due to this, we cannot determine if the factors associated with patient and visitor violence are the cause or the result of violence and no causal conclusions can be drawn. However, in order to describe a topic and to document important factors in a poorly developed area, the cross-sectional design is important to utilise for the first description. Conducting more rigorous studies is a necessary further step.

The retrospective time frame of 12 months could have lead to recall bias and some contradicting results. However, this time frame is important in order to gain enough data for multiple regression analysis and to compare data internationally. As revealed in chapter two, most studies in the field of patient and visitor violence in the general hospital setting used this 12 month self-assessment time frame.

Further limitations of the study design are the site-specific characteristics of general hospitals in Switzerland. Also, Switzerland has a unique health care system which combines private and compulsory insurance out of pocket, as well as policies and procedures specific for Switzerland. This combination may not be transferable to other countries. However, this problem is a general limitation which all studies face when the study is conducted in a single country. Health care systems are highly variable in regards to insurance systems, organisation, availability of resources, education level of health care staff, etc.. In order to improve international comparability in this complex field of research, it is important and it is a strength of this study, that the theoretical background and the definition of patient and visitor violence is described both carefully and in detail.

Participation may also have been biased by the greater awareness regarding patient and visitor violence with staff more exposed to violence, or by the absence or reporting bias of staff experiencing patient and visitor violence. Exposed staff could have left the workplace or changed professions. Also, the fact that in Switzerland the topic of patient and visitor violence was addressed for the first time in the general hospital setting could have had an effect on the response rate in a positive 
or a negative way. Nevertheless, as previously mentioned, the response rate was high and the participants were reflective of typical health care staff working in Swiss general hospitals. This indicates that no specific group of staff are missing.

Due to the nature of the study design, the characteristics of the health care staff can be examined in detail and all factors can be described from the viewpoint of the staff. The viewpoint of patients and visitors regarding the violent interaction is therefore not included in the study results.

\subsection{DISCUSSION OF THE RESULTS}

\section{Homogenous definition of patient and visitor violence}

As discussed in the first chapter, patient and visitor violence is not defined in a consistent and generally accepted way. This is problematic not only for research, but also for when having professional discussions regarding the problem and when determining interventions. It is also problematic when attempting to improve the reporting behaviour of all health care staff groups (Mayhew \& Chappell 2001). This thesis presents a broad definition based on literature and a working model which emphasises the effects of violence against the assaulted person. It includes all forms of violence. Such a definition seems important as only the assaulted person can judge whether the incident can be considered to be violent or not. The decision about having experienced violence or not remains subjective, because only the effect of the violent incident is critical (feelings of being abused or threatened with physical, verbal and non-verbal assault).

\section{Prevalence and consequences}

The international literature shows a broad range of prevalence of patient and visitor violence against different groups of health care staff in all general wards. As previously discussed, there are very few studies containing data from Continental Europe. The topic is most often investigated in the UK, North America and Australia. Most studies use a cross-sectional design and analyse data in a descriptive way. The results of this thesis reveal that in Switzerland, in the middle of Continental Europe, the prevalence of patient and visitor violence, especially of verbal violence, is high and is comparable with other countries. The lack of studies, including comparable samples from different health care staff, makes comparisons of the present data difficult.

As discussed in the first chapter, investigating prevalence rates among different staff groups, as was done in this thesis, is important for identifying staff at risk. International literature focuses most often on violence against nursing staff. Focusing on the most often investigated staff group could lead to an over estimation of their risk. This is illustrated in chapter six, where multiple regression analysis re- 
vealed that out of all staff groups, only medical doctors had a significantly lower rate of experiencing patient and visitor violence. This thesis revealed that using solely frequencies to describe the risk of violence can lead to inaccuracies. Nurses are at high risk, but not as matter of course, as some international guidelines and studies indicate. Physiotherapists and dieticians also have a high risk for experiencing patient and visitor violence, but these staff groups are seldom investigated (Stubbs et al. 2009).

The theoretical framework of this study describes that personal factors, such as previous experience with patient and visitor violence, can influence the final outcome of a violent situation. Studies investigating the impact of patient and visitor violence on staff outline that this experience can have a very negative influence on psychological and physical health, job satisfaction and intent to leave the profession (Needham et al. 2005, Ryan et al. 2008, Sofield \& Salmond 2003). Overall this leads to negative effects on the quality of care (Arnetz \& Arnetz 2001, Milczarek 2009). The results of this thesis showed a moderate to upsetting emotional impact of patient and visitor violence for the participants. Out of the 2,495 participating health care staff, 164 were slightly physically injured, 17 required medical treatment and 28 took sick leave. A significant result was that staff working at workplaces with an official position experienced less violence and felt more confident. We can therefore conclude that according to the General Aggression Model (GAM), an environment that addresses the topic adequately is important for staffs' feeling of safety. This feeling of safety seems to influence the climate of the workplace, and enables prevention and management of violent incidences to be dealt with in a positive way. It is therefore surprising that the topic is not higher on the priority list among general hospital management, as well as in professional discussions in Switzerland and in other countries (Milczarek 2009). No reliable data was found regarding consumer or third party (patient and visitor) violence in the Swiss Federal Statistics Office, the Swiss Health Observatory or Switzerland's obligatory insurance agency for accidents and occupational diseases (SUVA). Data regarding work-place violence in Switzerland is available in the European Risk Observatory Report (Milczarek 2009). Only 7 out of 22 participating European countries reported an appropriate level of acknowledgement regarding work related third party violence. Compared to the significance of the problem, this seems to be a small quota. According to the European Risk Observatory Report, approximately $10 \%$ of workers in Switzerland are subject to violence or threats of violence. Comparing this prevalence to the prevalence in the data of this thesis, general hospitals have a very high rate of third party violence. As van den Brandth-Gädel (2010) emphasises, personal safety within a company or an institution is a priority management task that is required by law. While it is customary to review, for example, the procedures for fire safety issues and regularly conduct appropriate training, prevention of violence rarely enters into the risk management discussions of companies. Patient and visitor violence also seems to be addressed with a low priority by the Swiss Society of 
Nursing Staff. This organisation developed a new brochure regarding sexual harassment, but the brochure dealing with aggression in the workplace (issued in 1999) was never adapted to reflect new evidence, and is no longer available on the website of the Society (http://www.sbk-asi.ch). Additionally, quality development programs increase their demands for effective and efficient care, but do not consider patient and visitor violence as sign of inadequate resources or staffing or low quality of care (ANQ 2011, Roche et al. 2010). In times of reduced human and financial resources, patient and visitor violence is an unnecessary burden of daily practice (Child \& Mentes 2010, Stokowski 2010). The high response rate of this study and the fact that staff have reported the occurrence of violent incidents in patients' documentation, possibly indicates a change in staffs' attitude. For some staff members, violence in the workplace seems to be no longer acceptable. It therefore seems important that the problem is addressed by hospital management, health care policy and staff, alike.

\section{Factors associated with patient and visitor violence}

This thesis describes a working model that includes important factors associated with patient and visitor violence that are more adequate and specific for the general hospital setting (Figure 7.1). The results describe the situation in the general hospital setting in Switzerland, and provide important information on how to prevent violence and intervene in a suitable way (Figure 7.2). The working model and description of the situation provide useful knowledge for prevention and intervention strategies in clinical practice, and in training courses that are focused on the general hospital setting. The results also provide basic knowledge for further indepth research and illustrate that a complex situation, such as patient and visitor violence, requires complex models and complex prevention and intervention strategies in order to solve the problem. Corresponding with the theoretical background of this thesis, the results point out that the characteristics of the interactions between patient and/or visitors are strongly influenced by the characteristics of the involved persons, the environment and the organisation.

As described in the theoretical background in the first chapter, the characteristics of a person are a significant precondition for the situation, as well as for the individual preparedness for violence in the interaction. The gender of staff did not seem to be a significant personal characteristic, and it revealed contradictory results for patients. The study did however reveal a tendency towards the male gender as a risk factor. According to the GAM (Anderson \& Bushman 2002), males and females differ in violent behaviours. With males, there is a tendency to engage in more direct violence during interactions. This form is perhaps more easily recognisable by staff or is more physically harmful, and therefore could explain the higher prevalence rates of violence seen among males. This aspect also seems to be very 
important from a gender perspective. The majority of health care staff are female. The Swiss Federal Statistic Office presents the most actual data regarding violence in Swiss society. This data determines that women have a five times higher risk of experiencing domestic violence, and that fatal outcomes are 2.5 times higher for women than for men. Victims of crimes are women $73 \%$ of the time, and the perpetrators are men in over $83 \%$ of the cases (http://www.bfs.admin.ch). Therefore, women are at a much higher risk of experiencing violence and crime from men, and women seem to act less violently. Based on the Conceptual Model of Origins of Violence at Work in the Health Care System by Curbow (2002), we can assume that this behaviour in the Swiss society is significant when examining violence in the general hospital setting. There could be a tendency that male patients and visitors behave in a more violent manner, and that female staff carry hurtful experiences from the past with them. This point has to be considered when prevention and intervention strategies are implemented and training techniques are improved.

In contrast to Curbow (2002), the results of this thesis indicate that patients over 65 years of age act more violently than younger patients. Switzerland has one of the highest life expectancies worldwide (Kickbusch et al. 2009). With older age, the prevalence of cardiovascular diseases, cognitive impairment, as well as other health challenges increases, along with the co-morbidity among them (SeematterBagnoud \& Paccaud 2010, Höpflinger \& Hugentobler 2003). The results clearly indicate that cardiovascular disease and dementia are risk factors for violent behaviour. Due to these health problems, it is not surprising that elderly patients often react more violently. These patients could have more problems understanding situations. The cognitive model of patient aggression by Winstanley (2005) illustrates what happens if someone does not understand or is not adequately informed and supported when attempting to comprehend a situation. The theoretical background of this thesis and other models of patient and visitor violence, do not adequately consider the increasing influence of this problem with the interaction in the technological environment of a general hospital setting. Prevention measures in the interaction should be tailored for this age group and for their potentially reduced cognitive abilities.

According to the GAM, "input variables influence the final outcome behaviour through the present internal state that they create" (Anderson 2000 p. 38). Cardiovascular conditions and diseases of the immune system are related to stress (Bhattacharyya \& Steptoe 2007, Steptoe et al. 2007, Yoichi \& Steptoe 2010). The accessibility of internal stress reactions and the fact that hospitalisation does not automatically reduce predisposition for stress could lead to violent reactions in this patient group. However, as described in the GAM, the fact of the disease itself and its symptoms could increase anxiety about personal health and survival for all patients and their families, which could then increase the stress or reaction patterns. All negative feelings such as stress and anxiety correspond to the models presented in the theoretical background, especially to the GAM and the Cognitive Model of 
Patient Aggression. Patients and visitors need orientation in an environment that is difficult for them to understand (as discussed in chapters four and five). Staff require the competence to assess anger, frustration, anxiety, stress and disorientation. Adequate communication skills and empathetic and consumer friendly attitudes are very important in reducing negative feelings and in improving security and trust. Close observation, use of plain language and constant patient and visitor information which is consistent among all professionals, is essential in these situations. Due to the fact that anxiety provoking behaviour is directly associated with staff action or inaction, staff must identify the patients' information needs in order to avoid negative emotions. As discussed in chapter five, the responsibility that staff have enough resources to optimally perform, lies mainly with hospital management.

It seems obvious that the more time health care staff spend in direct contact with patients the more situations occur which could lead to patient and visitor violence (Gascon et al. 2009). The results of chapter five show that medical doctors have less patient contact than physical therapists, occupational therapists, dieticians, nurses and midwives. This could then be the reason for their significantly lower risk of experiencing violence in comparison to other staff groups. However, over $48 \%$ of medical doctors also have experienced violence. Along with staff's frequency and duration of patient and visitor contact, their level of work experience, which relates to the competency and security in which professional tasks are carried out, could also be an influencing factor in the experiencing of violent incidences. The occurrence of violence may be related to the inability of younger staff to simultaneously accomplish the technically correct professional activity, maintain informative communication, and supervise the patient's situation in regards to emotional care needs (Shields \& Wilkins 2009).

In accordance to international literature, this thesis reveals that there is a moderate level of visitor violence. Visitors are the second most frequent assaulters of physical violence (Campbell et al. 2011). A new result is that those most at risk for physical violence were staff who were interacting with husbands and wives, partners or sibling visitors. Staff working most often with the sibling visitor group, have a higher estimated risk of threats. There was no literature found to explain this result.

As discussed in the literature and in earlier chapters, the attitude of health care staff can influence their experience and perception of patient and visitor violence. Utilising the POAS-S, no such significant association was found. A reason for this result could be the moderate validity of the POAS-S, as discussed in chapter three. Staff's attitude about the reason for the violent behaviour could influence their management strategy (Duxbury \& Whittington 2005, Hahn et al. 2006). The results of this study revealed for the first time, that staff with the perception that aggression is emotionally letting off steam, and those rating preventive measures as being 
less important, appear to be less likely to experience violence. It can be assumed, that during the interaction, staff with this perception take violence less personally (immediate appraisal) and therefore rate it as being less important. This is a speculation, but with more information regarding this interesting result, further improvement of the management of violence could be reached.

Furthermore, the results of this thesis point out that training is not necessarily correlated with a decrease in the occurrence of patient and visitor violence. Reasons for this result are discussed in chapters five and six. However, training could re-enforce prevention and coping strategies (Oostrom \& van Mierlo 2008). The results of this thesis emphasise that prevention depends upon communication and information skills, as well as on competencies in the assessment and reduction of anxiety. Therefore, even though staff feel confident regarding their verbal intervention skills, the main content of training should focus on communication strategies (Azoulay et al. 2000, Siassakos et al. 2011) and continual reflection (Chapman et al. 2010). As shown by Chapman et al. (2010), staff modify their experiences with patient violence in order to improve adaptation to these difficult situations. Chapman et al. (2010) also identified the following three cognitive processes: finding meaning, gaining mastery and self-enhancement. Self-enhancement boosts selfesteem. Staff compare their own skills with the competencies of their colleagues (downward comparison) and rate their own as superior to others. This strategy can, however, negatively influence critical thinking and learning about the situation. Chapman et al. (2010) therefore recommend revision and continual reflection of violent experiences in order to reframe them and achieve self-enhancement and self-protection.

The theoretical background, the results and the discussion all stress that patient and visitor violence is an interactional problem in which anxiety and information needs seem to play a crucial role. However, the actual scenarios in which the violence occurs is not described in the theoretical background. This study does, however, provide an initial idea about the most dangerous situations in the general hospital setting. Violence emerged (1) in close physical contact in medical, diagnostic and therapeutic interventions, (2) when staff were negotiating patients' or visitors' treatment acceptance and (3) when providing counselling in difficult situations. This information is important in order to improve prevention and management strategies, and could be used as a basis when developing exercises to use in standardized patients situations (Hahn \& Metzenthin 2010). A standardized patient situation is role playing performed by an actor or actress in the learning setting of the skills lab. The role of the patient is enacted in a standardized way, which means that the same script is performed for each student. The actors behave like real patients in real situations. Students learn, in a protected situation, how to assess anxiety, how to de-escalate potentially violent situations or what behavior is most suitable when they are in danger of violence. The actors are both patients and teachers at the same time. Also, reflection of the learning situation from the per- 
spective of the patients, is very important in this learning method. The actor or actress provides feedback to the students in order to facilitate this. Furthermore, the results of this study illustrate that not only the professional acting or not acting can be interpreted as violent, but also the intervention strategies used to deal with the violence could be seen as violent (for example leaving the situation, or especially with the use of coercive measures) (Görgen et al. 2007). The appropriateness of these interventions is discussed in chapter five.

In summary, the results outline that the interaction between the involved persons is strongly influenced by communication and by personal, environmental and organisational factors. The information provided from these results is very relevant in regards to the prevention and intervention of patient and visitor violence. Figure 7.2 illustrates SAVEinH, a Model of Strategies Addressing ViolencE in Hospitals. It summarises the implications for the prevention and intervention of patient and visitor violence based on the relevant factors found in this thesis. 


\section{Community/neighbourhood}

Professional organisations for health care staff need to consider:

- Violence as topic of priority.

- Provide adequate further education.

- Provide information strategies for politics, community and professionals.
Politics needs to consider:

- Violence in health care as topic of priority.

- Provide data (prevalence, forms, etc.).

- Security law and health insurance should address violence at work.

\section{General hospitals}

Hospitals need safety management programs including:

- Organizational attitude inclusive definition.

- Quality measures and quality development programs (ward atmosphere, processes, personal level).

- Guidelines and standards including reporting and counseling.

- Interdisciplinary training in violence prevention and management including topics such as anxiety and stress assessment and intervention, communication, especially with cognitively impaired and elderly patients and visitors, team work with two person approach.

- Public information about the topic.

\section{Situation}

Staff interactions needing more attention:

- In a highly technological environment

- In outpatient clinics

- In situation with close patient contact

- In situation involving young and/or inexperienced staff.

- Involving female staff.

- About characteristics of patients and visitor involved when:

o Caring for older adults over 65 years.

o Patients' physical condition is connected with consequences of stress, anxiety and/or pain.

o Patients' cognitive condition leading to reduced capacity to orientation about the situation

o Patients' and/orvisitors' emotional condition leading to frustration, dissatisfaction, anxiety, stress

- When negotiating patients' or visitors' treatment acceptance.

- When providing counseling in difficult situations.

Staff skills needing to include knowledge about:

- The information needs and processing of patients and visitors.

- Assessing anger, frustration, anxiety, stress, disorientation and adequate intervention.

- Communication skills to act as a agent of personal safety and understanding.

- Careful reflection of (potential) violent situation.

- How to take violence not personally.

Figure 7.2: SAVEinH, a Model of Strategies Addressing ViolencE in Hospitals 


\subsection{IMPLICATIONS FOR HEALTH CARE STAFF AND CLINICAL PRACTICE}

The study results clearly demonstrate that management in Swiss general hospitals must, much more carefully and thoroughly, consider patient and visitor violence as a workplace hazard that has significant consequences for staff and patients alike. If staff shortages, personal safety responsibilities and issues regarding quality of care are taken seriously by hospital management, then patient and visitor violence is one topic that is long overdue to be also taken seriously and considered a priority. When addressing patient and visitor violence a broad definition seems to be appropriate, in which the assaulted staff decides whether or not violence was experienced, and which intervention and reporting procedures are suitable.

The study revealed some important factors associated with patient and visitor violence for clinical practice. Organisations need to develop and implement hospital wide official anti-violence strategy policies, including a corporate definition of patient and visitor violence, guidelines, standards, reporting procedures and measures necessary for controlling and supporting violent incidences. Staff also need to recognise the significant factors that influence patient and visitor violence, including how their interactions can influence an interaction in a negative or a violent way.

The model developed in this thesis can assist in the reflection of ward specific risk situations. Utilising this model, incidences or interactions with a higher risk could be described and knowledge regarding the risk factors improved. This can then increase the understanding of violent incidences and reveal information for adequate prevention and intervention strategies. Risk factors that staff must discuss are patients' ages and health states in relation to risk of violence, and the tendency of male patients to behave more violently. Special attention is required regarding the necessary exchange of information with patient and visitors. This reflection has to critically assess if the needs of those with cognitive impairment or of elderly patients are met by staff. The information, communication and safety needs in a stressful situation have to be adequately addressed. For this process, staff require supervision from experts in order to avoid down comparison, such as described by Chapman et al (2010). These preventive care processes have to be routinely implemented in daily practice, and for this to occur, the support of management and the interdisciplinary team is important.

The results of this study point out that staff with a lot of patient contact and younger staff need more support. It is important not to stigmatise staff because they experience more violence. If there are persons experiencing a lot of violence, perhaps a two person approach such as discussed in chapter five, would be useful. However, for staff in clinical practice, it is of the upmost of importance that the acceptance of patient and visitor violence by hospital administrators and by society 
comes to an end. If hospitals are safer for staff they will be also safer for patients. Unnecessary costs will also then be avoided.

Research results regarding training programs for patient and visitor violence indicate that modules need to provide basic knowledge about anxiety and stress prevention, communication and information strategies. Focused modules for specific staff groups, workplaces and interdisciplinary teamwork are useful. As discussed in chapter five, new approaches with two persons and resilience strategies (not taking violent behaviour personally) have to be considered for the general hospital setting. This does increases the complexity in the development of curricula for violence prevention and management. The development and teaching of such focused training is more ambitious and requires particular experience in the specific field of practice. This means that trainers also need specialised knowledge for communication, prevention, de-escalation and management of patient and visitor violence in the different fields of practice. The results of this thesis provide important information for a revision in the curricula of staff training. Training has to be tailored to the workplace of the participants and to their specific risk factors. The development of these curricula and training courses require significant resources. Therefore, training programs should be carefully implemented and evaluated (Anderson et al. 2010, Nau et al. 2010).

For practice, the thesis demonstrated that the theoretical background of the GAM, Corbows' model and the cognitive model of patient aggression towards health care staff, combined with the research results, improve the understanding of patient and visitor violence in general hospitals. However, the results and the discussion also illustrate that the relevant models for clinical practice in the general hospital setting need to better address the interaction (verbal and non verbal) between staff and patient/visitor as well as the influencing environmental characteristics.

\subsection{IMPLICATIONS FOR RESEARCH}

The focus on the survey design and on the nurses in investigating patient and visitor violence in the general hospital setting is important in order to describe the prevalence of the problem, and the factors associated with patient and visitor violence. As described, focusing on certain staff groups can lead to an over estimation of the risk for these groups. In practice, interdisciplinary teams treat patients. Patient and visitor violence therefore occurs in the interdisciplinary treatment setting. Further studies should investigate, in more detail, the factors proposed in the working model of this thesis in the interdisciplinary context. Also ward setting specific investigations are important because the results show relevant differences between different ward types. The use of incidence measurements, including all health care staff groups and different ward types, improves the description of important risk factors. The working model developed in this study builds a reference 
framework to adapt research instruments used in psychiatric care, such as the Attempted and Actual Assault Scale (Attacks) (Bowers et al. 2007) and the Staff Observation Scale (Nijman et al. 2005), to the specific ward settings in general hospitals. It is however important that future research conduct studies that provide a higher confidence level for causal inference using longitudinal or intervention designs. The model developed in this thesis presents a robust background for hypothesis based research.

This thesis also revealed further interesting topics for research. One of those is the influence of staffs' attitudes in the experience of violence. Research on resiliency in health care staff against patient and visitor violence, could investigate how one's attitude could assist in coping with these emotionally and physically incriminatory situations and give new insight for prevention and management of them. Also, the effect of earlier experiences of violence and the management of patient and visitor violence in general hospitals, needs more attention. Until presently, the development and evaluation of training did not include all involved parties.

In general, the results of this thesis support research for describing the correlation between the complex factors associated with visitor and patient violence and the occurrence of violent situations. As emphasised by Hegney et al. (2010), Hills (2008) and Paterson et al. (2005), such research is important because it leads to improvement of the information. Up until presently, strategies have had limited success because they have considered neither the work environment nor the context in which strategies have been implemented. As the perspective of the patient/visitor involved is almost nonexistent in research regarding patient and visitor violence, it also should be included in future research. Until this occurs, models will not be comprehensive. 


\subsection{REFERENCES}

Anderson CA (2000) Violence and Aggression. In Encyclopedia of Psychology (Kazding AE ed.). Oxford University Press and the American Psychological Association, New York \& Washington D.D.

Anderson CA \& Bushman BJ (2002): Human aggression. Annual Review of Psychology 53, $27-51$.

Anderson L, FitzGerald M \& Luck L (2010): An integrative literature review of interventions to reduce violence against emergency department nurses. J Clin Nurs 19, 2520-2530.

ANQ (2011) Nationaler Qualitätsvertrag (Nationaler Verein für Qualitätsentwicklung in Spitälern und Kliniken ed.). ANQ, Bern, pp. 1-25.

Arnetz JE \& Arnetz BB (2001): Violence towards health care staff and possible effects on the quality of patient care. Social Science and Medicine 52, 417-427.

Azoulay E, Chevret S, Leleu G, Pochard F, Barboteu M, Adrie C, Canoui P, Le Gall JR \& Schlemmer B (2000): Half the families of intensive care unit patients experience inadequate communication with physicians. Critical Care Medicine 28, 3044-3049.

Bhattacharyya MR \& Steptoe A (2007): Emotional triggers of acute coronary syndromes: strength of evidence, biological processes, and clinical implications. Prog Cardiovasc Dis 49, 353-365.

Bjorkly S (2006) Psychological Theories of Aggression: Principles and Application to Practice. In Violence in Mental Health Settings (Richer D \& Whittington R eds.). Springer Science and Business Media, LLC, New York, pp. 27-46.

Bowers L, Nijman H \& Palmstierna T (2007): The Attempted and Actual Assault Scale (Attacks). International Journal of Methods Psychiatric Research 16, 171-176.

Campbell JC, Messing JT, Kub J, Agnew J, Fitzgerald S, Fowler B, Sheridan D, Lindauer C, Deaton J \& Bolyard R (2011): Workplace violence: prevalence and risk factors in the safe at work study. American College of Occupational and Environmental Medicine 53, 82-89.

Chapman R, Styles I, Perry L \& Combs S (2010): Nurses' experience of adjusting to workplace violence: a theory of adaptation. International Journal of Mental Health Nursing 19, 186-194.

Child RJ \& Mentes JC (2010): Violence Against Women: The Phenomenon of Workplace Violence Against Nurses. Issues in Mental Health Nursing 31, 89-95.

Curbow B (2002) Origins of violence at work. In Workplace violence in the health sector. State of the Art (Cooper CL \& Swanson N eds.). International Labour Office, International Council of Nurses, World Health Organization and Public Service International, Geneva, pp. 35-48.

Duxbury J \& Whittington R (2005): Causes and management of patient aggression and violence: staff and patient perspectives. Journal of Advanced Nursing 50, 469-478.

Gascon S, Casalod Y, Jarreta BM, Abecia E, Luna A, Carceles MD, Santed MA, Gonzalez-Andrade F \& Bolea M (2009): Aggressions against healthcare workers: an approach to the situation in Spain and the victims psychological effects. Legal Medicine (Tokyo) 11 Suppl 1, S366-367.

Görgen T, Rabold S \& Herbst S (2007) Ist die Hand, die pflegt, auch die Hand, die schlägt? KFNMaterialien für die Praxis Nr. 4. Kriminologisches Forschungsinstitut Hannover.

Hahn S \& Metzenthin P (2010) Patient Violence in the General Hospital Setting; a Challange for Prevention and De-escalation Techniques. In Evidence, Efficacy, Economics \& Ethics: The Challenges Facing Management of Aggression Training in the 21st Century. European Network for Training in the Management of Aggression. (Van Engelen Y, Paterson P \& McKenna K eds.). Drukkerij Schaap \& Zandvliet, Duivendrecht., Amsterdam.

Hahn S, Needham I, Abderhalden C, Duxbury JAD \& Halfens RJG (2006): The effect of a training course on mental health nurses' attitudes on the reasons of patient aggression and its management. Journal of Mental Health and Psychiatric Nursing 13, 197-204.

Hegney D, Tuckett A, Parker D \& Eley RM (2010): Workplace violence: differences in perceptions of nursing work between those exposed and those not exposed: a cross-sector analysis. Int J Nurs Pract 16, 188-202. 
Hills D (2008): Relationships between aggression management training, perceived self-efficacy and rural general hospital nurses' experiences of patient aggression. Contemp Nurse 31, 20-31.

Höpflinger F \& Hugentobler V (2003) Pflegebedüftigkeit in der Schweiz - Prognosen und Szenarien für das 21. Jahrhundert. Hans Huber, Bern.

ILO ICN WHO PSI (2003) Workplace Violence in the Health Sector: Country Case Studies Research Instruments Survey Questionnaire (English). Joint Programme on Workplace Violence in the Health Sector. ILO/ICN/WHO/PSI, Geneva, pp. 1-14.

Kickbusch I, Ospelt-Niepelt R \& Seematter L (2009) Gesundheit in der Schweiz. In Nationaler Gesundheitsbericht 2008. Buchreihe des Schweizerischen Gesundheitsobservatoriums (Meyer K ed.). Hans Huber, Bern.

Mayhew C \& Chappell D (2001) Occupational violence: types, reporting patterns, and variations between health sectors. In Working paper series / University of New South Wales, School of Industrial Relations and Organisational Behaviour. School of Industrial Relations, University of New South Wales, Sydney, NSW, p. 20 leaves.

McKenna K (2004) Study of work-related violence. Committee on Workplace Violence, North Eastern Health Board, Ireland, pp. 1-121.

Milczarek M (2009) Workplace Violence and Harassment: a European Picture. European Agency for Safety and Health at Work, EU-OSHA, Luxembourg.

Morrison E (1990): Violent psychiatric inpatients in a public hospital. Scholarly Inquiry for Nursing Practice 4, 65-82.

Nau J, Halfens R, Needham I \& Dassen T (2010): Student nurses' de-escalation of patient aggression: a pretest-posttest intervention study. Int J Nurs Stud 47, 699-708.

Needham I, Abderhalden C, Halfens RJ, Fischer JE \& Dassen T (2005): Non-somatic effects of patient aggression on nurses: a systematic review. Journal of Advanced Nursing 49, 283-296.

Nijman HL, Palmstierna T, Almvik R \& Stolker JJ (2005): Fifteen years of research with the Staff Observation Aggression Scale: a review. Acta Psychiatrica Scandinavica 111, 12-21.

Oostrom JK \& van Mierlo $\mathrm{H}$ (2008): An evaluation of an aggression management training program to cope with workplace violence in the healthcare sector. Research in Nursing \& Health 31, 320-328.

Paterson B, Leadbetter D \& Miller G (2005): Beyond Zero Tolerance: a varied approach to workplace violence. Br J Nurs 14, 810-815.

Qiu C, De Ronchi D \& Fratiglioni L (2007): The epidemiology of the dementias: an update. Current Opinion in Psychiatry 20, 380-385.

Roche M, Diers D, Duffield C \& Catling-Paull C (2010): Violence Toward Nurses, the Work Environment, and Patient Outcomes. Journal of Nursing Scholarship 42, 13-22.

Ryan EP, Aaron J, Burnette ML, Warren J, Burket R \& Aaron T (2008): Emotional responses of staff to assault in a pediatric state hospital. Journal of the American Academy of Psychiatry and the Law 36, 360-368.

Seematter-Bagnoud L \& Paccaud F (2010) The Future of Longevitiy in Switzerland: Background and Perspectives. Centre hospitalier universitaire vaudois, Département universitaire de médecine et de santé communautaires, Institut universitaire de médecine sociale et préventive Lausanne, Lausanne.

Shields M \& Wilkins K (2009): Factors related to on-the-job abuse of nurses by patients. Health Reports 20, 7-19.

Siassakos D, Bristowe K, Hambly H, Angouri J, Crofts JF, Winter C, Hunt LP \& Draycott TJ (2011): Team communication with patient actors: findings from a multisite simulation study. Simul Healthc 6 , 143-149.

Sofield L \& Salmond SW (2003): Workplace violence. A focus on verbal abuse and intent to leave the organization. Orthopaedic Nursing 22, 274-283.

Steptoe A, Hamer M \& Chida Y (2007): The effects of acute psychological stress on circulating inflammatory factors in humans: a review and meta-analysis. Brain Behav Immun 21, 901-912. 
Stokowski LA (2010) Violence: Not in My Job Description. www.medscape.com.

Stubbs B, Winstanley S, Alderman N \& Birkett-Swan L (2009): The risk of assault to physiotherapists: beyond zero tolerance? Physiotherapy 95, 134-139.

van den Brandt-Grädel V (2010): Prävention von interpersoneller Gewalt am Arbeitsplatz. Personensicherheit als Managementaufgabe. Mensch \& Arbeit 10, 59-61.

Winstanley S (2005): Cognitive model of patient aggression towards health care staff: The patient's perspective. Work \& Stress 19, 340-350.

Wiskow C (2003) Guidelines on Workplace Violence in the Health Sector. In Joint Programme on Workplace Violence in the Health Sector (ILO/ICN/WHO/PSI ed.). ILO/ICN/WHO/PSI, Geneva.

Yoichi C \& Steptoe A (2010): Greater Cardiovascular Responses to Laboratory Mental Stress Are Associated With Poor Subsequent Cardiovascular Risk Status : A Meta-Analysis of Prospective Evidence. Hypertension 55, 1026-1032:. 


\section{CHAPTER EIGHT}

\section{Summary}

Studies revealed that the health care sector constitutes almost a quarter of all incidences of violence in the workplace. Are general hospitals no longer safe places for patients and health care staff? Violence is seen as an important workplace hazard for health care staff by the World Health Organization as well as by international labour and nursing organisations. In many countries various governmental initiatives (legislation, zero tolerance policies) and organisational strategies (policies/procedures, environmental aspects, staff training) have been implemented. Regrettably, the work environment or the context in which the strategies were implemented, have not been considered carefully enough, and research suggests that these strategies were only partially successful. Additionally, violence in the health care setting is often seen as part of the job and has therefore been inadequately addressed. In the climate of a declining health care workforce, reduced financial resources and strong efforts for patient safety, it is now more than ever, important to adequately address workplace violence.

Most frequently, mental health settings and emergency units were investigated and this data was then transferred to the general hospital setting. Also, prevention and intervention strategies are based mostly upon mixed knowledge from psychiatric and emergency care. It is questionable how transferable this knowledge is to specific settings without consideration of the context or local work climate. A comprehensive description of the problem in the general hospital is lacking, and little is yet known about the detailed factors associated with patient and visitor violence in general hospital wards. Presently, in Switzerland and in other German speaking countries, there are virtually no initiatives that have been taken against workplace violence in the general hospital setting. Therefore, this dissertation addresses the topic of patient and visitor violence against healthcare staff on general wards in the general hospital setting. It investigates different health care staffs' experiences in order to describe the extent of patient and visitor violence and the factors associated with the problem. This knowledge is important for the improvement of guidelines and for prevention and intervention strategies at the staff and at the organisational level.

Research in the field of violence is hindered due to varying definitions of violence, as well as many domain-limited theories about human aggression. Therefore, in this dissertation, the following definition is used: Workplace violence refers to incidents in which health care staff are abused, threatened or assaulted in workrelated circumstances. Patient and visitor violence has various forms and is defined as any verbal, non-verbal or physical behaviour that threatens or is harmful to others or their property. In this thesis the General Aggression Model (GAM), the Model 
of Origins on Violence at Work in the Health Sector and the Cognitive Model of Patient Aggression towards Health Care Staff in the General Hospital Setting, are used as the theoretical background to assist in considering an event of violence as a complex interplay of different factors.

Due to lack of knowledge regarding patient and visitor violence in the general hospital setting, a literature review was conducted. In chapter two of this thesis, the state of current scientific knowledge on this topic is summarised for the first time. This literature review addressed the first and second questions of the thesis. The first question investigated the important factors as described in the international research according to patient and visitor violence against health care staff in the general hospital setting. The second question examined instruments used in describing patient and visitor violence against health care staff in the general hospital setting and how valid and reliable the German versions of these instruments were. After an extensive search in electronic databases in Medline, Cochrane Library, Cumulative Index to Nursing and Allied Health, 84 studies were identified. Following application of the exclusion criteria, the literature was reduced to 41 publications. In order to improve the quality of the review, two researchers independently critically appraised these studies. Thirty-one studies with good or moderate research quality were then selected for further analysis. In most studies, a retrospective self reported cross-sectional design and a broad definition of violence were employed. Usually the questionnaires applied were developed by the researchers and different retrospective time frames were utilised. No questionnaire in the German language was found, and information regarding the validity of the questionnaires were often lacking. The most frequently investigated group were nursing staff. There were rarely studies that included a variety health care staff groups. The results of the review confirmed that patient and visitor violence is a serious problem for all health care staff in the general hospital setting. According to the study results, nurses and staff working in medical and surgical units experienced the highest level of violence. Also, the results revealed that the workplace characteristics and the interaction between patients and staff, are important contextual factors associated with violent incidents. Due to the fact that the included studies employed different methodologies, instruments, and definitions, comparison of the studies was difficult. For future research, the use of a clear conceptual framework and unique instruments are recommended. Based on the results, a first working model on patient and visitor violence was developed.

In chapter three, the presented study addresses the second research question of this thesis regarding the validity and reliability of instruments in the German language. The first instrument used was the SOVES German Version Revised (SOVES-G$\mathrm{R})$. It is a survey instrument based on the Irish version which investigates workplace violence, and which collects data on the involved health care staff, patients and 
visitors as well as on the workplace environment. The feasibility of the SOVES-G-R after translation and modification was investigated. The second instrument was the 12 items shortened Perception of Aggression Scale (POAS-S). According to prevention and intervention strategies used in aggression management, the perception of aggression is an influential factor and should therefore be measured as characteristic of health care staff. As the third instrument, the Perception of Importance of Intervention Skills Scale (POIS) was used. This nine item scale was developed by the research team in order to measure the perception of common prevention and intervention strategies as characteristics of health care staff. After adaptation for use in a general hospital setting, these instruments were validated. In-between November 2006 and January 2007, 291 nurses working in general hospitals in the German-speaking region of Switzerland completed the SOVES-G-R, the POAS-S and the POIS (response rate $=71 \%$ ). The participants' responses revealed that modifications to enhance the feasibility of the SOVES-G-R were necessary in two categories, namely experiences with patient and visitor violence in 'the past 12 months' and in 'the past working week'. The POAS-S revealed the same factor solution as in earlier studies, with two factors explaining $38.0 \%$ of the variance. In the POIS, the following two factors were distinguished: (1) structured interventions and evaluation and (2) the importance of preventive measures. These two factors together explained $44.3 \%$ of the total variance. The SOVES-G-R presented in this study is the first validated self-administered German language questionnaire that captures patient and visitor violence in general hospitals. It shows a good feasibility and allows clinical practitioners to understand the questions appropriately. The study results showed that the SOVES-G-R, the POIS and the POAS-S can be used to monitor nurses' experiences or reflect patient and visitor violence in the specific setting of general hospitals. These instruments are now available and generate comparable data both in English and in German, and allow for data comparison between these linguistic areas. However, for a more adequate investigation of the perception of aggression and the perception of intervention strategies, the items of the POAS-S and POIS should be carefully revised.

Chapter four presents the topics of the third, fourth and fifth research questions to a sample of nursing staff. The aim was to explore nurses' experiences with patient and visitor violence, as well as other related factors, in Swiss general hospital settings. Nursing, in general, experiences the highest rate of patient and visitor violence compared to other health care staff. Previous studies have only partially described these factors in the general hospital setting. Mainland European general hospital settings are even less well researched. A retrospective cross-sectional survey was conducted in 2007, and included 291 nurses working in different clinical departments in general hospitals. The questionnaires used were the SOVES-G-R, the POAS-S and the POIS. These study results described, for the first time in Switzerland, that in the past 12 months, $72 \%$ of nurses had experienced verbal patient 
and visitor violence, and $42 \%$ physical patient and visitor violence. It revealed that $23 \%$ were physically injured and $1.4 \%$ took one or more days of sick leave. Patient and visitor violence was distressing for the nursing staff. A higher risk of patient and visitor violence was observed with registered nurses when caring for anxious or cognitively impaired patients, for rehabilitation units with longer-term nursepatient/nurse-relative interactions and for workplaces with an absence of formal procedures for patient and visitor violence. The results indicate that in general hospitals there is a serious workplace problem for nurses, and it is not restricted to high risk areas such as emergency and psychiatric wards. Patient and visitor violence appears to be influenced mainly by the type of interaction and situation. The results showed that nursing elderly and cognitively impaired patients whom are suffering from anxiety or prone to anger, is a challenging situation for nurses. Adequate intervention strategies need to be competently and professionally implemented. Further research should follow up on these findings in order to further improve knowledge about these complex situations.

The study results presented in chapter five focus on the experiences of healthcare staff in regards to patient and visitor violence in the general hospital setting. This study addressed question three, which investigated the prevalence of patient and visitor violence, and question five, which inquired about the support received following patient and visitor violence and the consequences for involved staff. The study also answered question six, which explored health care staffs' interventions for patient and visitor violence and staff's confidence in managing violent situations. Therefore, this study addressed the lack of knowledge concerning factors which influence the occurrence of patient and visitor violence against health care staff. Intervention strategies and consequences of patient and visitor violence are rarely investigated, because the existing studies often focus on nurses' experiences and single interactive factors between the staff and patients/visitors involved. In accordance to the research questions, a cross-sectional survey was conducted in 2007 including 2495 staff (from a total of 4845 health care staff members) working on different wards in a Swiss university general hospital. The questionnaire analysed was the SOVES G-R. The results revealed that half of the staff experienced patient and visitor violence in the past 12 months and $11 \%$ in the past week. Health care staff are at high risk for verbal patient and visitor violence. The staffs age and length of experience in their present workplace influenced their exposure to patient and visitor violence. Violence occurred mainly when staff carried out tasks involving close personal contact. Only $16 \%$ of the staff had training in aggression management. The feeling of confidence in managing patient and visitor violence depended significantly upon the organisational attitude towards violence. The principal interventions used were calming and informative discussion. In order to improve prevention and management strategies and to reduce the prevalence of patient and visitor violence, staff require appropriate training. This training should 
encompass communication skills, appropriate management of patient and visitor violence and must be situation specific. Health care staff in general hospitals are confronted with patient and visitor violence, however they must continue to provide patient centred care and empathic interaction. The results of this study indicate that a strong organisational commitment is imperative in order to reduce patient and visitor violence and to eliminate barriers in the reporting of violent incidences. In order to ensure a safe workplace, management should consider personal safety as priority, as it is also a requirement by law. Future research should more thoroughly describe the genesis of patient and visitor violence, and include all the risk factors recognised as important with large samples which would allow sophisticated statistical analyses.

Chapter six focuses on research question four, which addresses the risk factors for health care staff associated with patient and visitor violence in the general hospital setting. The retrospective cross-sectional survey conducted in 2007, included 2495 health care staff who were employed in a general hospital setting. The data was collected via questionnaires using the SOVES G-R, the POAS-S and the POIS. Descriptive statistics and multiple logistic regression analyses were used. This study revealed that the risk factors for experiencing patient and visitor violence depended upon the form of violence experienced. Those staff with training in aggression management and/or those working predominantly with patients over 65 years of age, experienced twice as much patient and visitor violence as others. Staff working in emergency rooms, outpatient units, intensive care units, recovery room, anesthesia, intermediate care and step-down units also experienced violence more often. When staff were older in age, were from the medical profession or were students, or/and when they had an attitude that rated preventive measures as being less important and aggression as emotionally letting off steam, they were less likely to experience patient and visitor violence. Verbal and non-verbal communication strategies emerged as significant competencies in the prevention and de-escalation of violent situations. In order to improve training in aggression management, verbal and non-verbal communication strategies should be a leading topic, especially for younger staff. In order to create safer situations, a two staff members approach in the handling of difficult situations could be considered for the general hospital setting. Both the reflection of attitudes and feelings regarding patient and visitor violence, as well as the professional tasks/roles, need to be considered when identifying personal risk behaviour, or the potential risk in a situation. This study also illustrates that the perspective of the patient/visitor involved is lacking in the discussion and conclusions regarding risk factors of patient and visitor violence. Therefore, current models reflect only one side of the view of the involved parties. It is recommended that future research incorporate qualitative approaches such as Grounded Theory, in order to investigate the entire interaction leading up to violence. More information is needed regarding the consequences 
and impact of patient and visitor violence on health care staff, the quality of care and the intent to leave the workplace or the profession.

Chapter seven describes the main factors that are associated with patient and visitor violence and the methodological aspects of the study. The core of this chapter encompasses the general discussion of the study results and the consequences for clinical practice and research. The risk factors associated with patient and visitor violence are described in detail for patient (age, health conditions, emotional conditions, orientations in a situation) and visitor (emotional condition and information level). The staff characteristics (profession, age, visitor contact, patient contact, attitude), the characteristics of the interaction (close contact, negotiation, counselling) and the work environment and organisation (workplaces, official position, ward atmosphere, processes) are also described. The methodological aspects reveal that the strength of this thesis is the selection and preparation (translation, reverse translation, pretesting) of the SOVES and the testing of POAS-S and POIS. The high response rate and the comparable characteristics of participants within the Swiss workforce is a further strength. The major limitation is the cross-sectional retrospective design of the study which allows no causal conclusions and which contains a risk for recall bias. The discussion highlights that the prevalence rate has to be investigated and should include a variety of minority staff groups, in order not to overestimate the risk for the most investigated staff groups such as nurses. According to the theoretical background and to the study results, strong institutional policies and procedures against patient and visitor violence are important in order to increase staff's feeling of safety and in order to reduce the frequency of patient and visitor violence. Therefore, it is disturbing that the topic is not higher on the priority list of general hospital management or in professional discussions in Switzerland and in other countries. The characteristics of persons involved in violent incidences are important regarding the outcome of the situation. The study results remain inconsistent in the drawing of conclusions regarding the gender of violent patients. However, the gender aspect is important, as women are much more often victims of crime and domestic violence than men are. This societal factor could also influence the interaction in the general hospital setting between male patients and female health care staff. An important influencing factor for patient violence is the prevalence of cardiovascular diseases and cognitive impairment. The negative impact of stress on interactions requires attention. Patients and visitor alike can suffer from a lot of stressors (health state, unknown environment and processes, unclear future, anxiety) which can then negatively influence the interaction. Adequate communication skills and empathetic and consumer friendly attitudes are most important in these interactions, in order to reduce negative feelings, to improve security and trust. Health care staff need to anticipate the key information needs of patients and visitors. The results also revealed that the staff's attitude influenced the experience of violence. It could be assumed that in the 
interaction, staff which rated aggression as letting off steam took the violence less personally and rated it therefore as less important. Staff with training did experience a high level of patient and visitor violence. For training in violence management a modular system might be useful, including knowledge about anxiety and stress prevention and communication and information strategies. Focused modules for specific staff groups, workplaces and interdisciplinary teamwork would also be beneficial. Training programs should be carefully implemented and evaluated. There is a need for reflection of the quality of the work environment and its influence on the psychological state of patients.

In general, the theoretical background and study results lead to a framework which provides important information regarding prevention of patient and visitor violence and intervention strategies. The framework supports research in describing the correlation between the complex factors associated with patient and visitor violence and the occurrence of violent situations. Such research is important because it leads to information which can improve the strategies that have been up until present unsuccessful, because they consider neither the work environment nor the context in which the strategies have been implemented. As the perspective of the patient/visitor involved is almost nonexistent in research regarding patient and visitor violence, it is essential that it be included in future research. With inclusion of the patients' and visitors' perspectives, this framework would then become more comprehensive. 



\section{Samenvatting}

Wetenschappelijk onderzoek onthult, dat geweld binnen de gezondheidszorgsector in vergelijking met andere sectoren bijna een vierde van alle geweld op de werkvloer omvat. Zijn ziekenhuizen daardoor niet langer veilige oorden, noch voor de patiënten noch voor het zorgpersoneel?. Geweld wordt zowel door de wereldgezondheidsorganisatie als door internationale werkgeversorganisaties en verpleegkundige beroepsorganisaties als een belangrijk gevaar voor het gezondheidspersoneel op de werkvloer gezien. In vele landen werden bestuurlijke initiatieven (wetgeving, zerotolerantiebeleid) en organisatorische strategieën (beleid, omgevingsaspecten, training van het personeel) geïmplementeerd. Helaas werd te weinig zorgvuldig rekening gehouden met de werkomgeving of de context waarin deze strategieën ingevoerd werden. Wetenschappelijk onderzoek geeft aanwijzingen dat deze strategieën slechts een gedeeltelijk succes kenden. Meer nog, geweld in de gezondheidssector wordt vaak als een bestanddeel van de baan gezien en ten gevolge daarvan ontoereikend gethematiseerd. In het licht van de toenemende schaarste bij het zorgpersoneel, de afnemende financiële middelen en sterke inspanningen voor de veiligheid van de patiënten, is het nu meer als ooit tevoren belangrijk om het thema geweld op de werkvloer adequaat aan te gaan.

Tot dusver werden meestal onderzoeken in de geestelijke gezondheidszorg en de spoedeisende hulp doorgevoerd en deze informatie werd op de algemene ziekenhuizen overgedragen. Ook strategieën ter preventie en interventie baseren meestal op een gemengde kennis uit de psychiatrische zorg en de spoedeisende hulp. Hier stelt zich de vraag in hoeverre deze kennis uit specifieke settings overdraagbaar is zonder rekening te houden met de context of het lokale werkklimaat. Een uitgebreide beschrijving van het probleem in algemene ziekenhuizen ontbreekt en er is weinig geweten over de specifieke factoren die met geweld door patiënten en bezoekers op algemene afdelingen in ziekenhuizen in verband gebracht kunnen worden. Voor het ogenblik zijn er noch in Zwitserland noch in de andere Duitstalige landen initiatieven tegen geweld op de werkvloer in algemene ziekenhuizen. Daarom thematiseert deze dissertatie het thema van geweld door patiënten en bezoekers ten opzichte van gezondheidspersoneel op algemene afdelingen in algemene ziekenhuizen. De ervaringen van verschillende beroepsgroepen binnen het gezondheidspersoneel worden onderzocht om zodoende de omvang van geweld door patiënten en bezoekers en de daarmee samenhangende factoren te beschrijven. Deze kennis is belangrijk voor de verbetering van richtlijnen, de strategieën ter preventie en interventie op het niveau van het personeel en de organisatie. 
Het onderzoek op het gebied van geweld wordt enerzijds bemoeilijkt door de verschillende definities van geweld en anderzijds door de vele stromingen binnen het vakgebied betreffend de theorieën over menselijke agressie. Daarom wordt in deze dissertatie de volgende definitie gebruikt: Geweld op de werkvloer verwijst naar voorvallen waarbij zorgpersoneel wordt lastig gevallen, bedreigd of aangevallen in werk gerelateerde omstandigheden. Geweld door patiënten en bezoekers kent verschillende vormen en wordt als elke vorm van verbaal, non-verbaal of fysiek gedrag dat bedreigt of andere personen of hun eigendommen beschadigt, gedefinieerd. In deze thesis worden het General Aggression Model (GAM), het Model of Origins on Violence at Work in the Health Sector en het Cognitive Model of Patient Aggression towards Health Care Staff in the General Hospital Setting als theoretische achtergrond gebruikt om een voorval van geweld als een complex samenspel van verschillende factoren te kunnen beschouwen.

Wegens het gemis aan kennis met betrekking tot geweld van patiënten en bezoekers in algemene ziekenhuizen werd een literatuurstudie doorgevoerd. In hoofdstuk twee van deze thesis is voor de eerste keer de stand van de wetenschappelijke kennis betreffende dit onderwerp samengevat. De literatuurstudie behandelt de eerste en tweede onderzoeksvraag van deze thesis. De eerste vraag onderzocht belangrijke factoren met betrekking tot geweld door patiënten en bezoekers in algemene ziekenhuizen in het internationale wetenschappelijk onderzoek. De tweede vraag onderzocht instrumenten die in de beschrijving van geweld door patiënten en bezoekers ten opzichte van zorgpersoneel in algemene ziekenhuizen gebruikt worden alsook hoe valide en consistent de Duitstalige versies van deze instrumenten zijn. Na een breedvoerige zoektocht in de elektronische databanken Med-line, Cochrane Library, Cumulative Index to Nursing and Allied Health werden 84 onderzoeken geïdentificeerd. Aan de hand van de exclusiecriteria werd de literatuur tot 42 publicaties gereduceerd. Om de kwaliteit van het literatuuroverzicht te verbeteren, hebben twee onderzoekers deze studies onafhankelijk van elkaar kritisch beoordeeld. Eenendertig onderzoeken met een goede tot moderate onderzoekskwaliteit werden voor verdere analyse geselecteerd. In de meeste onderzoeken werd een retrospectief dwarsdoorsnedeonderzoek en een brede definitie van geweld toegepast Doorgaans werden de gebruikte vragenlijsten door de onderzoekers ontwikkeld en werden verschillende retrospectieve tijdvensters gebruikt. Er werd geen enkele vragenlijst in het Duits geïdentificeerd en informatie betreffende de validiteit van de vragenlijsten ontbrak vaak. De beroepsgroep die het vaakst onderzocht werd omvatte verpleegkundigen. Onderzoeken die meerdere groepen van het zorgpersoneel insloten waren zelden. De resultaten van het literatuuroverzicht bevestigden dat geweld door patiënten en bezoekers een ernstig probleem is voor zorgpersoneel in algemene ziekenhuizen. Volgens deze gegevens ervaren verpleegkundigen en personeel van de afdelingen interne geneeskunde en chirurgie het hoogste peil van geweld. De resultaten onthulden tevens dat kenmerken van de werkplaats en de interactie tussen de patiënten en het perso- 
neel belangrijke contextfactoren, geassocieerd met geweldvoorvallen zijn. Omwille van het feit dat de ingesloten studies verschillende methodologie, instrumenten en definities benut hebben, is een vergelijking van de studies moeilijk. Voor verder onderzoek worden de aanwending van een helder conceptueel referentiekader en één instrument aanbevolen. Op basis van deze resultaten werd een eerste conceptueel arbeidsmodel met betrekking tot geweld door patiënten en bezoekers ontwikkeld.

De in hoofdstuk drie voorgestelde studie behandelt de tweede onderzoeksvraag van deze thesis met betrekking tot de validiteit en consistentie van de Duitstalige instrumenten. De SOVES German Version Revised (SOVES- G-R) was het eerste instrument dat gebruikt werd. Dit is een op de lerse versie gebaseerde vragenlijst, die geweld op de werkvloer onderzoekt en zowel gegevens over het betrokken zorgpersoneel, de patiënten en bezoekers als ook over de werkomgeving verzamelt. De haalbaarheid van de SOVES-G-R na vertaling en modificatie werd onderzocht. Het tweede instrument was de verkorte versie van de Perception of Aggression Scale (POAS-S) met 12 items. Volgens strategieën ter preventie en interventie, die in het agressiemanagement gebruikt worden, is de waarneming van agressie een beïnvloedende factor die als kenmerk bij het zorgpersoneel gemeten moet worden. Als derde instrument werd de Perception of Importance of Intervention Skills Scale (POIS) gebruikt. Deze scala met 9 items werd ten behoeve van de meting van de algemene strategieën ter preventie en interventie als kenmerk van het zorgpersoneel door het onderzoeksteam ontwikkeld. Na de aanpassing voor het gebruik in algemene ziekenhuizen, werden deze instrumenten gevalideerd. Tussen november 2006 en januari 2007 vulden 291 verpleegkundigen in algemene ziekenhuizen in het Duitssprekende deel van Zwitserland de SOVES-G-R, de POAS-S en de POIS in (response $=71 \%$ ). De antwoorden van de deelnemers maakten kenbaar dat ter verbetering van de haalbaarheid modificaties voor de SOVES-G-R in twee categorieën nodig waren, namelijk betreffend de ervaringen met geweld van patiënten en bezoekers "in de laatste 12 maanden" en in "de voorbije werkweek". Bij de POAS-S zijn dezelfde factoren ontstaan als in vroegere onderzoeken, waarbij twee factoren $38.0 \%$ van de variantie verklaarden. In de POIS werden de volgende twee factoren onderscheiden: (1) gestructureerde interventies en evaluatie en (2) het belang van preventieve maatregelen. De in deze studie voorgestelde SOVES-G-R is de eerste gevalideerde vragenlijst in het Duits om zelf in te vullen, die geweld door patiënten en ziekenhuizen capteert. Ze vertoont een goede haalbaarheid en veroorlooft de klinische praktijk de vragen op een juiste manier te verstaan. De resultaten van het onderzoek tonen aan dat de SOVES-G-R, de POIS en de POAS-S gebruikt kunnen worden om de ervaringen van verpleegkundigen te monitoren of geweld door patiënten en bezoekers in algemene ziekenhuizen te reflecteren. Deze instrumenten zijn nu beschikbaar en genereren vergelijkbare gegevens zowel in het Engels als in het Duits en maken daardoor een vergelijking tussen deze taalgebieden mogelijk. Hoe dan ook, voor een meer adequaat onderzoek naar de waarne- 
ming van agressie en de waarneming van strategieën ter interventie moeten de items van de POAS-S en de POIS zorgvuldig gerevideerd worden.

Hoofdstuk vier behandelt de onderwerpen van de derde, vierde en vijfde onderzoeksvraag in een steekproef met verpleegkundigen. Deze studie had tot doel de ervaringen van verpleegkundigen met geweld door patiënten en bezoekers en daarmee samenhangende factoren in Zwitserse algemene ziekenhuizen te onderzoeken. Over het algemeen vertonen verpleegkundigen in vergelijking met andere groepen binnen het zorgpersoneel de hoogste proportie van geweld door patiënten en bezoekers. Vroegere onderzoeken hebben de beïnvloedende factoren binnen de algemene ziekenhuizen slechts gedeeltelijk beschreven. Op het Europese vasteland is de setting van de algemene ziekenhuizen zelfs nog minder goed onderzocht. In 2007 werd een retrospectief dwarsdoorsnedeonderzoek uitgevoerd waaraan 291 verpleegkundigen uit verschillende departementen in algemene ziekenhuizen deelnamen. Daartoe werden de vragenlijsten SOVES-G-R, de POAS-S en de POIS gebruikt. Deze onderzoeksresultaten beschrijven voor de eerste keer in Zwitserland, dat $72 \%$ der verpleegkundigen verbaal geweld door patiënten en bezoekers alsook $42 \%$ fysiek geweld door patiënten en bezoekers ervoeren. Ook werd aangetoond dat $23 \%$ fysieke letsels verkreeg en $1.4 \%$ der verpleegkundigen één of meer dagen ziekteverzuim had. Geweld door patiënten en bezoekers werd door het verpleegkundig personeel als belastend ervaren. Er werd een hoger risico voor geweld door patiënten en bezoekers geobserveerd bij gegradueerde verpleegkundigen bij de verzorging van angstige of cognitief beperkte patiënten, op revalidatieafdelingen met langdurige relaties tussen verpleegkundigen en patiënten en familieleden en voor werkomgevingen zonder formele protocollen voor geweld door patiënten en bezoekers. De resultaten geven aan dat er voor verpleegkundigen in algemene ziekenhuizen een ernstig probleem in hun werkomgeving bestaat. Zodoende is dit probleem niet tot sectoren met een hoog risico zoals de afdelingen spoedeisende hulp en psychiatrie beperkt. Geweld door patiënten en bezoekers lijkt hoofdzakelijk door de soort van interactie en de situatie zelf beïnvloed te worden. De resultaten tonen aan dat het verplegen van oudere en cognitief beperkte patiënten die angst hebben of tot woedeaanvallen neigen uitdagende situaties zijn voor verpleegkundigen. Aangepaste strategieën ter interventie moeten geschikt en professioneel geïmplementeerd worden. Verder onderzoek moet deze bevindingen opvolgen om de kennis over deze complexe situaties verder te verbeteren.

De in hoofdstuk vijf voorgestelde onderzoeksresultaten concentreren zich op de ervaringen van het zorgpersoneel in verband met geweld door patiënten en bezoekers in de context van de algemene ziekenhuizen. Dit onderzoek behandelt vraag drie, waarin de prevalentie van geweld door patiënten en bezoekers onderzocht wordt alsook vraag vijf. Deze exploreerde de verleende ondersteuning en de gevolgen voor het betreffende personeel na een voorval van geweld door patiënten en bezoekers. De studie gaf ook een antwoord op vraag zes, die de door zorgpersoneel gebruikte interventies bij geweld door patiënten en bezoekers en het 
vertrouwen van het personeel in de handhaving van geweldsituaties onderzoekt. Zodoende behandelt deze studie het gebrek aan kennis over de beïnvloedende factoren bij het ontstaan van geweld ten opzichte van zorgpersoneel door patiënten en bezoekers. Strategieën ter interventie en de gevolgen van geweld door patienten en bezoekers zijn zelden onderzocht, aangezien bestaande studies zich vaak op ervaringen van verpleegkundigen en alleenstaande interactieve factoren tussen het betreffende personeel en de patiënten/bezoekers concentreren. In overeenstemming met de onderzoeksvragen, werd 2007 een dwarsdoorsnedeonderzoek uitgevoerd waaraan 2495 personeelsleden (van in totaal 4845 leden van het zorgpersoneel) werkzaam op verschillende verpleegeenheden in een Zwitsers algemeen universitair ziekenhuis deelnamen. De vragenlijst die geanalyseerd werd, was de SOVES G-R. De resultaten onthulden dat de helft van het personeel in de laatste twee weken en $11 \%$ in de voorbije week geweld door patiënten en bezoekers ervaren hebben. Het zorgpersoneel loopt een groot risico voor verbaal geweld door patiënten en bezoekers. De leeftijd en de duur van de beroepservaring op de actuele werkplek beïnvloedden hun blootstelling aan geweld door patiënten en bezoekers. Geweld kwam vooral voor als het personeel taken uitvoerde die een eng persoonlijk contact vereisten. Enkel $16 \%$ van het zorgpersoneel had een training in agressiemanagement. Het gevoel van vertrouwen in het managen van geweld door patiënten en bezoekers was significant afhankelijk van de attitude van de organisatie ten opzichte van geweld. Hoofdzakelijk werden kalmeren en een informatieve discussie als interventies ingezet. Met het oog op de verbetering van preventieve en management-strategieën en om de prevalentie van geweld door patiënten en bezoekers te reduceren, is er nood aan een aangepaste training voor het personeel. Deze training zou communicatievaardigheden en een aangepast management van geweld door patiënten en bezoekers moeten integreren en op specifieke situaties uitgericht moeten zijn. Zorgpersoneel in algemene ziekenhuizen wordt met geweld door patiënten en bezoekers geconfronteerd, maar moet toch doorgaan met het verlenen van patiëntgerichte zorg en empathische interacties. De resultaten van dit onderzoek geven aan dat een sterk commitment op het niveau van de organisatie noodzakelijk is om geweld door patiënten en bezoekers te reduceren en om hinderpalen in de rapportage van voorvallen van geweld te elimineren. Om een veilige werkomgeving te kunnen verzekeren, zou het management de veiligheid van het personeel als een absolute prioriteit moeten beschouwen, zoals het ook een vereiste van de wetgeving is. Toekomstig onderzoek zou het ontstaan van geweld door patiënten en bezoekers nog gefundeerder kunnen beschrijven. Daarbij zouden alle geïdentificeerde risicofactoren met grote steekproeven, die gesofisticeerde statistieke analysen toelaten, ingesloten moeten worden.

Hoofdstuk zes concentreert zich op onderzoeksvraag vier, die de risicofactoren voor geweld door patiënten en bezoekers voor zorgpersoneel in de context van een algemeen ziekenhuis behandelt. De gegevens werden met de vragenlijsten the SOVES G-R, the POAS-S and the POIS verzameld. Descriptieve statistiek en multiple 
logistische regressieve analyse werden ingezet. Dit onderzoek onthulde, dat de risicofactoren voor het ervaren van geweld door patiënten en bezoekers van de vorm van de beleefde geweldsituatie afhankelijk was. Personeelsleden met een opleiding in agressiemanagement en/of personeelsleden die overwegend met patiënten ouder dan 65 jaar werkten, ervoeren dubbel zoveel geweld door patiënten en bezoekers als andere. Personeel tewerkgesteld in de spoedeisende hulp, op ambulante verpleegeenheden, op de intensieve zorg, de intermediate care en de verkoeverkamer ervoeren eveneens vaker geweld. Oudere personeelsleden, leden van de medische staf of studenten en/of indien deze vanuit hun attitude preventieve maatregelen als niet belangrijk en agressie als een mogelijkheid om stoom af te late, inschatten leken minder geneigd om geweld door patiënten en bezoekers te ervaren. Verbale en non-verbale communicatie ontpopten zich als significante competenties bij de preventie en de de-escalatie van gewelddadige situaties. Om de opleiding in agressiemanagement te verbeteren, zouden verbale en non-verbale communicatiestrategieën een speerpunt moeten zijn, in het bijzonder voor jonge personeelsleden. Om veiligere situaties te scheppen zou een aanpak door twee personeelsleden in de afhandeling van moeilijke situaties in algemene ziekenhuizen overwogen moeten worden. Zowel de reflectie van attitudes en gevoelens ten opzichte van geweld door patiënten en bezoekers, alsook de professionele opdrachten/rollen moeten bedacht worden bij de identificatie van risicogedrag door het personeel of de identificatie van potentiele risico's in een situatie. Dit onderzoek illustreert ook dat het perspectief van de patiënt/bezoeker in de discussie en de conclusies omtrent de risicofactoren van geweld door patiënten en bezoekers volledig ontbreekt. Zodoende weerspiegelen de actuele modellen enkel één kant van de zichtwijze van de betrokken partijen. Voor verder onderzoek wordt het gebruik van kwalitatieve methoden, zoals Grounded Theory, aanbevolen om zodoende de interacties die tot geweld kunnen leiden gefundeerder te kunnen onderzoeken. $\mathrm{Er}$ is een noodzaak aan betere informatie over de consequenties en de uitwerking van het geweld door patiënten en bezoekers op het gezondheidspersoneel, de kwaliteit van de zorg en het voornemen om de werkomgeving of het beroep te verlaten.

Hoofdstuk zeven beschrijft de voornaamste factoren die met geweld door bezoekers en patiënten geassocieerd worden alsook de methodologische aspecten van het onderzoek. De kern van die hoofdstuk omvat de algemene discussie van de onderzoeksresultaten en de consequenties voor de klinische zorg en voor de wetenschap. De met geweld door patiënten en bezoekers geassocieerde risicofactoren worden gedetailleerd beschreven voor patiënten (leeftijd, gezondheidstoestand, emotionele toestand, oriëntatie in een situatie) en bezoekers (emotionele toestand en informatiestand). De kenmerken van het personeel (beroep, leeftijd, contact met bezoekers, attitude), de kenmerken van de interactie (eng contact, onderhandeling, advies) en de werkomgeving en de organisatie (werkplaats, officiële positie, atmosfeer op de afdeling, procedures) worden eveneens beschreven. De 
methodologische aspecten onthullen dat de selectie en de voorbereiding (vertaling, terugvertaling, pretest) van de SOVES en de test van de POAS-S en POIS een sterkte van deze thesis uitmaken. De hoge respons en de vergelijkbare kenmerken van de deelnemers binnen de Zwitserse beroepsbevolking is eveneens een sterkte. De grootste beperking is de onderzoeksopzet als retrospectief dwarsdoorsnedeonderzoek, dat geen causale conclusies toelaat en een risico voor een vertekening van de herinnering inhoudt. De discussie benadrukt dat de prevalentie onderzocht moet worden en een brede waaier van kleine personeelsgroepen zou moeten insluiten teneinde een overschatting van het risico van de best onderzochte beroepsgroep, zoals verpleegkundigen te vermijden. In overeenstemming met de theoretische achtergrond en de onderzoeksresultaten zijn een krachtig institutioneel beleid en procedures tegen geweld door patiënten en bezoekers belangrijk om het veiligheidsgevoel bij het personeel te verhogen en de frequentie van het geweld door patiënten en bezoekers te reduceren. Derhalve is het zorgwekkend dat dit thema niet hoger op de prioriteitenlijst staat van het management in algemene ziekenhuizen of in de professionele discussie in Zwitserland en in andere landen. De kenmerken van in voorvallen van geweld verwikkelde personen zijn van groot belang met betrekking tot de uitkomst van deze situaties. De resultaten blijven inconsistent bij het omlijnen van conclusies in betrekking met het geslacht van gewelddadige patienten. Hoe dan ook, het aspect van het geslacht is belangrijk omdat vrouwen vaker als mannen het slachtoffer van misdaden en huiselijk geweld zijn. Deze maatschappelijke factor zou ook een invloed kunnen hebben op de interactie tussen mannelijke patiënten en het vrouwelijke zorgpersoneel in algemene ziekenhuizen. Een beïnvloedende factor voor geweld door patiënten is de aanwezigheid van cardiovasculaire ziekten en cognitieve beperkingen. De negatieve impact van stress op interacties verdient enige aandacht. Zowel patiënten als bezoekers ondergaan vele stressoren (gezondheidstoestand, onbekende omgeving en procedures, onduidelijke toekomst, angst) die de interactie negatief kunnen beïnvloeden. Geschikte communicatievaardigheden en een empathische, cliëntgerichte attitude zijn bij deze interacties van groot belang om zodoende negatieve gevoelens te reduceren, de veiligheid en het vertrouwen te verhogen. Het gezondheidspersoneel dient de elementaire informatiebehoeften van patiënten en bezoekers te anticiperen. De resultaten geven tevens aan dat de attitude van het personeel de ervaring van geweld beïnvloedt. Er kan aangenomen worden dat binnen de interactie personeelsleden die agressie als een manier om stoom af te laten taxeerden, de voorvallen van geweld minder persoonlijk namen en deze daardoor als minder belangrijk inschatten. Personeel met training ervoer een hoog peil van geweld door patiënten en bezoekers. Voor de training in het management van geweld zou een modulair system met daarin kennis over angst, stresspreventie en communicatieve en informatieve strategieën nuttig kunnen zijn. Gefocusseerde modules voor specifieke personeelsgroepen, werkplaatsen en interdisciplinaire teams zouden eveneens een hulp kunnen zijn. Trainingsprogramma's moeten zorgvuldig worden geïmplemen- 
teerd en geëvalueerd. Er is nood aan de reflectie van de kwaliteit van de werkomgeving en haar invloed op de psychologische status van de patiënten. Over het algemeen leiden de theoretische achtergrond en de onderzoeksresultaten naar een referentiekader met belangrijke informatie met betrekking tot de preventie van geweld door bezoekers en patiënten en strategieën ter interventie. Dit referentiekader ondersteunt wetenschappelijk onderzoek bij het beschrijven van de correlatie tussen de complexe factoren die met geweld door patiënten en bezoekers en voorvallen van gewelddadige situaties geassocieerd worden. Zulk onderzoek is van hoog belang omdat ze tot informatie kunnen voeren die de tot op heden niet succesvolle strategieën zouden kunnen verbeteren, omdat deze noch met de werkomgeving noch met de context waarin deze strategieën geïmplementeerd werden rekening houden. Omdat het perspectief van de betreffende patiënt/bezoeker bijna niet voorkomt in onderzoek met betrekking tot geweld door patiënten en bezoekers is het van essentieel belang dat deze in toekomstig onderzoek ingesloten wordt. Door de inclusie van de perspectieven van patiënten en bezoekers zou dit referentiekader daardoor veelomvattender worden. 


\section{Zusammenfassung}

Internationale Studien zeigen auf, dass im Vergleich mit anderen Bereichen im Gesundheitswesen fast ein Viertel aller Gewalt am Arbeitsplatz generiert wird. Sind Spitäler für Patienten wie auch für Gesundheitsfachpersonen daher keine sicheren Orte mehr? Die Weltgesundheitsorganisation, die Internationale Arbeiter- und Angestelltenvereinigung sowie die Internationale Vereinigung der Pflegefachpersonen sehen Gewalt am Arbeitsplatz für Gesundheitsfachpersonen als grösste Gefahr bei der Arbeit. In vielen Ländern wurden daher verschiedene staatliche Initiativen ergriffen (Gesetzgebung, Null-Toleranz-Politik) und Organisationsstrategien implementiert (Richtlinien, Vorgehensweisen, Umgebungssicherheit, Mitarbeitendenschulung). Bedauerlicherweise wurden spezifische Aspekte des Arbeitsplatzes oder der Kontext, in dem die Strategien umgesetzt werden, nicht sorgfältig genug betrachtet. Untersuchungen dieser Strategien zeigen auf, dass sie daher nur teilweise erfolgreich waren. Darüber hinaus wird Gewalt im Gesundheitswesen durch das Personal oft als „zum Arbeitsalltag gehörig“ und als „normal“ angesehen und deshalb häufig nicht ernst genommen bzw. zu wenig in der Sicherheitsstrategie der Institution berücksichtigt. Angesichts der Probleme der immer knapper werdenden Ressourcen im Gesundheitswesen und des drohenden weltweiten Personalnotstands sowie der vermehrten Anstrengungen im Risikomanagement, ist es mehr denn je wichtig, angemessen auf Gewalt am Arbeitsplatz zu reagieren.

Am häufigsten wurde Gewalt im Gesundheitswesen in der psychiatrischen Gesundheitsversorgung und im Notfallbereich erforscht. Diese Daten sowie daraus generierte Präventions- und Interventionsstrategien wurden auf das Allgemeinkrankenhaus transferiert. Es ist fraglich, wie übertragbar das so generierte Wissen auf das spezifische Setting des Allgemeinkrankenhauses ist, ohne Berücksichtigung des spezifischen Kontexts oder des lokalen Arbeitsklimas. Eine umfassende Beschreibung des Problems für das Allgemeinkrankenhaus fehlt bis heute. Über die Faktoren im Zusammenhang mit Patienten- und Besuchergewalt auf den verschiedenen Stationen im Allgemeinkrankenhaus ist daher wenig bekannt. Zurzeit gibt es in der Schweiz und in anderen deutschsprachigen Ländern kaum Initiativen gegen Gewalt am Arbeitsplatz im Allgemeinkrankenhaus. Daher behandelt diese Dissertation das Thema Patienten- und Besuchergewalt auf den verschiedenen Abteilungen im Allgemeinkrankenhaus. Die Arbeit untersucht die Erfahrung verschiedener Gesundheitsfachpersonen mit Patienten- und Besuchergewalt, um das Ausmass dieser Gewalt und die Faktoren, die mit dem Problem verbunden sind, aus der Sicht der Gesundheitsfachpersonen zu beschreiben. Dieses Wissen ist für die Verbesserung von Richt- und Leitlinien sowie für Präventions- und Interventionsstrategien 
im Umgang mit Gewaltereignissen auf Ebene der Mitarbeitenden und auf Ebene der Organisation wichtig.

Die Forschung im Bereich der Gewalt wird beeinträchtigt aufgrund unterschiedlicher Definitionen von Gewalt und der verschiedenen, auf unterschiedliche Wissenschaftsbereiche limitierten, Theorien über die menschliche Aggression. Daher ist für jedes Forschungsprojekt eine klare Definition zum Thema Gewalt wichtig. In dieser Dissertation wird die folgende Definition verwendet: Gewalt am Arbeitsplatz bezieht sich auf Vorfälle, bei denen Gesundheitsfachpersonen in arbeitsbezogenen Situationen misshandelt, bedroht oder angegriffen werden. Patienten- und Besuchergewalt hat vielfältige Formen; dazu gehören jedes verbale, nonverbale oder physische Verhalten, das bedrohend oder schädlich für andere oder deren Eigentum ist. In dieser Arbeit werden das "General Aggression Model“ (GAM), das "Model of Origins on Violence at Work in the Health Sector" und das "Cognitive Model of Patient Aggression towards Health Care Staff in the General Hospital Setting" als theoretischer Hintergrund verwendet. Basierend auf diesem theoretischen Hintergrund wird ein Gewaltereignis als ein komplexes Zusammenspiel von verschiedenen Faktoren betrachtet.

Aufgrund der Wissenslücke zu Patienten- und Besuchergewalt im Allgemeinkrankenhaus wurde eine systematische Literaturrecherche durchgeführt. Im zweiten Kapitel dieser Arbeit ist der Stand der aktuellen wissenschaftlichen Erkenntnisse zum Thema erstmals zusammengefasst. Die Literaturstudie bezieht sich auf die erste und die zweite Fragestellung dieser Dissertation. Die erste Frage befasst sich mit den wichtigsten Faktoren, welche die internationale Forschung bezüglich $\mathrm{Pa}$ tienten- und Besuchergewalt gegen Gesundheitsfachpersonen im Allgemeinkrankenhaus beschreibt. Die zweite Frage bezieht sich auf vorhandene Instrumente, welche Patienten- und Besuchergewalt gegen Gesundheitsfachpersonen im Allgemeinkrankenhaus beschreiben und wie valide und reliabel die deutschsprachigen Versionen dieser Instrumente sind. In einer umfangreichen Suche in den elektronischen Datenbanken „Medline“, der „Cochrane Library“ und dem „Cumulative Index to Nursing and Allied Health“ wurden 84 Studien identifiziert. Nach Anwendung der Ausschlusskriterien verblieben 41 Publikationen zur vertieften Analyse. Zur Verbesserung der Qualität der Literaturstudie wurden diese Studien von zwei Forscherinnen unabhängig voneinander kritisch beurteilt. 31 Studien mit mittlerer bis guter Studienqualität wurden aufgrund dieser Beurteilung zur weiteren Analyse ausgewählt. Die Mehrheit dieser 31 Studien verwenden ein retrospektives Querschnittdesign und eine breite Definition von Gewalt. Meist wurden die verwendeten Erhebungsbogen von den Forschenden selbst entwickelt und bezogen sich auf unterschiedliche retrospektive Zeiträume. Es konnte kein Fragebogen in deutscher Sprache ermittelt werden und zudem fehlten meist die Beschreibungen zur Güte der Erhebungsinstrumente in den analysierten Manuskripten. Die am häufigsten untersuchte Berufsgruppe war das Pflegepersonal und Studien, welche verschiedene Gruppen von Gesundheitsfachpersonen einschlossen, waren selten. Die Ergebnisse 
der Literaturstudie bestätigen, dass Patienten- und Besuchergewalt ein ernstes Problem für alle Gesundheitsfachpersonen im Allgemeinkrankenhaus ist. Gemäss den Studienergebnissen, erleben Pflegfachpersonen und Mitarbeitende von medizinischen und chirurgischen Stationen am meisten Gewalt. Auch zeigen die Ergebnisse auf, dass die Eigenschaften des Arbeitsplatzes und die Interaktion zwischen Patienten und Personal wichtige, kontextuelle Faktoren im Zusammenhang mit gewalttätigen Zwischenfällen sind. Aufgrund der unterschiedlichen Methoden, Instrumente und Definitionen, welche die eingeschlossenen Studien verwenden, ist der Vergleich zwischen den Studienresultaten erschwert. Für weitere Forschung wird daher die Verwendung eines klaren konzeptionellen Bezugsrahmens und einheitlicher Instrumente empfohlen. Basierend auf den Ergebnissen wurde ein erstes Arbeitsmodell zu Patienten- und Besuchergewalt entwickelt.

Die im dritten Kapitel beschriebene Studie befasst sich ebenfalls mit der zweiten Forschungsfrage dieser Arbeit zur Gültigkeit und Zuverlässigkeit der deutschsprachigen Untersuchungsinstrumente. Das erste verwendete Instrument, die „Umfrage zu Gewalterfahrungen von Gesundheitsfachpersonen“ (Survey of Violence Experienced by Staff (German version revised, SOVES-G-R) basiert auf der irischen Originalversion, welche Gewalt am Arbeitsplatz untersucht. Der Fragebogen sammelt Daten über die am Gewaltereignis beteiligten Gesundheitsfachperson, des Patienten/der Patientin und des Besuchers/der Besucherin sowie über das Arbeitsumfeld. Die Studie untersucht die Anwendbarkeit des Fragebogens SOVES-G-R nach der Übersetzung ins Deutsche und ergänzt durch einzelne Anpassungen. Das zweite verwendete Instrument war die auf 12 Items gekürzt Version der „Perception of Aggression Scale“ (POAS-S). Die persönliche Einstellung gegenüber Aggression ist ein Einflussfaktor darauf, welche Präventions- und Interventionsstrategien im Aggressionsmanagement verwendet werden und sollte daher als Charakteristik der Gesundheitsfachpersonen gemessen werden. Als drittes Instrument wurde die „Skala der Einstellung gegenüber der Wichtigkeit von Interventionen und Fertigkeiten gegen Gewalt" (Perception of Importance of Intervention Skills Scale, POIS) verwendet. Diese neun Item-Skala wurde vom Forschungsteam entwickelt, um die persönliche Einstellung der Fachpersonen gegenüber der Verwendung von gebräuchlichen Präventions- und Interventionsstrategien zu erheben. Nach der Anpassung dieser beiden Instrumente für die Verwendung in einem Allgemeinkrankenhaus wurden sie validiert. Zwischen November 2006 und Januar 2007 füllten 291 Pflegefachpersonen, die in verschiedenen Allgemein Krankenhäusern der deutschsprachigen Schweiz arbeiteten, die drei Fragebogen SOVES-G-R, die POAS-S und die POIS aus (Rücklaufquote $=71 \%$ ). Die Antworten der Teilnehmenden zeigten, dass Änderungen bezüglich der Verwendbarkeit der SOVES-G-R in den zwei Kategorien zur Erfahrungen mit Patienten- und Besuchergewalt in "den letzten 12 Monaten" und in "der letzten Arbeitswoche" erforderlich waren. Die POAS-S zeigte die gleiche Faktoren-Lösung wie in früheren Studien. Beide Faktoren erklären 38.0\% der Varianz. In der POIS konnten die folgenden zwei Faktoren unterschieden wer- 
den: (1) strukturierte Interventionen und Evaluation und (2) die Wichtigkeit von präventiven Massnahmen. Diese beiden Faktoren erklären zusammen 44.3\% der gesamten Varianz. Die in dieser Studie präsentierte SOVES-G-R ist der erste validierte Fragebogen in deutscher Sprache zur Beschreibung von Patienten- und Besuchergewalt in Allgemein Krankenhäusern. Die SOVES-G-R zeigt eine gute Anwendbarkeit in der Praxis und ermöglicht es Gesundheitsfachpersonen, die Fragen angemessen zu verstehen. Die Ergebnisse der Studie zeigten, dass die SOVES-G-R, die POIS und die POAS-S verwendet werden können, um die Erfahrungen von Pflegefachpersonen mit Patienten- und Besuchergewalt im spezifischen Setting des Allgemeinkrankenhaus zu erfassen, zu überwachen oder zu reflektieren. Diese Instrumente sind jetzt verfügbar und generieren vergleichbare Daten, sowohl in Englisch als auch in Deutsch. Dies verbessert den Datenvergleich zwischen diesen Sprachregionen. Die Resultate der Studie zeigen jedoch auch auf, dass für eine angemessene Untersuchung der Einstellung von Gesundheitsfachpersonen gegenüber Aggression sowie Präventions- und Interventionsstrategien, die Items der POAS-S und der POIS nochmals sorgfältig überprüft werden sollten.

Kapitel vier bearbeitet die Themen der dritten, vierten und fünften Fragestellungen, fokussiert auf eine Stichprobe von Pflegefachpersonen. Das Ziel der Studie war, die Erfahrungen von Pflegefachpersonen mit Patienten- und Besuchergewalt sowie die damit in Zusammenhang stehenden Faktoren in Schweizer Allgemeinkrankenhäusern zu erforschen. Pflegende erleben in der Regel die höchste Rate an Patienten- und Besuchergewalt verglichen mit anderen Gesundheitsfachpersonen. In Bezug auf die Situation im Allgemeinkrankenhaus beschrieben bisherige Studien meist nur einzelne oder einen Teil dieser Faktoren. Auf dem europäischen Festland wurde das Problem bisher selten und nur ansatzweise erforscht. Die im vierten Kapitel beschriebene retrospektive Querschnittsstudie wurde im Jahr 2007 durchgeführt und bezog 291 Pflegefachpersonen ein, welche auf verschiedenen Abteilungen in Allgemein Krankenhäusern arbeiten. Als Erhebungsinstrumente dienten die SOVES-G-R, die POAS-S und die POIS. Die Ergebnisse dieser Studie beschrieben, erstmalig für die Schweiz, dass in den letzten 12 Monaten $72 \%$ der Pflegenden verbale und $42 \%$ physische Patienten- und Besuchergewalt erlebt hatten. Es zeigte sich, dass $23 \%$ der Teilnehmenden körperlich verletzt wurden und $1.4 \%$ eine oder mehrere Tage krankgeschrieben werden mussten. Patienten- und Besuchergewalt wurde von den Pflegenden als belastend erlebt. Ein höheres Risiko für Patienten- und Besuchergewalt wurde für Diplomierte Pflegefachpersonen beobachtet, die ängstliche oder kognitiv beeinträchtigten Patienten pflegen. Ebenfalls ein höheres Risiko haben Diplomierte Pflegefachpersonen die auf Rehabilitationsabteilungen mit länger andauernden Beziehungen zwischen Pflegenden und Patienten beziehungsweise Besuchern arbeiten. Auch Diplomierte Pflegefachpersonen welche an Arbeitsplätze, die über keine formalen Vorgaben im Umgang mit Patienten- und Besuchergewalt und deren Folgen verfügen, haben ein erhöhtes Risiko Gewalt zu erleben. Die Ergebnisse zeigen auf, dass in Allgemein Krankenhäu- 
sern Gewalt ein ernstzunehmendes Problem für Pflegepersonen ist. Sie zeigen zudem auf, dass Patienten- und Besuchergewalt nicht nur auf Notfallstationen und psychiatrischen Abteilungen auftritt. Patienten- und Besuchergewalt scheint hauptsächlich durch die Art der Interaktion und Situation, in der die Interaktion stattfindet, beeinflusst zu werden. Die Ergebnisse zeigten, dass die Pflege von älteren und kognitiv beeinträchtigten Patienten, die Angst haben oder ärgerlich sind, anspruchsvoll für Pflegefachpersonen ist. In Bezug auf diese Herausforderung müssen adäquate Interventionsstrategien kompetent und professionell eingeführt und umgesetzt werden. Weitere Untersuchungen sollten die gewonnen Erkenntnisse vertiefen, um das Wissen zu diesen komplexen Situationen weiter zu entwickeln.

Die Ergebnisse der im fünften Kapitel präsentierten Studie beschreiben die Erfahrungen von Gesundheitsfachpersonen mit Patienten- und Besuchergewalt im Allgemeinkrankenhaus. Diese Studie adressiert die dritte Frage, nämlich die nach der Prävalenz von Patienten- und Besuchergewalt und die fünfte Frage, welche die erhaltene Unterstützung nach erfahrener Patienten- und Besuchergewalt und die Konsequenzen für die beteiligten Mitarbeitenden beinhaltet. Die Studie behandelt auch die sechste Frage, nach den angewandten Interventionen bei Patienten- und Besuchergewalt und das Vertrauen der Befragten in ihre Fähigkeiten bezüglich dem Umgang mit gewalttätigen Situationen. Die von Gesundheitsfachpersonen verwendeten Interventionsstrategien und die Folgen der Patienten- und Besuchergewalt wurden bisher nur selten untersucht und vorhandene Studien konzentrieren sich häufig nur auf die Berufsgruppen der Pflegenden sowie auf einzelne für die Interaktion zwischen den beteiligten Personen relevante Faktoren. Daher ergänzt diese Studie wichtiges fehlendes Wissen über Faktoren, die das Auftreten von Patientenund Besuchergewalt beeinflussen. Entsprechend der Forschungsfragen wurde eine Querschnittsstudie im Jahre 2007 durchgeführt, an welcher 2495 Personen teilgenommen haben (von insgesamt 4845 Gesundheitsfachpersonen), die auf verschiedenen Stationen in einer Schweizer Universitätsklinik für somatische Erkrankungen arbeiten. Die SOVES-G-R wurde als Erhebungsinstrument verwendet. Die Ergebnisse zeigen, dass die Hälfte der teilnehmenden Gesundheitsfachpersonen Patientenund Besuchergewalt in den letzten 12 Monaten und 11\% in der vergangenen Woche erlebt haben. Gesundheitsfachpersonen tragen ein hohes Risiko, verbale Patienten- und Besuchergewalt zu erfahren. Das Alter der Mitarbeitenden und ihre Erfahrung am gegenwärtigen Arbeitsplatz beeinflusst ihre Exposition gegenüber Patienten- und Besuchergewalt. Gewalt trat überwiegend dann auf, wenn Aufgaben durchgeführt wurden, die einen engen persönlichen Kontakt erforderten. Nur $16 \%$ der Gesundheitsfachpersonen verfügten über eine Ausbildung in Aggressionsmanagement. Das Vertrauen in die eigenen Fähigkeiten bezüglich des Umgangs mit Patienten- und Besuchergewalt ist signifikant abhängig von der Haltung der Organisation gegenüber Gewalt. Die wichtigsten verwendeten Interventionen waren beruhigende Gespräche und Information. Um Präventions- und Managementstrategien zu verbessern und die Prävalenz der Patienten- und Besuchergewalt zu 
reduzieren, benötigen Mitarbeitende eine an die Situation des Allgemeinkrankenhaus angepasste Schulung. Das Training sollte insbesondere die Optimierung der Kommunikationsfähigkeit und angemessenes Management von Patienten- und Besuchergewalt beinhalten und muss der spezifischen Arbeitssituation angepasst sein. Gesundheitsfachpersonen in Allgemeinkrankenhäusern sind erwiesernmassen mit Patienten- und Besuchergewalt konfrontiert. Trotzdem ist es wichtig, dass sie weiterhin eine patientenzentrierte Versorgung und empathische Interaktionen anbieten. Die Ergebnisse dieser Studie zeigen auf, dass ein starkes Engagement der Organisation unerlässlich ist, um Patienten- und Besuchergewalt zu reduzieren und Barrieren bei der Berichterstattung über gewalttätige Vorfälle zu beseitigen. Um einen sicheren Arbeitsplatz zu gewährleisten, sollte die Geschäftsleitung die persönliche Sicherheit des Personals als Priorität betrachten, wie dies auch gesetzlich verlangt wird. Zukünftige Forschung sollte sich mit der präziseren Beschreibung der Entstehung von Patienten- und Besuchergewalt befassen unter Einbezug aller bisher erkannten Risikofaktoren. Wichtig sind Studien, welche grosse Stichproben umfassen und somit anspruchsvolle statistische Analysen ermöglichen.

Kapitel sechs befasst sich mit der vierten Forschungsfrage zu den Risikofaktoren für Gesundheitsfachpersonen in Bezug auf Patienten- und Besuchergewalt im Allgemeinkrankenhaus. Die im Jahr 2007 durchgeführte retrospektive Querschnittsstudie umfasst 2495 Gesundheitsfachpersonen, die in der allgemeinen stationären und ambulanten Versorgung eines Schweizer Universitätsspitals beschäftigt waren. Die Daten wurden mittels Fragebogen erfasst, welcher die SOVES-G-R, die POAS-S und die POIS umfassten. In der Analyse wurden beschreibende Statistik und die multiple logistische Regressionsanalyse verwendet. Diese Studie ergab, dass die Risikofaktoren in Bezug auf das Erleben der Patienten- und Besuchergewalt abhängig sind von der Form der erlebten Gewalt. Die Mitarbeitenden mit einer Ausbildung in Aggressionsmanagement und / oder diejenigen, die überwiegend mit Patienten über 65 Jahre alt arbeiten, erfahren doppelt so viel Patienten- und Besuchergewalt als andere Gesundheitsfachpersonen. Mitarbeitende, welche in der Notaufnahme, in Ambulatorien, auf Intensivstationen, im Aufwachraum, in der Anästhesie, der Intermediate Care und dem Aufwachraum arbeiten, erfahren ebenfalls öfter Patienten- und Besuchergewalt. Ältere Mitarbeitende, Ärzte und Ärztinnen, Studierende und /oder Mitarbeitende mit einer Haltung, die präventive Massnahmen als weniger wichtig und Aggression als "emotionales Dampfablassen" bewerteten, trugen ein geringeres Risiko Patienten- und Besuchergewalt zu erfahren. Verbale und non-verbale Kommunikationsstrategien erwiesen sich als bedeutende Kompetenzen in der Prävention und Deeskalation von gewalttätigen Situationen. Um die Ausbildung in Bezug auf Aggressionsmanagement zu verbessern, sollten verbale und non-verbale Kommunikationsstrategien inhaltliche Schwerpunkte darstellen, vor allem für jüngere Mitarbeitende. Um die Sicherheit in Situationen zu erhöhen, könnte ein Ansatz, bei welchem sich zwei Mitarbeitende im Management von schwierigen Situationen unterstützen, in Betracht gezogen wer- 
den. Sowohl die Reflexion der Einstellung und Gefühle in Bezug auf Patienten- und Besuchergewalt, als auch die beruflichen Aufgaben und Rollen müssen bei der Ermittlung des persönlichen Risikoverhalten oder des potentiellen Risikos in einer Situation einbezogen werden. Diese Studie zeigt zudem auf, dass die Perspektive der beteiligten Patienten und Besucher in der Diskussion und in den Schlussfolgerungen zu Risikofaktoren der Patienten- und Besuchergewalt fehlen. Untersuchungsresultate beziehen meist nur die Sicht der Gesundheitsfachpersonen ein und daher entstanden die aktuellen Modelle basierend auf deren Sichtweise und nicht der aller an der Situation beteiligten Parteien. Es wird empfohlen, dass zukünftige Forschung qualitative Ansätze, wie beispielsweise Grounded Theory nutzt, um die gesamte Interaktionskette, welche zu Gewalt führen kann, zu untersuchen. Mehr Informationen sind erforderlich, um die Folgen und Auswirkungen von Patienten- und Besuchergewalt auf die Gesundheitsfachpersonen sowie deren Absicht den Arbeitsplatz oder den Beruf zu wechseln sowie die Qualität der Versorgung zu erfahren.

Das siebte Kapitel beschreibt die wichtigsten Faktoren im Zusammenhang mit Patienten- und Besuchergewalt und die methodischen Aspekte der Studie. Der Schwerpunkt dieses Kapitels beinhaltet die allgemeine Diskussion der Ergebnisse der Studie und deren Konsequenzen für die klinische Praxis und Forschung. Die Risikofaktoren, die mit Patienten- und Besuchergewalt verbunden sind, werden im Detail für Patienten (Alter, Gesundheitszustand, emotionaler Zustand, Orientierungen in einer Situation) und Besucher (emotionaler Zustand und Informationsebene) beschrieben. Die Merkmale der Mitarbeitenden (Beruf, Alter, Kontakt mit Besuchern, Patientenkontakt, Einstellung), die Eigenschaften der Interaktion (Nähe, Verhandlungsspielraum, Beratung) und die Arbeitsumgebung und -organisation (Arbeitsplätze, offizielle Position, Abteilungsatmosphäre, Ablaufprozesse) werden ebenfalls beschrieben. Die methodischen Aspekte zeigen, dass die Stärke dieser Dissertation die Auswahl und Vorbereitung (Übersetzung, Rückübersetzung, Pretest) des SOVES-G-R und die Testung der POAS-S und POIS beinhalten. Die hohe Rücklaufquote und die vergleichbaren Eigenschaften der Teilnehmenden mit der Population der Schweizer Arbeitskräfte ist eine weitere Stärke. Die größte methodologische Einschränkung ist das retrospektive Querschnittdesign der Studie, das keine kausalen Schlussfolgerungen zulässt und eine Gefahr für Erinnerungsfehler beinhaltet. Die Diskussion zeigt, dass es wichtig ist, die Prävalenz von Patientenund Besuchergewalt zu untersuchen und dabei eine Vielzahl von kleineren Berufsgruppen des Gesundheitswesens einzubeziehen, damit nicht das Risiko für die am häufigsten erforschte Gruppe der Pflegefachpersonen überschätzt wird. Gemäss dem theoretischen Hintergrund und den Ergebnissen der Studien sind klare und verbindliche institutionelle Strategien und Verfahren gegenüber Patienten- und Besuchergewalt wichtig, um das Sicherheitsempfinden der Mitarbeitenden zu erhöhen und um die Häufigkeit von Patienten- und Besuchergewalt zu verringern. Daher ist es beunruhigend, dass das Thema nicht höher auf der Prioritätenliste des 
Führungsmanagements von Allgemeinkrankenhäusern oder der Diskussionen der Fachpersonen der Schweiz und in anderen Ländern steht. Die Merkmale der Fachpersonen, welche in gewalttätige Vorfälle involviert sind, sind wichtig im Hinblick auf das Ergebnis der Situation. Die Ergebnisse der Studie führen zu uneinheitlichen Schlussfolgerungen in Bezug auf das Geschlecht der gewalttätigen Patienten. Allerdings ist der Genderaspekt wichtig, da Frauen viel häufiger Opfer von Kriminalität und häuslicher Gewalt sind, als Männer. Diese gesellschaftlichen Faktoren könnte ebenfalls Einfluss nehmen auf die Interaktion im Allgemeinkrankenhaus zwischen männlichen Patienten und weiblichen Gesundheitsfachpersonen. Ein wichtiger Einflussfaktor auf die Gewalttätigkeit von Patienten scheinen die Prävalenz von Herz-Kreislauf-Erkrankungen und kognitive Beeinträchtigung zu haben. Den negativen Auswirkungen von Stress auf die Interaktion sollte mehr Aufmerksamkeit geschenkt werden. Patienten und Besucher können an einer Vielfalt von Stressoren (Gesundheitszustand, unbekannte Umgebung und Abläufe, unklare Zukunft, Angst), welche die Interaktion negativ beeinflussen, leiden. Angemessene Kommunikationsfähigkeit und Empathie sowie eine kundenfreundliche Haltung sind in solchen Situationen sehr wichtig, um negative Gefühle zu reduzieren sowie die Sicherheit und das Vertrauen zu verbessern. Gesundheitsfachpersonen müssen die wichtigsten Informationen, welche Patienten und Besucher benötigen, kennen und müssen diese adäquat vermitteln können. Die Ergebnisse zeigen auch, dass die Haltung der Mitarbeitenden die Erfahrung von Gewalt beeinflusst. Man kann vermuten, dass das Personal, welches Aggression als „Ablassen von Dampf“ interpretiert, Gewalt weniger persönlich bewertet und ihr daher weniger Bedeutung schenkt. Mitarbeitende, welche eine Ausbildung in Aggressionsmanagement absolvierten, erfuhren deutlich mehr Patienten- und Besuchergewalt. Für die Ausbildung im Umgang mit gewalttätigen Situationen könnte ein modulares System nützlich sein, welches Wissen über Angst und Stressprävention sowie Kommunikation und Informationsstrategien beinhaltet. Fokussierte Module für spezielle Gruppen von Mitarbeitenden, spezifiziert nach Arbeitsplätzen und unter Einbezug der interdisziplinären Teamarbeit, wären ebenfalls sinnvoll. Diese Ausbildungsprogramme sollten sorgfältig umgesetzt und evaluiert werden. Zudem besteht ein Bedarf bezüglich Reflexion der Qualität des Arbeitsumfeldes und deren Einfluss auf die psychische Verfassung der Patienten.

Der theoretische Hintergrund und die Ergebnisse dieser Dissertation liefern einen Bezugsrahmen, der wichtige Informationen über die Prävention von Patientenund Besuchergewalt und zu Interventionsstrategien bietet. Der Bezugsrahmen unterstützt die Forschung in der Beschreibung der Zusammenhänge zwischen den komplexen Faktoren, die mit Patienten- und Besuchergewalt sowie dem Auftreten von gewalttätigen Situationen verbunden sind. Diese Forschung ist wichtig, weil sie zu gewinnbringenden Informationen führen kann, welche die bis anhin noch wenig erfolgreichen Strategien verbessern können, da sie die Arbeitsumgebung und den Kontext, in welchem die Strategien implementiert werden, einbezieht. Da die Per- 
spektive der involvierten Patienten / Besucher noch fast nirgends in der Forschung über Patienten- und Besuchergewalt einbezogen wurde, ist es wichtig, dass diese in Zukunft in die Forschung einbezogen werden. Durch Einbeziehen dieser Perspektive kann der theoretische Hintergrund umfassend weiter entwickelt werden. 



\section{Acknowledgements}

I would like to thank, with my deepest gratitude, the many people and institutions who have supported this project and helped me in conducting this dissertation.

For the continued professional support, encouragement and instructive conversations, I thank my promoters Prof. Dr. Gerjo Kok, Maastricht University, Dr. Ruud JG Halfens, Maastricht University and Prof. Theo Dassen, Charité Berlin. I would like to thank Gerjo Kok for his respectful attitude and profound critique, which provided me with space for rethinking. I would like to thank Theo Dassen for his brief but accurate comments, which were particularly valuable in the revision of the manuscripts. I warmly thank Ruud Halfens who was always available, and quick in responding to my questions. He was an inexhaustible source of critical reflection and significantly supported the progress of my thesis. I thank Prof. Dr. Marianne Müller for her insight into statistics, as well as her patience with my talent in this miraculous field of data analysis.

I would like to thank all of the participants of the studies who completed the surveys. I am also very grateful to the head nurses of the general hospitals, who enabled me to investigate their wards. Furthermore, I would like to thank the Centre for Further Education of the Nursing Association of Switzerland, Zurich and the University Insel Hospital, Berne, for their support. Many thanks go to Jörg Gottschalk, Aija Kinnunen, Claudia Kuster Lüthi, Elisabeth Lanz, Ottilia Rohrer and Anja Thöny. These nursing experts accompanied the studies as a profound board of advice and support.

Many thanks go to Dr. Virpi Hantikainen, for allowing me easy access to the participants. Her optimism was infectious and always helped me in difficult situations. Dr. Ian Needham accompanied the beginning of this thesis with his thorough knowledge, and helped me to overcome my fears of writing in English. Without his support I would have likely not started this project. His invitation to become a member of the European Violence in Psychiatric Research Group (EViPRG), opened up a world full of inspirations about violence in health care. I also thank all members of the EViPRG for their cooperation and inspiring discussion of the topic. There is likely no other network which offers its members such unreserved professional assistance.

I would like to thank the Bern University of Applied Sciences, and in particular my colleagues, for their support and motivating discussions.

Dr. Dennis Ryan, Rebekah Kenyon and Tannys Helfer not only corrected my English, but they also contributed to a deeper reflection on what was written. I thank Christa Vangelooven and Frans Fluttert for the careful translation of the summary into Dutch. 
I would like to thank the student group and Prof. Dr. Christa Lohrmann of the PhD program in Maastricht, Berlin and Graz, for insight into the many interesting research projects. Heidi Zeller, another PhD student and my colleague since the beginning of this thesis, shared my passion in the field of research on violence. She always provided me with good advice and encouragement during difficult times and with the creation of this thesis. Diana Grywa, who unfortunately cannot be with us, I thank dearly for ensuring that I started and finished this dissertation.

Many thanks to my father, who taught me in my childhood in the Swiss mountains, that I could climb each mountain (even the PhD-Mountain) if I set one foot in front of the other. I thank my mother for always inviting me after finishing work, to visit with her and enjoy hours of relaxation in order to restore myself. The creativity of my sister showed me that there are other beautiful things in life besides cognitive brain work. I therefore have the deepest gratitude for my family. They have always encouraged and supported me.

Dear friends, I thank you for your patience and the many hours that you had to endure waiting for me, because my thoughts were full of voilence research.

Felix, without you this very dangerous mountain hike would never have been successful. You have always been with me for support. There are no words to describe the deep gratitude that I feel for you. 


\section{Curriculum vitae}

Sabine Hahn was born in October, 1964 in Switzerland. She completed her training in psychiatric nursing in 1988. As a registered nurse she worked in acute psychiatric units and in addiction and rehabilitation units for over 10 years. In 1998 she achieved a diploma as Clinical Nursing Expert and worked for four years in this position in psychiatry. Since 1999, she also has been engaged as a lecturer and project manager in knowledge development projects within higher education in nursing in Switzerland. She received her Masters Degree in Health Science and Nursing Science from Maastricht University in 2005. Since 2006 she is head of the Unit of Applied Research and Development in Nursing at the Berne University of Applied Sciences in Berne, Switzerland. In 2006, she started her PhD studies in the PhD-Programme at Maastricht University, Charité Centre for the Humanities and Sciences, Berlin and Medical University of Graz.

In her current position, she is leading research projects in the fields of psychosocial health promotion \& prevention, mental health, aggression in health systems, patient education and research transfer in order to improve evidence based nursing.

Sabine Hahn is head of the Scientific and Organisational Committee of the "Dreiländerkongress für Psychiatrische Pflege." She is a member of the editorial board of the PSYCH.PFLEGE HEUTE and a member of several review boards for national and international scientific journals. She is a founding member of the Academic Association of Swiss Mental Health Nurses, a member of the Swiss Federation of Nursing Sciences and Research and a member of the Swiss Network for Psychiatric Nursing Research. Sabine Hahn is also a member of the European Research Group on Violence in Psychiatry and is a delegate of the Swiss Nursing Association for the International Council of Nursing regarding the topics Violence and Mental Health Nursing. She is member of the expert board in the European Network of Psychiatric Nurses HORATIO. 


\section{CAPHRI}

The research presented in this thesis was conducted at the School for Public Health and Primary Care: CAPHRI, Department Health Services Research, of Maastricht University. CAPHRI participates in the Netherlands School of Primary Care Research CaRe. CAPHRI was classified as 'excellent' by the external evaluation committee of leading international experts that reviewed CAPHRI in December 2010. 